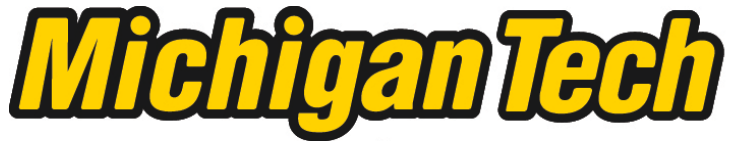 \\ Michigan Technological University Create the Future Digital Commons @ Michigan Tech
}

2013

EVALUATION OF NON-STATIONARITY IN ANNUAL MAXIMUM FLOOD SERIES OF MODERATELY IMPAIRED WATERSHEDS IN THE UPPER MIDWEST AND NORTHEASTERN UNITED STATES

Neila Salvadori

Michigan Technological University

Follow this and additional works at: https://digitalcommons.mtu.edu/etds

Part of the Environmental Engineering Commons, and the Water Resource Management Commons Copyright 2013 Neila Salvadori

Recommended Citation

Salvadori, Neila, "EVALUATION OF NON-STATIONARITY IN ANNUAL MAXIMUM FLOOD SERIES OF MODERATELY IMPAIRED WATERSHEDS IN THE UPPER MIDWEST AND NORTHEASTERN UNITED STATES", Master's Thesis, Michigan Technological University, 2013.

https://doi.org/10.37099/mtu.dc.etds/489

Follow this and additional works at: https://digitalcommons.mtu.edu/etds

Part of the Environmental Engineering Commons, and the Water Resource Management Commons 


\title{
EVALUATION OF NON-STATIONARITY IN ANNUAL MAXIMUM FLOOD SERIES OF MODERATELY IMPAIRED WATERSHEDS IN THE UPPER MIDWEST AND NORTHEASTERN UNITED STATES
}

\author{
By \\ Neila Salvadori \\ A THESIS \\ Submitted in partial fulfillment of the requirements for the degree of \\ MASTER OF SCIENCE \\ In Environmental Engineering
}

MICHIGAN TECHNOLOGICAL UNIVERSITY

2013

(C) 2013 Neila Salvadori 
This thesis has been approved in partial fulfillment of the requirements for the Degree of MASTER OF SCIENCE in Environmental Engineering.

Department of Civil and Environmental Engineering

Thesis Advisor: $\quad$ Dr. Veronica W. Griffis

Committee Member: Dr. Alex Mayer

Committee Member: Dr. Claudio Mazzoleni

Department Chair: Dr. David Hand 
to my wonderful mom, with love 


\section{Table of contents}

List of figures .................................................................................................................................. vii

List of tables .............................................................................................................

Acknowledgments..................................................................................................................... xiv

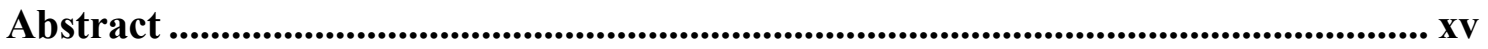

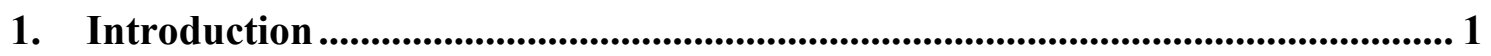

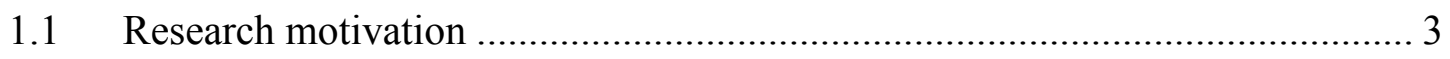

1.1.1 Non-stationary flood frequency analysis ................................................. 4

1.1.2 Evidence of non-stationarity in hydrologic series ..................................... 7

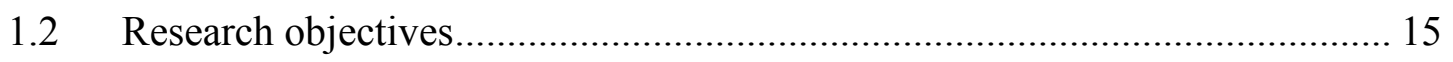

2. Moderately impaired watersheds ............................................................................... 16

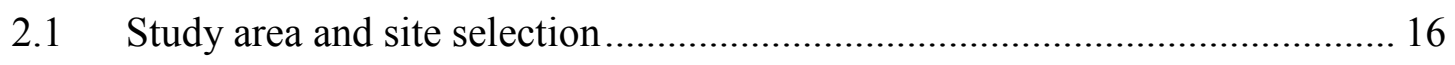

2.2 Annual maximum flood series.................................................................. 20

2.3 Physical characteristics of the watersheds .................................................... 24

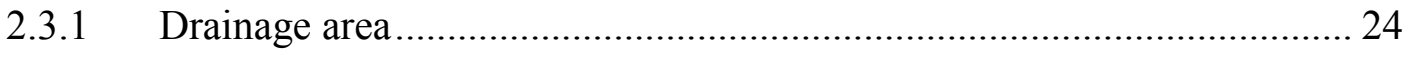

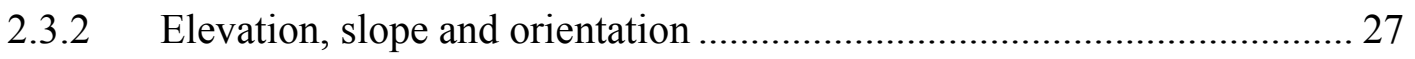

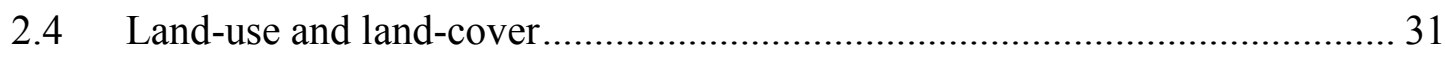

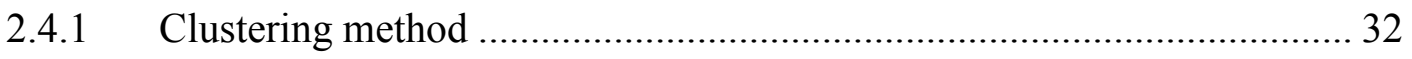

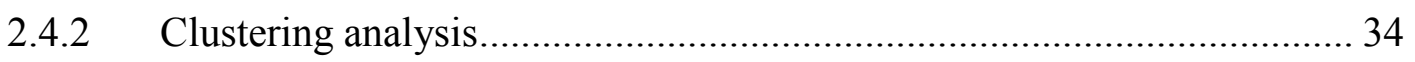

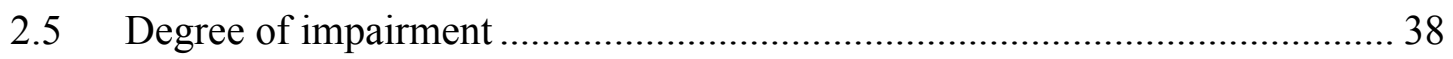

3. Non-stationarity in annual maximum flood series and potential human-

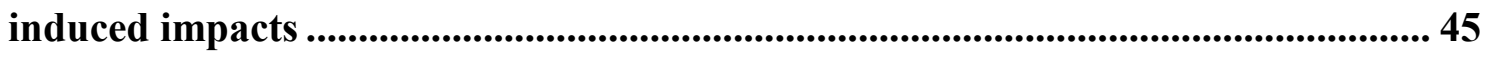

3.1 Methods to investigate non-stationarity......................................................... 45

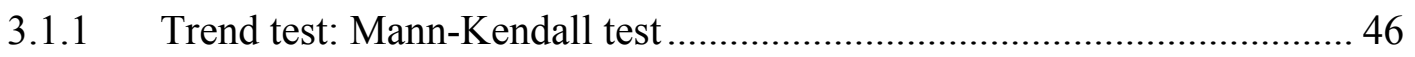


3.1.2 Change-point analysis: Pettitt test ……………….............................. 48

3.1.3 Multiple Change-Points analysis: a Bayesian approach............................ 49

3.2 Forms of non-stationarity in annual maximum flood series ............................. 51

3.2.1 Trends in annual maximum flood series ................................................. 51

3.2.2 Change-points in annual maximum flood series ...................................... 53

3.2.3 Multiple change-points in annual maximum flood series ........................ 58

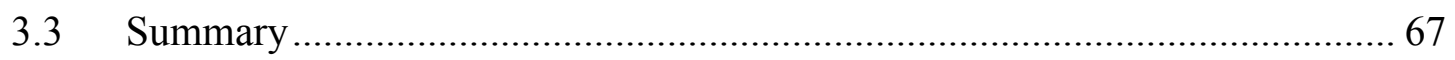

\section{Natural sources of non-stationarity: meteorological variables and climatic} patterns ......................................................................................................................................... 69

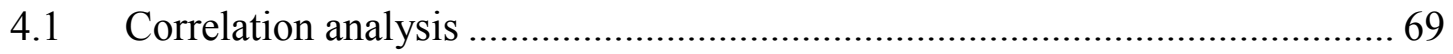

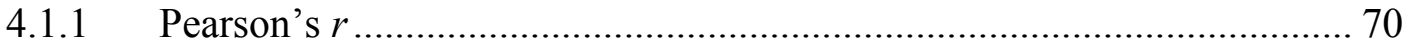

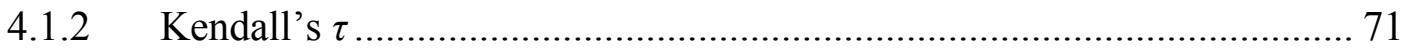

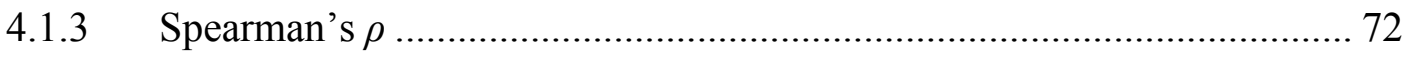

4.1.4 Comparison between correlation tests .................................................. 72

4.2 Meteorological causes of non-stationarity …………………........................... 73

4.2.1 Definition of flood-generating meteorological time series ...................... 73

4.2.2 Correlation between meteorological variables and flood magnitude ....... 74

4.2.3 Non-stationarity in flood-generating precipitation series .......................... 80

4.2.4 Correlation between temperature and timing of flood series .................... 83

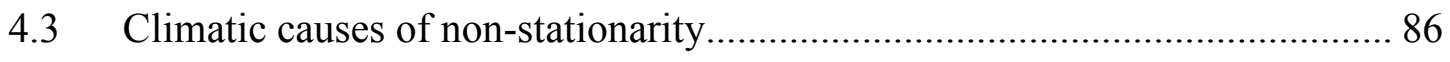

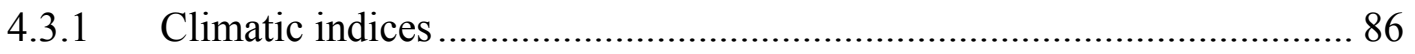

4.3.2 Teleconnections with annual maximum flood series ................................ 88

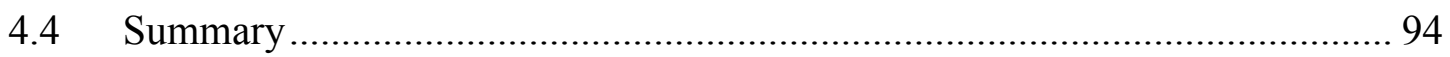

5. Conclusions ........................................................................................................................... 96

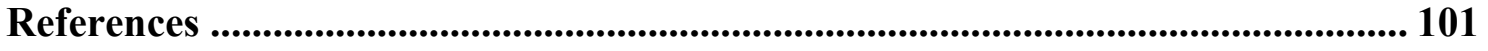


Appendix A - AMF series and watersheds characteristics

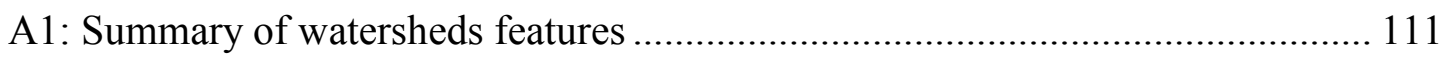

A2: Frequency distribution of watershed characteristics................................... 122

Appendix B - Non-stationarity in AMF series................................................. 128

Appendix C - Meteorological variables .................................................................. 133

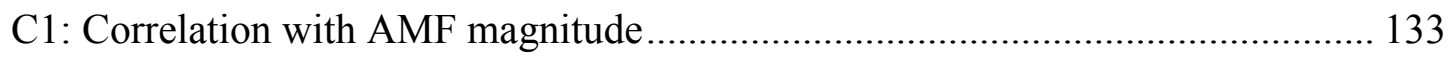

C2: Correlation with AMF timing ............................................................ 143

C3: Non-stationarity in precipitation series ............................................... 147

Appendix D - Large-scale climate patterns ........................................................... 149 


\section{List of figures}

Figure 2-1: Locations of 295 impaired watersheds in Hydrologic Regions 1, 4 and 5 with at least 65 years of continuous annual maximum flood observations........ 18

Figure 2-2: Locations of the 143 gauging stations defining the study area for moderately impaired watersheds in the Upper Midwest and Northeastern US..................... 20

Figure 2-3: Frequency distribution of mean annual maximum flood magnitudes for the

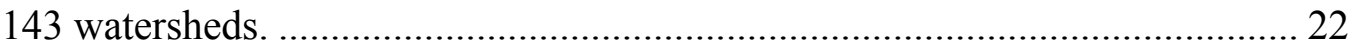

Figure 2-4: Spatial representation of the mean annual maximum flood magnitudes $\left[\mathrm{m}^{3} \mathrm{~s}\right.$

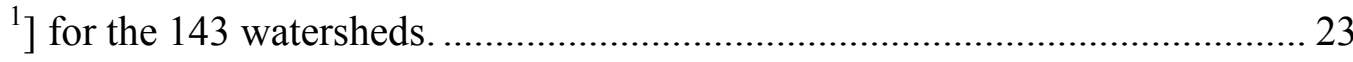

Figure 2-5: National Land-Cover for the year 2006 for the Northeastern United States 23 Figure 2-6: Frequency distribution of drainage areas for the 143 watersheds. .............. 25

Figure 2-7: Geographical distribution of drainage areas $\left[\mathrm{km}^{2}\right]$ for the 143 watersheds. 25 Figure 2-8: Mean annual maximum flood magnitude versus drainage area in log-scale. 26

Figure 2-9: Frequency distribution of mean elevation values [m] for the 143 watersheds. 28

Figure 2-10: Frequency distribution of mean slope values [\%] for the 143 watersheds. 28 Figure 2-11: Geographical distribution of mean elevation [m] for the 143 watersheds. 29 Figure 2-12: Geographical distribution of mean slope [\%] for the 143 watersheds. ..... 29 Figure 2-13: Mean annual maximum flood magnitude versus mean watershed elevation in $\log$-scale 30

Figure 2-14: Mean annual maximum flood magnitude versus mean watershed slope in log-scale. 30

Figure 2-15: Topographic orientation of the 143 watersheds. 31

Figure 2-16: Dendrogram obtained considering land-cover/land-use attributes of the 143 watersheds in Ward's clustering algorithm. 34

Figure 2-17: Geographical distribution of clustered sites based on land-use/land-cover attributes. Five clusters were identified: Cluster 1 (green dots), Cluster 2 (grey dots), Cluster 3 (brown dots), Cluster 4 (orange dots) and Cluster 5 (red dots). 37 
Figure 2-18: Clustering results based on land-use/land-cover attributes relative to US urban boundaries. 37

Figure 2-19: Hydrologic disturbance indices for the 143 moderately impaired watersheds. High/low values correspond to high/low levels of human-induced alteration. 39

Figure 2-20: Locations of the 16 moderately impaired sites with hydrologic disturbance indices greater than 25 relative to Gages II sites in Hydrologic Regions 1, 4 and 5 with high hydrologic disturbance indices $(>25)$. 40

Figure 2-21: Geographic distribution of the number of dams within each of the 143 watersheds in the year 2009. 42

Figure 2-22: Geographic distribution of the number of major dams within each of the 143 watersheds in the year 2009. 43

Figure 2-23: Total number of dams contained/constructed in 10-years increments within each land-use/land-cover cluster. 44

Figure 3-1: Trends in annual maximum flood series detected by applying Mann-Kendall test at 5\% (red) and 10\% (green) significance levels. Upright triangles identify increasing trends; inverted triangles decreasing trends. Black dots indicate the remaining sites for which no significant trends were identified. 52

Figure 3-2: Direction of shift (change-point) in annual maximum flood series detected by applying Pettitt test at 5\% (red) and 10\% (green) significance levels. Upright triangles identify positive shifts; inverted triangles negative shifts. Black dots indicate locations of watersheds for which significant results were not obtained.

Figure 3-3: Timing of change-points in annual maximum flood series as identified by the Pettitt test at both 5\% and 10\% significance levels. Black dots indicate locations of watersheds for which no significant results were obtained. 55

Figure 3-4: Results of multiple change-points (MCP) analysis applied to AMF series. Blue dots indicate sites at which the MCP analysis identified one change-point, and red dots sites at which two change-points were identified. Green dots indicate sites where the Pettitt test identified a change-point, but the MCP 
analysis did not. Black dots represent the remaining sites with no significant shifts identified by either approach.

Figure 3-5: Change-point in 1973 for the annual maximum flood (AMF) series of site 04122500 as identified by the Pettitt test at the $10 \%$ level. 60

Figure 3-6: Change-point in 1979 for the annual maximum flood (AMF) series of site 03141500 as identified by the Pettitt test at the $10 \%$ level 60

Figure 3-7: Change-point in 1968 for the annual maximum flood (AMF) series of site 01017000 as identified by the Pettitt test at the $10 \%$ level 61

Figure 3-8: Change-point in 1969 for the annual maximum flood (AMF) series of site 03024000 as identified by the Pettitt test at the $10 \%$ level 62

Figure 3-9: Change-point in 1979 for the annual maximum flood (AMF) series of site 03140000 as identified by the MCP analysis. 63

Figure 3-10: Change-point in 1968 for the annual maximum flood (AMF) series of site 03157000 as identified by the MCP analysis. 63

Figure 3-11: Change-points in 1935 and 1955 for the annual maximum flood series of site 01173500 as identified by the MCP analysis.

Figure 3-12: Change-points in 1935 and 1956 for the annual maximum flood series of site 01185500 as identified by the MCP analysis. 65

Figure 3-13: Change-point in 1945 for the annual maximum flood series (AMF) of site 01094500 as identified by the MCP analysis considering 10 years as the minimum allowable distance between consecutive change-points 66

Figure 3-14: Change-point in 1956 for the annual maximum flood (AMF) series of site 01094500 as identified by the MCP analysis considering 15 years as the minimum allowable distance between consecutive change-points. 66

Figure 4-1: Results of Kendall's $\tau$ correlation tests between annual maximum flood peak magnitude and precipitation series at $5 / N \%$ significance level. For each site, the X-days lead time yielding the highest correlation with flood magnitude is indicated. Black dots indicate sites for which no significant correlations were obtained; grey squares represent sites for which tests were not conducted. ….. 77 
Figure 4-2: Trends in flood-generating precipitation series detected by applying MannKendall test at $5 \%$ (red) and 10\% (green) significance levels. Upright triangles identify increasing trends. Black dots indicate sites for which no trend was identified out of $N=136$ sites. 80

Figure 4-3: Direction of shift (change-point) in flood-generating precipitation series detected by applying Pettitt test at 5\% (red) and 10\% (green) significance levels. Upright triangles identify positive shift; inverted triangles negative shift. Black dots indicate locations of watersheds for which significant results were not obtained out of $N=136$ sites. 81

Figure 4-4: Comparison of results of the Pettitt test applied at the 10\% significance level to detect change-points $(\mathrm{CP})$ in AMF magnitude and precipitation series. Green dots indicate sites where shifts were observed in both series; black dots indicate sites for which no significant shifts were identified in either series out of $N=$ 136 sites. 83

Figure 4-5: Results of Pearson's $r$ correlation tests between flood peak timing and maximum temperature series at $10 \%$ significance level. For each site, the Xdays lead time yielding the highest correlation with flood peak timing is indicated. Black dots indicate sites for which no significant correlations were obtained; grey squares represent sites for which tests were not conducted. ...... 85

Figure 4-6: Results of Pearson's $r$ correlation tests between flood peak timing and minimum temperature series at $10 \%$ significance level. For each site, the $\mathrm{X}$-days lead time yielding the highest correlation with flood peak timing is indicated. Black dots indicate sites for which no significant correlations were obtained; grey squares represent sites for which tests were not conducted. 86

Figure 4-7: Results of Kendall's $\tau$ correlation tests (at 5\% and 10\% levels) between 10years moving averaged flood series and 3-months averaged PDO anomalies with 9-months lead time. Black dots indicate sites for which no significant correlations were observed; grey squares represent sites for which tests were not conducted 91 
Figure 4-8: Results of Kendall's $\tau$ correlation tests (at 5\% and 10\% levels) between 10years moving averaged flood series and 3-months averaged AMO anomalies with 3-months lead time. Black dots indicate sites for which no significant correlations were observed; grey squares represent sites for which tests were not conducted. 92

Figure 4-9: Results of Kendall's $\tau$ correlation tests (at 5\% and 10\% levels) between 10years moving averaged flood series and 3-months averaged NAO anomalies with 3-months lead time. Black dots indicate sites for which no significant correlations were observed; grey squares represent sites for which tests were not conducted.

Figure 4-10: Results of Kendall's $\tau$ correlation tests (at 5\% and 10\% levels) between 10years moving averaged flood series and 3-months averaged MEI anomalies with 9-months lead time. Black dots indicate sites for which no significant correlations were observed; grey squares represent sites for which tests were not conducted. 93

Figure 4-11: Results of Kendall's $\tau$ correlation tests (at 5\% and 10\% levels) between 10years moving averaged flood series and 3-months averaged NINO 3.4 anomalies with 6-months lead time. Black dots indicate sites for which no significant correlations were observed; grey squares represent sites for which tests were not conducted.... 93 


\section{List of tables}

Table 2-1: Number of sites per state (total of 143 sites).

Table 2-2: Summary statistics for annual maximum flood series of the 143 watersheds.

Table 2-3: Statistics for mean watershed elevation and slope for the 143 watersheds. . 27

Table 2-4: Mean percentages of land-use/land-cover types for each cluster and number of sites included therein. Bold values identify dominant land-use/land-cover. . 35

Table 2-5: Summary statistics (\%) by cluster for each land-cover/land-use variable. Bold values identify dominant land-use/land-cover within each cluster 36

Table 2-6: Summary statistics for the hydrologic disturbance index, population density and road density by land-use/land-cover cluster.

Table 2-7: Total and mean number of dams and major dams within each cluster. 42

Table 3-1: Number of sites exhibiting change-points within various time intervals as identified by Pettitt test at both 5\% and 10\% significance levels 55

Table 3-2: Relationship between year of significant shift in annual maximum flood peaks and human-induced alterations as recorded in Gages II. 56

Table 3-3: Posterior probability of the number of possible change-points derived from the MCP analysis for annual maximum flood series of example sites 61

Table 4-1: Number of sites yielding significant correlations between AMF magnitude and leading X-days total precipitation series based on Kendall's $\tau$ correlation test at both $5 \%$ and 10\% levels (with and without Bonferroni correction for $N=$ 136) 75

Table 4-2: Results of Kendall's $\tau$ correlation test (at both 5\% and 10\%) with Bonferroni correction considering the number of sites for which the X-days lead time yields the greatest degree of association between AMF magnitude and precipitation. 76

Table 4-3: Number of sites in each land-use/land-cover cluster for which the X-days lead time yields the greatest degree of association between AMF magnitude and precipitation depth 
Table 4-4: Comparison of the timing and direction of change-points detected by the Pettitt test for both precipitation and AMF series at the 10\% level (bold values

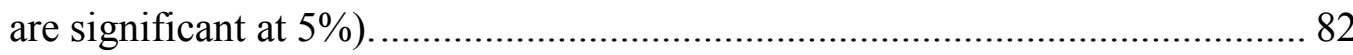

Table 4-5: Results of Pearson's $r$ correlation test at the $10 \%$ significance level between flood peak timing and minimum/maximum temperature series with $\mathrm{X}$-days lead time yielding the greatest degree of association......................................... 84

Table 4-6: Sources and available period of records for climate indices (anomalies) associated with large-scale oceanic-atmospheric patterns. ............................ 87

Table 4-7: Number of sites with significant Kendall's $\tau$ correlation (at 5\% and 10\% levels) between the 10 -year moving averaged flood series and climate patterns represented by 3-months averaged climate indices with 3-, 6- and 9-months lead times. 90 


\section{Acknowledgments}

I wish to express my greatest gratitude to Dr. Veronica Griffis for her guidance, help and invaluable assistance throughout the course of this thesis. She has been a supportive, patient and understanding advisor; her passion and knowledge has motivated my research and has enriched my professional background as an environmental engineer. I am immensely grateful I had the chance to work with her, and without her this thesis would have not been written.

I would like to thank my committee members Dr. Alex Mayer and Dr. Claudio Mazzoleni for their time and their suggestions to refine this thesis; and the National Science Foundation (EAR-1053655) for the financial support.

I am heartily thankful to Swarup China whose love and care have encouraged and supported me day by day during my studies at the Michigan Tech. He has been always present to comfort and help me in any moment of distress. It is thanks to him if I could achieve this goal and feel home although far from my family and my country.

Very special thanks to my mother Carmen for her immense love, encouragement and support. Anyone of my successes has been possible only thanks to her; she is always there for me in both joyful and difficult moments. She is the mentor of my life and I will always be thankful to her to be such a special and careful mom whom I deeply love. I'm thankful to my sister Ingrid who supported my decision to come to the United States although it meant to be far from each other. No miles can change the love that joins us. I would like also to thank Lorenzo for his support, care and kindness during the last few years and for becoming a fundamental member of my family.

Last, but not least, thanks to my dear friends Ezequiel, Tristan and Loredana for their words of encouragement and support. Thanks to Casey Fritsch who helped me in getting started with my research and to Jonathan Nelson for his hard work and invaluable help during the last summer in handling the data. 


\section{Abstract}

United States federal agencies assess flood risk using Bulletin 17B procedures which assume annual maximum flood series are stationary. This represents a significant limitation of current flood frequency models as the flood distribution is thereby assumed to be unaffected by trends or periodicity of atmospheric/climatic variables and/or anthropogenic activities. The validity of this assumption is at the core of this thesis, which aims to improve understanding of the forms and potential causes of nonstationarity in flood series for moderately impaired watersheds in the Upper Midwest and Northeastern US. Prior studies investigated non-stationarity in flood series for unimpaired watersheds; however, as the majority of streams are located in areas of increasing human activity, relative and coupled impacts of natural and anthropogenic factors need to be considered such that non-stationary flood frequency models can be developed for flood risk forecasting over relevant planning horizons for large scale water resources planning and management.

Results of standard statistical tests performed herein to identify trends and/or changepoints in flood magnitude series provide evidence of non-stationarity at several gauging stations for moderately impaired watersheds across the study region. Both natural and anthropogenic factors were investigated as driving causes of this non-stationarity. Although significant correlation was observed between flood magnitude and precipitation series, a causal dependency was not assured as the trends and timing of change-points observed in precipitation series were inconsistent with those associated with flood series. Moreover, temperature series yielded higher correlation with the timing of flood peaks rather than their magnitude. For several sites, strong association was observed between flood series and large-scale climate patterns. Teleconnections in response to the Pacific Decadal Oscillation (PDO) and Atlantic Multidecadal Oscillation (AMO) are evident across the study area; relatively weaker relationships exist with the North Atlantic Oscillation (NAO) and El Niño/Southern Oscillation (ENSO). In addition, attempts were made to relate observed non-stationarity in flood 
magnitude with human activities such as the construction and presence of engineering infrastructure, degree of urbanization and dominant land-use/land-cover. Overall, findings herein suggest that alterations of flows due to human activities attenuate the influence of the temporal variability observed in meteorological variables such as precipitation and temperature; however, more detailed investigations at a watershedspecific scale are required to provide stronger evidence. 


\section{Introduction}

Floods have been and continue to be a natural hazard of significant importance, imparting human risk and environmental damages, and resulting in both social and economic costs in many parts of the world. Several major flood events have occurred throughout Europe and North America in recent years, and the perception is that floods have increased in terms of both magnitude and frequency over the last century (Milly et al., 2002; Svensson et al., 2005). In the United States, statistically significant increasing trends have been identified for total and per capita annual flood damage since 1934 (Pielke et al., 2002). With growing population and intense construction of infrastructure in flood prone areas (e.g., Ashley and Ashley (2008)), changes in flood occurrence and flood costs have been a stimulus for the scientific community to increase understanding of the underlying drivers responsible for these changes.

Climate change has provoked an intensification of the hydrologic cycle that can reasonably be related to the increased frequency of extreme hydrologic events such as floods (Huntington et al., 2009; Milly et al., 2002; Robson, 2002). Increments in temperature have been identified as altering snow cover extent and causing a more blended seasonal cycle in streamflows. Soil conditions have changed with a tendency toward being wetter in the Northeastern United States and drier in the Southwestern regions. Evaporation, near-surface humidity and total cloud cover have also increased (Groisman et al., 2001; Groisman et al., 2004). The United States are experiencing the increase in annual precipitation (zonally averaged) that the second IPCC (1996) predicted for higher latitudes as a consequence of climate change; this has resulted in increased runoff, making floods more likely to occur and their frequency to increase (Burn and Hag Elnur, 2002; IPCC, 1996; Svensson et al., 2005).

Groisman et al. (2004) found that high flows, defined as those exceeding the $90^{\text {th }}$ percentile of daily streamflow data (Groisman et al., 2001), are more likely to occur since the $1950 \mathrm{~s}$ as a consequence of changes in precipitation, evapotranspiration and snow cover extent. Moreover, shifts in large-scale climate patterns might influence the 
hydrological response of US basins, and an increased frequency of hurricane landfalls might result in more intense flow events on the Atlantic and Gulf coasts (Groisman et al., 2001; Groisman et al., 2004). Considering monthly regional streamflow series for several basins across the United States, Lins and Michaels (1994) detected increasing trends since the early 1940s occurring mostly in fall and winter, while Lettenmaier et al. (1994) identified positive trends mainly in winter and spring. The authors of the latter study emphasize the role played by soil moisture storage in interpreting the temporal relationship between flows and precipitation series. They speculate that the lag between fall precipitation and winter floods could be explained by the recharge of the soil moisture depleted by evaporation during the summer.

As the impacts of increased urbanization are well known to increase the magnitude and frequency of flood peaks (Moglen and Schwartz, 2006; Sauer et al., 1983), recent efforts have focused on investigating the potential linkages of climatic changes with changes in flood occurrence (Fritsch, 2012; Kundzewicz et al., 2005; Olsen et al., 1999; Villarini et al., 2009a; Villarini and Smith, 2010; Villarini et al., 2011; Wilby et al., 2008). Most of these studies focused on unimpaired watersheds for which the streamflows are deemed relatively unaffected by human impacts, and thus are considered more suitable to isolate and investigate the effects of atmospheric variability (e.g., changes in precipitation and temperature series and large-scale climatic patterns) on streamflows. Nevertheless, analyses should be extended in order to evaluate the influences on the hydrologic response of the basins due to coupling of natural and anthropogenic disturbances. Moreover, both sources of non-stationarity in annual maximum flood series should be included in the development of improved long-term flood forecasts for large-scale water resources planning and management. These considerations represent the foundation of this thesis, wherein both the form and causes of non-stationarity in flood series for moderately impaired watersheds in the Upper Midwest and Northeastern United States are investigated. The definition of a moderate degree of impairment and the criteria adopted for site selection are discussed in detail in Chapter 2. 


\subsection{Research motivation}

The standard procedures currently employed in the United States for assessing and forecasting flood risk are documented in Bulletin 17B issued in 1982 (IACWD, 1982). The guidelines state that a log-Pearson type 3 (LP3) distribution must be adopted as the theoretical distribution used to model the frequency of annual maximum flood events defined by the largest instantaneous flow observed in a given year. Using the available period of record at an individual gauging station, the at-site flood frequency distribution is obtained by applying the method of moments in which the distribution parameters are directly related to the sample mean, standard deviation and skewness of the annual maximum flood series (containing $N$ flood peaks for $N$ years of record). The Bulletin $17 B$ procedures also account for regional skew information, historical flood events, and the presence of low outliers or zero flows (Griffis and Stedinger, 2007a). From the fitted distribution, the magnitude of any design flood (e.g., the 100-year event corresponding to an annual exceedance probability of $1 \%$ ) can be determined for multiple engineering purposes such as river management (e.g., floodplain delineation and channelization), land-use planning, construction of water-use and water-control structures (e.g., dams, derivations, reservoirs and culverts), and for design of transportation infrastructure (e.g., bridges and roads).

Since 1982, the necessity of updating Bulletin $17 B$ to improve flood risk estimates has emerged due to increasing evidence of the impacts related to climate change. The most significant limitation of the current procedures resides in the assumption that annual maximum flood series are stationary (Franks and Kuczera, 2002; Griffis and Stedinger, 2007b). Traditional moment estimators are used to compute the sample moments employed to estimate the distribution parameters, and thus they are time-invariant. The assumption of stationarity has important consequences as it implies that flood frequency is not influenced by human activities within the watershed or climatic variability such as trends or cyclical patterns in atmospheric variables. Moreover, the flood risk associated with a given magnitude of flow is assumed to be constant over time, and historical flood events are deemed representative of future floods. 
Alterations to the water cycle induced by climate change (e.g., changes in temperature and precipitation and atmospheric circulations) along with disturbances derived from anthropogenic activities (e.g., urbanization, deforestation, agricultural practices and channelization) should not be further neglected in flood definition (Burn and Elnur, 2002; references therein). Results of recent studies bring into question the validity of the assumption of stationarity in flood series, calling for a change in methods employed for flood risk assessment and water resources planning and management (Fritsch, 2012; Kashelikar, 2009; Milly et al., 2008). If flood series are non-stationary, then the design discharge (e.g., 100-year event) is not constant over time, meaning that a flood magnitude with a specified exceedance probability this year (e.g., $1 \%$ for the 100 -year event) could be associated with a different exceedance probability (level of risk) in a future year (Raff et al., 2009). Raff et al. (2009) included Global Circulation Model (GCM) projections of temperature and precipitation, properly scaled in time and space, in a hydrologic model applied to four watersheds in the Western United States. The simulated annual maximum flood obtained for specified future periods (2011-2040, 2041-2070 and 2071-2099) increased over time implying that current procedures underestimate magnitude and frequency of flood by neglecting climate variability.

\subsubsection{Non-stationary flood frequency analysis}

Several studies have discussed the development of models for flood risk forecasting which take into account the non-stationary behavior of flood series. Many authors have proposed use of probability distributions with time-dependent parameters. For example, Cunderlik and Burn (2003) and El Adlouni et al. (2007) suggest applying the Generalized Extreme Value (GEV) distribution with time-dependent parameters. Strupczewski et al. (2001) present a technique to account for trends in flood series by applying the maximum likelihood method in the estimation of the parameters of six different flood frequency distributions (normal, 2-parameter lognormal, 3-parameter lognormal, gamma, Pearson type III and Gumbel). Nevertheless, use of time-dependent parameters in frequency analyses may not be the most appropriate method to account for variability in flood risk, as it implies that the observed trends would continue in 
perpetuity. According to Stedinger and Griffis (2011), a better approach would be to relate variations in flood peaks to climatic or meteorological characteristics in order to provide a "physical-causal basis for multidecadal projection" of flood risk.

Teleconnections between annual maximum flood peaks and climatic indices have been identified and used to improve the estimates of flood risk (Chiew and McMahon, 2002; Fritsch, 2012; Jain and Lall, 2001; Kashelikar, 2009; Kiem et al., 2003; Kwon et al., 2008; Wood et al., 2002). Franks and Kuczera (2002) found correlations between flood distributions and Pacific and Indian Ocean climate anomalies (e.g., sea surface temperature) in New South Wales, Australia. The authors remark on the necessity to distinguish between short- and long-term flood risk, and that a better understanding of the climatic variability related to multidecadal patterns needs to be achieved in order to estimate short-term flood risk. In fact, without accounting for multiyear climate patterns, current procedures can only provide estimates of "long-term or unconditional flood risk" (Franks and Kuczera, 2002). Similarly, Jain and Lall (2001) consider the influence of the El Niño/Southern Oscillation (ENSO) on flood risk, and emphasize the importance of increasing understanding of "climate-related flood risk" in order to improve water resources management (e.g., construction of dams, floodplain planning and delineation).

Following these recommendations, Kwon et al. (2008) applied a Bayesian model to improve forecasts of flood risk at Clark Fork River in Montana by incorporating the effects of multiple climate indicators: sea surface temperature, predicted GCM precipitation, Pacific Decadal Oscillation (PDO) and ENSO climate indices, and snow pack. Griffis and Stedinger (2007b) proposed using a regression model to estimate timedependent LP3 parameters (mean $\mu_{X}(t)$, standard deviation $\sigma_{X}(t)$ and coefficient of skewness $\left.Y_{X}(t)\right)$ as function of three-month averaged climate indices observed in year $t$. A model for the mean would be developed as follows:

$$
\mu_{X}(t)=\omega_{0}+\omega_{1} c(t)+\varepsilon(t)
$$


where $\mu_{X}(t)$ is computed as the average of the log-transformed flood observations through time $t, \omega_{i}$ are regression parameters, $c(t)$ corresponds to the climate index at time $t$, and $\varepsilon(t)$ is the independent model error. Based on these considerations, Kashelikar (2009) developed a model to forecast flood risk one-year ahead by accounting for influences of ENSO on the mean of the flood distribution as represented by:

$$
\hat{\mu}_{X}(t+1)=\omega_{0}+\omega_{1} \hat{c}(t+1)
$$

where $\hat{c}(t+1)$ is the forecasted value of ENSO at time $t+1$ obtained from the Climate Prediction Center (http://www.pmel.noaa.gov/tao/elnino/forecasts.html\#enso). In order to define the three months of values of ENSO to consider, Kashelikar (2009) assumed flood peaks occur in the month of April in each of the US watersheds considered. However, Fritsch (2012) demonstrated this assumption to be invalid for most cases, and proposed an improved and extended version of the model.

For an individual site, Fritsch (2012) recommends first identifying the most likely month of occurrence of flood peaks, and then developing the regression model in equation (1) as a function of climate anomalies for both the mean $\mu_{X}(t)$ and standard deviation $\sigma_{X}(t)$. Moreover, he extended the model to include four climate indices: Atlantic Multidecadal Oscillation (AMO), PDO, North Atlantic Oscillation (NAO) and ENSO. For example, the mean would be given by:

$$
\mu_{X}(t)=\omega_{0}+\omega_{1} c_{1}(t)+\omega_{2} c_{2}(t)+\omega_{3} c_{3}(t)+\omega_{4} c_{4}(t)+\varepsilon(t)
$$

where $c_{i}(t)$ represent the three-month averaged observations at time $t$ for each of the four climatic indices relative to mode month of flood peak occurrence. Applying the model to provide forecasts of flood risk one-year ahead, Fritsch (2012) found differences from what would be computed according to Bulletin 17B. Nevertheless, further validation of the model is required at the watershed scale and an extension for long-term forecasting should be considered. Moreover, while these proposed modifications of the Bulletin $17 B$ guidelines would effectively account for nonstationarity in flood series occurring in response to climatic variability, a better 
understanding of non-stationarity in annual maximum flood series induced by different sources (e.g., meteorological, climatic, anthropogenic or some combination thereof) is needed in order to develop a statistical model which can provide adequate projections of flood risk over relevant planning horizons (e.g., 20- or 50-years). Methodologies to assess forms and causes of non-stationarity in hydrologic series, and findings from previous studies are summarized below.

\subsubsection{Evidence of non-stationarity in hydrologic series}

Many authors have investigated the existence of trends in streamflow series at different temporal (e.g., daily, monthly, annual) and spatial scales (e.g., local, regional, national); relatively fewer studies have considered the instantaneous annual maximum flood series used to define design events for large scale water resources planning and management projects. In general, the detection of monotonic trends in hydrologic time series has been conducted by applying three tests: Mann-Kendall, Spearman's Rho, and/or Linear Regression (Kalra et al., 2006; Olsen et al., 1999; Svensson et al., 2005). The first two tests are non-parametric tests, the latter is parametric. Kalra et al. (2006) applied all three methods to detect trends in average annual series for 639 unimpaired watersheds across the United States with gauged data from 1951 to 2002. The different methods provided similar results identifying upward trends in the Upper and Middle Mississippi River basin and downward trends in the Pacific Northwest, as well as at some stations in Florida (Kalra et al., 2006).

Overall, the non-parametric Mann-Kendall test is most commonly used for trend detection. Lettenmaier et al. (1994) found positive trends in average monthly streamflows for numerous basins across the United States. Considering series of average daily flow for 395 stations across the United States, Lins and Slack (1999) identified a number of statistically significant positive trends in low and moderate streamflows ranging from the annual minimum daily mean to the $70^{\text {th }}$ quantile; relatively few streams exhibited trends in high flows defined by the $90^{\text {th }}$ quantile up to the annual maximum daily mean. Similarly, McCabe and Wolock (2002a) considered 
annual minimum, median and maximum daily streamflows across the United States. They found significant increases in the annual minimum and median flows since 1970 primarily in the Eastern US; however, no clear trends were identified for maximum daily flows. Douglas et al. (2000) detected trends in lower quantiles of daily average flows, but not in larger quantiles, at large (Midwest) and small (Ohio, north central and upper Midwest) spatial scales. The authors also noticed that regional cross-correlation of streamflows highly influenced their trend analysis; the number of sites exhibiting statistically significant trends was reduced when accounting for cross-correlation, and thereby avoiding spurious positive results.

Despite an observed increase in total precipitation by $10 \%$ over the last century across the United States (Collins, 2009; Karl and Knight, 1998), increasing trends were mainly observed in low flow quantiles and less evidence of trends was found in high streamflows; these findings support the idea that the "conterminous United States are getting wetter but less extreme" (Lins and Slack, 1999). For instance, investigating annual flood series for 28 natural streams in New England, Collins (2009) detected increasing trends for low flow quantiles, but trends for high flow quantiles were not so evident. Nevertheless, it is believed that annual maximum flood peaks should be more highly correlated with heavy precipitation occurring in the Northeastern United States than the annual maximum average daily discharge (Collins, 2009; Hodgkins and Dudley, 2005; Olsen et al., 1999). Moreover, Groisman et al. (2001) found that variations of high/very high streamflows and heavy/very heavy precipitation, defined by the $90^{\text {th }}$ and $99^{\text {th }}$ monthly percentiles of daily series, were similar since the $1950 \mathrm{~s}$ in the continental United States. Significant positive trends in annual maximum flood series have been identified within the Upper Midwest and Northeastern portions of the United States confirming Groisman et al.'s findings (Fritsch, 2012; Kashelikar, 2009; Kashelikar and Griffis, 2008; Olsen et al., 1999). Kashelikar (2009) applied the MannKendall test to annual maximum flood series of 396 unimpaired watersheds across the United States and found significant trends in the North Pacific, Midwest and Eastern United States. Analogously, Fritsch (2012) performed the test for a larger number of 
stations (569) observing statistically significant trends in the Eastern and Midwestern United States.

Non-stationarity in hydrologic series has also been investigated in terms of abrupt shifts (step changes) in the mean and/or variance of the time series by applying both nonparametric (Rank-Sum, Pettitt test) and parametric (Student's t) methods (Kalra et al., 2006). When testing for non-stationarity in flow records of 400 US streams, McCabe and Wolock (2002a) found increasing trends of minimum, median, and less evidently, of maximum daily streamflows since 1970, but they also observed that changes in the series are more likely to manifest as a step change rather than a gradual change (trend) over time. Similar results were obtained by Kalra et al. (2006) for average annual streamflows. Moreover, shifts in precipitation series have also been identified around the 1970s (Collins, 2009; Mauget, 2003; Perreault et al., 1999), suggesting a possible causal relationship between precipitation and streamflow from a statistical view point.

The Pettitt test was adopted in several recent studies to identify the existence of abrupt shifts in annual maximum peak discharge time series (Fritsch, 2012; Villarini et al., 2009a; Villarini and Smith, 2010; Villarini et al., 2011). One advantage derived by applying a non-parametric test, such as the Pettitt test, is decreased sensitivity to the presence of outliers or skewness in the distribution of flows as compared to use of standard hypothesis tests based on the Student $t$ distribution (Villarini and Smith, 2010). Villarini et al. (2011) applied the Pettitt test for both mean and variance of annual maximum flood peaks for 196 stations in the Midwestern US, and observed that nonstationarity in flood series is generally related to change-points (step changes) rather than gradual trends. The authors speculated that abrupt changes could be caused by both natural and anthropogenic factors such as climate patterns, changes in rainfall regimes, changes in land-use and land-cover and/or construction of engineering structures for flow regulations (i.e., dams and reservoirs) (Villarini et al., 2011).

A prime limitation of the Pettitt test is that it can only identify a single change-point in a given time series. As such, in the last decade many studies have focused on the development of Bayesian models capable of detecting multiple change-points 
(Ehsanzadeh et al., 2011; Fearnhead, 2005, 2006; Ruggieri, 2012; Seidou and Ouarda, 2007). The Bayesian approach has been applied to different types of hydrologic and climatic variables; however, applications to streamflow records are limited (Ehsanzadeh et al., 2011; Rasmussen, 2001; Seidou et al., 2007).

Further analysis of non-stationarity in flow series has involved the application of peaksover-threshold (POT) techniques, in which the relevant flood series is composed of all observed flow events which exceed some predefined threshold, and thus possibly includes a higher number of events than the annual maximum flood series which is composed of only the largest event observed in each year of record. Overall, the general consensus is that the POT approach "allows for a more rational selection of events to be considered as floods" (Lang et al., 1999), and the additional information gained from inclusion of a larger number of flood peaks allows for a better definition of the extreme upper tail of the flood distribution (Katz et al., 2002). However, application of POT analyses is still limited due to the difficulties intrinsic to the method such as the choice of a proper threshold (Lang et al., 1999; Svensson et al., 2005). Nonetheless, this may be a moot point as Svensson et al. (2005) indicated that use of the POT series would fail to take into account small flood events corresponding to dry years which should not be neglected for the trend determination.

Beyond simply evaluating the non-stationarity of flow series, numerous studies have employed correlation analyses between streamflows and meteorological variables (e.g., precipitation and temperature) to investigate potential causal dependency. In the continental United States, Lettenmaier et al. (1994) investigated trends not only in average monthly flows as discussed above, but also in average monthly and daily minimum and maximum temperature, average daily temperature range and monthly total precipitation for the period from 1948 to 1988. Discrepancies were observed between trends in streamflows and changes in the other variables, which Lettenmaier et al. (1994) speculated were due to a combination of climatic variability and water management practices. 
Many authors considered the relationship between snowpack, peak streamflows and precipitation/temperature trends in the Western United States (Cayan et al., 2001; Dettinger and Cayan, 1995; Dettinger et al., 2004; Hamlet et al., 2005; McCabe and Wolock, 2002b; Mote, 2003; Sheppard et al., 2002). In the Eastern United States, where snowpack does not play a dominant role as in the West, evidence of a strong relationship between heavy precipitations and high flows was found as previously discussed (Groisman et al., 2001; Karl and Knight, 1998). Similar results were observed in the Midwest as well (Changnon and Kunkel, 1995; Kunkel et al., 1999; Sankarasubramanian et al., 2001). Fritsch (2012) found strong correlation between annual maximum flood and precipitation series for several unimpaired watersheds in the Upper Midwest and Northeastern US. Considering minimum and maximum temperature series, the author observed higher association with the timing of the flood peaks rather than with the magnitude (Fritsch, 2012). Pielke Jr and Downton (2000) evaluated the correlation between changes in precipitation and damaging floods defined as those that result in human losses and/or damages to property; and they related the increased flood damages over the last few decades to both increased precipitation and societal factors (i.e., increasing population and wealth).

In some studies, different approaches were proposed to distinguish between the contributions of climatic changes (e.g., changes in precipitation over time) from the influences of anthropogenic activities on flows. For instance, Changnon and Demissie (1996) considered annual mean flow and peak flow data for four watersheds in the Midwest, two mainly urbanized and two mainly rural. The region was characterized by increments in annual precipitation and heavy rain events in the period from 1940 to 1990. The authors found that flows in the urban basins were significantly more affected by the increasing precipitation and changes in runoff than in the rural basins. Moreover, in one of the two urban basins, the urbanized area significantly increased over the 19401990 time period providing stronger justification to the increments in both mean and peak flows exhibited by the watershed. 
As implied in Section 1.1.1, climatic variability due to large-scale oceanic atmospheric patterns might also represent a significant contribution to the non-stationary character of streamflows. PDO, NAO, and AMO have low frequency variability with shifts occurring on a decadal scale, meaning that they may induce long-term variability in streamflows and flood risk (Griffis and Stedinger, 2007b). Instead, climatic patterns with more frequent variability (i.e., ENSO with shifts on the order of 12-18 months) will unlikely affect flood risk on the long term, but would be useful for short-term forecasts of flood risk one or two years ahead (Griffis and Stedinger, 2007b).

Consequently, numerous studies have considered the effects of climatic patterns on streamflow and/or flood series (Barlow et al., 2001; Dracup and Kahya, 1994; Fritsch, 2012; Jain and Lall, 2001; Kashelikar, 2009; Kashelikar and Griffis, 2008; Kiem et al., 2003; McCabe and Dettinger, 1999; Olsen et al., 1999; Tootle et al., 2005). Tootle et al. (2005) evaluated the effects of the phases of both Pacific Ocean (ENSO and PDO) and Atlantic Ocean (AMO and NAO) climate patterns on average monthly flows measured from 1951 to 2002 for 639 watersheds across the United States. They observed high degrees of association between streamflows and the phase of ENSO in Florida, and in the Southwest and Pacific Northwest. In the central and Southwestern US correlation was found between PDO and AMO warm phases and increasing/decreasing streamflows, respectively, and relationships were identified between increasing flows and the warm phase of NAO and the cold phase of AMO in the central US (Tootle et al., 2005). Cayan et al. (1999) used the Southern Oscillation Index as an ENSO phase indicator to investigate relationships with daily streamflows in the Western US. They detected a high degree of correlation of flows with the two phases of ENSO.

With respect to annual maximum flood series, for stations in the Upper Mississippi, Lower Mississippi and Illinois River Basins, Olsen et al. (1999) investigated possible relationships between annual maximum flood flows and ENSO, PDO and NAO, and although no strong relationships were identified, their results did suggest the variability over time of flood risk; however, no alternative source for this non-stationary behavior was identified. Kashelikar (2009) observed significant teleconnections between annual 
maximum flood series and ENSO and PDO for several unimpaired watersheds in the Pacific Northwest and South Atlantic-Gulf regions; strong correlation with NAO was not evident. Similarly, focusing on unimpaired US watersheds, Fritsch (2012) found significant association of annual maximum flood magnitudes with AMO and PDO across the US. For NAO, stronger teleconnections were detected in the Pacific Northwest, South Central US, and New England. Less evidence of correlations with ENSO was observed.

In order to isolate the impacts of climatic variability, the majority of the aforementioned studies were conducted in unimpaired watersheds that are relatively free from human activity (i.e., engineering structures for flow diversion and regulation, urbanization, agriculture practices). Many authors (Douglas et al., 2000; Hamlet and Lettenmaier, 2007; Kashelikar, 2009; McCabe and Wolock, 2002a) selected unimpaired watersheds based on their inclusion in the Hydro-Climatic Data Network (HCDN) prepared by Slack et al. (1993). Unimpairment was defined as streamflows being reasonably natural, due to the absence of disturbances causing significant alterations of the monthly average discharge observed at the gauge (Slack et al., 1993; Slack and Landwehr, 1992). An update to the HCDN was included in the Gages II dataset (Falcone et al., 2010b) and it has been utilized for site selection in more recent studies (Fritsch, 2012).

Villarini et al. (2011) pointed out that many basins in the Midwestern US have been altered by changes in land-use and land-cover, urbanization and construction related to water management, and thus "human alterations can be considered a characteristic of the flood records" (Villarini et al., 2011). A similar conclusion can be derived for basins in the Eastern US (Villarini et al., 2009a; Villarini and Smith, 2010). Collins (2009), investigating unimpaired basins in New England, realized reforestation has been substantial in the region tending to reduce flood peaks.

In other studies the influence on flows due to increasing urbanization has been emphasized. For example, Rose and Peters (2001) compared the urbanized watershed of Peachtree Creek with six other less urbanized basins in the Atlanta area (GA), and found that peak flows of Peachtree Creek ranged from $30 \%$ to more than $100 \%$ greater 
than the peak flows in the other basins; Konrad (2003) linked observed increases in the magnitude and frequency of floods to urbanization, providing as proof a few examples for different basins across the US. Villarini et al. (2009a) justified streamflow alterations with increasing surface runoff and decreasing infiltration caused by the extension of urbanized areas. The authors investigated non-stationarity in annual maximum flood peaks of the Little Sugar Creek, watershed in North Carolina which has been subjected to intense urbanization (Villarini et al., 2009b); they identified increasing annual flood magnitudes since the 1960s, years characterized by intense urbanization and growing population.

In regards to land-use/land-cover changes, several studies considered changes in agricultural practices as flow-influencing factors; however, the effects were less evident than those due to urbanization (Poff et al., 2006; Qi et al., 2009; Wang and Hejazi, 2011; Zhang and Schilling, 2006). Zhang and Schilling (2006) related observed increases in average monthly and annual streamflows and baseflow in the Mississippi River since the 1940s to changes in agricultural practices, especially the extension of soybean cultivation. Qi et al. (2009) analyzed monthly streamflows of Trent River, North Carolina, under seven different scenarios of land-use (from forest to crop lands and urban areas). Their results showed less significant effects on flow due to land-use as compared to climatic variability. Evaluating the effects of both climate and anthropogenic activities on mean annual streamflows across the US, Wang and Hejazi (2011) identified cropland extension, irrigation and reservoirs as direct human impacts to account for.

It is clear that multiple factors, both natural and anthropogenic, might induce nonstationary behavior in the hydrologic response of US watersheds, and thus current procedures for evaluating flood risk are insufficient for long-term planning and management. More appropriate techniques should be adopted to avoid environmental and economic damages and, especially, to guarantee human safety. However, the knowledge of causes of non-stationarity in flood series needs to be extended before proposed models for non-stationary flood risk assessment can be put into practice. 


\subsection{Research objectives}

The objective of this thesis is to increase knowledge of the physical/anthropogenic sources of non-stationary behavior in annual maximum flood series relative to climatic and meteorological sources. This is necessary given that non-stationarity induced by anthropogenic activities has become an intrinsic feature of US streamflows even in watersheds previously deemed unimpaired; and traditional models of flood frequency (i.e., Bulletin 17B) need to be extended for use in watersheds with a moderate degree of impairment. Analyses herein are conducted for moderately impaired watersheds located in the Northeastern quadrant of the United States. In particular, this study investigates the following:

- non-stationarity in annual maximum flood series in the form of gradual trends and change-points (abrupt shifts);

- relationships between observed non-stationarity in annual maximum flood magnitudes and human activities within the watersheds;

- existence of statistically significant relationships between annual maximum flood series and meteorological variables (precipitation and temperature);

- teleconnections for multiple climatic indices.

This thesis constitutes a component in a larger project with the purpose of combining statistical and physical analyses to develop a model of flood risk projections which accounts for both climatic and anthropogenic effects on flood flows and can be applied over relevant planning horizons (20- to 50 -years ahead) for large scale water resources planning and management. The development of this type of non-stationary model would represent a turning point in flood risk forecasting, as it would hopefully lead to the modification of well-established procedures adopted in multiple engineering applications (e.g., floodplain delineation, land-use planning, design of dams and bridges) throughout the United States. 


\section{Moderately impaired watersheds}

Many studies considering non-stationarity in hydrologic series have focused on unimpaired sites in order to isolate the effects of climatic variability (Douglas et al., 2000; Fritsch, 2012; Hamlet and Lettenmaier, 2007; Kashelikar, 2009; McCabe and Wolock, 2002a); however, more recently these analyses have been extended to watersheds within which human impacts (e.g., urbanization, cultivations, engineering structures for water use and management) are not negligible. Alterations induced by anthropogenic activities on annual maximum flood flows have been identified for several streams across the United States (Collins, 2009; Konrad, 2003; Rose and Peters, 2001; Villarini et al., 2009a; Villarini and Smith, 2010; Villarini et al., 2011; Villarini et al., 2009b). These findings motivated the research presented in this thesis, which seeks to provide a better understanding of the degree and causes of non-stationarity in flood series in moderately impaired watersheds. This chapter describes the criteria adopted to identify the dataset of 143 basins in the Upper Midwest and Northeastern United States, whose annual maximum flood peak series were subjected to the analysis of nonstationarity as presented in the following chapters. Physical features, land-use/landcover and anthropogenic impacts were considered to characterize the watersheds and to define their degree of impairment.

\subsection{Study area and site selection}

This research builds upon the study performed by Fritsch (2012) wherein the degree of non-stationarity in annual maximum flood (AMF) series was investigated for unimpaired sites throughout the contiguous United States. Relevant sites were identified by the author based on their inclusion in the Hydro-Climatic Data Network (HCDN) (Slack and Landwehr, 1992), which is said to contain watersheds associated with US Geological Survey (USGS) gauging stations that can be considered "relatively free of anthropogenic influences" and thus "streamflow measured at these sites is considered to 
be natural" (McCabe and Wolock, 2002a). More specifically, Slack and Landwehr (1992) defined unimpaired watersheds as follows:

"There should be no over adjustment of "natural" streamflows, such as flow diversion or augmentation, regulation of the streamflow by some containment structure, or reduction of base flow by extreme ground-water pumping, nor should the degree of human activity in the watershed, such as changes in land use during the period of record, be so large as to significantly affect the value of monthly mean discharge at the station" (Slack and Landwehr, 1992).

Use of these types of sites allows for the isolation of impacts of climate on flow. However, for the purpose of this research, human alterations within the watersheds were fundamental to define a moderate degree of impairment, and thus HCDN sites are not considered herein. Details of what qualifies a watershed as moderately impaired are provided below. In addition, following USGS conventions (USGS, 2011), the watersheds referred to herein are defined by the area of land that contributes to runoff at the specified USGS gauging station, and thus the terms watershed, gauge, or site may be used interchangeably.

In this thesis, the degree of non-stationarity in annual maximum flood (AMF) series was investigated for moderately impaired watersheds located in the Northeastern quadrant of the United States. In particular, the study area is defined by US Hydrologic Regions 1, 4, and 5 (see Figure 2.1). Hydrologic Region 2 was not considered as watersheds associated with USGS gauges therein generally have a lower degree of impairment, and thus the degree of non-stationarity in flood series for associated gauging stations has already been assessed by Fritsch (2012). Impaired watersheds were identified by first considering all USGS gauging stations located within Hydrologic Regions 1, 4, and 5, but not contained in the HCDN, and for which AMF series are available. Then, to ensure that sufficient flood data were available for subsequent statistical analyses to assess non-stationarity, the set of impaired sites was further reduced by considering only those stations with at least 65 continuous years of records. The locations of the remaining 295 sites are shown in Figure 2.1. 


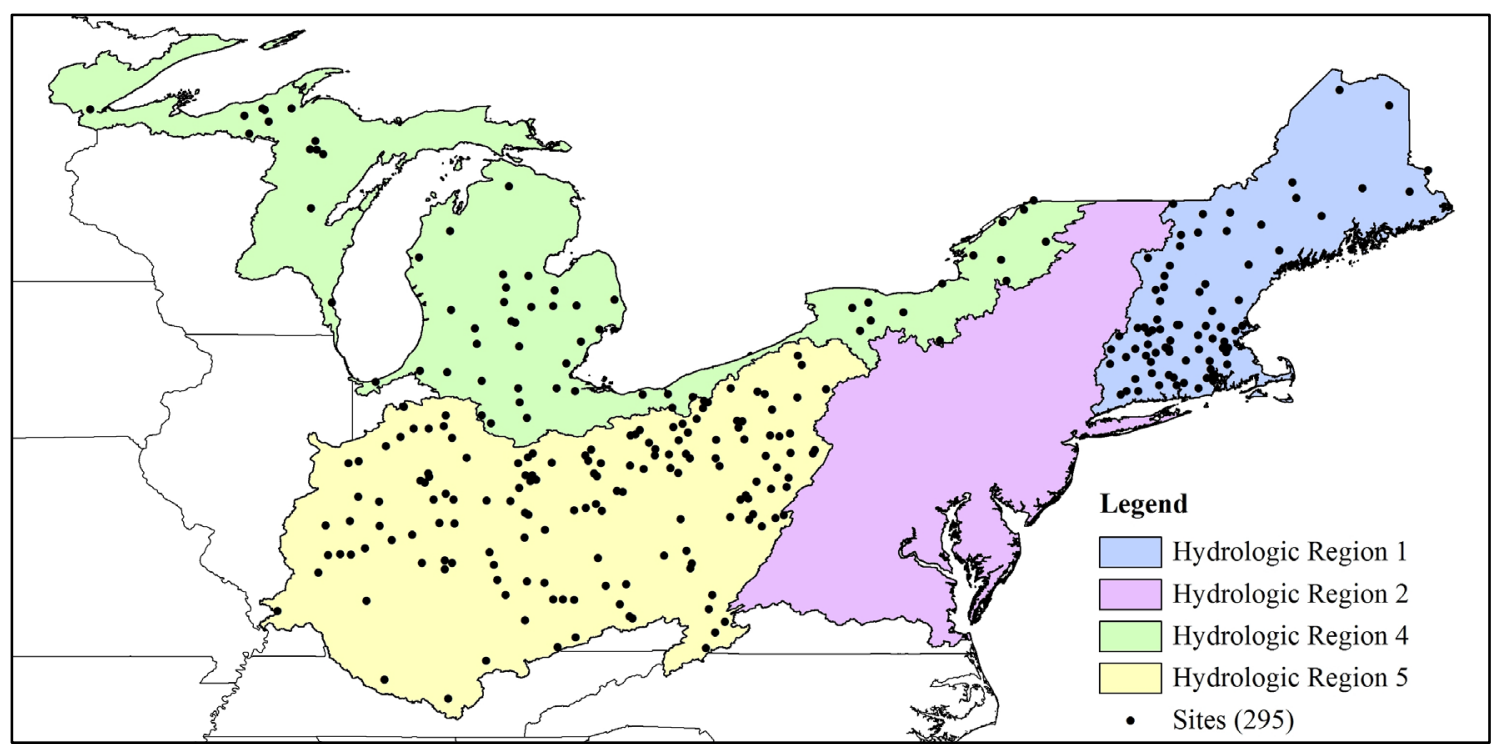

Figure 2-1: Locations of 295 impaired watersheds in Hydrologic Regions 1, 4 and 5 with at least 65 years of continuous annual maximum flood observations.

As this research contributes to a larger effort for which the end goal is an improved version of the LP3 model for flood risk forecasting capable of accounting for climatic and anthropogenic influences on flood peaks in moderately impaired watersheds, additional criteria were adopted to limit the degree of impairment as described below:

- A visual analysis of the boundaries of each watershed relative to US urban boundaries ${ }^{1}$ was performed. Basins were disregarded if the majority of the drainage area was contained within an urban boundary. Further, watersheds in close proximity to highly urbanized areas (e.g., Milwaukee, Chicago, Detroit and Boston) were not considered due to the high degree of anthropogenic impacts therein (e.g., extensive urbanization, channelization, reservoirs, diversions and intensive surface water withdrawals).

- Population data were also considered as a general indicator of urbanization. A watershed was considered highly urbanized, and therefore not considered herein,

\footnotetext{
${ }^{1}$ Data of the US urban boundaries were retrieved from the National Weather Service GIS-AWIPS Shapefile Database (http://www.nws.noaa.gov/geodata/) as defined by the US Census Bureau as urban areas (Source: TIGER 2000).
} 
if the population of cities and towns ${ }^{2}$ located within the watershed boundary exceeded 100,000 ab.

- USGS peak streamflow qualification codes were also taken into account. Sites for which the annual maximum flood peak in at least one year of the record was associated with the following codes were removed: "B: month or day of occurrence is unknown or not exact" and "9: discharge due to snowmelt, hurricane, ice-jam or debris dam breakup". However, sites associated with codes 5 and 6 were retained ("5: discharge affected to unknown degree by regulation or diversion", "6: discharge affected by regulation or diversion").

Finally, in the case of nested watersheds, only the sub-basins were retained for further consideration in order to avoid inflating any existing spatial correlation. Based on all of these criteria, the initial set of 295 watersheds was reduced to 143 which represent the dataset for the analyses presented in this thesis. The locations of these 143 gauging stations are shown in Figure 2.2 with respect to the US Hydrologic Regions. A total of 42 basins were included in Hydrologic Region 1, 36 in Hydrologic Region 4, and 65 in Hydrologic Region 5.

\footnotetext{
${ }^{2}$ Data of the cities and towns for the United States were retrieved from the National Weather Service GIS-AWIPS Shapefile Database (http://www.nws.noaa.gov/geodata/) as defined by the US Census Bureau (2000 Census).
} 


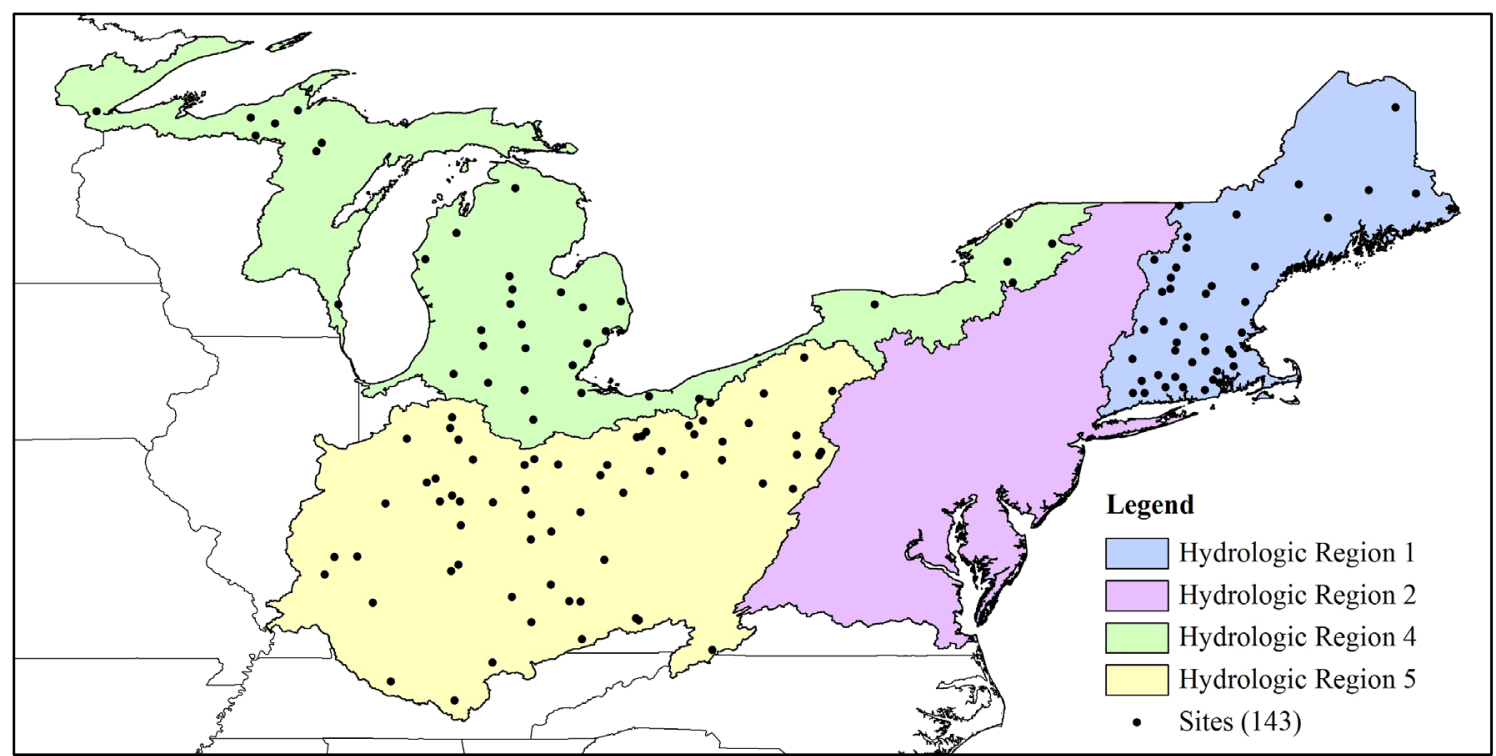

Figure 2-2: Locations of the 143 gauging stations defining the study area for moderately impaired watersheds in the Upper Midwest and Northeastern US.

\subsection{Annual maximum flood series}

Table 2.1 reports the number of basins within each state of the study area and the corresponding average record length. As previously mentioned, only sites with at least 65 years of continuous record were selected for analysis, and thus the average record lengths are reasonably long. Among the 143 sites, the minimum record length was consequently 65 years, and the maximum record length was 122 years for the gauging station of Licking River at Catawba, KY, with observations from 1888 to 2009. The average record length available for the entire dataset was 76 years. Table 2.2 provides additional summary statistics for the three sample moments $\left(\theta_{j}\right.$ for $j=1,2$ and 3$)$ of the annual maximum flood series computed across all 143 sites. These statistics represent the mean, standard deviation, coefficient of skewness, and maximum and minimum values of the 143 at-site sample values of the average $\left(\bar{x}_{i}\right)$, standard deviation $\left(s_{i}\right)$ and skewness $\left(G_{i}\right)$ of the flood series obtained for each watershed ( $i=1$ to 143). These statistics and record lengths are reported on a site-by-site basis in Appendix A. 
Table 2-1: Number of sites per state (total of 143 sites).

\begin{tabular}{|c|c|c|c|c|c|}
\hline State & $\begin{array}{c}\text { Number } \\
\text { of sites }\end{array}$ & $\begin{array}{c}\text { Average } \\
\text { record length }\end{array}$ & State & $\begin{array}{c}\text { Number } \\
\text { of sites }\end{array}$ & $\begin{array}{c}\text { Average } \\
\text { record length }\end{array}$ \\
\hline CT & 8 & 78 & NH & 6 & 80 \\
\hline IL & 2 & 71 & NY & 6 & 86 \\
\hline IN & 15 & 77 & OH & 27 & 72 \\
\hline KY & 11 & 75 & PA & 8 & 72 \\
\hline MA & 11 & 81 & RI & 4 & 69 \\
\hline MD & 1 & 72 & TN & 3 & 77 \\
\hline ME & 6 & 93 & VA & 3 & 78 \\
\hline MI & 22 & 74 & VT & 7 & 75 \\
\hline MN & 1 & 104 & WI & 2 & 81 \\
\hline
\end{tabular}

Table 2-2: Summary statistics for annual maximum flood series of the 143 watersheds.

\begin{tabular}{|c|c|c|c|}
\hline \multirow{2}{*}{ Summary statistic } & \multicolumn{3}{|c|}{ At-site flood statistic $\boldsymbol{\theta}_{\boldsymbol{j}}$} \\
\cline { 2 - 4 } & Mean $\left[\mathbf{m}^{\mathbf{3}} / \mathbf{s}\right]$ & $\begin{array}{c}\text { Standard } \\
\text { Deviation }\left[\mathbf{m}^{3} / \mathbf{s}\right]\end{array}$ & $\begin{array}{c}\text { Coefficient of } \\
\text { Skewness }\end{array}$ \\
\hline mean of $\theta_{j}$ & 205.3 & 102.5 & 1.749 \\
\hline standard deviation of $\theta_{j}$ & 273.0 & 122.0 & 1.342 \\
\hline coefficient of skewness of $\theta_{j}$ & 3.4 & 2.5 & 1.551 \\
\hline maximum of $\theta_{j}$ & 1912.8 & 749.2 & 7.045 \\
\hline minimum of $\theta_{j}$ & 5.5 & 1.0 & -1.118 \\
\hline
\end{tabular}

Given the large degree of skewness in the mean magnitudes of the flood series (3.4), a frequency analysis was performed to visualize variation in the dataset. Figure 2.3 shows the resulting distribution of the mean annual maximum flood magnitudes for the 143 watersheds. Additionally, the geographic distribution of the mean flood magnitude in the Upper Midwest and Northeastern US is illustrated in Figure 2.4. From Figure 2.4 it emerges that lower values of mean annual maximum flood magnitude tend to be concentrated in areas with more extensive urbanization such as the coastal part of New England, and portions of Michigan, Ohio and Indiana. In close proximity to urban areas, human alterations on the streams are expected to be more significant, and intensive water management and use (e.g., construction of reservoirs, power plants, dams and withdrawals) might reduce the magnitude of the mean annual maximum flood. On the contrary, higher values of the mean were mainly observed in areas of Indiana, 
Kentucky, Tennessee and the upper part of New England where cultivated crops and forests are the dominant land cover as reported in the 2006 National Land-Cover Dataset (Fry et al., 2011). Figure 2.5 shows the Northeastern part of the NLCD2006 with a scale of green colors for forests, blue for open water, brown for cultivated areas, yellow for pasture and red for developed regions.

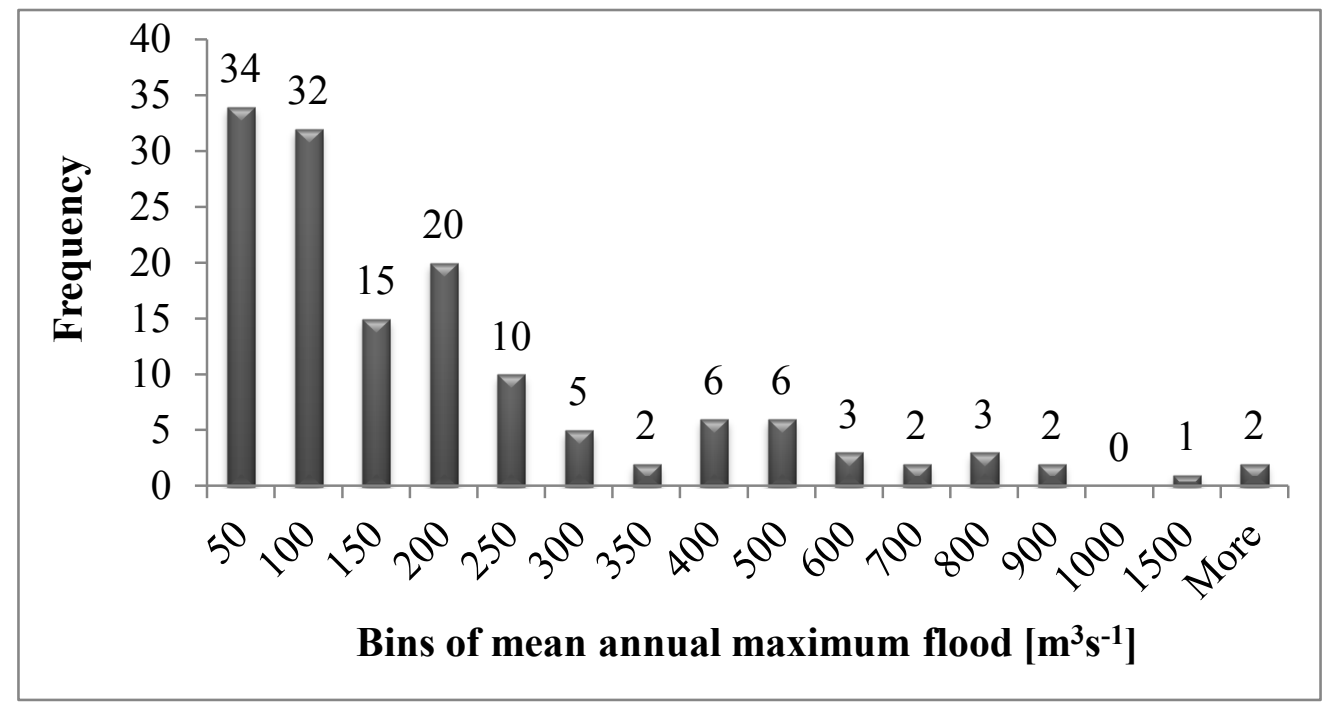

Figure 2-3: Frequency distribution of mean annual maximum flood magnitudes for the 143 watersheds. 


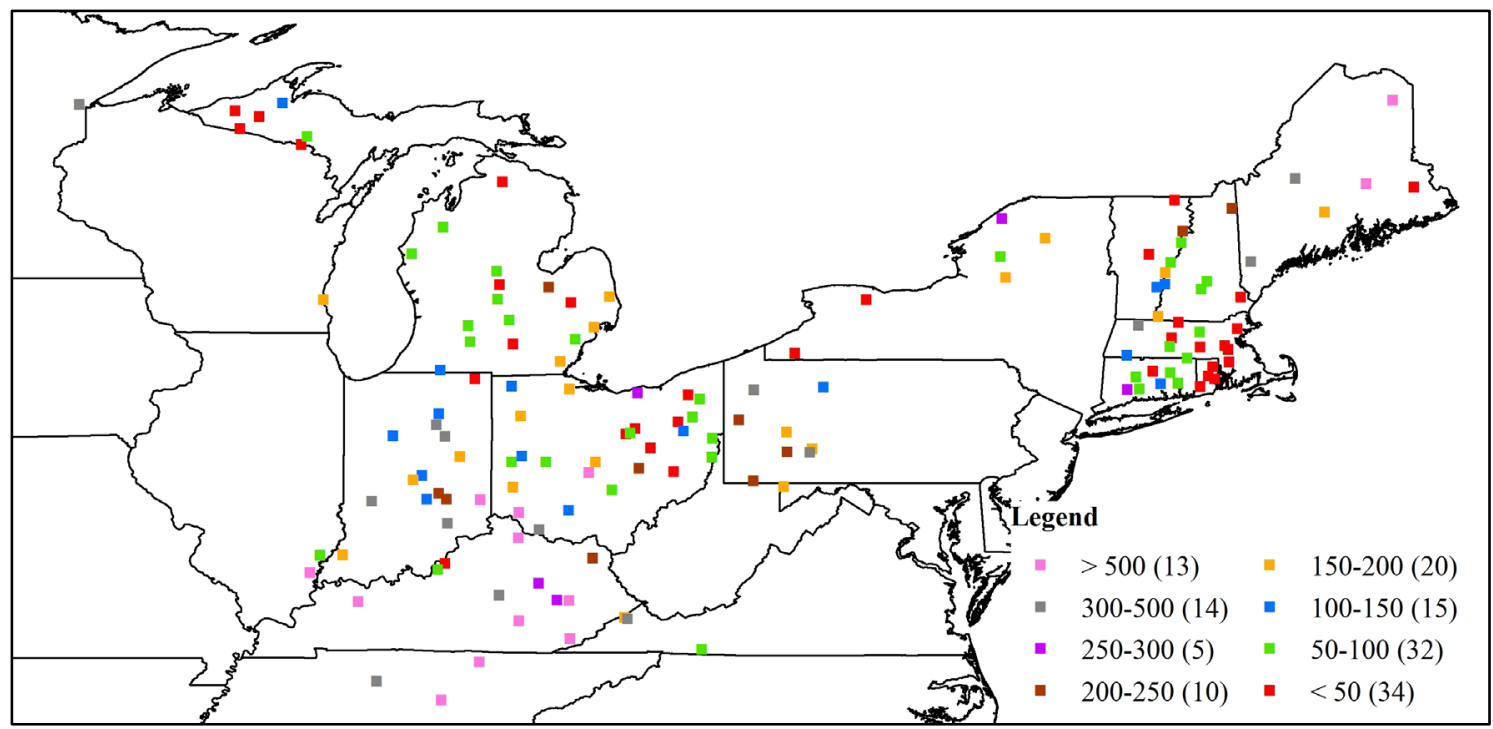

Figure 2-4: Spatial representation of the mean annual maximum flood magnitudes $\left[\mathrm{m}^{3} \mathrm{~s}^{-1}\right]$ for the 143 watersheds.

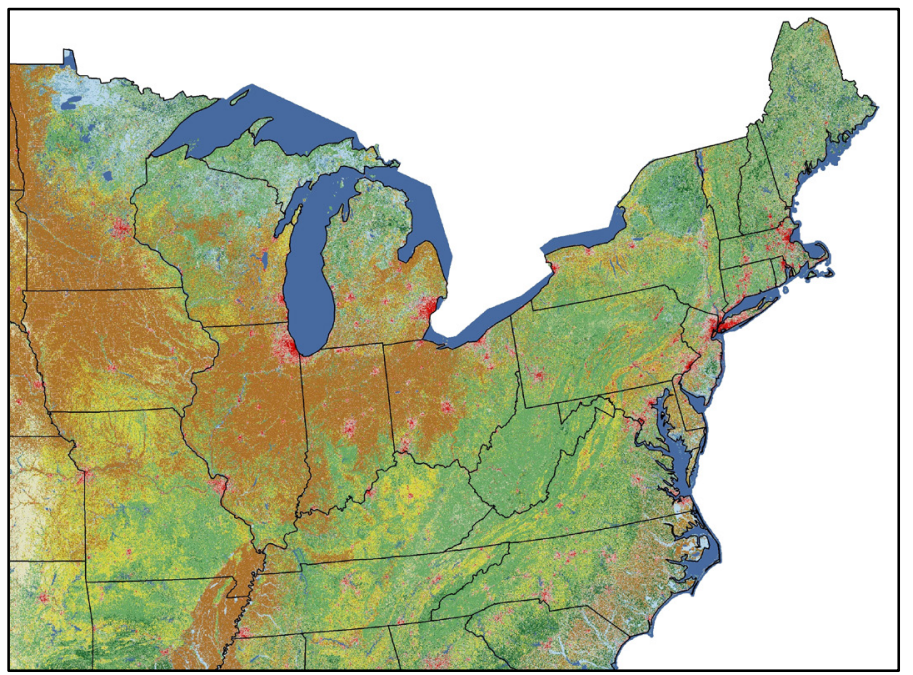

11 Open Water

12 Perennial Ice/Snow

21 Developed, Open Space

22 Developed, Low Intensity

23 Developed, Medium Intensity

24 Developed, High Intensity

31 Barren Land

41 Deciduous Forest

42 Evergreen Forest

43 Mixed Forest

51 Dwarf Scrub*

52 Shrub/Scrub

71 Grassland/ Herbaceous

72 Sedge/ Herbaceous *

74 Moss *

81 Pasture Hay

82 Cultivated Crops

$\square 90$ Woody Wetlands

95 Emergent Herbaceous Wetlands

* Alaska Only

Figure 2-5: National Land-Cover in 2006 for the Northeastern United States (image courtesy, US Geological Survey (Fry et al., 2011)). 


\subsection{Physical characteristics of the watersheds}

Physical characteristics for each of the 143 watersheds were obtained from the Gages II (Geospatial Attributes of Gages for Evaluating Streamflow, version II) database that provides geospatial features for more than 9,000 streams across the United States and represents an extension of the database discussed by Falcone et al. (2010b). The following types of information were obtained:

- physical characteristics: drainage area, elevation, slope, orientation;

- land-use and land-cover: percentages of urban areas, forest and agriculture;

- engineering structures: number of dams and major dams;

- water uses and management: regulations from reservoirs, lakes, power plants; diversions for municipal supplies; freshwater withdrawals (county level).

The following subsections provide an overview of the physical characteristics of the 143 watersheds. Other aspects associated with land-use/land-cover, anthropogenic impacts and degree of impairment are discussed in later sections of this chapter. Additional details for each of these watershed characteristics and human factors are provided in Appendix A.

\subsubsection{Drainage area}

To understand the variability in drainage areas across the 143 watersheds, Figure 2.6 provides the frequency distribution of the drainage areas and Figure 2.7 illustrates their geographical distribution. The smallest and largest areas were $31.3 \mathrm{~km}^{2}$ and 19591.4 $\mathrm{km}^{2}$, respectively, and the mean value for the 143 watersheds was $1369.8 \mathrm{~km}^{2}$. While geographic patterns in drainage area are not anticipated, comparing Figures 2.4 and 2.7 it appears that smaller drainage areas are generally associated with a lower mean annual maximum flood magnitude such as in Northern Michigan, Ohio, and the coastal part of New England. Larger watersheds are identified in the upper part of New England, Kentucky and Tennessee where mean annual maximum floods were classified in the higher bins. To better understand this potential relationship between annual maximum 
floods and the physical extent of the watersheds, Figure 2.8 plots the mean annual maximum flood magnitude versus drainage areas in log-scale.

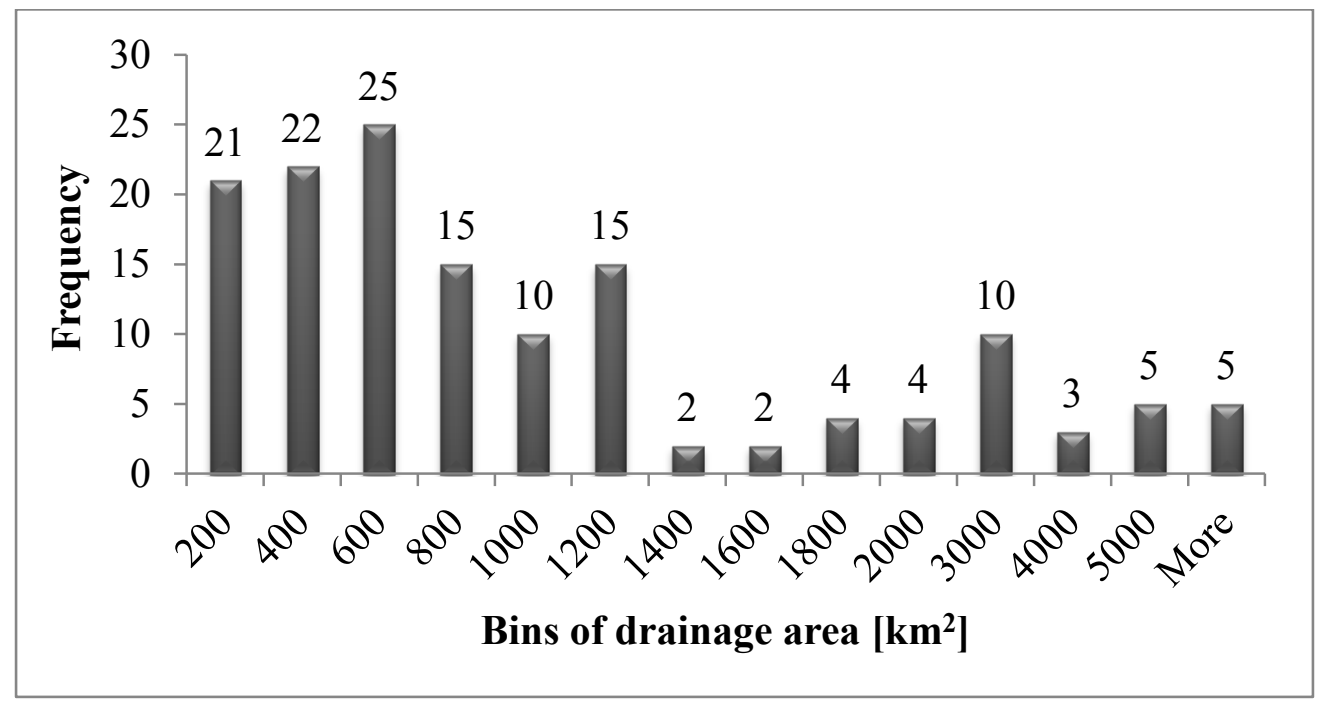

Figure 2-6: Frequency distribution of drainage areas for the 143 watersheds.

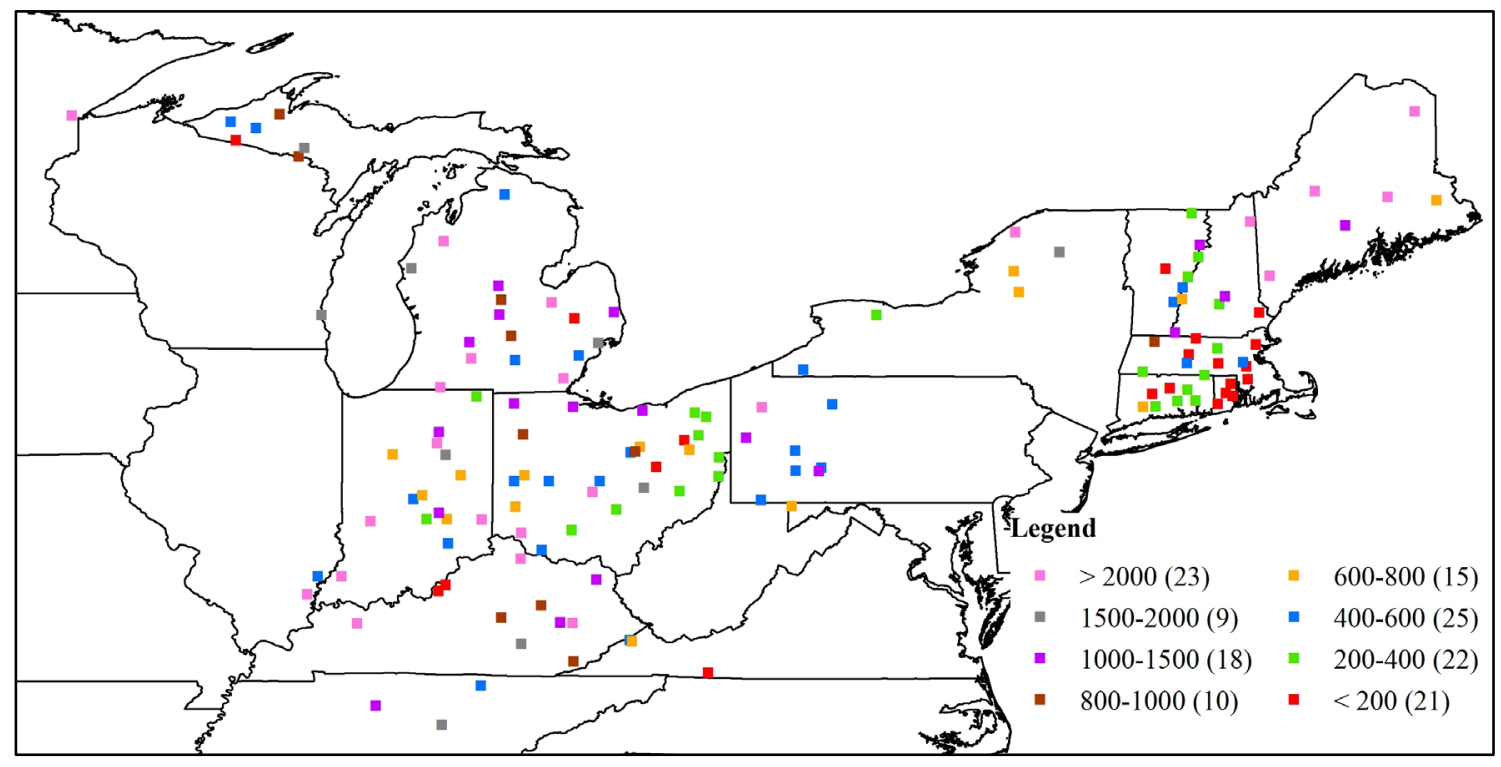

Figure 2-7: Geographical distribution of drainage areas $\left[\mathrm{km}^{2}\right]$ for the 143 watersheds. 


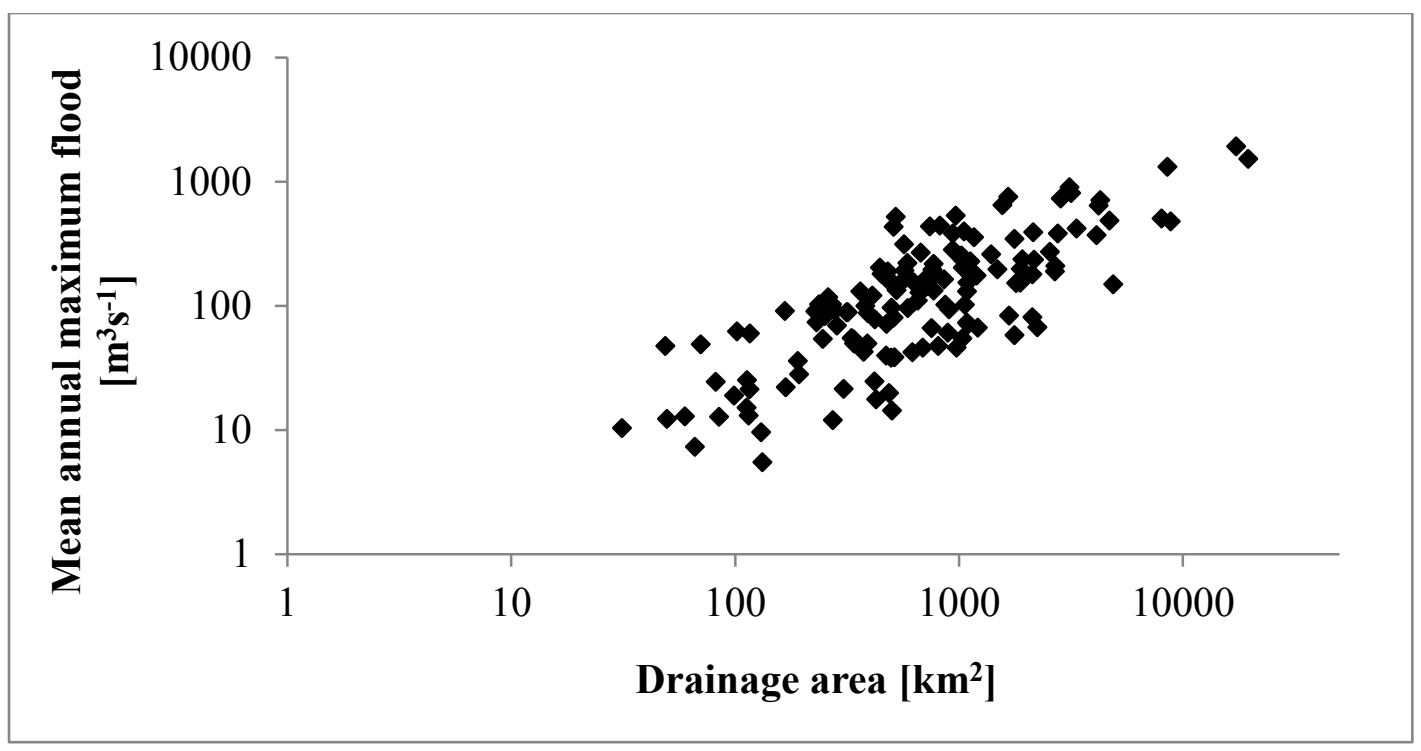

Figure 2-8: Mean annual maximum flood magnitude versus drainage area in log-scale.

Figure 2.8 confirms that a relationship exists between flood magnitude and drainage area. Smaller areas tend to correspond to lower values of mean annual maximum flood and, vice versa, higher flows are associated with larger areas. This result is consistent with several models commonly applied for engineering calculations of flood quantiles. The rational method computes the flood quantile of return period T, $Q_{T}$, as the product of the rainfall intensity $i_{T}$ for the $\mathrm{T}$-year storm, the drainage area $A$ and a runoff coefficient $C\left(Q_{T}=C i_{T} A\right)$. This method mainly applies in urban areas with a high percentage of impervious surfaces. Moreover, a limitation resides in the unconditional assumption that the T-year storm event returns the T-year flood quantile. More accurate methods adopted in engineering design are regional flood frequency equations derived from a multiple linear regression analysis to estimate flood quantiles as a function of watershed characteristics (Young et al., 2009). In this case, $Q_{T}$ is computed as:

$$
Q_{T}=C X_{1}^{a} X_{2}^{b}
$$

where the explanatory variables $X_{i}$ are physiographic characteristics and/or climatic variables associated with gauged basins; and $a, b \ldots$ are regression parameters. The drainage area is commonly used as an explanatory variable for its potentially "significant impact on flood/frequency estimates" (Mishra et al., 2010). Drainage area is 
also considered in index flood methods which apply to hydrologically homogeneous regions. Sites are deemed hydrologically homogeneous when the flood distributions of the individual sites are similar in shape and thus can be represented by a parent regional flood distribution. In this context, the drainage area represents a site-specific scaling parameter used to adjust quantiles of the parent regional flood distribution (Mishra et al., 2010). These approaches confirm the influence of the drainage area in the hydrologic response of a basin.

\subsubsection{Elevation, slope and orientation}

In addition to drainage area, elevation, slope and orientation data obtained from Gages II were considered in order to provide a better characterization of the basins, and to understand their potential influences on flood magnitude. The source of Gages II elevation and slope data is the USGS National Elevation Dataset (http://ned.usgs.gov/) with a resolution of $100 \mathrm{~m}$. Table 2.3 reports the mean, standard deviation, skew, and maximum and minimum values computed across the 143 observations of mean watershed elevation and mean watershed slope. Figures 2.9 and 2.10 show the frequency distribution of mean watershed elevation and slope, respectively.

Table 2-3: Statistics for mean watershed elevation and slope for the 143 watersheds.

\begin{tabular}{|c|c|c|}
\hline Statistic & Mean watershed elevation [m] & Mean watershed slope [\%] \\
\hline mean & 323.5 & 5.65 \\
\hline standard deviation & 143.9 & 5.76 \\
\hline $\begin{array}{c}\text { coefficient of } \\
\text { skewness }\end{array}$ & 0.688 & 1.920 \\
\hline maximum & 809.51 & 30.76 \\
\hline minimum & 32.54 & 0.13 \\
\hline
\end{tabular}




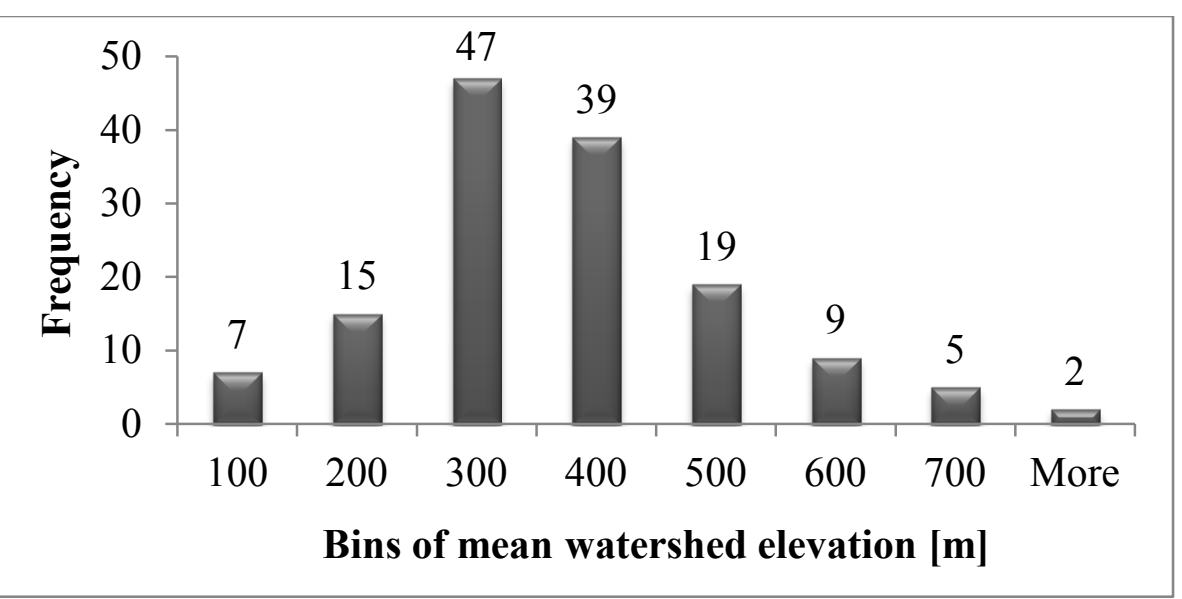

Figure 2-9: Frequency distribution of mean elevation values [m] for the 143 watersheds.

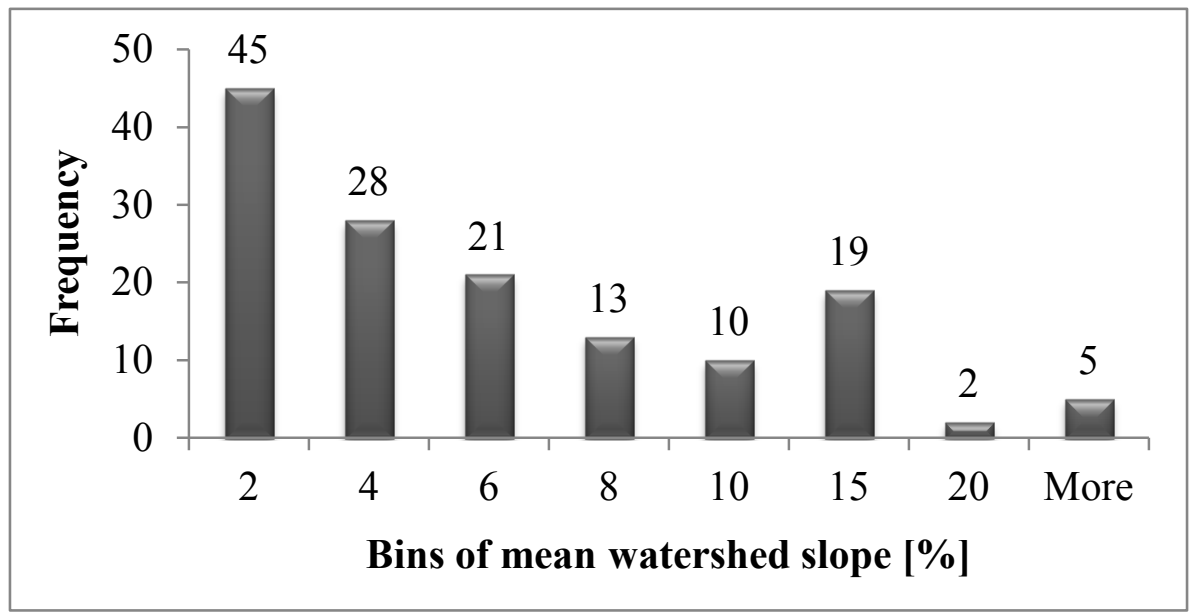

Figure 2-10: Frequency distribution of mean slope values [\%] for the 143 watersheds.

Figures 2.11 and 2.12 display the geographical distributions of the two physical features. It is apparent that both elevation and slope depend on the morphology of the territory with watersheds of lower elevation and milder slopes clustered in the Upper Midwest and along the Atlantic Coast. However, the results in Figures 2.13 and 2.14 indicate the absence of a significant relationship between mean annual maximum flood magnitude and mean watershed elevation or slope, respectively. 


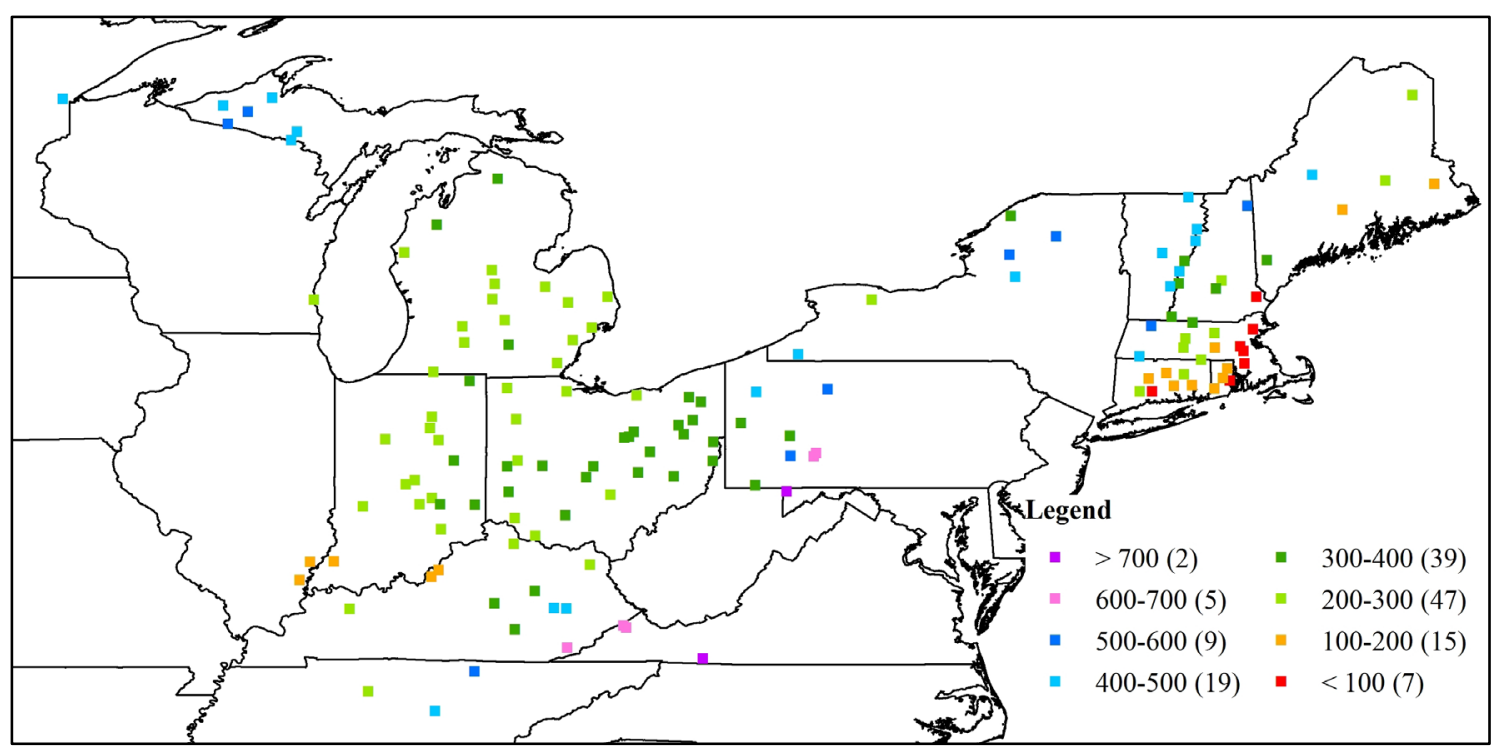

Figure 2-11: Geographical distribution of mean elevation [m] for the 143 watersheds.

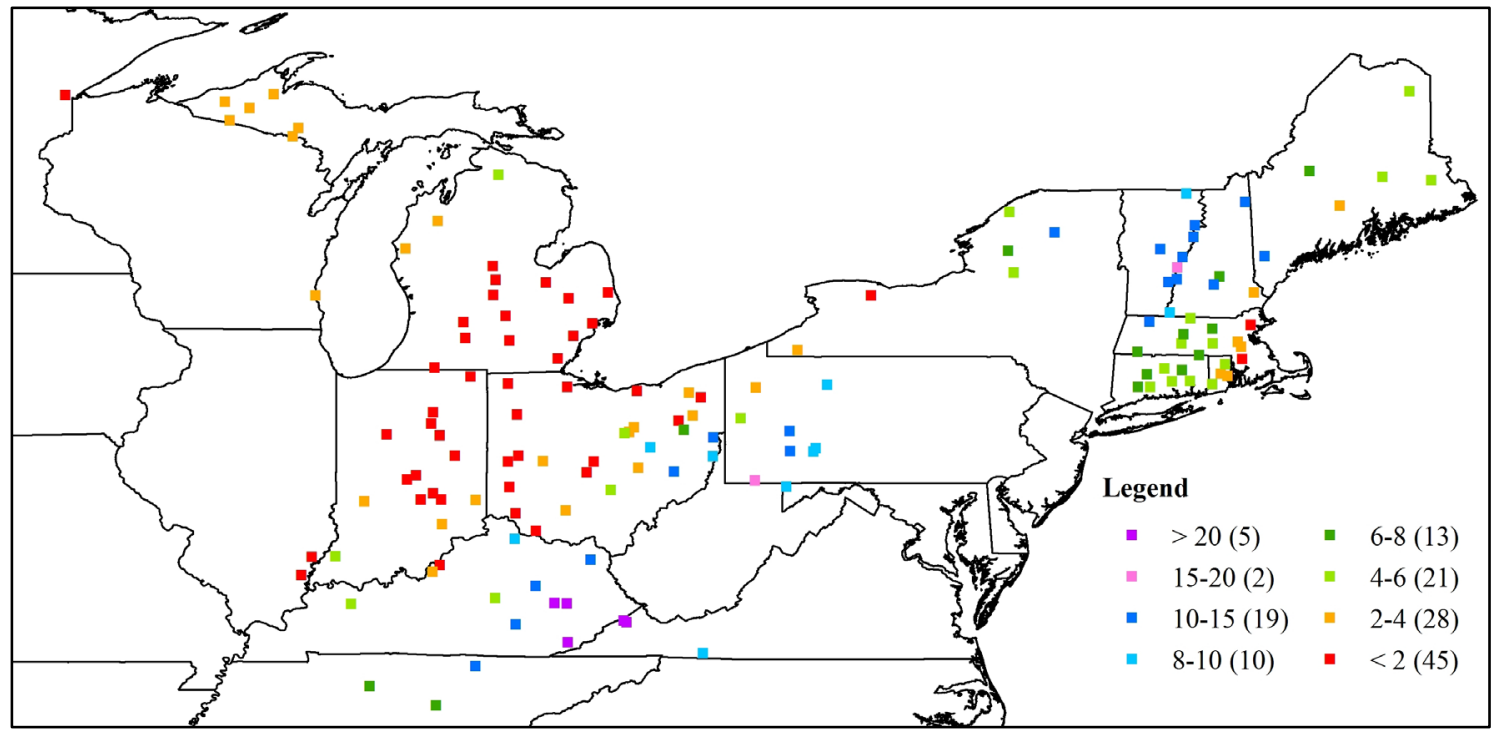

Figure 2-12: Geographical distribution of mean slope [\%] for the 143 watersheds. 


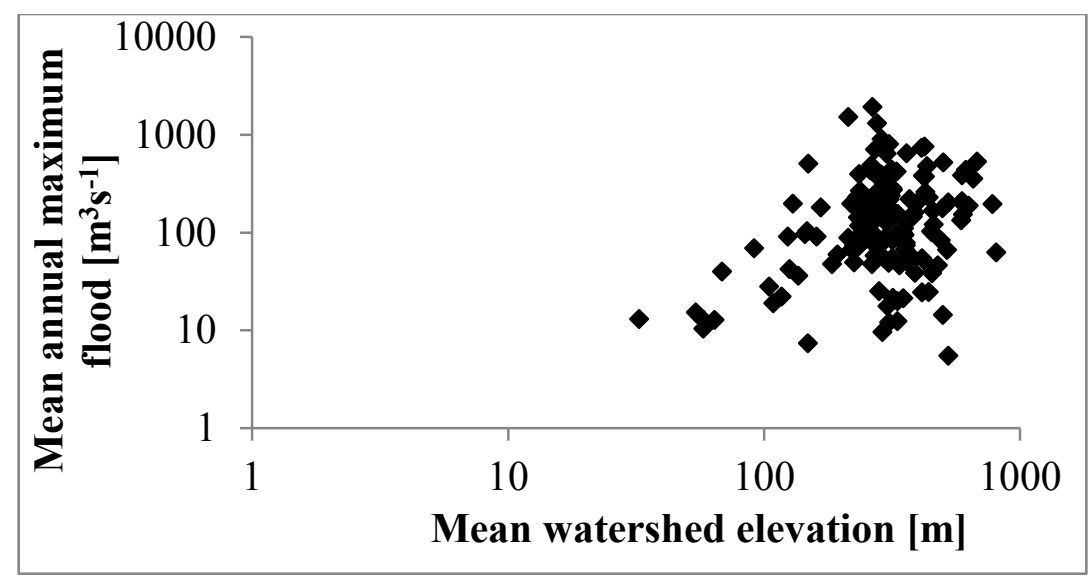

Figure 2-13: Mean annual maximum flood magnitude versus mean watershed elevation in log-scale.

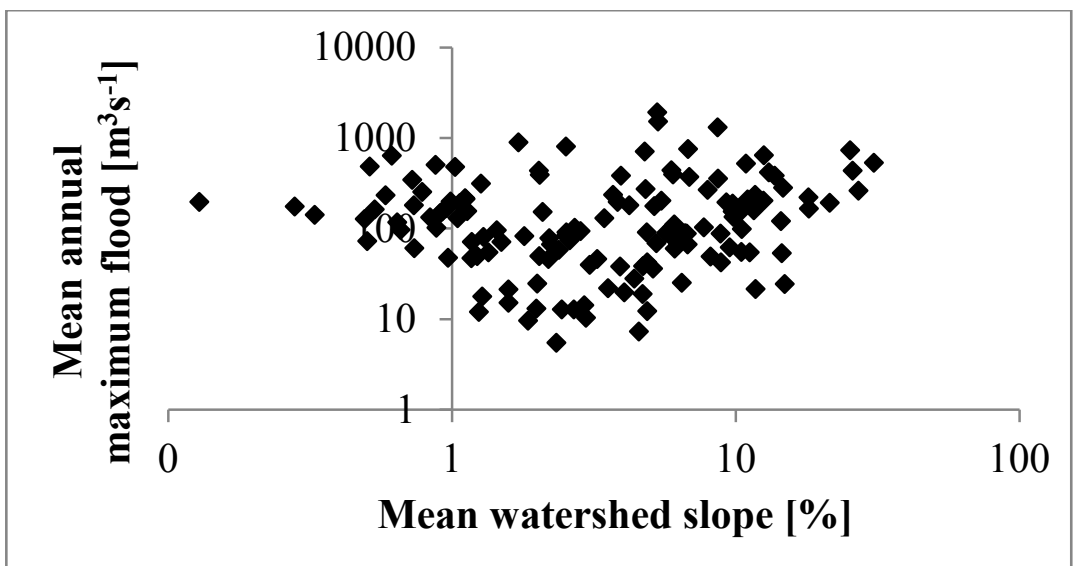

Figure 2-14: Mean annual maximum flood magnitude versus mean watershed slope in log-scale.

Gages II also includes information related to the topographic orientation of the basins providing a percentage of "aspect northness" and "aspect eastness". For the first variable, a value of +1 identifies watersheds facing/draining due North, -1 due South. Analogously, the second variable defines orientation in the East $(+1)$ and West $(-1)$ directions. The orientation of the basin might affect streamflows due to influences on runoff, evaporation and transpiration as a consequence of the different exposure to the sun-heat and contributions from snowpack (Caltrans, 2001). Moreover, the "orientation with respect to the direction of storm movement can affect a flood peak" (Caltrans, 2001). The peak is intensified if storm direction and basin orientation are the same. 
Figure 2.15 shows the orientation for the 143 watersheds. New England is mainly characterized by South-East and South-West oriented basins, more variability is evident in the other portions of the study area. Nevertheless, a primarily southerly orientation is common to most of the watersheds (93), increasing their exposure to the sun-heat. Although the topographic orientation might influence a watershed's hydrologic response and streamflow, a visual comparison of Figures 2.4 and 2.15 is not sufficient to assess a correlation between the two variables.

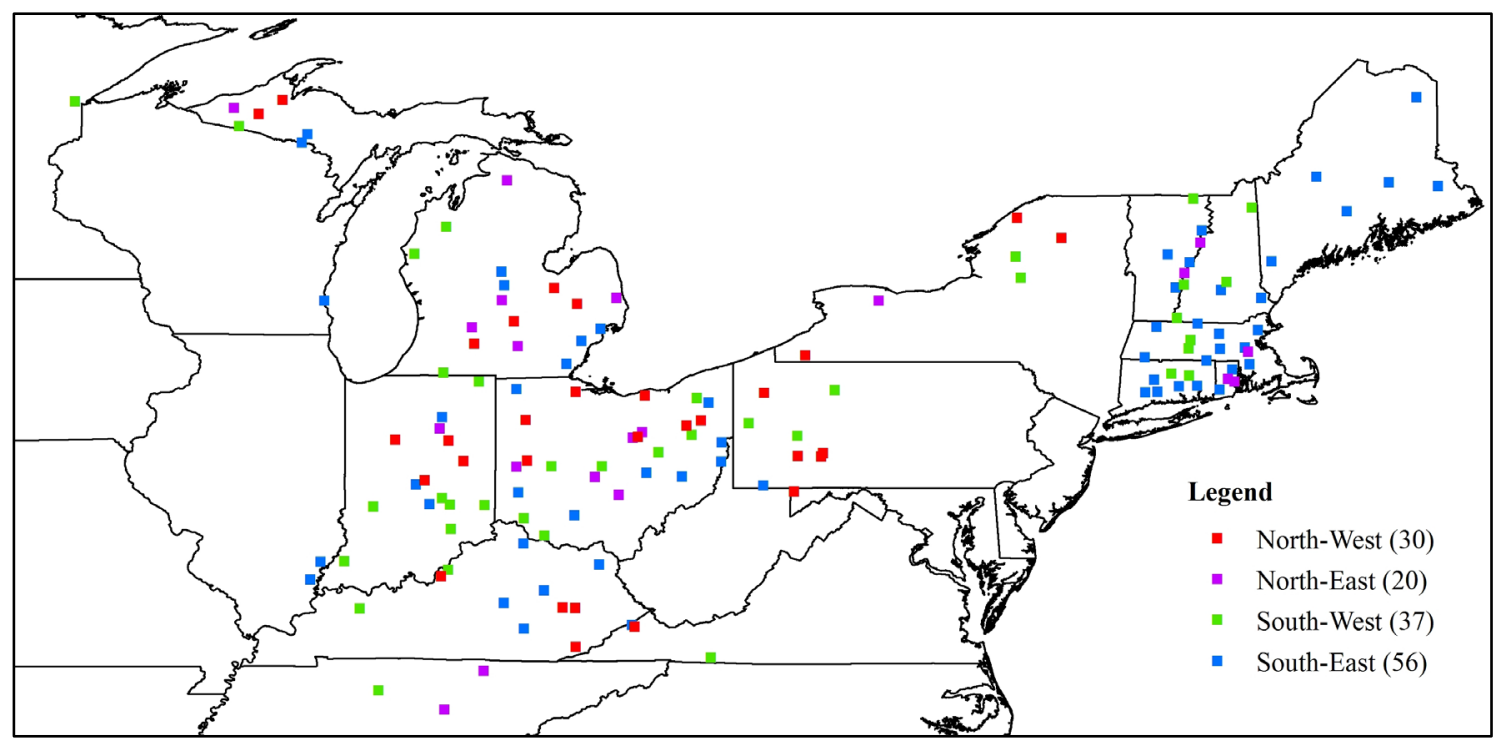

Figure 2-15: Topographic orientation of the 143 watersheds.

\subsection{Land-use and land-cover}

A further characterization of the watersheds was conducted through a clustering analysis based on Gages II information about land-use/land-cover (Falcone, 2011). The process of clustering is different than a general classification method. Classification involves a known number of groups, and new observations are assigned to one of those groups (Johnson and Wichern, 2002). Instead, clustering allows grouping the observations on the basis of multiple variables (attributes) in such a way that similarities among the attributes of observations within a group are maximized, as are distances 
(dissimilarities) between attributes of observations in different groups (Johnson and Wichern, 2002).

A clustering procedure was adopted herein considering the proportion of the watershed that is developed (urban), forested, and planted/cultivated (agricultural). The aim of clustering was to identify natural groups of watersheds with similar land-cover/land-use as measured by all three attributes, rather than to simply classify the basins in three main groups based solely on the dominant type of land-cover within their boundaries. It is important to note that in some cases, this simple classification would be misleading as the percentages of different land-covers within a watershed are similar, and a mere classification would list the watershed on the basis of the highest percentage without considering the significant contribution of the other land-uses. This limitation is overcome by adopting the clustering procedure. The three attributes considered were defined using the National Land-Cover Database 2006 (Fry et al., 2011) that classifies the land-cover of the United States into 16 classes with a spatial resolution of $30 \mathrm{~m}$ (see Figure 2.5). Each attribute was derived by joining different NLCD2006 classes: urban includes classes 21 (developed, open space), 22, 23 and 24 (developed, low/medium/high intensity, respectively); forested accounts for classes 41, 42 and 43 (deciduous/evergreen and mixed forest); agricultural combines classes 81 (pasture/hay) and 82 (cultivated crops). The following sections describe the clustering procedure and the main results.

\subsubsection{Clustering method}

The clustering approach adopted in this study corresponds to an agglomerative hierarchical algorithm. Each watershed is initially assumed to be a cluster, then the computations allow combining clusters together if sufficient similarity exists among the specified attributes (Johnson and Wichern, 2002). The analysis was performed in Minitab16 which requires the user to specify a linkage method and a measure of distance. Ward's method was adopted as the linkage model to determine the distance between two clusters; this method is commonly used in the context of regional flood 
frequency analysis to delineate hydrologically homogenous regions on the basis of measureable site-characteristics as it yields clusters of similar size (Hosking and Wallis, 2005).

For cluster $k$ containing $n_{k}$ sites, the Ward's method seeks to minimize the sum of the squared differences $\left(E S S_{k}\right)$ between the attributes of each observation $x_{j}$ (or watershed) and the group centroid $x_{c}$ (Johnson and Wichern, 2002):

$$
E S S_{k}=\sum_{j=1}^{n_{k}}\left(x_{j}-x_{c}\right)^{2}
$$

At each step, clusters are merged in such a way that the overall ESS across all clusters is minimized. The measure of the association between the variables was obtained by computing Euclidean distances. Considering $N$ observations of an attribute $x_{z}$, the difference between each pair of observations $\left(x_{z i}\right.$ and $\left.x_{z j}\right)$ is computed as $x_{z i}-x_{z j}$. In this thesis, the attributes considered correspond to the mean percentages of urban, forested and planted/cultivated areas within each watershed, and the distance is computed across all $N=143$ sites. The Euclidean distance is then defined as the square-root of the sum of the squared differences for each variable considered (Minitab16, 2012):

$$
d_{i j}=\sqrt{\sum_{z=1}^{N}\left(x_{z i}-x_{z j}\right)^{2}} .
$$

At each step of the algorithm, Minitab16 records in a table any joined clusters, the similarity level, the ID associated with the new cluster and the number of observations (watersheds) included therein. The user can specify the final partition of the dataset by selecting either the number of clusters or the similarity level desired. A second output table contains important results for each cluster such as the number of observations therein, the error sum of squares $\left(E S S_{k}\right)$, and the average and maximum distances between the observations and the centroid. A third output table summarizes the percentages of each variable within each cluster. Results are displayed in a dendrogram with the observations (watersheds) on the $\mathrm{x}$-axis and their similarity level (ESS) on the $\mathrm{y}$-axis. Further information about the clustering procedure is available in the Minitab16 user's guide (Minitab16, 2012). 


\subsubsection{Clustering analysis}

The clustering analysis was performed with the aim of identifying groups with high similarity among the 143 watersheds wherein the degree of similarity is measured on the basis of percentages of developed, forested and planted/cultivated areas within each watershed. The analysis was initially conducted by specifying varying numbers of clusters to be formed rather than specifying a desired level of similarity (ESS). Overall, five clusters seemed to provide the most appropriate results as four of the clusters are reasonably similar in size (see Table 2.4), and excessive fragmentation of the dataset was avoided. The dendrogram of the five clusters obtained is provided in Figure 2.16.

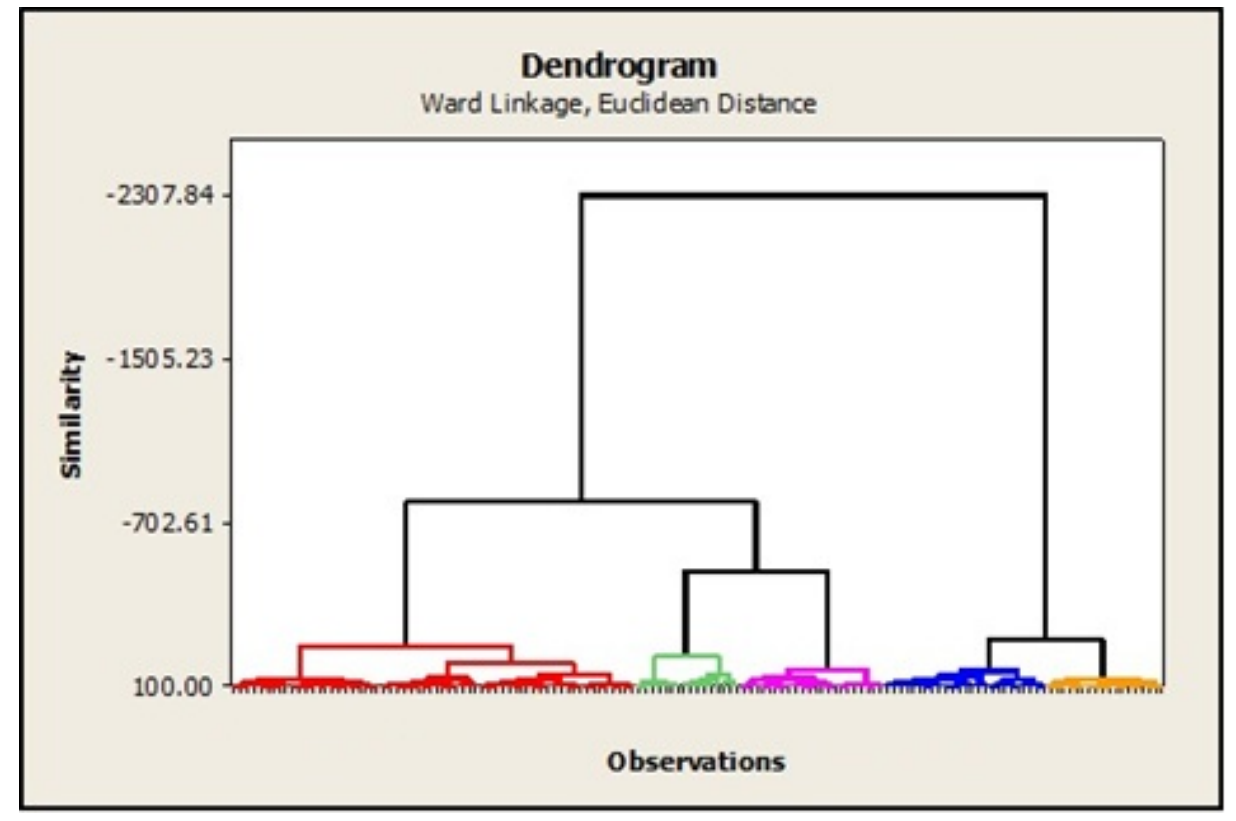

Figure 2-16: Dendrogram obtained considering land-cover/land-use attributes of the 143 watersheds in Ward's clustering algorithm.

Table 2.4 summarizes the average proportion of each land-use/land-cover type observed across the watersheds contained in each of the five clusters; note that percentages reported do not sum to $100 \%$ as other land-use/land-cover types exist within the watersheds, though to a relatively small degree. Overall, four of the clusters are characterized by a dominant land-cover: Cluster 1 is mainly forested (71\%), Cluster 2 is mainly urban (49\%), and Clusters 3 and 4 are mainly agricultural $(60 \%$ and $79 \%$, 
respectively). Given that the latter two clusters are both predominantly agricultural, a net separation between Clusters 3 and 4 will not be maintained in the following analyses; results associated with watersheds contained in these two clusters will simply refer to basins with high percentages of planted/cultivated areas. It should also be noted that although most of the areas in Cluster 2 are developed, forests do represent an important component. Cluster 5 presents a higher variability in land-cover, with forest and agriculture present in similar percentages. Table 2.5 provides additional summary information for the percentage of each of the land-use/land-cover attributes observed in each cluster.

Table 2-4: Mean percentages of land-use/land-cover types for each cluster and number of sites included therein. Bold values identify dominant land-use/land-cover.

\begin{tabular}{|c|c|c|c|c|c|}
\hline Land-cover [\%] & Cluster 1 & Cluster 2 & Cluster 3 & Cluster 4 & Cluster 5 \\
\hline urban & 5.5 & $\mathbf{4 9 . 0}$ & 13.9 & 8.1 & 8.3 \\
\hline forested & $\mathbf{7 1 . 4}$ & 36.6 & 16.7 & 9.0 & $\mathbf{4 3 . 9}$ \\
\hline agricultural & 6.6 & 4.4 & $\mathbf{5 9 . 9}$ & $\mathbf{7 9 . 5}$ & $\mathbf{4 0 . 3}$ \\
\hline number of sites & 62 & 16 & 25 & 18 & 22 \\
\hline
\end{tabular}

Figure 2.17 displays the geographical distribution of the clustered sites. The land-cover for most of the watersheds in New England, Pennsylvania, Kentucky and Northern Michigan is mainly forest (Cluster 1/green dots). Agricultural areas dominate most of the basins in Indiana, Ohio and Southern Michigan (Clusters 3 and 4/brown and orange dots). Watersheds with similar percentages of agricultural and forested areas (Cluster 5/red dots) are mainly located in Ohio, Kentucky, Tennessee and Southern Indiana. The distribution of watersheds within Cluster 2 (mainly developed/grey dots) is better understood by overlapping the US urban boundaries on Figure 2.17; results are shown in Figure 2.18. Most of the developed watersheds are in close proximity of urban boundaries such as in the coastal part of New England and the Detroit area; however, it is important to remark that all of the basins selected were moderately impaired and sufficiently far from the core of highly urbanized areas. Cluster 2 identified mainly watersheds in proximity of urban areas, but for which most if not all of the drainage 
area was outside of urban boundaries. Further, in many cases, the gauge is located upstream of small towns, and thus has forested headwaters.

Table 2-5: Summary statistics (\%) by cluster for each land-cover/land-use variable. Bold values identify dominant land-use/land-cover within each cluster.

\begin{tabular}{|c|c|c|c|c|}
\hline \multirow{2}{*}{ Cluster } & \multirow{2}{*}{ Statistic } & \multicolumn{3}{|c|}{ Land-cover [\%] } \\
\hline & & Urban & Forested & Agricultural \\
\hline \multirow{4}{*}{ Cluster 1} & maximum & 15.5 & 87.3 & 23.9 \\
\hline & minimum & 0.2 & 34.7 & 0.0 \\
\hline & mean & 5.5 & 71.4 & 6.6 \\
\hline & standard deviation & 3.2 & 10.0 & 6.1 \\
\hline \multirow{4}{*}{ Cluster 2} & maximum & 91.8 & 59.8 & 20.3 \\
\hline & minimum & 26.5 & 4.6 & 0.1 \\
\hline & mean & 49.0 & 36.6 & 4.4 \\
\hline & standard deviation & 18.8 & 16.1 & 4.8 \\
\hline \multirow{4}{*}{ Cluster 3} & maximum & 31.3 & 29.8 & 71.4 \\
\hline & minimum & 5.8 & 5.1 & 35.0 \\
\hline & mean & 13.9 & 16.7 & 59.9 \\
\hline & standard deviation & 7.0 & 7.6 & 7.6 \\
\hline \multirow{4}{*}{ Cluster 4} & maximum & 10.8 & 17.1 & 88.0 \\
\hline & minimum & 6.2 & 3.7 & 72.9 \\
\hline & mean & 8.1 & 9.0 & 79.5 \\
\hline & standard deviation & 1.5 & 3.7 & 4.0 \\
\hline \multirow{4}{*}{ Cluster 5} & maximum & 15.7 & 57.8 & 55.2 \\
\hline & minimum & 4.9 & 30.2 & 21.5 \\
\hline & mean & 8.3 & 43.9 & 40.3 \\
\hline & standard deviation & 2.6 & 6.9 & 9.0 \\
\hline
\end{tabular}




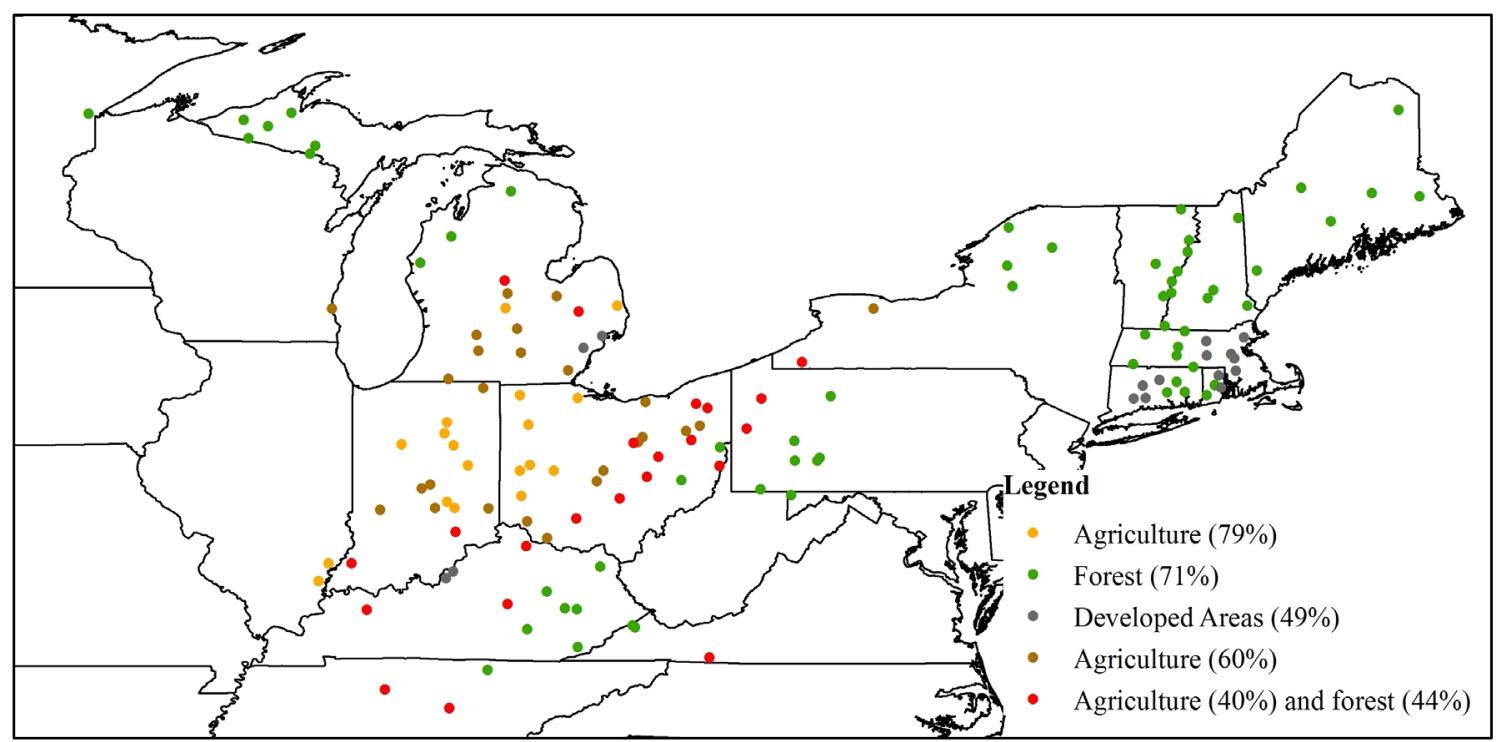

Figure 2-17: Geographical distribution of clustered sites based on land-use/land-cover attributes. Five clusters were identified: Cluster 1 (green dots), Cluster 2 (grey dots), Cluster 3 (brown dots), Cluster 4 (orange dots) and Cluster 5 (red dots).

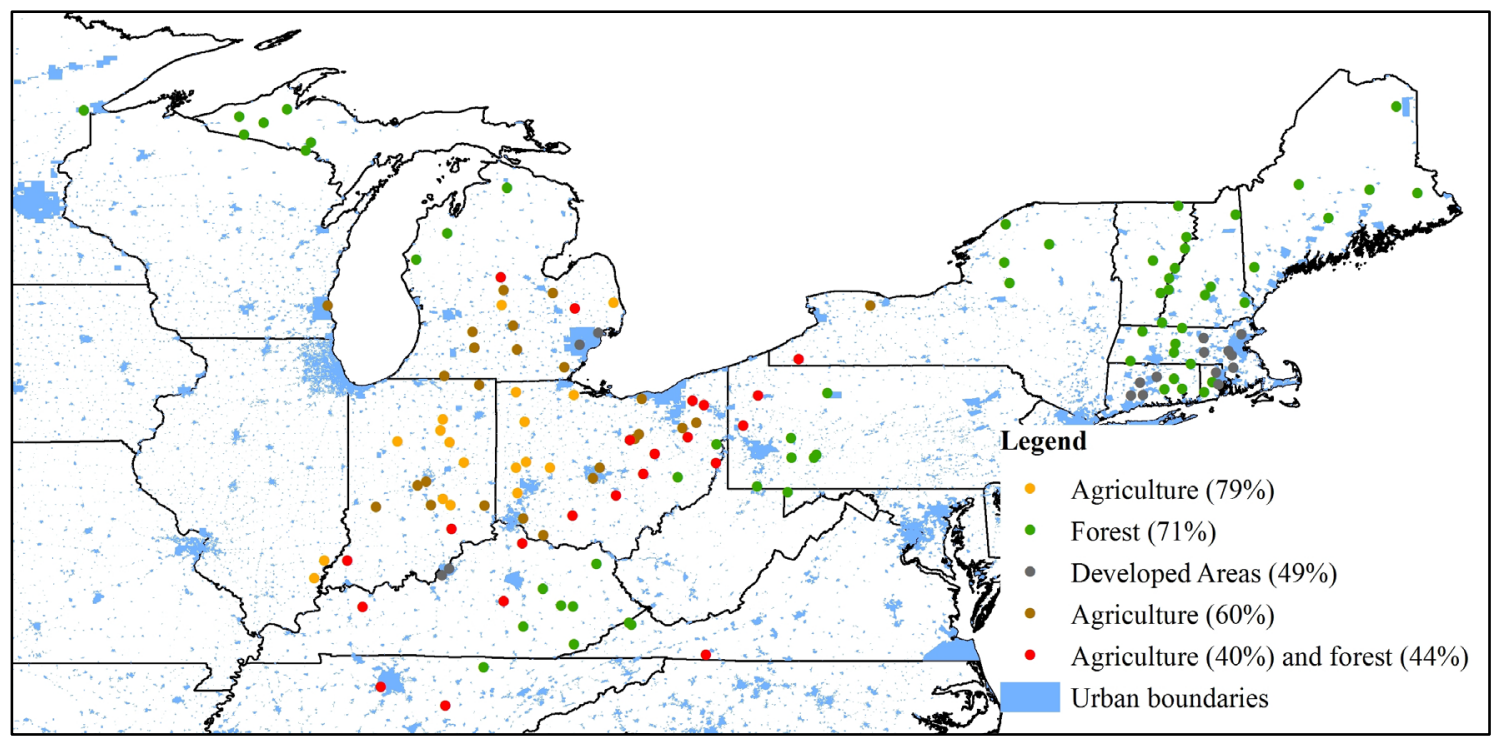

Figure 2-18: Clustering results based on land-use/land-cover attributes relative to US urban boundaries.

The identification of the five clusters allowed for further consideration of the distribution of the mean annual maximum flood magnitude, as well as that of a few physical characteristics (drainage area, mean elevation and slope). Histograms for these 
four variables were created for each cluster and are included in Appendix A. With respect to the magnitude of the mean annual flood peak, higher magnitudes $\left(>400 \mathrm{~m}^{3} \mathrm{~s}^{-1}\right)$ were observed for watersheds in clusters with a high percentage of forest cover (Clusters 1, 3 and 5). On the contrary, the majority of mean annual flood magnitudes for watersheds in Cluster 2 (mainly developed) were less than $100 \mathrm{~m}^{3} \mathrm{~s}^{-1}$, probably due to a relatively high degree of flow regulation. A relationship between drainage area and dominant land-use/land-cover was not evident; however, considering mean elevation and slope, watersheds which are primarily urban or agricultural tend to be at low elevation and mostly flat, whereas mainly forested basins are characterized by higher elevations and slopes.

\subsection{Degree of impairment}

The 143 watersheds were selected as moderately impaired basins implying that a certain degree of human alterations was present. Land-use and land-cover classifications suggest where more impacts are expected (for example, watersheds in close proximity to urban areas are more likely to be subjected to stream alterations, diversions or withdrawals), but they do not represent exhaustive information. To investigate the degree of impairment, additional measures of human activity reported in the Gages II database were considered.

In Gages II, a "hydrologic disturbance index" is attributed to each basin. The parameter was developed as a combination of seven variables (Falcone, 2011; Falcone et al., 2010a; Falcone et al., 2010b): 1. major dam density [number/100 km²] in 2009, where major dams are defined as those $\geq 15 \mathrm{~m}$ (50 feet) in height or with storage $\geq 6.167 \mathrm{E}+06$ $\mathrm{m}^{3}$ (5,000 acre-feet); 2. freshwater withdrawal [ML/(year- $\left.\left.\mathrm{km}^{2}\right)\right]$ based on 1995-2000 county-level estimates; 3. change in dam storage between 1950 and 2009; 4. percent of stream length $[\mathrm{km}]$ coded as canal, ditch or pipeline in NHDPlus; 5. raw straight-line distance $[\mathrm{km}]$ from the gage location to the nearest major NPDES (National Pollutant Discharge Elimination System) point in the watershed; 6. road density $\left[\mathrm{km} / \mathrm{km}^{2}\right]$; and 7. fragmentation index of undeveloped land in the watershed. Low values of the 
hydrologic disturbance index indicate low levels of human-induced hydrologic modification within the watershed; high values correspond to greater amounts of disturbance. Values of the hydrologic disturbance index for the 143 watersheds considered herein range from 5 to 33 , with an average value of 18 . The geographic variability of the index is shown in Figure 2.19.

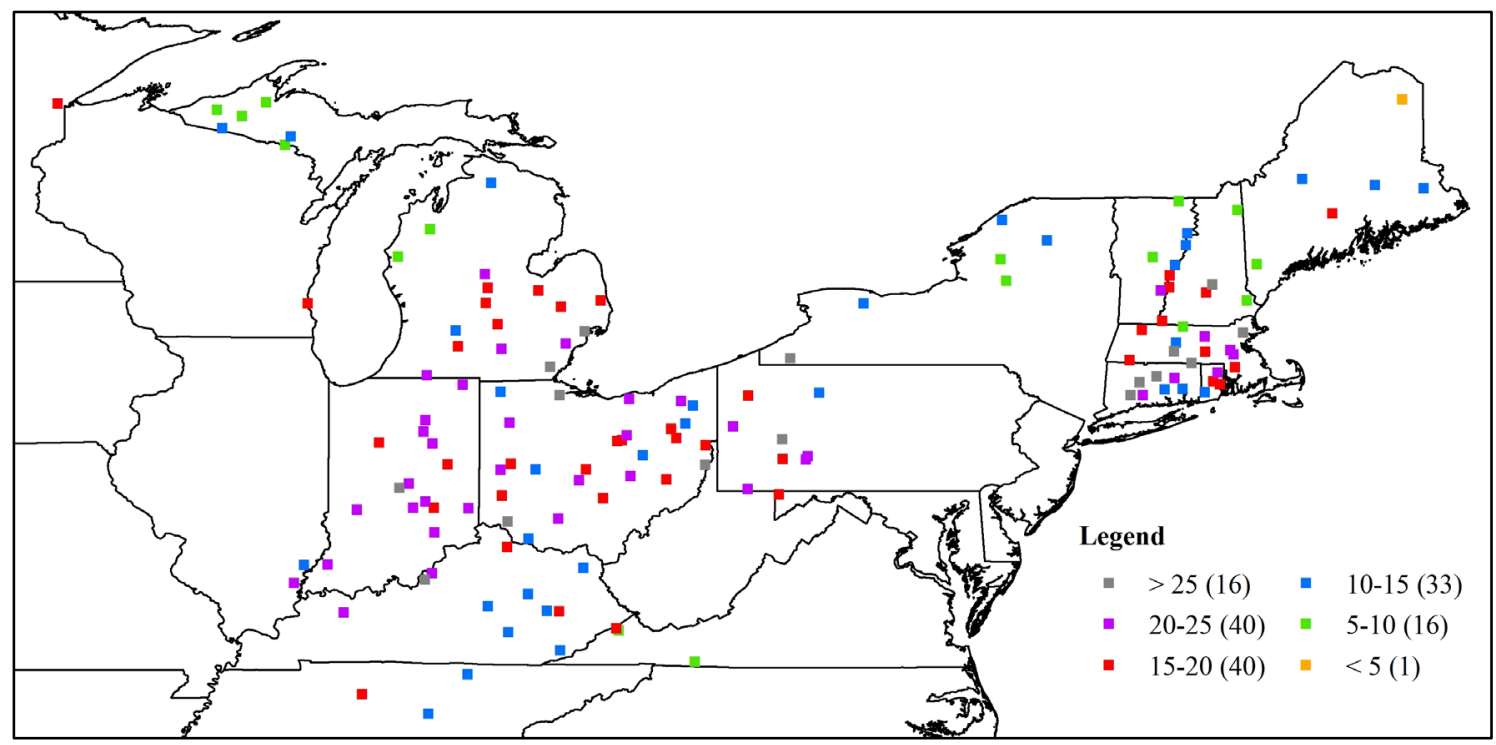

Figure 2-19: Hydrologic disturbance indices for the 143 moderately impaired watersheds. High/low values correspond to high/low levels of human-induced alteration.

The hydrologic disturbance index is greater than 15 for the majority of the basins (96 out of 143) under consideration, indicating a sufficient degree of disturbance. To contextualize the results, the remaining Gages II sites included in Hydrologic Regions 1, 4 and 5, but which did not meet our stated site selection criteria, with hydrologic disturbance indices greater than 25 were considered. Figure 2.20 displays the location of these additional sites relative to the US urban boundaries, and for comparison, of the 16 sites included in our dataset of 143 sites with hydrologic disturbance indices $>25$. The latter 16 sites are labeled with the value of their disturbance index. Moreover, Table 2.6 reports additional information pertaining to the hydrologic disturbance index as it relates to land-use/land-cover based on the clusters identified in Section 2.4.2, as well as 
two other variables derived from Gages II as indicators of impairment: population density $\left[\mathrm{person} / \mathrm{km}^{2}\right]$ and road density $\left[\mathrm{km} / \mathrm{km}^{2}\right]$ within the watershed.

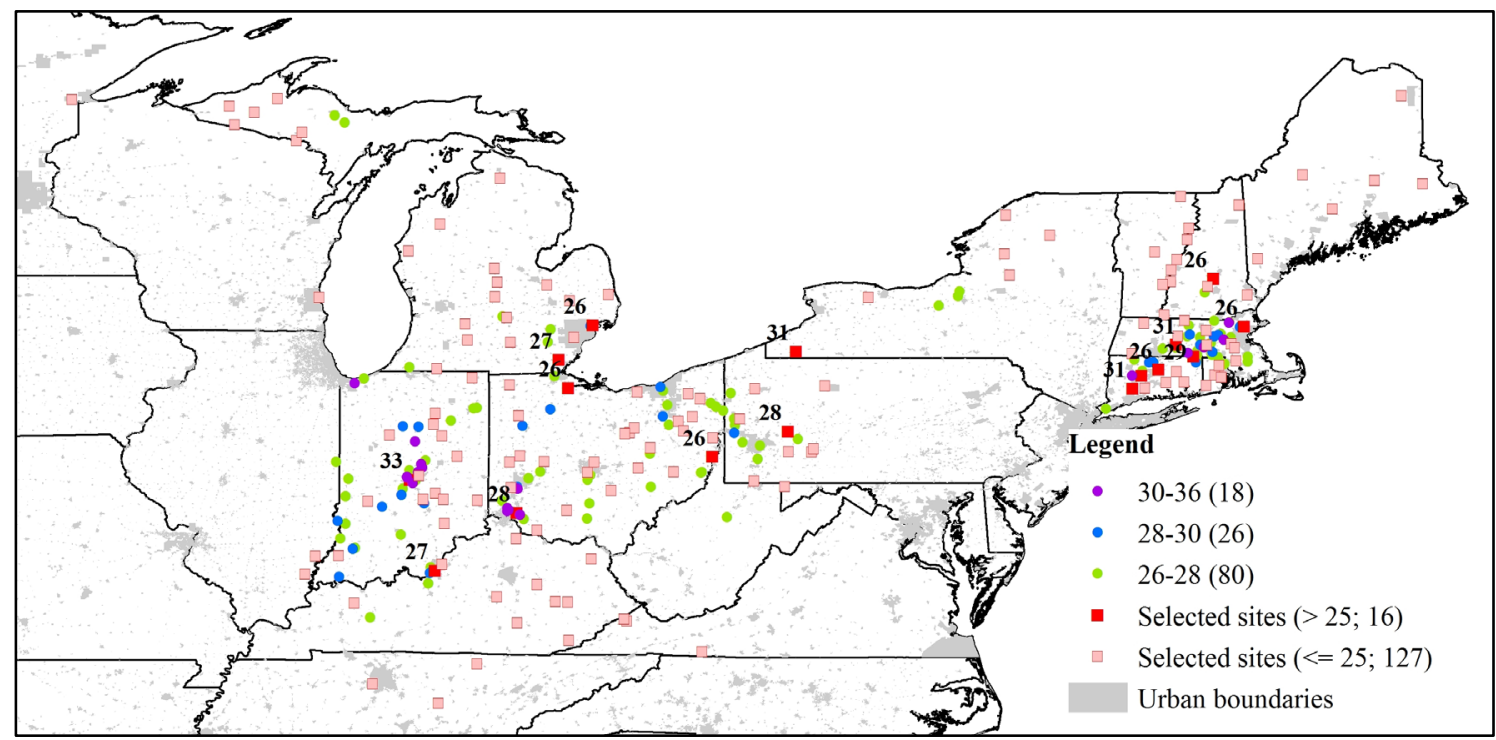

Figure 2-20: Locations of the 16 moderately impaired sites with hydrologic disturbance indices greater than 25 relative to Gages II sites in Hydrologic Regions 1, 4 and 5 with high hydrologic disturbance indices (>25).

Combining the information from Figures 2.18 and 2.19 and Table 2.6, it emerges that Cluster 2, which is mainly developed (49\%), has the highest mean value of hydrologic disturbance index (23.3), population density and road density as is to be expected. It is followed by Cluster 3, which has the second largest proportion of developed areas $(13 \%)$, and has a mean hydrologic disturbance index of 20.8. Instead, Cluster 1, which is mainly forested, has the lowest mean values of the three variables. 
Table 2-6: Summary statistics for the hydrologic disturbance index, population density and road density by land-use/land-cover cluster.

\begin{tabular}{|c|c|c|c|c|}
\hline Cluster & Statistic & $\begin{array}{c}\text { Hydrologic } \\
\text { disturbance index }\end{array}$ & $\begin{array}{c}\text { Population density } \\
{\left[\text { person } / \mathbf{k m}^{2}\right]}\end{array}$ & $\begin{array}{c}\text { Road density } \\
{\left[\mathrm{km} / \mathrm{km}^{2}\right]}\end{array}$ \\
\hline \multirow{4}{*}{ Cluster 1} & maximum & 31.0 & 109.5 & 2.3 \\
\hline & minimum & 5.0 & 0.2 & 0.5 \\
\hline & mean & 14.9 & 22.9 & 1.5 \\
\hline & standard deviation & 5.6 & 26.9 & 0.5 \\
\hline \multirow{4}{*}{ Cluster 2} & maximum & 31.0 & 1099.8 & 8.6 \\
\hline & minimum & 17.0 & 228.9 & 2.9 \\
\hline & mean & 23.3 & 524.2 & 4.7 \\
\hline & standard deviation & 3.7 & 263.7 & 1.6 \\
\hline \multirow{4}{*}{ Cluster 3} & maximum & 33.0 & 203.5 & 2.9 \\
\hline & minimum & 11.0 & 25.1 & 1.4 \\
\hline & mean & 20.8 & 92.2 & 2.0 \\
\hline & standard deviation & 5.0 & 61.1 & 0.5 \\
\hline \multirow{4}{*}{ Cluster 4} & maximum & 26.0 & 60.8 & 2.0 \\
\hline & minimum & 11.0 & 7.2 & 1.4 \\
\hline & mean & 19.9 & 31.8 & 1.7 \\
\hline & standard deviation & 4.3 & 14.2 & 0.2 \\
\hline \multirow{4}{*}{ Cluster 5} & maximum & 31.0 & 101.0 & 2.2 \\
\hline & minimum & 10.0 & 19.1 & 1.4 \\
\hline & mean & 19.1 & 44.1 & 1.7 \\
\hline & standard deviation & 4.9 & 24.3 & 0.2 \\
\hline
\end{tabular}

Often the impairment of a stream is related to the construction of engineering structures for water use and management (e.g., dams, reservoirs) or some form of channelization. Based on Gages II data, Figures 2.21 and 2.22 report the number of dams and the number of major dams, respectively, within each watershed in the year 2009. Major dams are defined as those greater than $15 \mathrm{~m}$ (50 feet) in height or with storage exceeding $6.167 \mathrm{E}+06 \mathrm{~m}^{3}$ (5,000 acre-feet). Moreover, Table 2.7 provides a summary of the number of dams/major dams within each cluster. About half of the watersheds (66) contained more than 10 dams in 2009 , and these watersheds are primarily classified as mainly developed or agricultural. Most of the mainly forested basins (Cluster 1) contained less than 10 dams. Considering moderately impaired watersheds, most were not impacted by major dams as shown in Figure 2.22. 
Table 2-7: Total and mean number of dams and major dams within each cluster.

\begin{tabular}{|c|c|c|c|c|c|c|c|c|c|c|}
\hline & \multicolumn{2}{|c|}{ Cluster 1 } & \multicolumn{2}{c|}{ Cluster 2 } & \multicolumn{2}{c|}{ Cluster 3 } & \multicolumn{2}{c|}{ Cluster 4 } & \multicolumn{2}{c|}{ Cluster 5 } \\
\hline & total & mean & total & mean & total & mean & total & mean & total & mean \\
\hline dams & 889 & 14 & 292 & 18 & 381 & 15 & 176 & 10 & 444 & 20 \\
\hline major dams & 221 & 4 & 21 & 1 & 34 & 1 & 19 & 1 & 63 & 3 \\
\hline
\end{tabular}

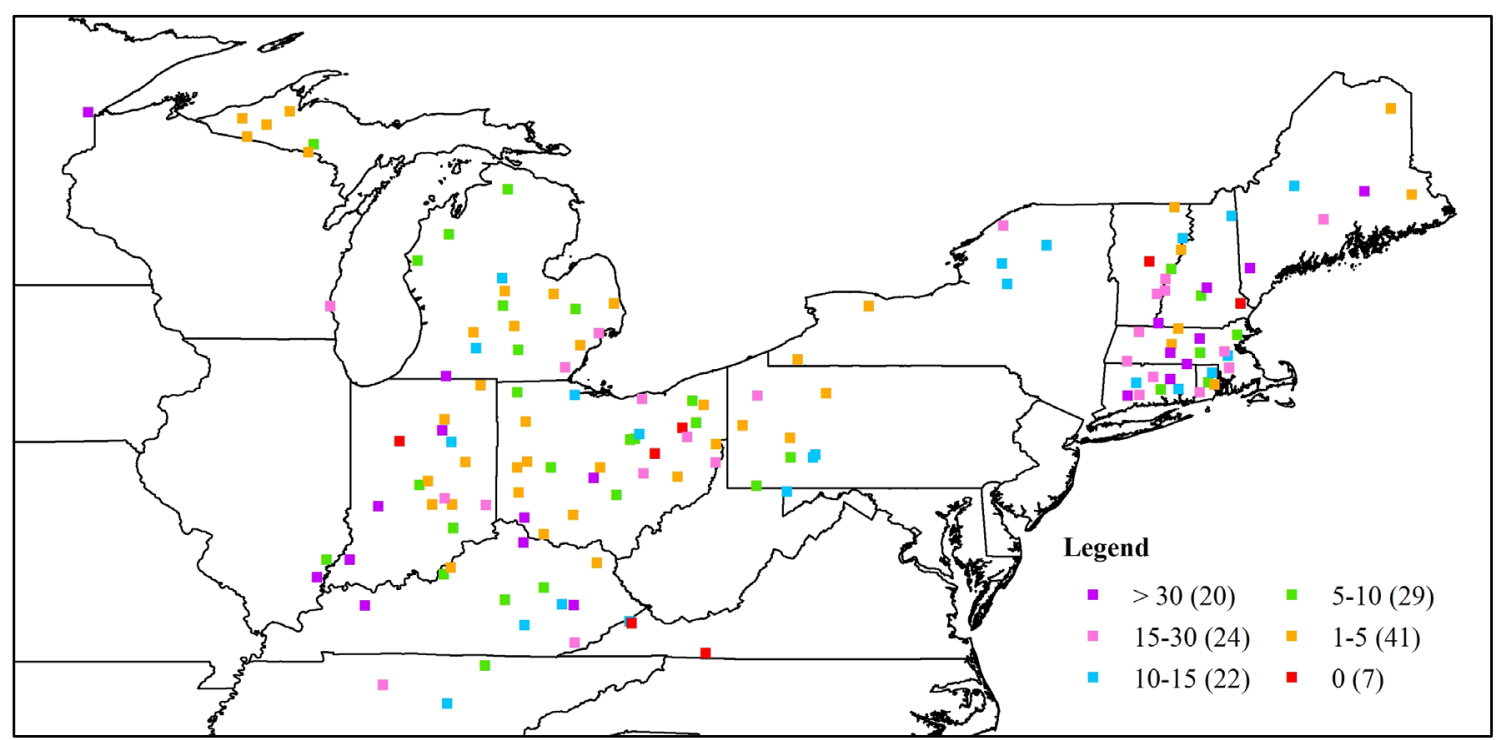

Figure 2-21: Geographic distribution of the number of dams within each of the 143 watersheds in the year 2009.

To consider the construction of dams over the years, Gages II also provides the number of dams contained in the watersheds in 10-years increments from 1940 to 1990. These data were plotted for each of the five clusters in Figure 2.23, wherein each data point corresponds to the average number of dams within a cluster at the end of a 10-years period. For example, the first data point in each series corresponds to the total number of dams in existence prior to 1940. The last data point in each series corresponds to the average number of dams contained within a given cluster in 2009. It is interesting to note that for each cluster, the period from 1950 to 1980 represents a time of significant dam construction. Clusters 3,4 and 5, characterized by a significant percentage of agricultural areas, experienced the highest increments in dam construction, especially since 1960, perhaps for irrigation purposes. 


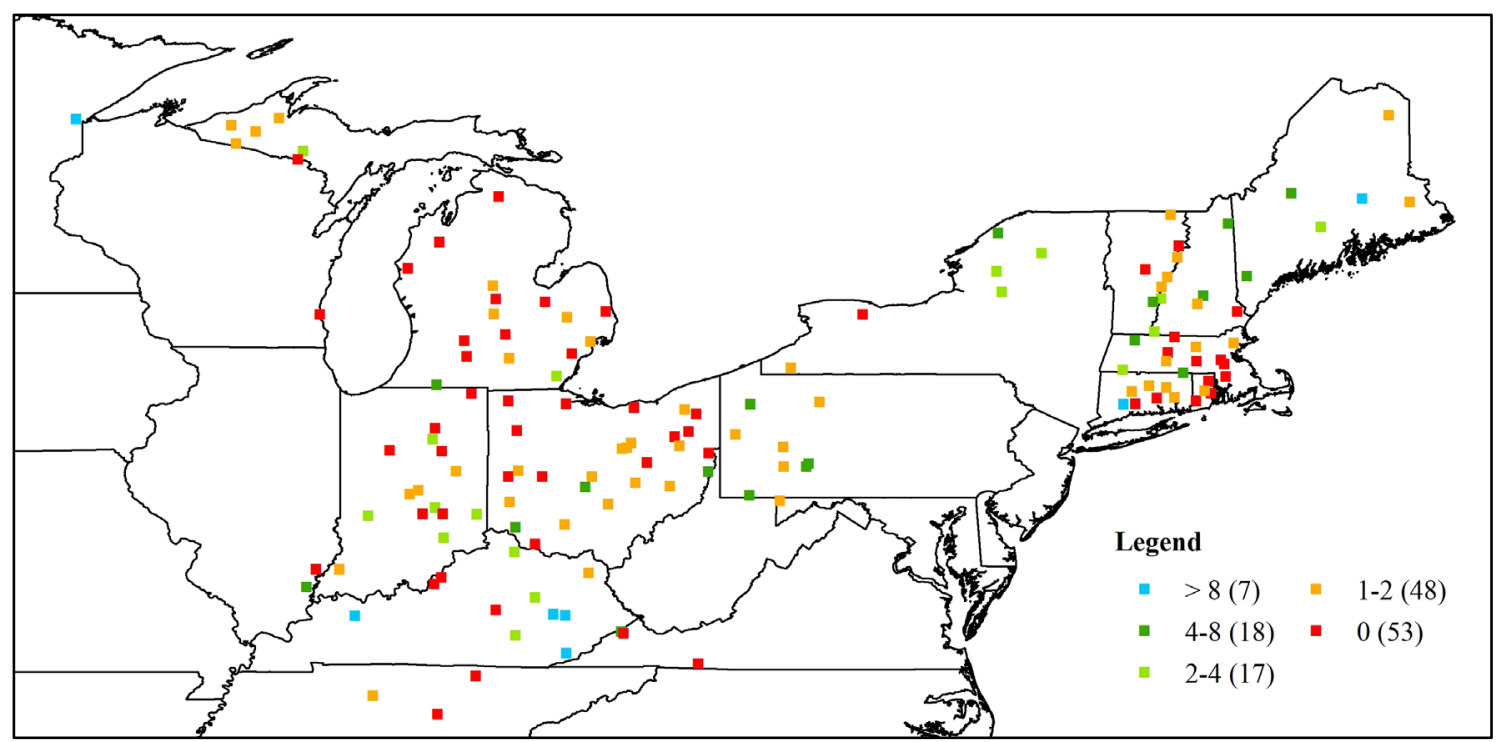

Figure 2-22: Geographic distribution of the number of major dams within each of the 143 watersheds in the year 2009.

In addition to the metrics discussed above, Gages II includes notes about human alterations of the streamflows derived from Annual Data Reports (ADRs) or visual screening of high-resolution imagery (Falcone, 2011). For most of the 143 sites, clear evidence of human-induced alterations is reported, including flows regulated by lakes, reservoirs, power plants and mills; presence of diversions and dams; channelization and/or proximity to urban areas. In some cases, the year in which flow regulation began is specified. An attempt will be made in Section 3.2 to relate these human influences, as well as the general physical characteristics of the watersheds, to the non-stationary behavior of annual maximum flood series. 


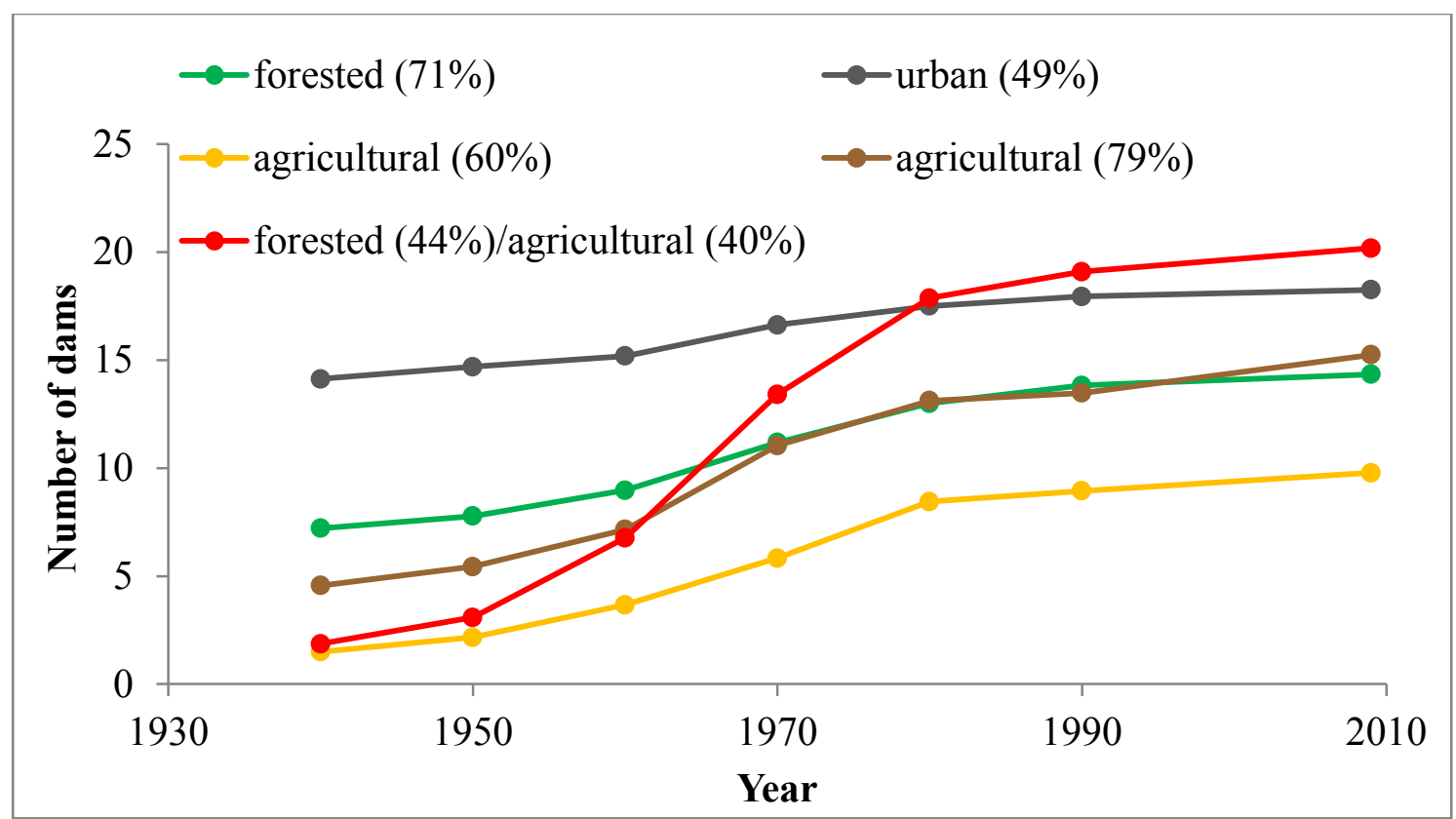

Figure 2-23: Total number of dams contained/constructed in 10-years increments within each land-use/land-cover cluster. 


\section{Non-stationarity in annual maximum flood series and potential human-induced impacts}

Several studies have provided evidence that the assumption of stationarity in streamflow time series should be reconsidered and current procedures for flood risk assessment should be updated and improved. Both natural and anthropogenic factors might induce non-stationary behavior in flood series, thus requiring a more proper definition of the frequency distribution and a better understanding of the associated flood risk in order to guarantee human safety. A few recent studies focused on nonstationarity in annual maximum flood series (Fritsch, 2012; Kashelikar, 2009; Villarini et al., 2009a; Villarini et al., 2011) by investigating the presence of trends and/or change-points in the time series for gauging stations throughout the United States. This chapter conducts similar analyses to assess the degree of non-stationarity of annual maximum flows for 143 USGS gauging stations in the Upper Midwest and Northeastern US. As discussed in Chapter 1, moderately impaired watersheds are considered given that human disturbances influence numerous US streams/watersheds and should not be further neglected (Villarini et al., 2011). Attempts are made to relate the observed changes in flood series to human activities within the watersheds, considering the potential alterations of the hydrologic response due to urbanization, land-use/land-cover and engineering structures.

\subsection{Methods to investigate non-stationarity}

Analyses were conducted to identify non-stationarity in the form of both trends and abrupt shifts in the mean of the annual maximum flood magnitudes. Trends were investigated by applying the non-parametric Mann-Kendall test (Kendall, 1975; Mann, 1945) appropriately accounting for the influence of serial correlation (Yue et al., 2002a; Yue and Wang, 2004). The non-parametric Pettitt test (Pettitt, 1979) was adopted to identify the presence of abrupt shifts in the mean over time. In the instance that a change-point occurred in the time series, the Mann-Kendall test was applied a second 
time to investigate possible trends in both the subseries before and after the identified shift. A limitation of the Pettitt test is that it can only identify a single change-point. Thus, a Bayesian change-point approach (Ruggieri, 2012) was also applied to investigate the possible presence of multiple change-points in the annual maximum flood series. The following sections review the methods in more detail, discussing the main equations and variables involved.

\subsubsection{Trend test: Mann-Kendall test}

Considering the time series of a selected variable, a trend test is commonly applied to determine if the mean of the distribution has changed over time (Helsel and Hirsch, 2002). Trend tests are formulated to test the null hypothesis $\left(\mathrm{H}_{0}\right)$ of no trend (constant mean) against the alternative hypothesis $\left(\mathrm{H}_{\mathrm{a}}\right)$ that a trend exists. For hydroclimatic variables, one of the most common procedures adopted to assess the presence of a gradual, monotonic trend is the Mann-Kendall test. This test has been performed in several studies considering streamflow, precipitation and temperature series (Burn and Hag Elnur, 2002; Collins, 2009; Douglas et al., 2000; Fritsch, 2012; Kashelikar, 2009; Lettenmaier et al., 1994; Villarini and Smith, 2010; Villarini et al., 2011).

The Mann-Kendall test is a non-parametric, rank-based method. Given a time series of $n$ observations (or $n$ years given that one annual maximum flood peak is recorded for each year), the magnitude of the flood peak observed in year $i\left(x_{i}\right)$ is compared to each value recorded in subsequent years $\left(x_{j}\right.$ for $j=i+1$ to $n$ ). For each pair of observations $\left(x_{i}, x_{j}\right)$ the sign of their difference is evaluated and the Kendall's $S$ test statistic (Kendall, 1962) is computed as (Douglas et al., 2000):

$$
S=\sum_{i=1}^{n-1} \sum_{j=i+1}^{n} \operatorname{sign}\left(x_{i}-x_{j}\right)
$$

For $n$ greater than 10, as is the case in this study with a minimum record length of 65 years, the test statistic $S$ can be assumed to follow a normal distribution, and thus the test can be conducted on the basis of a standard normal test statistic $Z$ (Kendall, 1962). The $Z$ test statistic is defined as: 


$$
Z= \begin{cases}(S-1) / \sigma_{S} & \text { for } S>0 \\ 0 & \text { for } S=0 \\ (S+1) / \sigma_{S} & \text { for } S<0\end{cases}
$$

where $\sigma_{S}$ is computed as the square root of the variance $\sigma_{S}^{2}$ which is derived as follows in the case of tied data values:

$$
\sigma_{S}^{2}=\frac{n(n-1)(2 n+5)-\sum_{i=1}^{n} t_{i}(i)(i-1)(2 i+5)}{18}
$$

where $t_{i}$ is the number of ties of extent $i$. If no tied data are present in the time series, then the summation term is zero and $\sigma_{S}^{2}$ reduces to:

$$
\sigma_{S}^{2}=\frac{n(n-1)(2 n+5)}{18}
$$

To decide whether or not to reject the null hypothesis of no trend, the test statistic $Z$ is compared against the critical value $z_{\alpha / 2}$ corresponding to the specified significance level $\alpha$ of the test. For a two-tailed test, the critical value is defined as $\Phi^{-1}(1-$ $\alpha / 2)$ where $\Phi$ represents the cumulative distribution function of the standard normal distribution (Helsel and Hirsch, 2002). The null hypothesis is rejected and the trend is deemed statistically significant in two cases: if $Z \geq+z_{\alpha / 2}$, then an increasing trend is identified in the time series; if $Z \leq-z_{\alpha / 2}$, then a decreasing trend is detected.

The adoption of a non-parametric test, such as the Mann-Kendall test, has the advantage of being as powerful as regression in many cases, but it is not influenced by outliers in the data (Helsel and Hirsch, 2002). Moreover, the Mann-Kendall test does not require the data to follow a normal distribution, and the results are not altered by power transformations of the data (Helsel and Hirsch, 2002). However, it does require serial independence of the data. Various techniques to adjust for serial correlation have been proposed. Storch (1995) suggested a pre-whitening technique to remove the contribution of serial correlation before applying the Mann-Kendall test; many authors adopted this procedure in their analyses (Burn and Hag Elnur, 2002; Douglas et al., 2000; Hamilton et al., 2001). However, Yue and Wang (2002) found that Storch's method effectively eliminated the effects of serial correlation on the Mann-Kendall test 
only when the null hypothesis was accepted (i.e., no trend was evident in the data). The authors also realized that serial correlation affects the variance, $\sigma_{S}^{2}$, of the distribution of the test statistic $S$. In fact, the variance of $S$ increases as positive serial correlation increases, inducing greater likelihood of rejecting the null hypothesis (no trend) when actually correct (type I error) or, in other terms, of detecting a significant trend in the time series when it does not exist (Yue et al., 2002b). For this reason, a new approach to correct $\sigma_{S}^{2}$ was proposed in order to eliminate impacts of serial correlation on the results of the Mann-Kendall test (Khaliq et al., 2009; Yue and Wang, 2004). In this study, the Mann-Kendall test was performed in XLSTAT (2012) using the correction of Yue and Wang (2004).

\subsubsection{Change-point analysis: Pettitt test}

The Pettitt test was adopted to identify the presence and timing of an abrupt shift in the mean of the annual maximum flood series over time. It is a rank-based, non-parametric test, and thus does not require the data to follow a particular distribution (Pettitt, 1979; Reeves et al., 2007), and it is more robust in the presence of outliers and/or non-zero skew of the data (Villarini and Smith, 2010; Villarini et al., 2011). Some studies have performed the Pettitt test not only for the mean, but also for the variance in order to detect abrupt changes in the scatter of the data (McCabe and Wolock, 2002a; Villarini et al., 2009a; Villarini and Smith, 2010; Villarini et al., 2011). In fact, step changes in the variance might have larger effects on the frequency of extreme events than changes in the mean (Katz and Brown, 1992; Meehl et al., 2000).

Given a time series of $n$ observations, a generic time $t$ divides the series into two subseries. The test allows determining if the two means computed for both subseries, before and after $t$, are statistically different. The null hypothesis $\mathrm{H}_{0}$ represents the condition that no change-point exists at time $t$, and thus the means of the subseries are deemed equivalent. The alternative hypothesis $\mathrm{H}_{\mathrm{a}}$ represents the condition that a change-point exists at time $t$, wherein $t=1, \ldots, n$ as all possible subdivisions of the time series are considered. For a given $t$, this is equivalent to the Mann-Whitney Rank-Sum 
test on the difference in means; however, $t$ is unknown herein. The test statistic $K_{n}=$ $\max _{1 \leq t \leq n}\left|U_{t, n}\right|$ is used to identify the time $t$ which is most likely to represent a changepoint in the time series (Kundzewicz et al., 2000). The parameter $U_{t, n}$ is computed as:

$$
U_{t, n}=\sum_{i=1}^{t} \sum_{j=t+1}^{n} \operatorname{sign}\left(x_{i}-x_{j}\right)
$$

where $x_{i}$ and $x_{j}$ are the values of two observations consecutive in time ( $x_{i}$ preceeds $x_{j}$ ). The function sign returns a value of 1 when the argument is positive, -1 if negative, and 0 in the case of a tie (Kundzewicz et al., 2000). A change-point is deemed statistically significant (i.e., $\mathrm{H}_{0}$ is rejected) if $K_{n}$ sufficiently differs from zero. This occurs when the associated p-value is less than the specified significance level $\alpha$ of the test. For the analyses presented in this thesis, the Pettitt test was performed in XLSTAT (2012) at both $5 \%$ and $10 \%$ significance levels; p-values are computed within the software by applying a Monte Carlo resampling technique.

\subsubsection{Multiple Change-Points analysis: a Bayesian approach}

A prime disadvantage of the Pettitt test is that it is only capable of detecting a single statistically significant shift in the mean and/or variance of a given time series; therefore, recent research has focused on the development of Bayesian models able to identify multiple shifts in hydrologic series (Ehsanzadeh et al., 2011; Rasmussen, 2001; Seidou et al., 2007; Seidou and Ouarda, 2007). Both approaches provide an objective measure for use in the determination of the occurrence and timing of a change-point versus a simple visual assessment of the data; however, the Pettitt test is easy to apply, whereas Bayesian methods require the development of mathematical algorithms (Rodionov, 2005). The main advantage of a Bayesian model resides in the computation of a posterior distribution for both the number and location (year) of possible changepoints (Rasmussen, 2001). Nonetheless, some still favor the Pettitt test as identification

of multiple change-points results in multiple subdivisions of the time series which may limit the ability to detect trends (Villarini et al., 2009a; Villarini and Smith, 2010; Villarini et al., 2011). 
Common methods to approximate the posterior distribution of the number and location of change-points include Markov Chain Monte Carlo (MCMC) simulation and Gibbs Sampling combined with multiple linear regression (Fearnhead, 2005, 2006; Seidou et al., 2007), but these approaches suffer from difficulties with convergence, and require a priori specifications regarding both the number and position of change-points (Ruggieri, 2012). In addition, the method proposed by Seidou and Ouarda (2007), which is a generalization of Fearnhead's model, requires two training samples to define the parameters of the multiple linear regression model, and a prior distribution for the time interval between consecutive change-points must be provided.

In this thesis, the algorithm developed by Ruggieri (2012) for climatic variables was adapted to the annual maximum flood series under consideration. Unlike Seidou and Ouarda's model, Ruggieri's approach does not require a training data set or a prior distribution of the distance between consecutive change-points (Ruggieri, 2012). Given a time series with $n$ observations $\left(x_{i: n}\right), k$ change-points are assumed to occur within the series and their locations are identified by $c_{j}$ with $j$ varying from 1 to $k$ ( $c_{0}$ corresponds to the first year in the time series and $c_{k+1}$ to the last year). Ruggieri (2012) provides a Matlab code which determines the most probable number and location of change-points, computes the probability density of the data contained within each segment identified by two consecutive change-points, and the parameters of a linear regression model to fit the data in each segment. The code and the computational steps are extensively described by Ruggieri (2012).

The algorithm requires five parameters to be defined by the user: $1 . k_{\max }$ corresponds to the maximum number of change-points allowed; 2. $d_{\min }$ is the minimum distance between consecutive change-points; $3 . k_{0}$ is a parameter with the function of scaling the residual variance $\left(\sigma^{2}\right)$ to compute the variance of the regression coefficients $\left(\sigma^{2} / k_{0}\right) ; 4$ and 5. $v_{0}$ and $\sigma_{0}^{2}$ are parameters adopted to define the prior distribution of the residual variance. Based on the suggestions provided by Ruggieri (2012) and previous studies applied to streamflow series (Ehsanzadeh et al., 2011; Rasmussen, 2001; Seidou et al., 2007; Seidou and Ouarda, 2007) the following values were assumed herein: $k_{\max }$ was 
set to 3 (a maximum of 3 change-points were allowed to occur); for $d_{\min }, 15$ years was identified as the most appropriate minimum size of the interval so as not to excessively subdivide the time series and to be consistent with the decadal scale of potential sources of non-stationarity in annual maximum flood series such as climatic indices. For $k_{0}$, the value of 0.01 proposed by Ruggieri was adopted; $v_{0}$ was set to 2 as this parameter value should be less than $25 \%$ of $d_{\min }$ (Ruggieri (2012); and, $\sigma_{0}^{2}$ corresponded to the variance of the annual maximum flood series under consideration.

\subsection{Forms of non-stationarity in annual maximum flood series}

The following sections focus on the application of the aforementioned methods to investigate non-stationarity in annual maximum flood series. The main results obtained will be presented and potential effects of human activities on the non-stationary hydrologic response of the basins will be discussed.

\subsubsection{Trends in annual maximum flood series}

The Mann-Kendall test was conducted for each of the 143 watersheds at significance levels of $5 \%$ and $10 \%$. The results are summarized in Figure 3.1. At the 10\% significance level, the null hypothesis of no trend was rejected 26 times, with an increasing trend identified for 13 watersheds, and a decreasing trend for the other 13. At the 5\% level, a statistically significant trend was identified at 15 sites, with 6 streams exhibiting increasing magnitude of the annual maximum flood and 9 streams exhibiting decreasing magnitude. Additional results of the Mann-Kendall tests are reported in Appendix B for both 5\% and 10\% significance levels; p-values computed for each flood series are also included. 


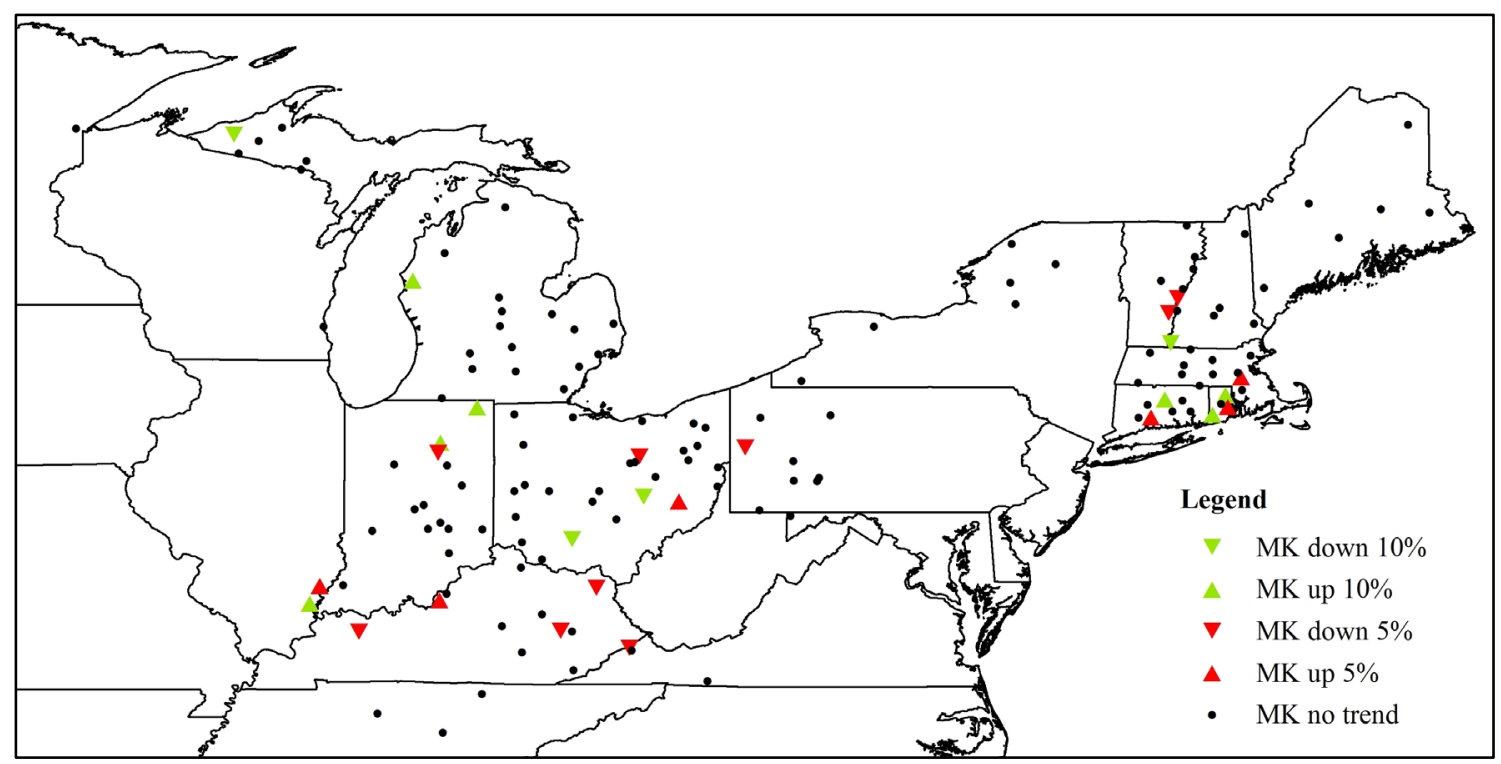

Figure 3-1: Trends in annual maximum flood series detected by applying MannKendall test at 5\% (red) and 10\% (green) significance levels. Upright triangles identify increasing trends; inverted triangles decreasing trends. Black dots indicate the remaining sites for which no significant trends were identified.

Figure 3.1 shows that sites with analogous trend tend to be close to each other, but no strong spatial dependency is evident. Similar findings were obtained in other studies for both unimpaired and impaired watersheds throughout the US (Fritsch, 2012; Villarini and Smith, 2010). Increasing trends are observed in Figure 3.1 for the watersheds in the coastal area of lower New England. These watersheds are all mainly developed (urban) based on land-use/land-cover data for 2006 as discussed in Section 2.4.2. This suggests that increasing magnitudes of flood peaks over time could be associated with more intense runoff due to increasing intensity of precipitation events and/or expansion of urban areas resulting in increased percent impervious cover. The increasing trends identified in Connecticut are consistent with the findings of Collins (2009) although the author considered annual maximum flood series for unimpaired watersheds. Moreover, Collins (2009) found that the New England region has experienced intense reforestation that tends to attenuate the flood peaks. This might justify the decreasing trends observed herein for two sites in Vermont and one in New Hampshire which are located in a mainly forested region. The majority of the sites for which significant trends were identified in the central area, corresponding to Ohio, Illinois and Kentucky, exhibit 
decreasing flood magnitudes over time. These basins are characterized by high percentages of planted/cultivated areas, and thus increased infiltration and diversions for irrigation could have induced the observed decreasing trends in flood series.

In order to quantify the relationships between trends in flood series and temporal changes in land-use/land-cover, the analyses in this thesis should be extended. Rather than limiting the evaluation to land-cover/land-use data for a single time point (i.e., 2006 NLCD herein), time series of representative variables (e.g., annual percentages of urban, forested and agricultural areas within the watersheds) should be derived and correlated to the annual maximum flood series. Moreover, considering the results in Figure 3.1, it is interesting to observe that there is a correspondence between the annual maximum flood trends and the trends of annual precipitation presented by Groisman et al. (2001); increasing flood magnitudes are experienced in those areas where also annual precipitation increased and vice versa for decreasing trends. The influence of meteorological variables (e.g., precipitation) as a source of non-stationarity in annual maximum flood series will be investigated in Chapter 4.

\subsubsection{Change-points in annual maximum flood series}

The Pettitt test was performed for each of the 143 watersheds to investigate the presence of a statistically significant shift in the mean of the annual maximum flood series at both $5 \%$ and $10 \%$ significance levels. Figure 3.2 shows the location of the sites for which change-points were identified and the direction of the associated shift in the mean. Given a flood series with $n$ observations and a change-point occurring at time $t$, the means of the floods before and after $t$ could be computed. Let $\mu_{1}$ represent the mean of the subseries preceding the shift (from time 1 to $t$ ), and $\mu_{2}$ represent the mean of the subseries following the shift (from $t+1$ to $n$ ). At the $10 \%$ level, 30 sites experienced a positive shift $\left(\mu_{2}>\mu_{1}\right)$ and 27 sites exhibited a negative shift $\left(\mu_{2}<\mu_{1}\right)$. At the $5 \%$ level,

24 of the shifts were positive and 18 were negative. Similar locations for positive and negative shifts were found by Fritsch (2012) considering unimpaired watersheds. For each watershed, additional Pettitt test results are summarized in Appendix B for both 
$5 \%$ and $10 \%$ significance levels, including the year in which the change-point was identified and the associated p-value.

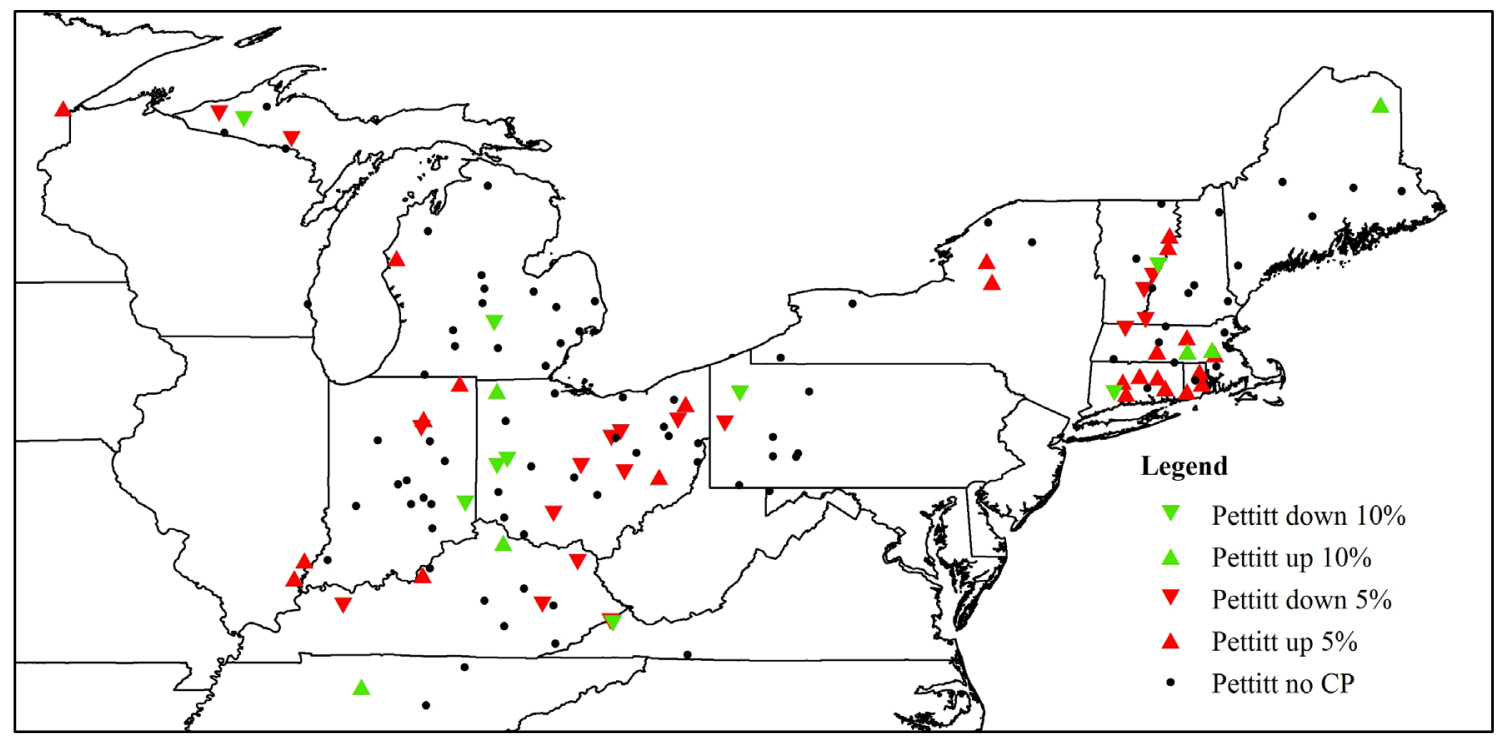

Figure 3-2: Direction of shift (change-point) in annual maximum flood series detected by applying Pettitt test at 5\% (red) and 10\% (green) significance levels. Upright triangles identify positive shifts; inverted triangles negative shifts. Black dots indicate locations of watersheds for which significant results were not obtained.

Taking into account the year in which the shift occurred, the sites with significant change-points were classified into four groups as shown in Figure 3.3. The choice of the time periods was suggested by the main results found in literature. In several studies, the late 60 s to early 70 s have been identified as a period of change in precipitation and flood series (Collins, 2009; Fritsch, 2012; Mauget, 2003; McCabe and Wolock, 2002a; Perreault et al., 1999; Villarini and Smith, 2010; Villarini et al., 2011). Two 10-years intervals were considered from 1960 to 1980 to better investigate these decades. Table 3.1 summarizes the number of sites exhibiting change-points in each time interval considered. These results are consistent with the findings of the aforementioned studies. Namely, the highest number of change-points, $43.9 \%$ of the total at the $10 \%$ level and $47.6 \%$ at the 5\% level, occurred in the period from 1960 to 1980. 


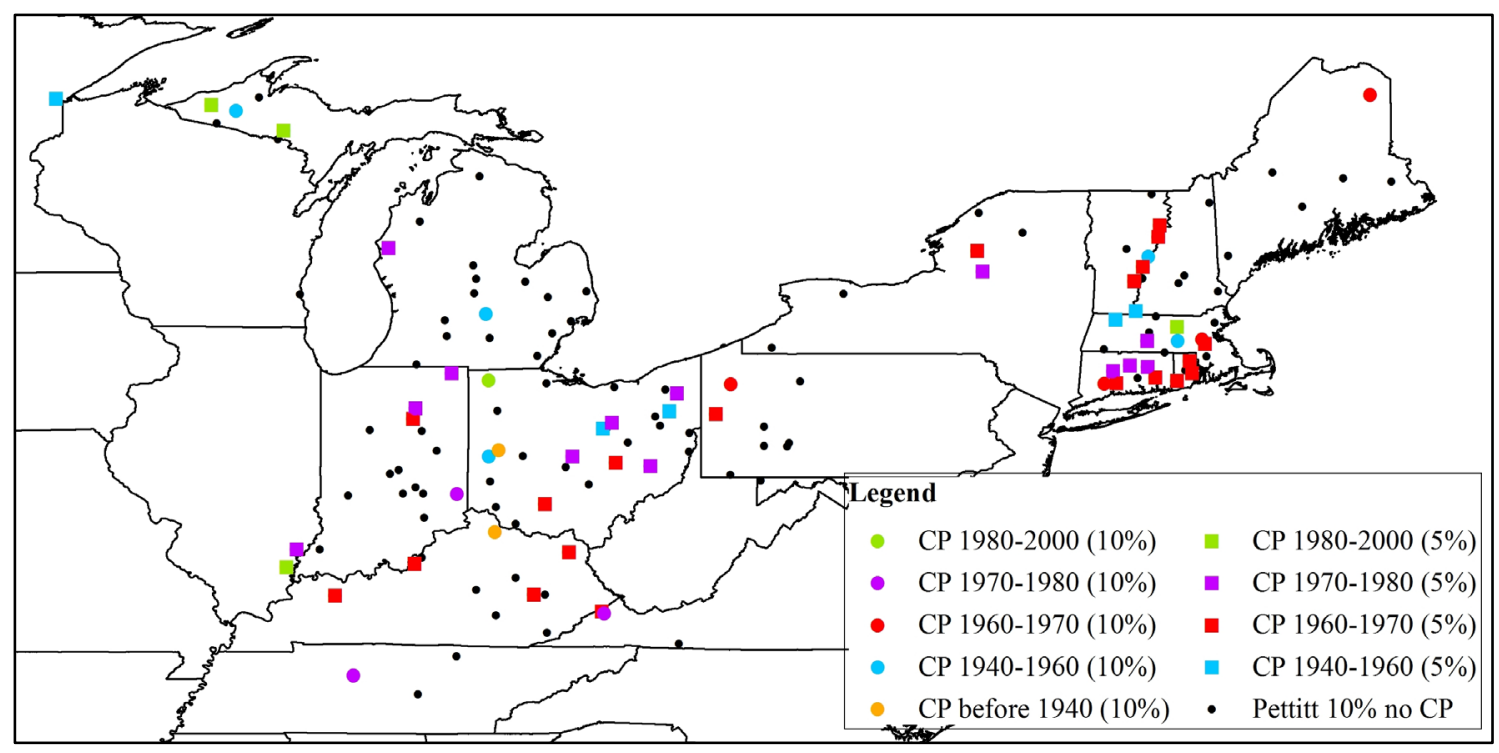

Figure 3-3: Timing of change-points in annual maximum flood series as identified by the Pettitt test at both 5\% and 10\% significance levels. Black dots indicate locations of watersheds for which no significant results were obtained.

Table 3-1: Number of sites exhibiting change-points within various time intervals as identified by Pettitt test at both 5\% and 10\% significance levels.

\begin{tabular}{|c|c|c|c|c|c|}
\hline & \multicolumn{5}{|c|}{ Number of sites with change-point } \\
\hline $\boldsymbol{\alpha}[\%]$ & before 1940 & $\mathbf{1 9 4 0}-\mathbf{1 9 5 9}$ & $\mathbf{1 9 6 0 - 1 9 6 9}$ & $\mathbf{1 9 7 0 - 1 9 7 9}$ & after 1980 \\
\hline 5 & - & 5 & 20 & 13 & 4 \\
\hline 10 & 2 & 9 & 25 & 16 & 5 \\
\hline
\end{tabular}

Two main observations are derived from the Pettitt test results. First, the number of sites exhibiting a change-point in the mean of annual maximum flood series was larger than the number of sites with a monotonic trend: at the $10 \%$ level, the Mann-Kendall test identified 26 stations with a trend, whereas the Pettitt test identified 57 stations with a change-point. This supports the idea derived from several studies in the United States that non-stationarity in streamflows (e.g., maximum daily streamflow, annual average and maximum flood flows) manifests in most cases as a change-point rather than a gradual trend (Kalra et al., 2006; McCabe and Wolock, 2002a; Villarini and Smith, 2010; Villarini et al., 2011). Second, non-stationarity could be partially related to specific anthropogenic activities altering the streams or the hydrologic response of the watershed. At the $10 \%$ level, the year in which a change-point was identified for 6 sites 
was the same as or the year immediately prior to the year indicated in Gages II as the start of water management practices (i.e., use by power plants, reservoir operations and regulation of flows by lakes); examples are provided in Table 3.2.

Table 3-2: Relationship between year of significant shift in annual maximum flood peaks and human-induced alterations as recorded in Gages II.

\begin{tabular}{|c|c|c|}
\hline Site & $\begin{array}{c}\text { Year of } \\
\text { change-point } \\
\text { (Pettitt test) }\end{array}$ & Gages II: report remarks \\
\hline 01118000 & 1967 & $\begin{array}{c}\text { Some seasonal regulation by Locustville Pond on } \\
\text { Brushy Brook since } 1968 \text {. }\end{array}$ \\
\hline 01151500 & 1960 & $\begin{array}{c}\text { Flow regulated by power plants upstream and by North } \\
\text { Hartland Reservoir since March } 1961 .\end{array}$ \\
\hline 01153000 & 1960 & $\begin{array}{l}\text { Flow regulated by power plants and mills upstream and } \\
\text { by North Springfield Reservoir since November } 1960 .\end{array}$ \\
\hline 03209000 & 1963 & $\begin{array}{l}\text { Flow regulated since March } 1965 \text { by John W. } \\
\text { Flannagan Reservoir. }\end{array}$ \\
\hline 03216500 & 1967 & Flow regulated since March 1968 by Grayson Lake. \\
\hline 03024000 & 1969 & $\begin{array}{c}\text { Flow regulated since July } 1970 \text { by Union City } \\
\text { Reservoir. }\end{array}$ \\
\hline 03133500 & 1952 & $\begin{array}{l}\text { Flow regulated by Pleasant Hill Lake. Water diverted } \\
\text { from Clear Fork Reservoir for municipal supply of city } \\
\text { of Mansfield since } 1953 .\end{array}$ \\
\hline
\end{tabular}

Table 3.2 shows that a positive shift in the mean was observed only for the first site. For the other sites listed, a negative step change was detected likely due to the humaninduced regulation of the flow. Unfortunately, for many of the other sites exhibiting a change-point, Gages II did not report information pertaining to the timing of human activities which may have influenced the flow.

The USGS qualification codes 5: "discharge affected to unknown degree by regulation or diversion", and 6: "discharge affected by regulation or diversion", were associated with 39 of the sites exhibiting a change-point at the 10\% level (22 at the 5\% level). For 
9 of these sites, the code was attributed to flood peaks starting with a year close to that in which the change-point was detected (maximum \pm 4 years of difference). A similar observation was made by Villarini et al. (2011). The authors performed the Pettitt test on both mean and variance of annual maximum flood series recorded at 196 USGS gauging stations in the Midwestern US. A change-point in the mean was identified for $40 \%$ of the 196 sites and in most cases the shift was associated to the USGS qualification code 6 (Villarini et al., 2011).

Considering findings of previous studies conducted at the local and regional scale (Billington and Jackson, 2006; Hadley et al., 1987; Hejazi and Markus, 2009; Juckem et al., 2008; Krug, 1996; Miller and Frink, 1984; Pegg et al., 2003; Perry, 1994; Schilling et al., 2008; Schilling and Libra, 2007; Zhang and Schilling, 2006), Villarini et al. (2011) also suggested that change-points could be related to anthropogenic sources of non-stationarity such as changes in land-use/land-cover, cultivations and construction of engineering structures for water management (e.g., dams and reservoirs). For the study area considered herein, it is interesting to note that the largest increment in dam construction (see Section 2.5) occurred in the same period for which most of the change-points were detected (1960 to 1980), as are the disturbances noted in Table 3.2. This result supports the idea that engineering structures for flow regulation contribute to the non-stationary character of the streamflows and might induce a shift in the magnitude of annual maximum floods.

The results of the Pettitt test are consistent with those of the Mann-Kendall test for the sites at which a monotonic trend was identified. A positive shift in the mean was observed at sites which exhibited a positive trend, and a negative shift was observed in the case of a negative trend. Further, for all of the sites with significant trends (26 at the $10 \%$ level; 15 at the $5 \%$ level), a change-point was also identified; however, the presence of an abrupt shift in the mean annual maximum flood magnitude could have influenced the results of the Mann-Kendall test. Ehsanzadeh et al. (2011) underlined that "abrupt shifts in the mean [...] can lead to misleading conclusions" when applying a monotonic trend test such as the Mann-Kendall test. For this reason, when a change- 
point in the mean of the flood series was detected herein, the Mann-Kendall test was performed a second time for each of the subseries constituted by the data before/after the shift. In most cases, no trend was observed in either subseries. Only 6 sites exhibited a significant trend before and/or after the change-point at the 10\% level (only 1 site at the $5 \%$ level). This might suggest that the presence of a change-point influenced the results of the Mann-Kendall test, falsely identifying gradual trends when an abrupt shift in the mean of the distribution is more likely. Identifying a potential cause of the shift becomes significantly important and it requires exploring either anthropogenic impacts or shifts in climatic patterns and/or meteorological variables. Results of the MannKendall tests on the subseries for the 6 sites in question are reported in Appendix B. The same approach was adopted in other studies to evaluate the non-stationary behavior of hydrologic variables (Ehsanzadeh et al., 2011; Villarini and Smith, 2010).

\subsubsection{Multiple change-points in annual maximum flood series}

In this section, the analysis of non-stationarity in terms of shifts in the mean of annual maximum flood series is extended using the Bayesian model proposed by Ruggieri (2012), which allows for the detection of multiple change-points and provides uncertainty estimates of both the number and location of shifts. The main results of this multiple-change points (MCP) analysis are presented below and compared with the results of the Pettitt test as discussed above.

The MCP analysis was applied to each of the 143 annual maximum flood series with the values of the input parameters $\left(k_{\max }, d_{\min }, k_{0}, v_{0}\right.$, and $\left.\sigma_{0}^{2}\right)$ specified in Section 3.1.3. Figure 3.4 shows the locations of sites for which significant shifts were detected using the MCP analysis; for comparison, sites for which a change-point was identified by the Pettitt test at the $10 \%$ level, but not using the MCP analysis, are also indicated. The MCP analysis identified a single change-point for 23 sites. For 16 of those 23 sites, a shift was also detected by the Pettitt test at the $10 \%$ level; further, the shift was determined to occur in the same year by both tests at 5 of those sites, and the difference was within 1 to 5 years at 6 sites. The results for the two sites at which the MCP 
analysis identified two change-points are discussed below. Appendix B provides a detailed summary of the results of the MCP analysis applied to each of the 143 watersheds.

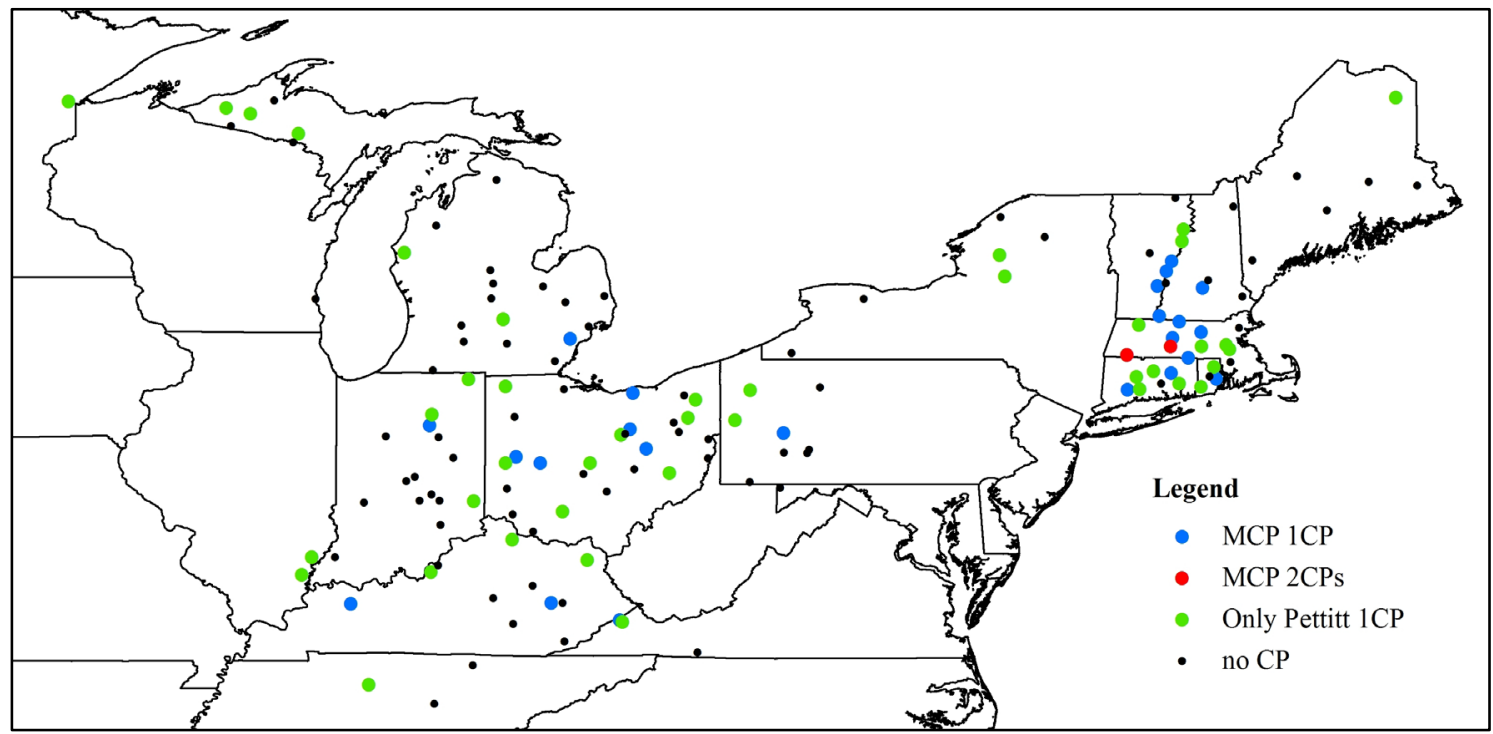

Figure 3-4: Results of multiple change-points (MCP) analysis applied to AMF series. Blue dots indicate sites at which the MCP analysis identified one change-point, and red dots sites at which two change-points were identified. Green dots indicate sites where the Pettitt test identified a change-point, but the MCP analysis did not. Black dots represent the remaining sites with no significant shifts identified by either approach.

For 41 of the sites that exhibited a change-point based on the Pettitt test at the $10 \%$ level, the MCP algorithm did not identify any significant shift. This result might indicate that the Bayesian approach is more robust than the Pettitt test, and it might be more resistant to spurious results caused by extreme wet or dry years. As an example, Figures 3.5 and 3.6 show two cases for which only the Pettitt test identified a step change, wherein the line labeled "mean" corresponds to the sample average computed for the entire period of record, while "mean 1" and "mean 2" denote the sample averages of the subseries before and after the identified shift. Visual assessment of the time series suggests that the difference in the mean before and after the change-point detected by the Pettitt test was mainly due to the presence of a single relatively extreme event: a relatively large event in 1986 for site 04122500 , and a relatively dry year in 1954 for site 03141500 (Figures 3.5 and 3.6, respectively). However, results of the 
MCP analyses for these sites, as reported in Table 3.3, reveal that the highest posterior distribution was associated with the occurrence of 0 change-points. Moreover, a null posterior probability was associated with the year identified by the Pettitt test as a change-point in each case (1973 and 1979, respectively).

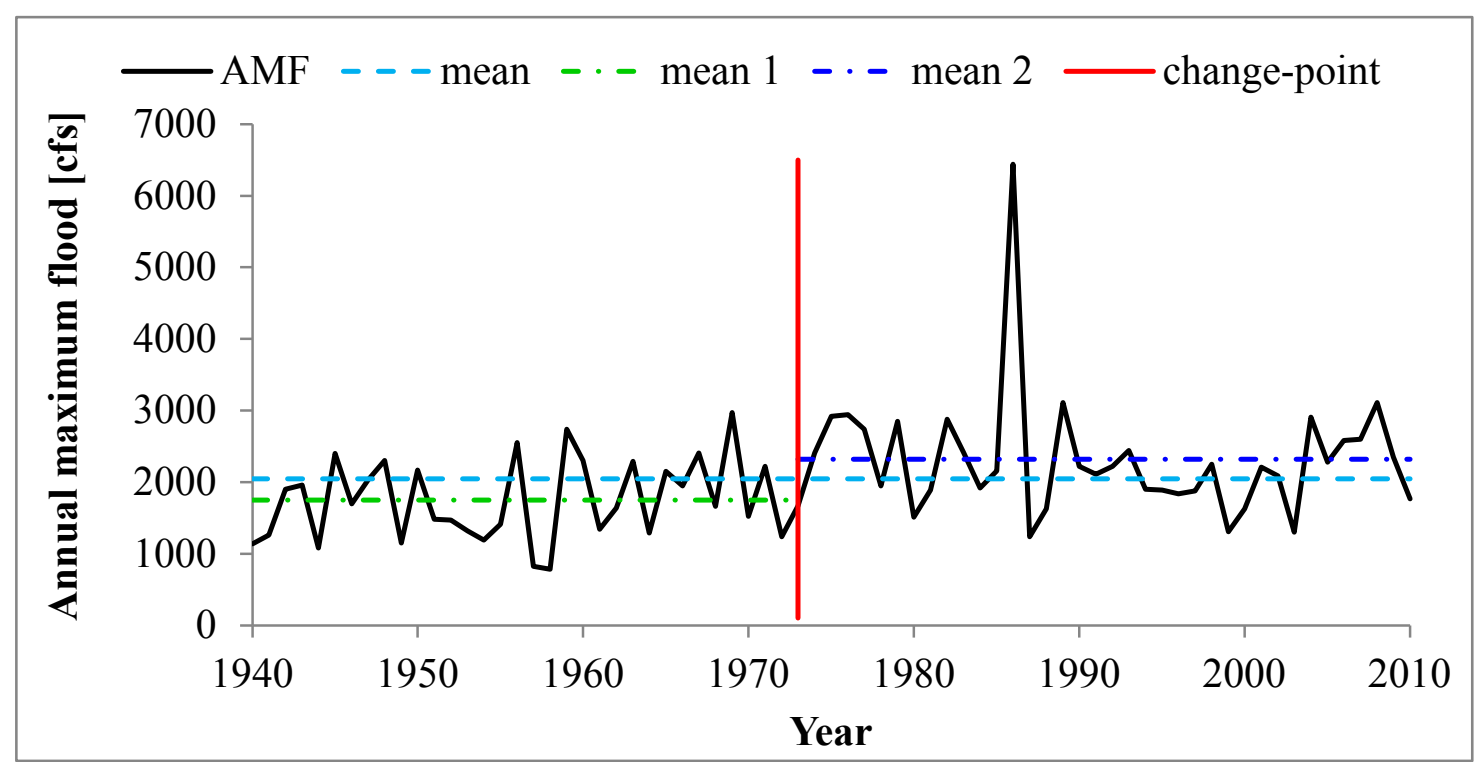

Figure 3-5: Change-point in 1973 for the annual maximum flood (AMF) series of site 04122500 as identified by the Pettitt test at the $10 \%$ level.

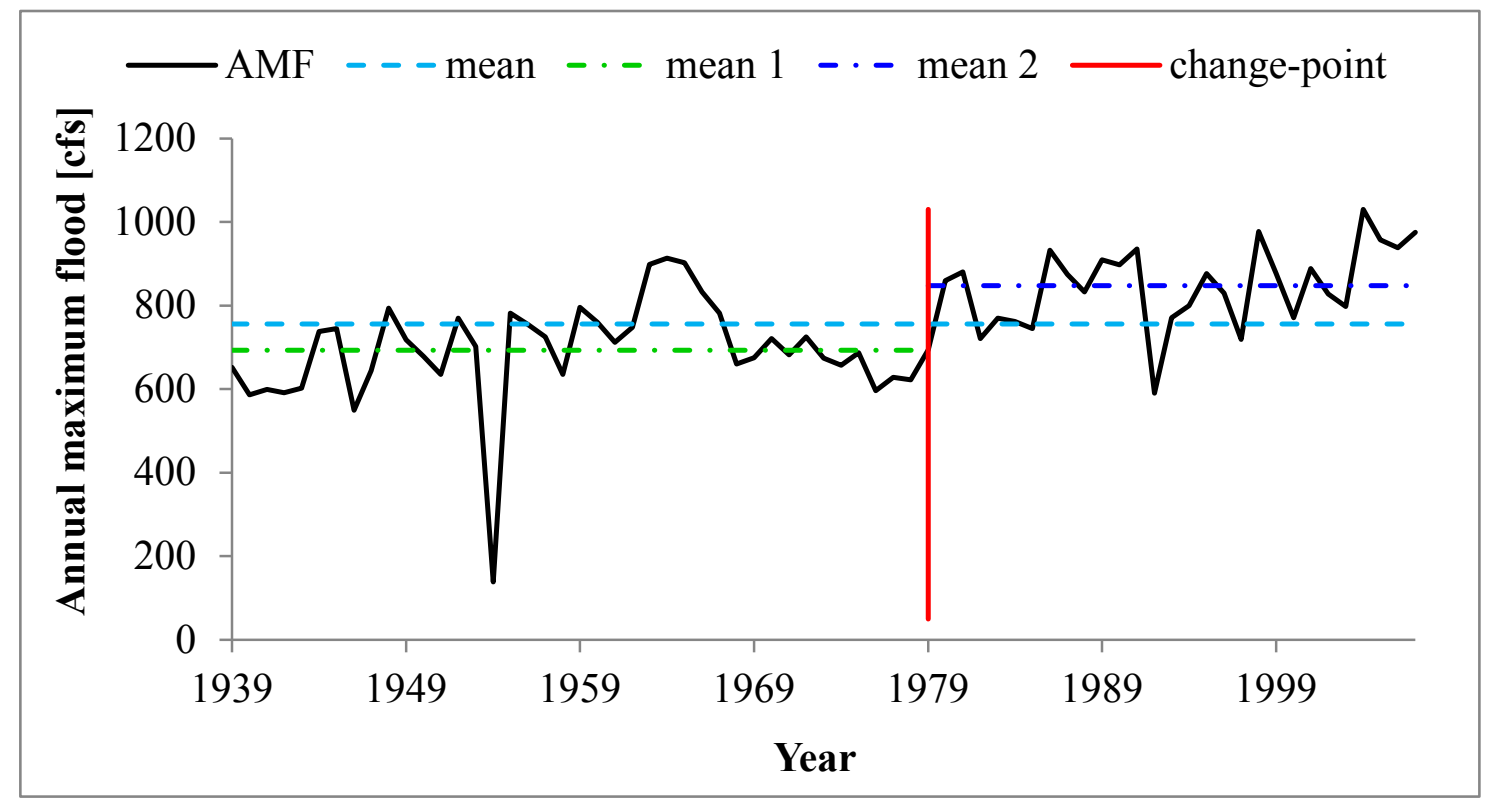

Figure 3-6: Change-point in 1979 for the annual maximum flood (AMF) series of site 03141500 as identified by the Pettitt test at the $10 \%$ level. 
Table 3-3: Posterior probability of the number of possible change-points derived from the MCP analysis for annual maximum flood series of example sites.

\begin{tabular}{|c|c|c|c|c|}
\hline \multirow{2}{*}{$\begin{array}{c}\text { Number of } \\
\text { change-points }\end{array}$} & \multicolumn{4}{|c|}{ Posterior probability } \\
\cline { 2 - 5 } & Site 04122500 & Site 03141500 & Site 01017000 & Site 03024000 \\
\hline 0 & 0.99662 & 0.99866 & 0.99996 & 0.99942 \\
\hline 1 & 0.00330 & 0.00134 & 0.00004 & 0.00057 \\
\hline 2 & 0.00008 & 0.00001 & 0.00000 & 0.00000 \\
\hline 3 & 0.00000 & 0.00000 & 0.00000 & 0.00000 \\
\hline
\end{tabular}

In other cases for which the Pettitt test identified a significant change-point, but not the MCP analysis, no evidence was found to justify the conflicting results of the two tests. Two examples are provided in Figures 3.7 and 3.8 for site numbers 0101700 and 03024000, respectively. Table 3.3 above reports the posterior probability of the number of change-points for these two sites as well. In both the cases, no misleading peaks appear to have influenced the Pettitt test given the high variability of the flood observations. Nevertheless, MCP analysis attributed a posterior probability of 1.000 and 0.999, respectively, to the occurrence of 0 change-points.

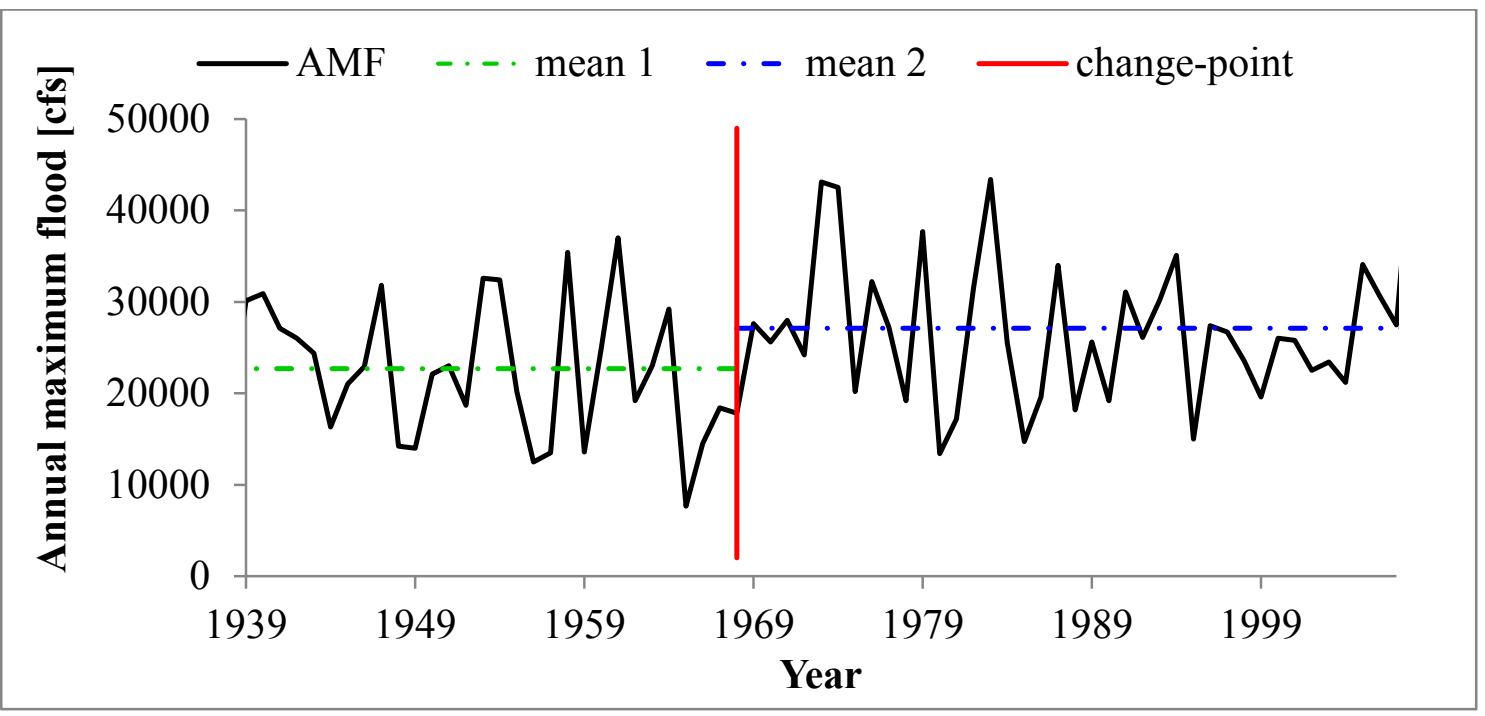

Figure 3-7: Change-point in 1968 for the annual maximum flood (AMF) series of site 01017000 as identified by the Pettitt test at the $10 \%$ level. 


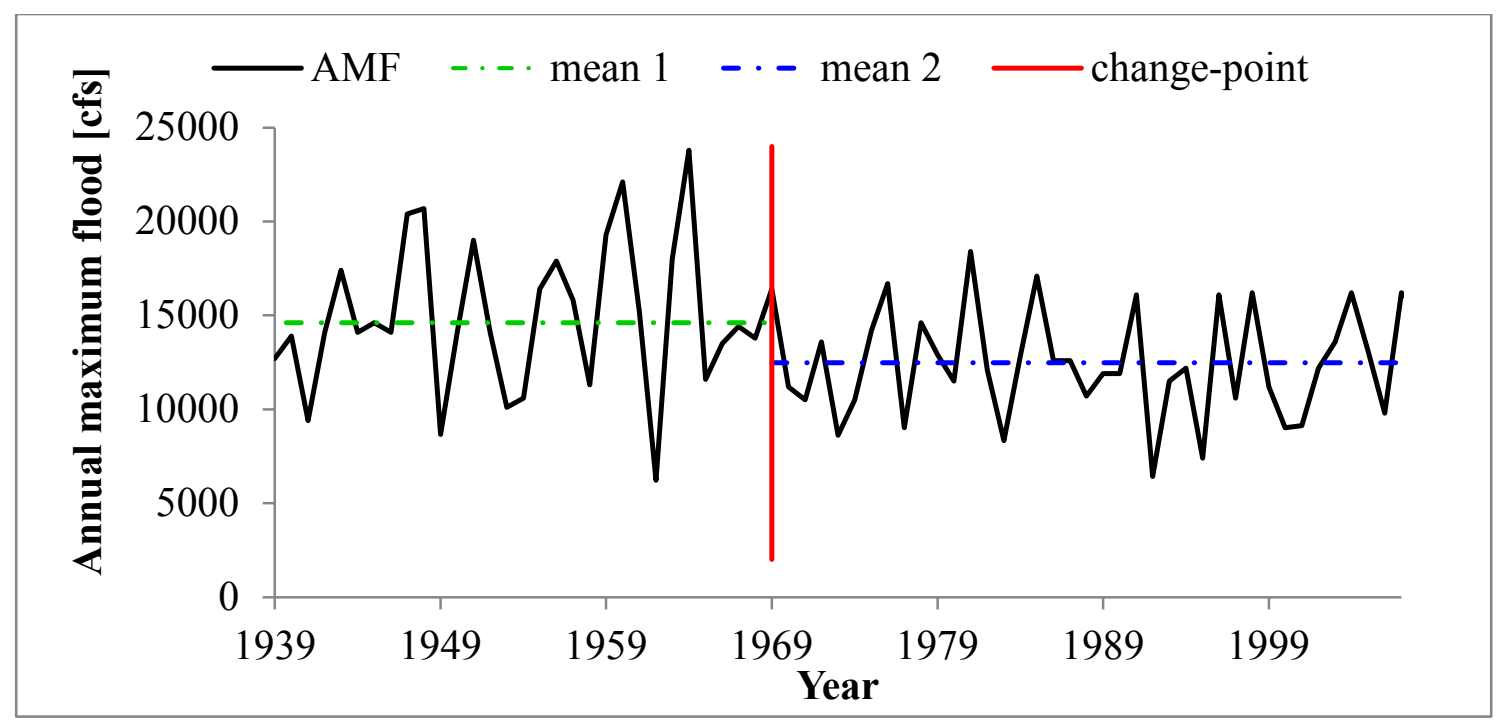

Figure 3-8: Change-point in 1969 for the annual maximum flood (AMF) series of site 03024000 as identified by the Pettitt test at the $10 \%$ level.

Conversely, in 8 cases a change-point was identified by the MCP approach but not by the Pettitt test. Two examples are provided in Figures 3.9 and 3.10. In both cases the presence of a few relatively extreme events could have influenced the results as previously discussed for the Pettitt test. Nevertheless, the posterior probability associated to the change-point was low, 0.452 for the change-point in 1979 in the first time series (Figure 3.9), and 0.302 for the change-point in 1968 in the second time series (Figure 3.10). The posterior probability associated with the change-point was greater than 0.8 in only one of the 8 cases; the probability was lower than 0.6 for 4 cases. 


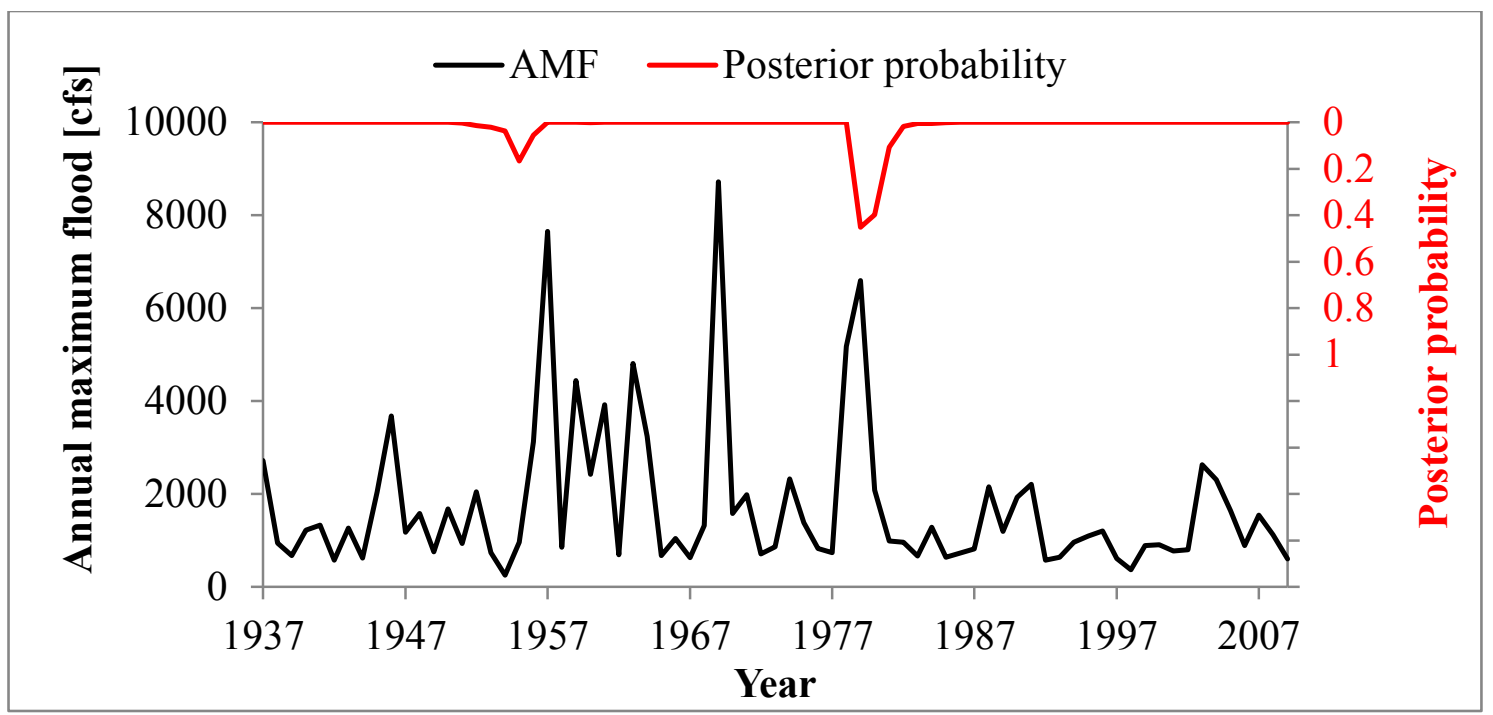

Figure 3-9: Change-point in 1979 for the annual maximum flood (AMF) series of site 03140000 as identified by the MCP analysis.

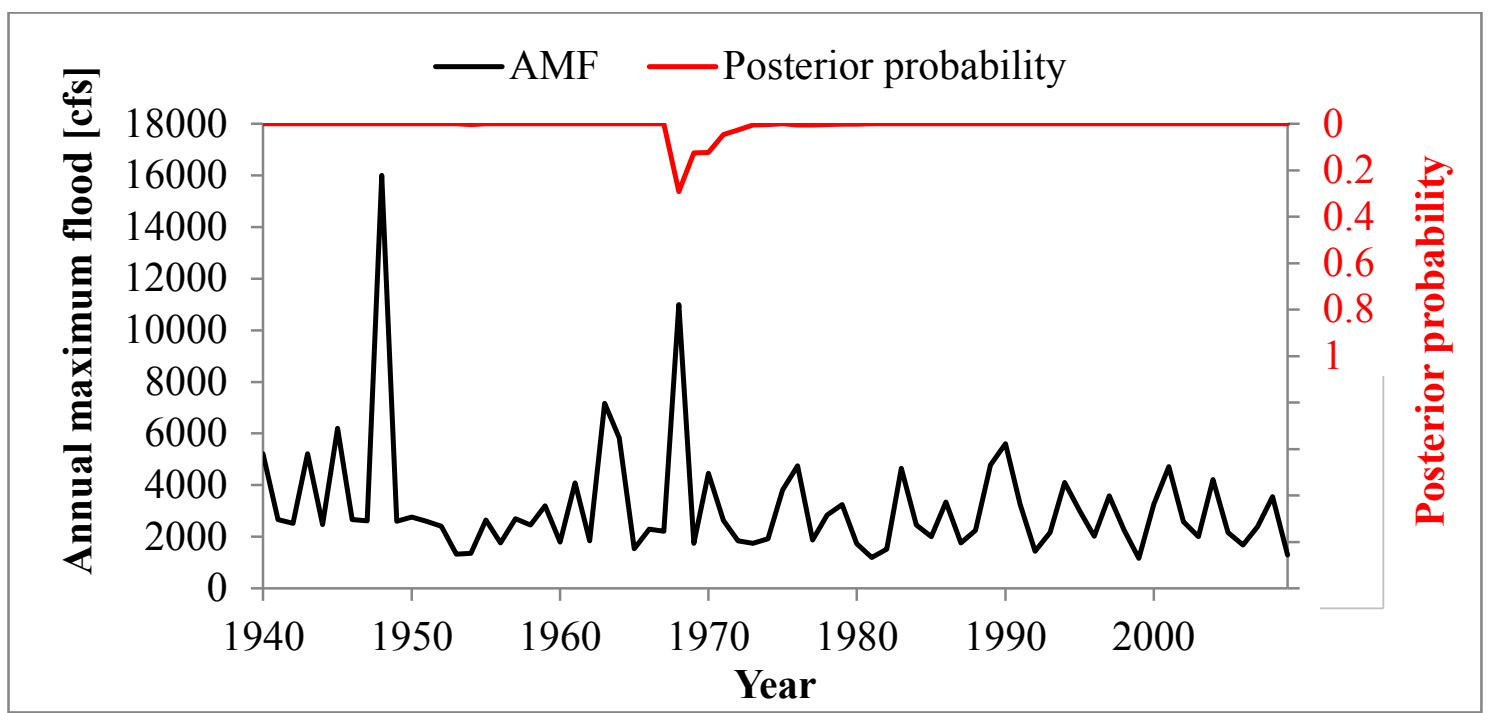

Figure 3-10: Change-point in 1968 for the annual maximum flood (AMF) series of site 03157000 as identified by the MCP analysis.

The MCP analysis identified multiple shifts (2 change-points) for only two sites (01173500 and 01185500), at which the Pettitt test identified a positive shift in the year 1972 for site 01173500 . With respect to the MCP results, the probability of occurrence of two peaks was greater than $99 \%$ in both cases. Nevertheless, the plots of the time series for these sites provided in Figures 3.11 and 3.12 revealed that the identification of 
two change-points may have been due to the presence of a few relatively large peaks in the data series. It is important to note that the two sites have long record lengths with 96 and 97 observations, respectively. As discussed in Chapter 2, the minimum record length considered was 65 years, whereas Seidou and Ouarda (2007) detected two change-points in the annual maximum flood of the Ogoki River considering 46 years of data from 1951 to 1997 . Thus, the lengths of the time series considered in this study were not improper for MCP analysis and should not have adversely impacted the results.

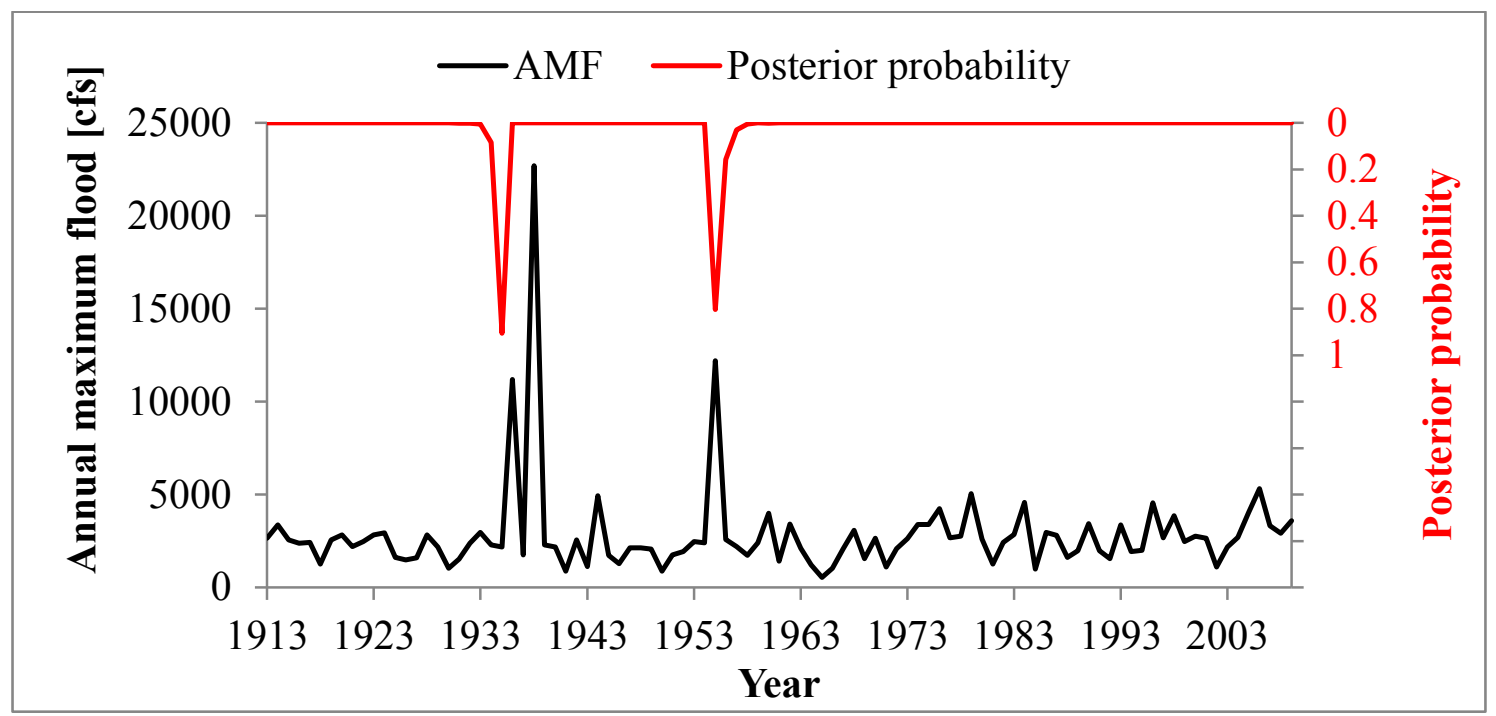

Figure 3-11: Change-points in 1935 and 1955 for the annual maximum flood series of site 01173500 as identified by the MCP analysis. 


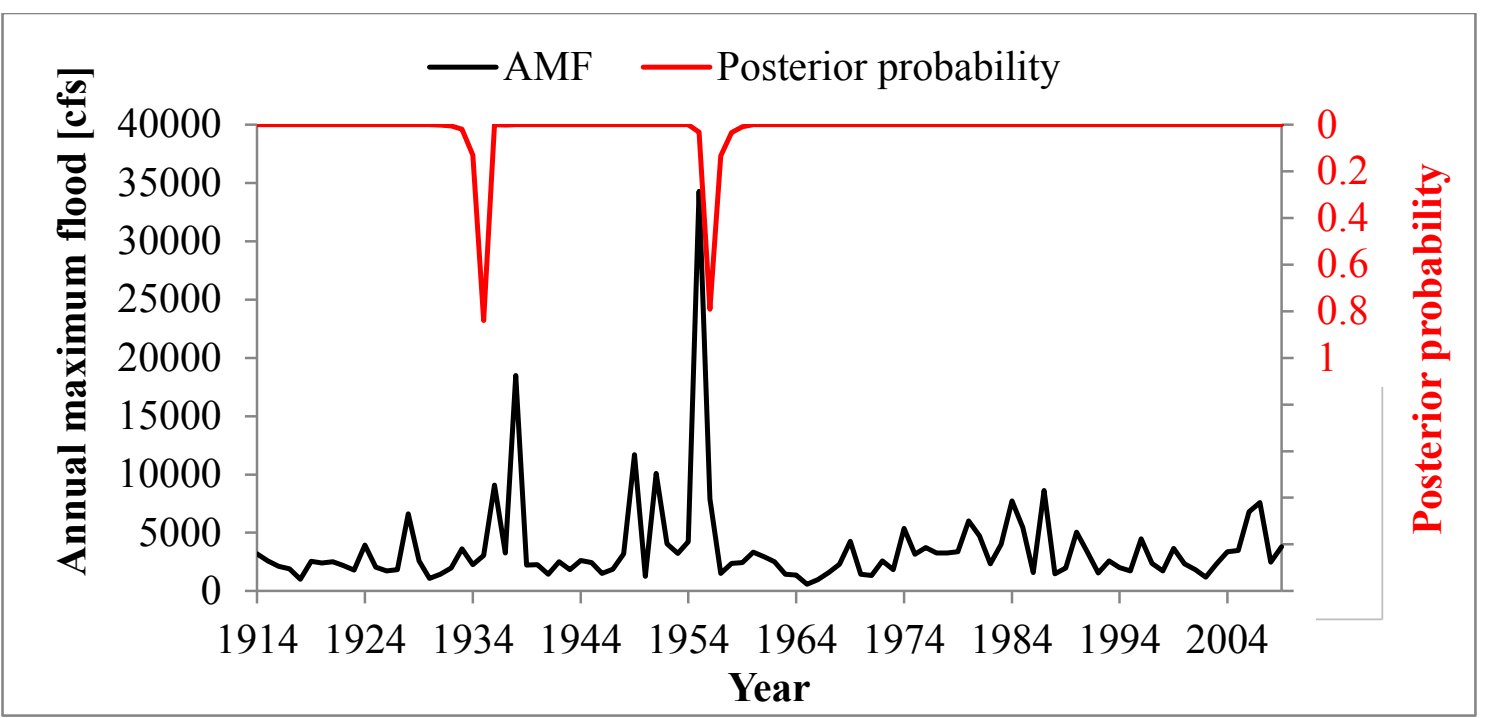

Figure 3-12: Change-points in 1935 and 1956 for the annual maximum flood series of site 01185500 as identified by the MCP analysis.

Overall, the values adopted for the input parameters, namely $k_{\max }=3$ and $d_{\min }=15$ years, used in the MCP analysis appear to be appropriate. As only two sites exhibited two change-points, setting the maximum number of change-points $\left(k_{\max }\right)$ to 3 was not a constrictive criterion, and it avoided excessive segmentation of the flood series. With respect to the minimum distance between consecutive change-points, Figures 3.13 and 3.14 allow for comparison of the results obtained considering $d_{\min }=10$ and 15 years, respectively. For $d_{\min }=10$ years, the relatively high value of the first flood peak in the series seems to induce misleading outcomes from the MCP analysis with a change-point identified in 1945. The probability associated to the occurrence of a single change-point was $97.5 \%$; however, the posterior probability of the change-point in 1945 was only 0.488. The second spike in Figure 3.13 with a posterior probability of only 0.154 was not identified as a change-point in this case. Instead, considering $d_{\min }=15$ years, more reasonable results were obtained with a change-point identified in 1956, further in time from the starting point of the series. In this latter case the probability associated to the occurrence of a single change-point was $99.8 \%$ with a posterior probability of 0.570 (greater than the 0.488 when $d_{\min }=10$ years) for a change-point in 1956. Moreover, the difference between the means of the subseries before and after the change-point is smaller in the second case (1709 cfs vs. $851 \mathrm{cfs})$; a smaller shift seems to be more 
reasonable given the observed variability over the period of record, and the year 1956 as change-point appears more appropriate for the time series.

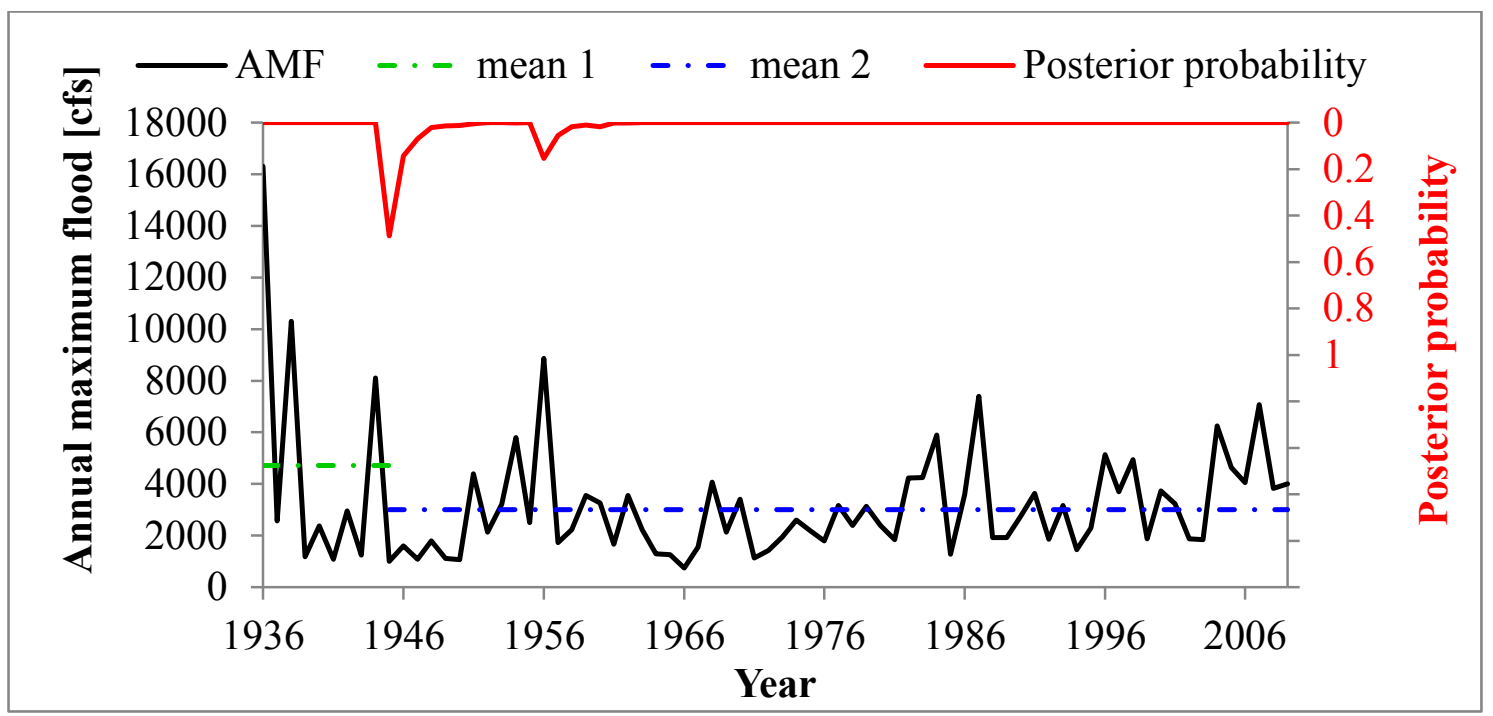

Figure 3-13: Change-point in 1945 for the annual maximum flood series (AMF) of site 01094500 as identified by the MCP analysis considering 10 years as the minimum allowable distance between consecutive change-points.

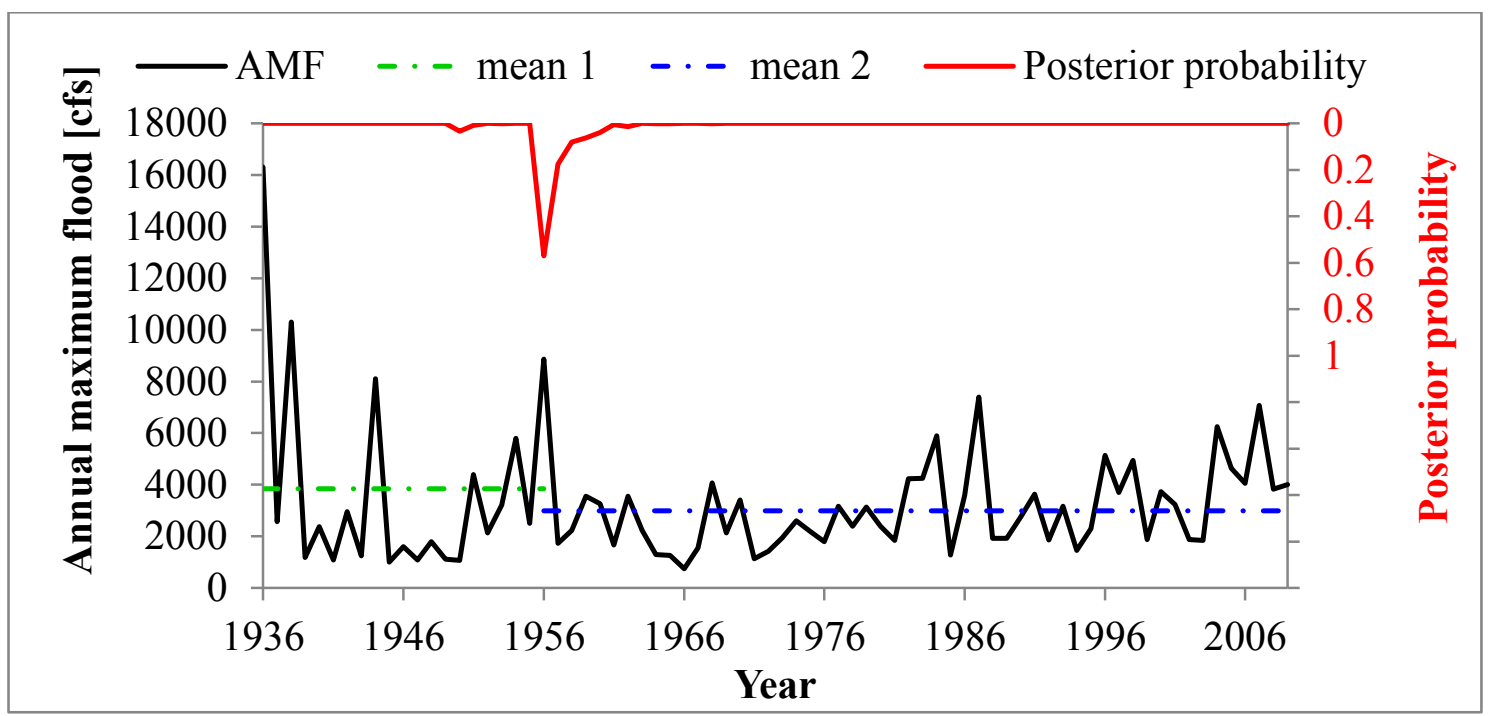

Figure 3-14: Change-point in 1956 for the annual maximum flood (AMF) series of site 01094500 as identified by the MCP analysis considering 15 years as the minimum allowable distance between consecutive change-points. 


\subsection{Summary}

In this chapter, non-stationarity in annual maximum flood series was investigated for the 143 watersheds considering the possible presence of both gradual trends and abrupt shifts. Potential anthropogenic causes of the observed non-stationarity were also investigated. Possible sources of trends include impacts associated with land-use/landcover. For instance, flood series for which increasing trends were observed in lower New England and Connecticut correspond to urban watersheds, and therefore the trends could be due to increasing percentages of impervious areas. The intense reforestation which has occurred in New England (Collins, 2009) could provide a plausible explanation for the decreasing trends observed for three mainly forested basins therein. Instead, decreasing trends in the central areas of the study region were related to basins which are predominantly agricultural; therefore, increased rates of infiltration and diversions for irrigation could have caused the decreasing magnitude of flood peaks over time.

Overall, the results of the Mann-Kendall trend tests and Pettitt tests are consistent with increasing (decreasing) trends generally identified at sites where significant positive (negative) shifts in the mean annual maximum flood magnitude were also observed. However, the lack of trends in the subseries preceding/following the shift suggests that the results of the Mann-Kendall tests on the flood series over the entire period of record are invalid, and thus non-stationarity in US flood series is more likely to manifest as a change-point rather than a gradual trend. Information derived from Annual Data Reports in Gages II, USGS qualification codes, and the frequency of dam construction within the basins were considered as potential causes for the observed change-points.

The Pettitt test is limited by its ability to only detect a single shift in a given time series. Therefore, a more sophisticated approach in Bayesian statistics (Ruggieri, 2012) was adopted to investigate the possible presence of multiple change-points. No evidence of multiple shifts in the flood series under consideration was observed; however, a comparison of the results of the two change-point detection methods revealed that results of the Pettitt test may be driven by the presence of extreme wet or dry years, and 
thus the Pettitt test appears to be less robust than the Bayesian approach. Nevertheless, the latter test does not represent a well-established algorithm for multiple change-points analyses in streamflow series; this type of approach is still a branch of scientific research in progress. 


\section{Natural sources of non-stationarity: meteorological variables and climatic patterns}

The analyses presented in Chapter 3 assess the degree of non-stationarity in annual maximum flood series for moderately impaired watersheds in the Upper Midwest and Northeastern United States. Non-stationarity was observed in the form of both monotonic trends and abrupt shifts at a number of sites. Human-related influences on streamflows (e.g., water use and management, construction of dams) combined with effects of land-cover variables (e.g., urbanization, reforestation) were considered to identify possible anthropogenic sources of the observed non-stationarity in the flood series. Nevertheless, the relationships found do not completely explain the hydrologic response of the basins which might also be influenced by meteorological and climatic variables such as temporal changes in precipitation, temperature, and large-scale oceanic-atmospheric patterns. Therefore, this chapter aims to identify the influence of these types of atmospheric variables on annual maximum flood series for moderately impaired watersheds by applying correlation analyses on a site-by-site basis.

\subsection{Correlation analysis}

A correlation test between two continuous variables, $X$ and $Y$, is adopted to assess their degree of association or, in other terms, to evaluate if a relationship between their variations exists: "of interest is whether one variable generally increases as the second increases, whether it decreases as the second increases or whether their patterns of variations are totally unrelated" (Helsel and Hirsch, 2002). Moreover, $X$ and $Y$ may disclose either linear or non-linear correlation. In general, to perform a correlation analysis a test statistic $k_{X Y}$ is computed:

- for $k_{X Y}>0, X$ and $Y$ are directly related, so if $X$ increases (decreases), then $Y$ also increases (decreases);

- for $k_{X Y}<0, X$ and $Y$ are inversely related, so if $X$ increases, then $Y$ decreases and vice versa; 
- for $k_{X Y}=0$, no correlation exists between $X$ and $Y$.

Further, $k_{X Y}$ ranges between \pm 1 : if $k_{X Y}$ equals +1 , perfect direct correlation between $X$ and $Y$ exists; if $k_{X Y}$ equals -1 , perfect indirect correlation exists.

Once the test statistic is computed, a two-sided hypothesis test is applied to determine if it is sufficiently different from zero, such that the null hypothesis $\mathrm{H}_{0}$ of no correlation between $X$ and $Y\left(k_{X Y}=0\right)$ can be rejected in favor of the alternative hypothesis $\mathrm{H}_{\mathrm{a}}\left(k_{X Y} \neq\right.$ 0 ), meaning that the observed degree of correlation is statistically significant (Helsel and Hirsch, 2002). There are three tests commonly used to evaluate the strength of the association between two variables: Pearson's $r$, Kendall's $\tau$ and Spearman's $\rho$. The following sections highlight the main features of each of these tests; Helsel and Hirsch (2002) provide additional details.

\subsubsection{Pearson's $r$}

Pearson's $r$ correlation test considers the degree of linear association between two variables, which is assessed using the coefficient of correlation $r$ computed as the ratio of the covariance between $X$ and $Y, \operatorname{cov}(X, Y)$, and the product of their individual standard deviations $\sigma_{X}$ and $\sigma_{Y}$ :

$$
r=\frac{\operatorname{cov}(X, Y)}{\sigma_{X} \sigma_{Y}}
$$

To perform the test, a maximum likelihood estimator of $r$, denoted $\hat{r}$, is computed as:

$$
\hat{r}=\frac{\sum_{i, j=1}^{n}\left(x_{i}-\bar{x}\right)\left(y_{i}-\bar{y}\right)}{\sqrt{\sum_{i=1}^{n}\left(x_{i}-\bar{x}\right)^{2} \sum_{j=1}^{n}\left(y_{j}-\bar{y}\right)^{2}}}
$$

where $x_{i}$ and $y_{i}$ are observations of $X$ and $Y, n$ is the number of observations in each series, and $\bar{x}$ and $\bar{y}$ are their sample averages. Assuming both variables are normally distributed, $\hat{r}$ follows a $t$-distribution with $n$-2 degrees of freedom. Therefore, the significance of the correlation can be assessed using the test statistic $t^{*}$ computed as: 


$$
t^{*}=\hat{r} \sqrt{\frac{n-2}{1-\hat{r}^{2}}}
$$

The correlation between $X$ and $Y$ is significant at level $\alpha$ if the p-value associated with $t^{*}$ is less than or equal to $\alpha$, or if $\left|t^{*}\right| \geq t_{\alpha / 2, n-2}$ where $t_{\alpha / 2, n-2}$ represents the critical value of the $t$-distribution with $n-2$ degrees of freedom and a probability of $\alpha / 2$ in the upper tail.

\subsubsection{Kendall's $\tau$}

Kendall's $\tau$ is a non-parametric rank-based test that considers the degree of monotonic correlation, whether linear or nonlinear, between two variables. The Kendall's $\tau$ coefficient varies from -1 (perfect indirect correlation between $X$ and $Y$ ) to +1 (perfect direct correlation); $X$ and $Y$ are independent if $\tau=0$. The coefficient is computed as:

$$
\tau=\frac{s}{n(n-1) / 2}
$$

where $n$ is the number of observations in each time series, and $S$ (or $Z$ when $n \geq 10$ ) is computed using equations (7) or (8) as for the Mann-Kendall trend test. The only difference resides in the computation of the $\operatorname{sign}(. .$.$) function, wherein the pair of$ observations $\left(x_{i}, y_{i}\right)$ for two variables corresponding to the same point in time are considered to evaluate correlation, rather than two observations of the same variable $\left(x_{i}\right.$ and $x_{j}$ ) recorded at different times for trend detection.

The significance of the correlation coefficient is assessed using a hypothesis test which evaluates if $S$ is sufficiently different than zero $\left(\mathrm{H}_{0}: S=0 ; \mathrm{H}_{\mathrm{a}}: S \neq 0\right)$. Considering the significance level $\alpha$ and $n \geq 10$ (valid for all of the time series investigated in this study), statistically significant correlation between $X$ and $Y$ exists if $|Z| \geq z_{\alpha / 2}$ where $z_{\alpha / 2}$ represents the critical value of the standard normal distribution corresponding to an exceedance probability of $\alpha / 2$. Equivalently, the null hypothesis would be rejected if the p-value associated with the test statistic is less than or equal to $\alpha$. 


\subsubsection{Spearman's $\rho$}

As for Kendall's $\tau$, Spearman's $\rho$ is also a non-parametric rank-based test. However, the test does not simply compute the $\operatorname{sign}(. .$.$) of the difference between a pair of$ observations $\left(x_{i}, y_{i}\right)$, but rather it attributes weights to the differences (Helsel and Hirsch, 2002). The Spearman's $\rho$ coefficient is computed as:

$$
\rho=\frac{\sum_{i=1}^{n}\left(R x_{i} R y_{i}\right)-n((n+1) / 2)^{2}}{n\left(n^{2}-1\right) / 12}
$$

where $R x_{i}$ and $R y_{i}$ are the ranks of observations $x_{i}$ and $y_{i}$ obtained by ranking the time series associated with $X$ and $Y$ independently, and $n$ is the number of concurrent observations in each time series. A two-tailed hypothesis test is performed to determine the significance of $\rho$ assuming it follows a $t$-distribution as in the case of Pearson's $\hat{r}$, and the test statistic $t *$ is derived in the same fashion:

$$
t^{*}=\rho \sqrt{\frac{n-2}{1-\rho^{2}}}
$$

Correlation between $X$ and $Y$ exists if $\left|t^{*}\right| \geq t_{\alpha / 2, n-2}$ or if the associated p-value is less than or equal to the specified significance level $\alpha$ of the test.

\subsubsection{Comparison between correlation tests}

All three measures of correlation have been applied in the hydrologic literature (Fritsch, 2012; Hodgkins et al., 2003; Kashelikar, 2009; McCormick et al., 2009; Yulianti and Burn, 1998), however, each has its own advantages and disadvantages. Pearson's $r$ only assesses the strength of a linear relationship between two continuous variables, and it requires that the data are normally distributed (zero skew) and free of autocorrelation. Moreover, Pearson's $r$ is affected by the presence of outliers in the data. On the contrary, as Kendall's $\tau$ and Spearman's $\rho$ are rank-based tests, they are more resistant to the presence of outliers and skew in the data. In addition, the statistics for these rankbased tests do not change if $X$ and/or $Y$ undergo a "monotonic power transformation" (Helsel and Hirsch, 2002), and both tests can detect either linear or non-linear 
monotonic relationships. In general, when applied to the same dataset, both of the rankbased tests return comparable p-values. Nevertheless, according to Croux and Dehon (2010) the Kendall test might be preferable to use rather than the Spearman test as the "Kendall correlation measure is more robust and slightly more efficient than Spearman's rank correlation”. Unfortunately, none of the tests can detect nonmonotonic dependency. Based on these considerations, preference was given to the Kendall's $\tau$ test results as discussed below; however, results for all the three correlation tests are summarized in Appendix $\mathrm{C}$ allowing for comparison.

\subsection{Meteorological causes of non-stationarity}

In this section temporal changes in precipitation and temperature are investigated as potential sources of non-stationarity in annual maximum flood series, although their effects might be attenuated by human activities within the watersheds. Correlation tests are performed to assess the degree of association between these meteorological variables and the magnitude of annual maximum floods. In addition, non-stationarity in precipitation series is investigated in terms of both trends and change-points, and attempts are made to relate any identified non-stationary behavior to that observed for flood series in Chapter 3. Finally, the potential influence of temperature on the timing of flood events is considered. The derivation of the relevant time series of meteorological variables is discussed in detail in the following section; the procedures adopted are consistent with those proposed in previous studies (Changnon and Kunkel, 1995; Fritsch, 2012).

\subsubsection{Definition of flood-generating meteorological time series}

Daily total precipitation $[\mathrm{mm} / \mathrm{day}]$ and maximum and minimum temperature $\left[{ }^{\circ} \mathrm{C}\right]$ series spanning from January 1949 to December 2010 were derived from an online database compiled by Maurer et al. (2002), which provides gridded observations with a spatial resolution of $1 / 8$ degree $(\approx 12 \mathrm{~km})$. Grid cells were aggregated to the watershed scale using the Spatial Analyst Tool "Extract by mask" in ArcMap 10. The tool allowed 
extracting the cells of the grid (raster) that corresponded to the area defined by the boundaries (mask) of a given watershed. Cells partially outside of the mask were retained in the case that their centroid fell within the boundaries. For each basin, the gridded values of the meteorological variables were averaged over the extracted cells in order to obtain a single daily observation for each time series. Flood-generating precipitation, minimum temperature, and maximum temperature series were then constructed by considering the day of occurrence of the flood peak in a given year and the associated daily meteorological data derived for the X-days prior to the flood peak. For precipitation data, the aggregated daily observations were summed over the $\mathrm{X}$-days to obtain the total precipitation which fell over the watershed in those X-days prior to the flood peak. On the other hand, the average of the aggregated daily observations for temperature (minimum/maximum) was computed over the $\mathrm{X}$-days period.

For each watershed considered herein, six flood-associated series were created for each of the three meteorological variables with $\mathrm{X}$ ranging from 2 to 7 days. The correlation test was performed for each combination of flood and precipitation/temperature series for 136 of the 143 watersheds. The analysis was not performed for the remaining seven sites because either gridded meteorological data were not available or sub-basins of nested watersheds had a drainage area too small to be identified by the grid.

\subsubsection{Correlation between meteorological variables and flood magnitude}

This section presents the main results of the Kendall's $\tau$ test applied to evaluate the degree of association between the annual maximum flood series for each of the 136 watersheds and the associated flood-generating precipitation and temperature series constructed with lead times of $X=2,3,4,5,6$ and 7 days as previously described. For a single watershed, the correlation between two continuous variables is statistically significant when the p-value is less than or equal to the specified significance level of the test $(\alpha)$. In a regional context with $N$ sites, however, the value of $\alpha$ must be lowered in order to account for possible spurious positive results due to random sampling error in $N$ repetitions of the test (Rice, 1989). Herein, the needed adjustment of $\alpha$ was 
accomplished by applying the unweighted Bonferroni method (Bonferroni, 1936; Cabin and Mitchell, 2000; Shaffer, 1995), in which the p-values are compared to $\alpha / N$ rather than to $\alpha$, and thus a significant degree of correlation exists when $\mathrm{p}$-value $\leq \alpha / N$.

For each X-days lead time considered, the number of sites with significant correlation between annual maximum flood peak magnitude and the associated precipitation depths are reported in Table 4.1; results are presented for tests conducted at both the 5\% and $10 \%$ significance levels before and after application of the Bonferroni correction for $N$ $=136$ sites. Overall, 80 sites disclosed a high degree of association between annual maximum flood and flood-generating precipitation series at the $5 / \mathrm{N} \%$ level; significant direct associations were identified at 85 sites at the $10 / N \%$ level (see Table 4.2). Many more significant results were obtained than would be expected due to chance (i.e., the null hypothesis should be rejected for roughly 7 out of 136 tests at the $5 \%$ level, and in 14 out of 136 tests at the $10 \%$ level). In addition, all identified correlations indicate a direct association between precipitation and flood magnitude, which is to be expected, especially if no changes are made within the watershed over the same period.

Table 4-1: Number of sites yielding significant correlations between AMF magnitude and leading X-days total precipitation series based on Kendall's $\tau$ correlation test at both $5 \%$ and $10 \%$ levels (with and without Bonferroni correction for $N=136$ ).

\begin{tabular}{|c|c|c|c|c|c|c|}
\hline & \multicolumn{7}{|c|}{ X-days lead time } \\
\cline { 2 - 7 } & $\mathbf{2}$ & $\mathbf{3}$ & $\mathbf{4}$ & $\mathbf{5}$ & $\mathbf{6}$ & $\mathbf{7}$ \\
\hline $\boldsymbol{\alpha}$ & \multicolumn{7}{|c|}{ Before Bonferroni Correction } \\
\hline $5 \%$ & 88 & 107 & 112 & 113 & 116 & 114 \\
\hline $10 \%$ & 95 & 113 & 113 & 117 & 119 & 118 \\
\hline $\boldsymbol{\alpha} / \boldsymbol{N}$ & \multicolumn{7}{|c|}{ After Bonferroni Correction } \\
\hline $0.0368 \%$ & 47 & 64 & 74 & 69 & 66 & 64 \\
\hline $0.0735 \%$ & 51 & 69 & 77 & 73 & 68 & 68 \\
\hline
\end{tabular}

The sites for which the correlation between flood peak magnitude and precipitation is still significant after application of the Bonferroni correction were further considered, and the X-days lead time yielding the greatest degree of association (minimum p-value) was identified. Table 4.2 reports the number of sites that exhibited greatest correlation 
with flood magnitude for each X-days lead time. For most of these sites, the greatest degree of correlation was obtained for precipitation event lead times of 3 and 4 days.

Table 4-2: Results of Kendall's $\tau$ correlation test (at both 5\% and 10\%) with Bonferroni correction considering the number of sites for which the X-days lead time yields the greatest degree of association between AMF magnitude and precipitation.

\begin{tabular}{|c|c|c|c|c|c|c|c|}
\hline \multirow{2}{*}{$\boldsymbol{\alpha} / \mathbf{N}$} & \multicolumn{6}{|c|}{ X-days lead time } & \multirow{2}{*}{ Total } \\
\hline & 2 & 3 & 4 & 5 & 6 & 7 & \\
\hline $0.0368 \%$ & 8 & 24 & 18 & 10 & 8 & 12 & 80 \\
\hline $0.0735 \%$ & 8 & 27 & 18 & 10 & 9 & 13 & 85 \\
\hline
\end{tabular}

Figure 4.1 provides a visualization of the results in Table 4.2 at the $5 / N \%$ level. Overall, no evidence of spatial coherence with respect to the most significant lead time is apparent. However, general patterns related to land-use/land-cover can be observed. In theory, the high percentage of impervious surfaces in developed areas would reduce the residence time of overland flow, resulting in a flashier response of the watershed. Consequently, the lag time between the centroid of the storm and the peak runoff/streamflow should be relatively short, corresponding to a smaller value of $\mathrm{X}$. Conversely, in watersheds which are primarily forested and/or agricultural, the response at the watershed outlet would be delayed due to the vegetative land-cover and an increased degree of infiltration into the soil, and thus these watersheds should be associated with a larger value of X. However, Table 4.3 and Figure 4.1 show that considering the land-use/land-cover clusters (Section 2.5), results do not perfectly match these expectations. Most of the urban basins are associated with 3-, or 4-days lead times, but some present lead times of 5 and 7 days, perhaps because the impacts of human activities within the watersheds (e.g., dam construction/operation, withdrawals, reservoirs and stormwater management) might attenuate or delay the effects of meteorological variables on the magnitude and timing of runoff and peak streamflow. A dominant X-days lead time is not evident for forested watersheds, but those sites for which lead times of 6- and 7-days yield the greatest degree of correlation between precipitation and flood peak magnitude do tend to be mainly forested. Still a high number of forested watersheds present lead times of 2-, 3- and 4-days; this unexpected 
result might be explained by the fact that those basins are located in lower New England in proximity of urban areas and are characterized by a high number of dams (Figures 2.19 and 2.20) which may delay the hydrologic response. For basins with high percentages of agricultural areas, higher correlation was found for 3- and 4-days lead times. Additional results are provided in Appendix C.

Table 4-3: Number of sites in each land-use/land-cover cluster for which the X-days lead time yields the greatest degree of association between AMF magnitude and precipitation depth.

\begin{tabular}{|c|c|c|c|c|c|c|}
\hline \multirow{2}{*}{ Cluster } & \multicolumn{7}{|c|}{ X-days lead time } \\
\cline { 2 - 7 } & $\mathbf{2}$ & $\mathbf{3}$ & $\mathbf{4}$ & $\mathbf{5}$ & $\mathbf{6}$ & $\mathbf{7}$ \\
\hline 1. forested & 5 & 8 & 5 & 4 & 5 & $\mathbf{9}$ \\
\hline 2. urban & 0 & $\mathbf{3}$ & 2 & 1 & 0 & 2 \\
\hline 3. agricultural & 2 & $\mathbf{6}$ & 3 & 1 & 0 & 0 \\
\hline 4. agricultural & 0 & $\mathbf{5}$ & $\mathbf{5}$ & 2 & 2 & 1 \\
\hline 5. agricultural/forested & 1 & $\mathbf{5}$ & 3 & 2 & 2 & 1 \\
\hline
\end{tabular}

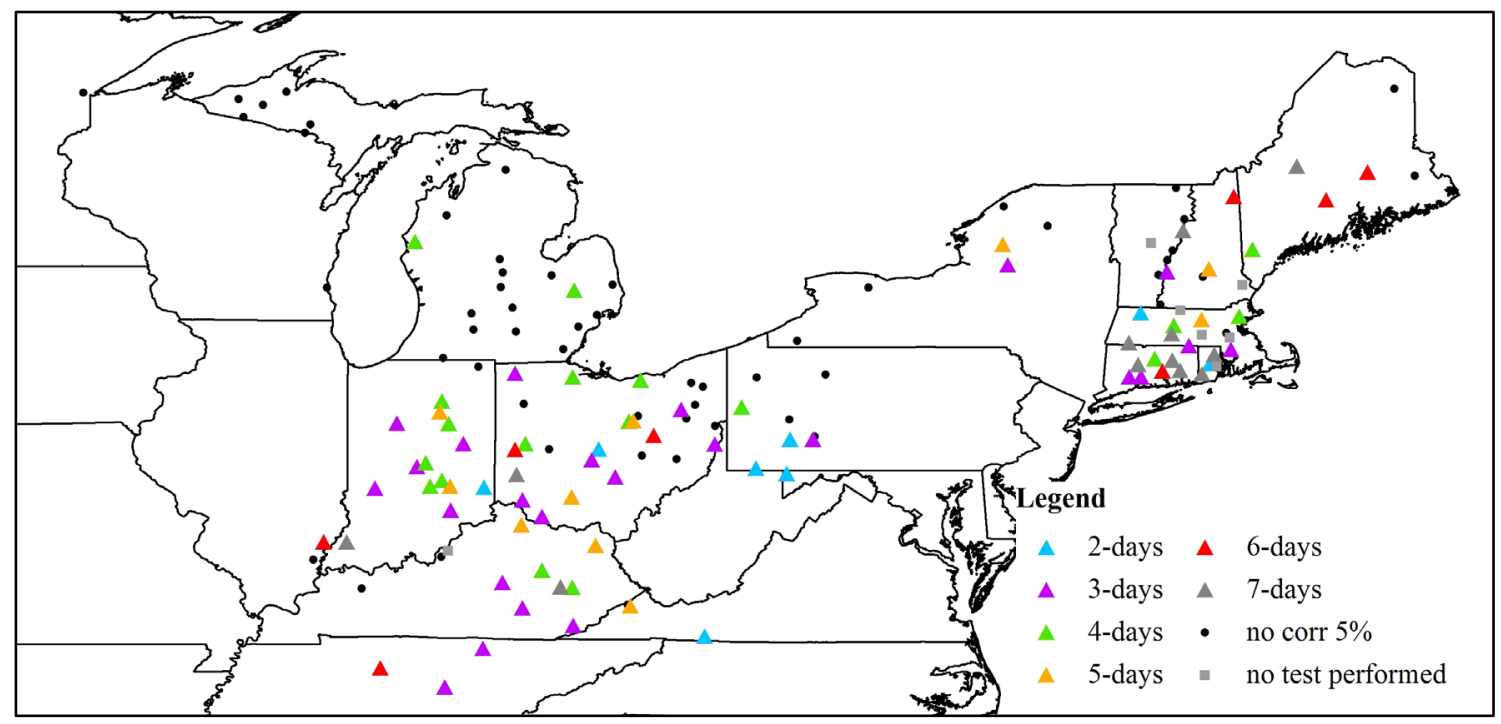

Figure 4-1: Results of Kendall's $\tau$ correlation tests between annual maximum flood peak magnitude and precipitation series at $5 / N \%$ significance level. For each site, the Xdays lead time yielding the highest correlation with flood magnitude is indicated. Black dots indicate sites for which no significant correlations were obtained; grey squares represent sites for which tests were not conducted. 
Human activities may attenuate the effects of the meteorological variables, and thus might represent driving causes of non-stationarity in flood series. For this reason, sites for which no significant correlation with precipitation series was obtained (black dots in Figure 4.1) were taken into consideration, and a comparison with the results presented in Chapter 3 was conducted. For example, decreasing trends (Figure 3.1) and negative shifts (Figure 3.2) in flood magnitude were exhibited by three sites near the Vermont/New Hampshire border, perhaps due to the intense reforestation experienced in that region over the last century (Collins, 2009). As shown in Figure 4.1, no correlation with precipitation series was observed at these three sites, thereby supporting the idea that reforestation has been the dominant influencing factor of nonstationarity in the flood series. Similar observations can be made for two sites in Kentucky (Figure 4.1). Site 03320000 exhibited both a decreasing trend in the flood series over the entire period of record and a negative shift in flood magnitude in the year 1964. Further, for this site, Gages II indicates regulation of the flow by Rough River Lake started in October 1959. Although a perfect match was not found between the year of change-point observed in the flood series and the beginning of flow regulation (1964 vs. 1959), human activities could still be the main factors influencing non-stationary behavior in flood flows. Site 03302000 presented both an increasing trend and a positive shift in the flood series that are likely related to the local channelization and high percentage of urban areas (more than 69\%) identified within Gages II. In Pennsylvania, site 03024000 exhibits a negative shift in flood magnitude in 1969, and as listed in Table 3.2, the change-point can be associated to flow regulation by reservoirs starting in 1970. Overall, as none of the aforementioned sites present significant correlation with precipitation series, this provides evidence that human activities do attenuate the effects of changes in meteorological variables.

Focusing on unimpaired sites in the Upper Midwest and Northeastern US, Fritsch (2012) observed that the highest number of sites exhibiting the greatest degree of association between flood peak magnitude and precipitation depths occurred with 3and 4-days lead times. In this thesis, these lead times were associated to watersheds with a high percentage of forested and agricultural areas, which is generally consistent 
with the make-up of watersheds considered by Fritsch (2012); this might suggest that the impairment for those types of watersheds considered herein does not significantly affect the response of the basins to precipitation events. Moreover, consistent with the findings of this thesis, Fritsch (2012) observed 6- and 7- days lead times for watersheds located in lower New England, which are likely to be characterized by forests as the dominant land-cover. In addition, applying Pearson's $r$ correlation test, Fritsch (2012) found that 221 sites of the 235 investigated $(\approx 94 \%)$ exhibited significant correlation between annual maximum flood and precipitation series at the $10 \%$ significant level; 173 sites of the 221 would have been retained after applying the Bonferroni correction. The high percentage observed for unimpaired basins relative to the findings herein strengthens the hypothesis that the effects of precipitation on annual maximum floods might be reduced by anthropogenic alterations of the flow.

Correlation tests were also conducted herein to assess the degree of association between flood peak magnitude and both the minimum and maximum temperature series with $\mathrm{X}$ days lead time. Unfortunately, only one site (01173500) in Massachusetts exhibited a significant correlation, identified for the case of minimum temperature series ( $X=2$ days) at the $5 / N \%$ significance level, following application of the Bonferroni correction; no additional sites exhibited significant correlation at the $10 / N \%$ level. However, without applying the Bonferroni correction, correlation would have been identified at 26 sites for maximum temperature, and at 40 sites for minimum temperature at the $10 \%$ level. Appendix $\mathrm{C}$ summarizes the results of the tests for each watershed.

For unimpaired watersheds, Fritsch (2012) also observed a lower number of sites exhibiting correlation between annual maximum flood peak magnitude and temperature series as compared to precipitation series. At the 10\% level, the author identified correlation for 86 and 65 sites for minimum and maximum temperature series, respectively (Fritsch, 2012); only 3 and 2 sites, respectively, would have exhibited significant correlation after applying Bonferroni correction. Based on these results, the following sections further investigate non-stationarity in the magnitude of flood series by considering variability in precipitation series as a possible meteorological source. 


\subsubsection{Non-stationarity in flood-generating precipitation series}

For a better understanding of the relationship between precipitation and annual maximum flood peak magnitude, possible non-stationary behavior in the precipitation series was investigated in terms of both trends and change-points, and the findings were compared with the results obtained for flood series as discussed in Chapter 3. Considering each of the 136 watersheds for which gridded precipitation data were available, the Mann-Kendall trend test was performed on the precipitation series with the X-days lead time yielding highest correlation with flood peak magnitude (see Figure 4.1). The results at both 5 and $10 \%$ significance levels are displayed in Figure 4.2. At the $10 \%$ level, only 7 sites exhibited an increasing trend in the precipitation series ( 3 sites at the 5\% level). Most of these sites do not have trends in the flood series (see Section 3.2.1); only for site 04099510 in Indiana (classified in Cluster 3) was an increasing trend detected in both precipitation (5\% level) and annual maximum flood series $(10 \%$ level $)$.

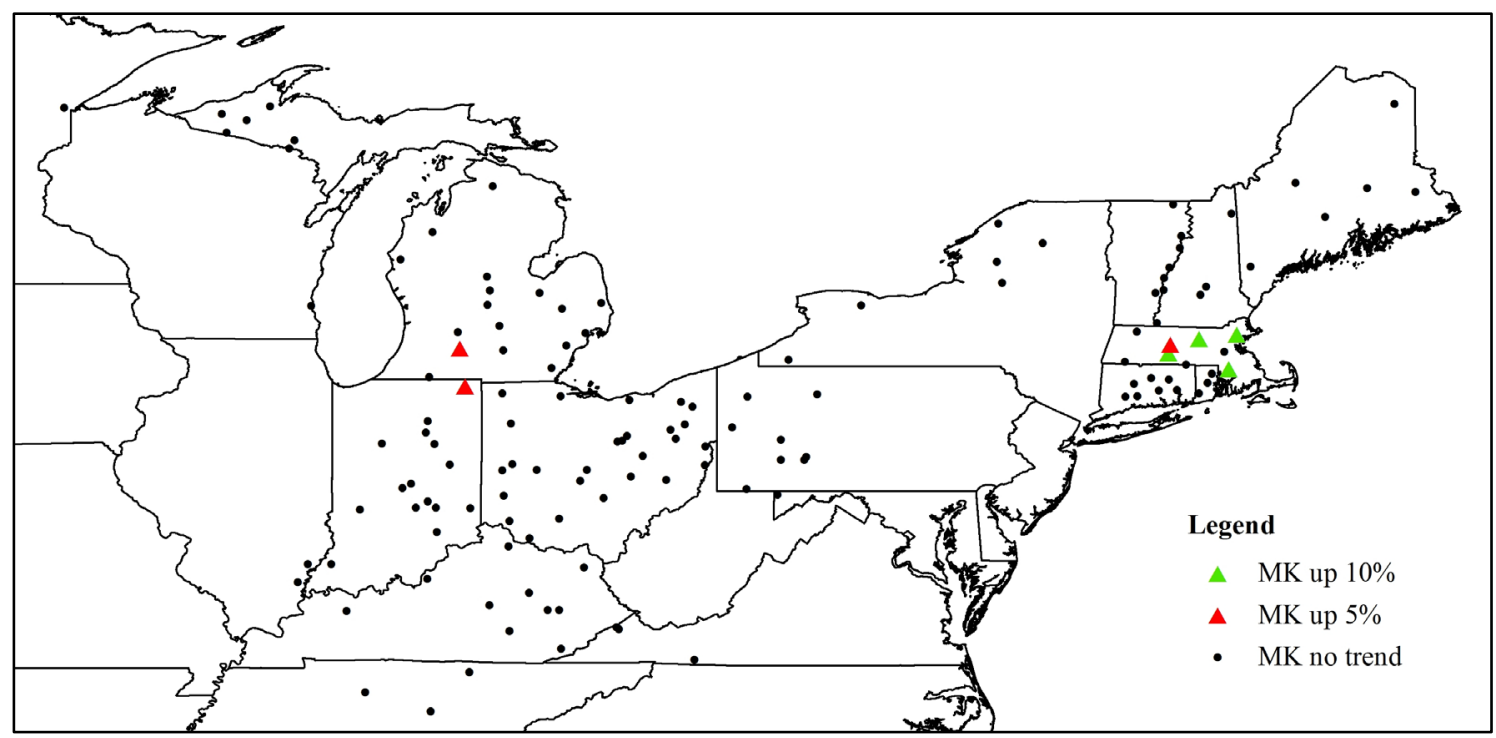

Figure 4-2: Trends in flood-generating precipitation series detected by applying MannKendall test at 5\% (red) and 10\% (green) significance levels. Upright triangles identify increasing trends. Black dots indicate sites for which no trend was identified out of $N=$ 136 sites.

To assess the presence of abrupt shifts in the mean of the precipitation series, both the Pettitt test and the multiple change-points (MCP) analysis were performed for each of 
the 136 watersheds. As discussed above, for a given site, only the precipitation series with X-days lead time which yielded the greatest association with flood peak magnitude was considered. No shifts were identified by the MCP algorithm; however, the Pettitt test detected a change-point in the precipitation series for 30 sites at the $10 \%$ level (20 at $5 \%$ ). The locations of these sites are shown in Figure 4.3.

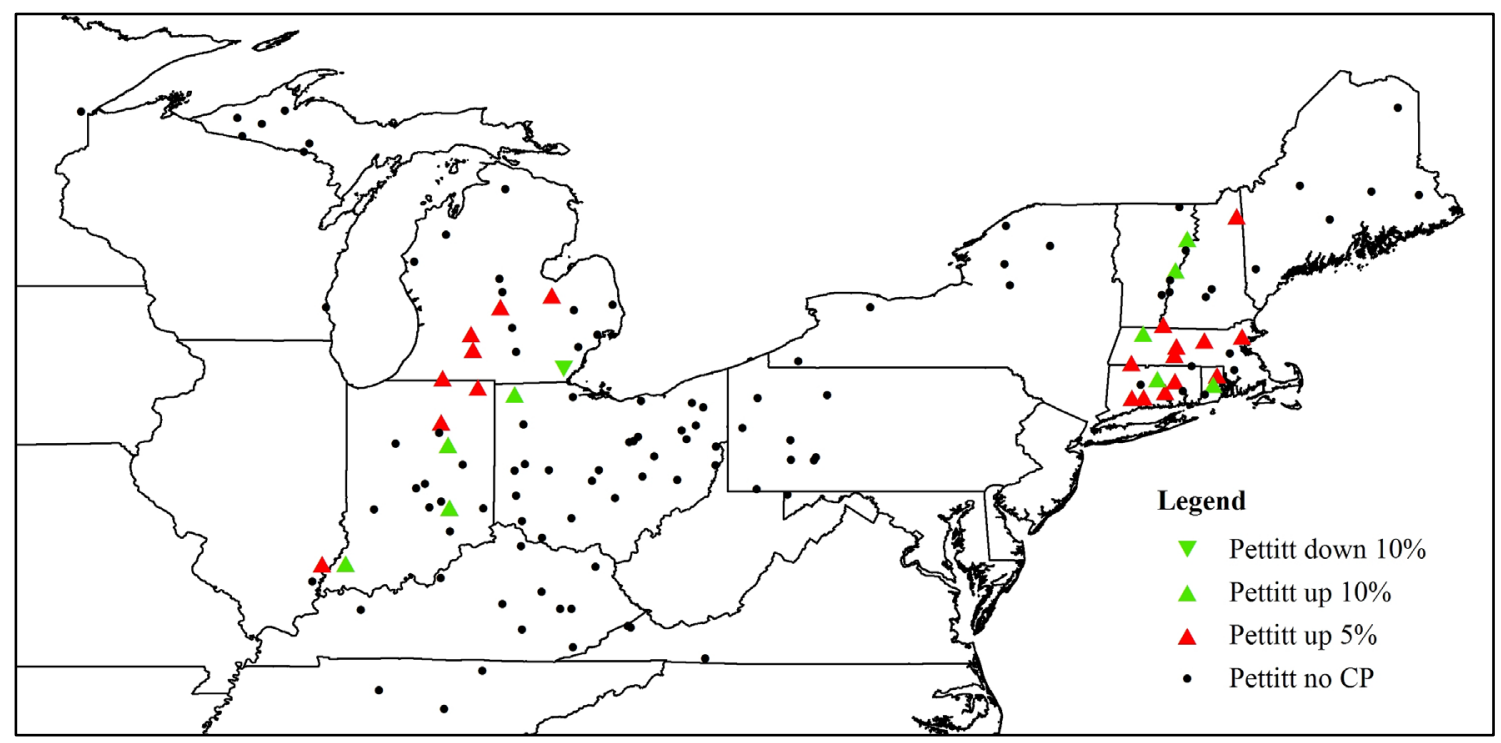

Figure 4-3: Direction of shift (change-point) in flood-generating precipitation series detected by applying Pettitt test at 5\% (red) and 10\% (green) significance levels. Upright triangles identify positive shift; inverted triangles negative shift. Black dots indicate locations of watersheds for which significant results were not obtained out of $N$ $=136$ sites.

As shown in Figure 4.3, only one site in Southern Michigan exhibits a decreasing trend in precipitation series. This result seems anomalous considering the increasing trends observed for several nearby sites; however, the disparity is due to the fact that precipitation series were independently constructed for each basin relative to the actual day of occurrence of the flood peak in a given year. The timing of flood peaks differs at these sites, and thus the flood events are not influenced by the same storms, and thus similar non-stationary behavior is not expected despite their spatial vicinity.

Figure 4.4 shows the locations of the sites for which both precipitation and flood series presented a shift in the mean at the $10 \%$ level. For 15 of the 30 sites exhibiting a shift in the precipitation series at the $10 \%$ level, a change-point was also detected in the mean 
of the annual maximum flood series (Section 3.2.2); nevertheless, as reported in Table 4.4, the shifts in the two series occurred in the same year at only one site, and within 5 years of one another at only 4 sites; however, in each of the latter cases, the shift in the flood series precedes that of the precipitation series, and thus a causal relationship is not evident.

Table 4-4: Comparison of the timing and direction of change-points detected by the Pettitt test for both precipitation and AMF series at the 10\% level (bold values are significant at $5 \%$ ).

\begin{tabular}{|c|c|c|c|c|c|}
\hline \multirow{2}{*}{ Site Number } & \multicolumn{2}{|c|}{ Timing of Change-Point } & \multicolumn{2}{c|}{ Shift of Change-Point } & \multirow{2}{*}{ Years of Difference } \\
\cline { 2 - 5 } & Precipitation & AMF & Precipitation & AMF & \\
\hline 01094500 & $\mathbf{1 9 7 3}$ & $\mathbf{1 9 8 1}$ & + & + & 8 \\
\hline 01114500 & $\mathbf{1 9 7 7}$ & $\mathbf{1 9 6 6}$ & + & + & -11 \\
\hline 01119500 & $\mathbf{1 9 7 2}$ & $\mathbf{1 9 7 1}$ & + & + & -1 \\
\hline 01135500 & 1994 & $\mathbf{1 9 6 8}$ & + & + & -26 \\
\hline 01141500 & 1987 & 1952 & + & - & -35 \\
\hline 01161000 & $\mathbf{1 9 7 3}$ & $\mathbf{1 9 4 0}$ & + & - & -33 \\
\hline 01168500 & 1968 & $\mathbf{1 9 5 2}$ & + & - & -16 \\
\hline 01173500 & $\mathbf{1 9 7 2}$ & $\mathbf{1 9 7 2}$ & + & + & 0 \\
\hline 01192500 & 1973 & $\mathbf{1 9 7 1}$ & + & + & -2 \\
\hline 01196500 & $\mathbf{1 9 7 7}$ & $\mathbf{1 9 6 8}$ & + & + & -9 \\
\hline 01208500 & 1973 & 1960 & + & - & -13 \\
\hline 03328000 & $\mathbf{1 9 8 9}$ & $\mathbf{1 9 7 7}$ & + & + & -12 \\
\hline 03378000 & $\mathbf{1 9 8 1}$ & $\mathbf{1 9 7 6}$ & + & + & -5 \\
\hline 04099510 & $\mathbf{1 9 8 6}$ & $\mathbf{1 9 7 5}$ & + & + & -11 \\
\hline 04185000 & 1984 & 1980 & + & + & -4 \\
\hline
\end{tabular}

At the 5\% level, change-points were identified in the flood series for 10 of the 20 sites which exhibited a change-point in precipitation; however, the shifts in the two series occurred within 5 years at only 3 sites. Overall, the causative relationship between precipitation and flood magnitude identified for unimpaired watersheds in other studies (Changnon and Kunkel, 1995; Fritsch, 2012; Groisman et al., 2001; Lins and Michaels, 1994) was not identified for this dataset of moderately impaired basins. This further supports the idea that for a certain degree of impairment, human activities within the watershed exercise greater influence on the streamflows than variations in 
meteorological variables. Appendix $\mathrm{C}$ reports additional results for the above analyses of non-stationarity in precipitation series.

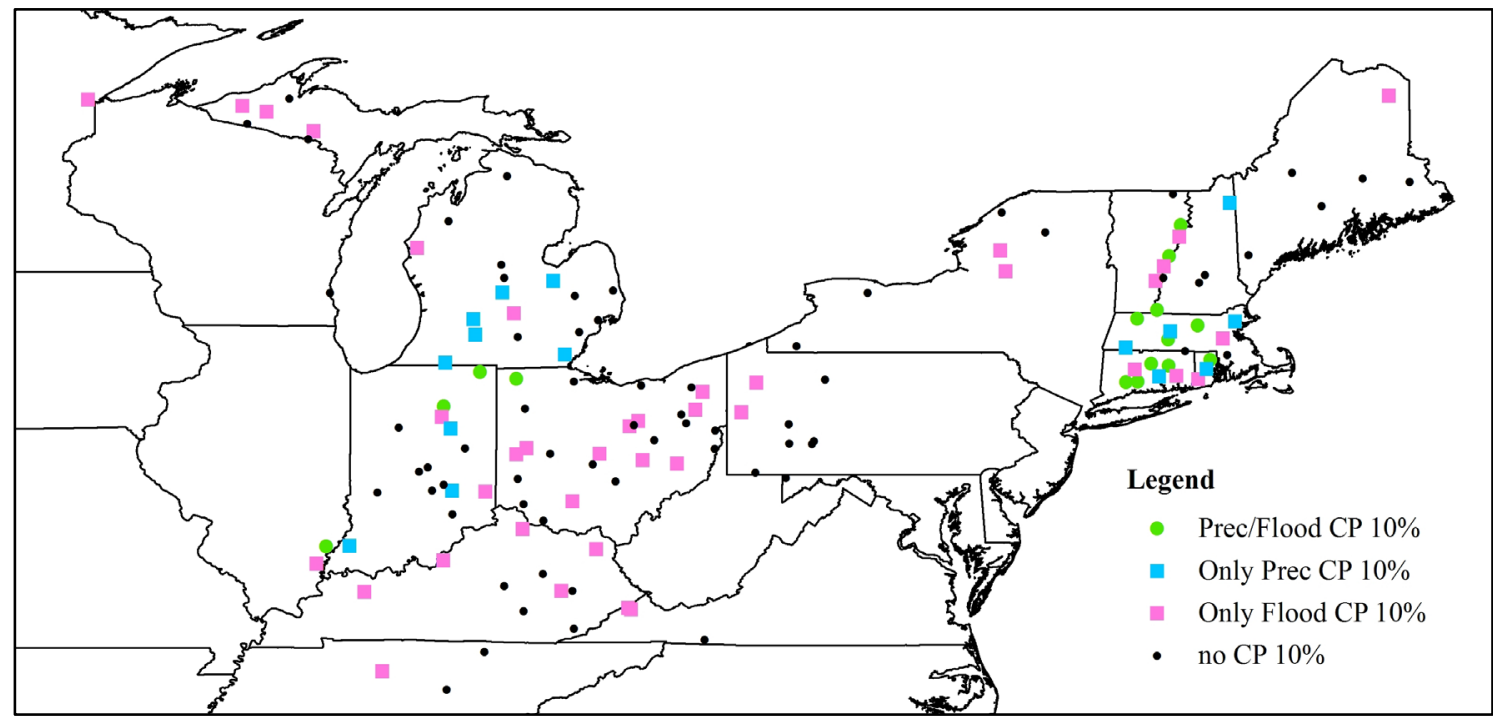

Figure 4-4: Comparison of results of the Pettitt test applied at the 10\% significance level to detect change-points (CP) in AMF magnitude and precipitation series. Green dots indicate sites where shifts were observed in both series; black dots indicate sites for which no significant shifts were identified in either series out of $N=136$ sites.

\subsubsection{Correlation between temperature and timing of flood series}

Although the Kendall's $\tau$ correlation test did not identify significant association between temperature series and annual maximum flood magnitudes, results of Fritsch (2012) suggest that correlation might exist between temperature series and the timing of the flood events. In that case, temperature data could be used as an explanatory variable in a non-stationary model for flood frequency forecasting in order to identify the month when the flood is more likely to occur in a future year. This information would be needed to extract the appropriate data for other atmospheric variables from GCM projections based on the lead times indicated by correlation analyses with flood magnitude as presented above with respect to precipitation.

Following recommendations of Fritsch (2012), the Pearson's $r$ correlation test was adopted to investigate the linear correlation between temperature and flood timing. Timing was expressed by considering the day of the water year corresponding to the 
day of occurrence of the flood peak. Table 4.5 reports the number of sites which exhibited correlation between temperature and timing of the flood peak at the $10 \%$ level, both before and after applying the Bonferroni correction for $N=136$ sites, considering for each site only the temperature series corresponding to the X-days lead time that yielded the greatest degree of association (minimum p-value/maximum Pearson's $r$ ) with flood peak timing. Overall, statistically significant positive correlation was found for 134 sites for both maximum and minimum temperature. At the 10\% level, most sites exhibited the greatest correlation between flood peak timing and maximum temperature series defined with a 7-days lead time. With respect to minimum temperature series, however, the largest group (47 sites) corresponded to the 2-days lead time, although the number of sites most strongly correlated with the 7-days lead time (44 sites) is only slightly smaller. Additional results of these correlation tests are summarized in Appendix C.

Table 4-5: Results of Pearson's $r$ correlation test at the $10 \%$ significance level between flood peak timing and minimum/maximum temperature series with X-days lead time yielding the greatest degree of association.

\begin{tabular}{|c|c|c|c|c|c|c|c|}
\hline \multirow{2}{*}{$\begin{array}{c}\text { Temperature } \\
\text { series }\end{array}$} & \multicolumn{6}{|c|}{ X-days lead time } & \multirow{2}{*}{$\begin{array}{l}\text { Total } \\
\text { sites }\end{array}$} \\
\hline & 2 & 3 & 4 & 5 & 6 & 7 & \\
\hline & \multicolumn{6}{|c|}{ Before Bonferroni Correction } & \\
\hline maximum & 20 & 6 & 15 & 15 & 20 & 58 & 134 \\
\hline \multirow[t]{2}{*}{ minimum } & 47 & 12 & 13 & 14 & 4 & 44 & 134 \\
\hline & \multicolumn{6}{|c|}{ After Bonferroni Correction } & \\
\hline maximum & 20 & 6 & 13 & 15 & 19 & 56 & 129 \\
\hline minimum & 46 & 11 & 12 & 12 & 4 & 40 & 125 \\
\hline
\end{tabular}

Figures 4.5 and 4.6 display these correlation test results geographically at the $10 \%$ level for maximum and minimum temperature, respectively. Despite the high spatial variability of the results, the mainly developed watersheds of the coastal area in New England present greatest correlation with both maximum and minimum temperature series for lead times $\geq 5$ days. Instead, results for the basins in mainly planted/cultivated areas are not concordant: for maximum temperature most of the sites had high correlation with lead times $\geq 5$ days; for minimum temperature, the greatest correlation 
was found for lead times $\leq 3$ days. For watersheds classified as primarily forested, the results were not consistent across the study area. The majority of the forested watersheds in New England exhibited highest correlation for lead time $\geq 4$ days for both maximum and minimum temperature. Instead, forested sites located in the central area were more correlated with lead time $\leq 3$ days for minimum temperature; non-uniform results were found for these sites with respect to maximum temperature. Fritsch (2012), using the same approach to investigate the correlation between flood timing and temperature series for unimpaired watersheds, found similar results for both minimum and maximum temperature series. Overall, he identified higher lead times for both the series in the New England Region; in the central area he observed higher lead times for maximum temperature and lower lead times for minimum temperature.

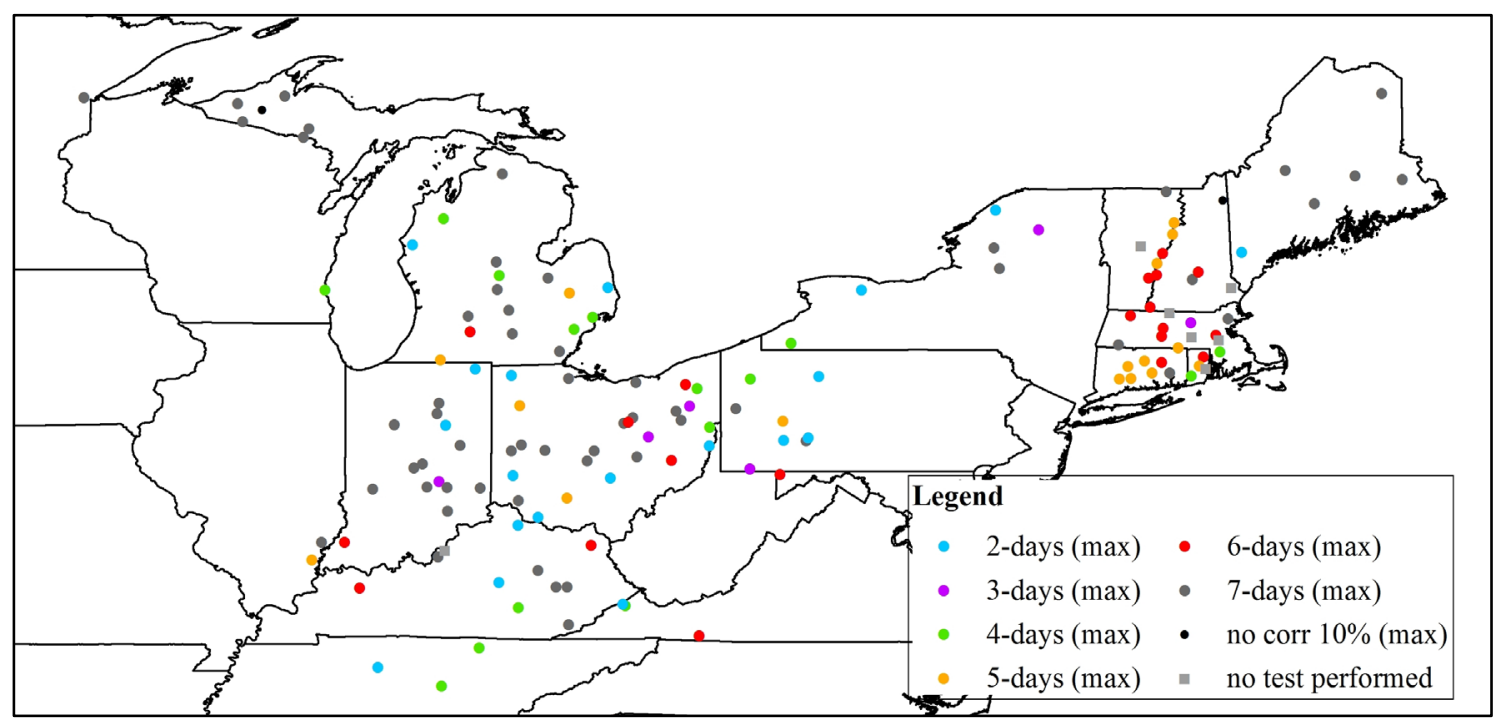

Figure 4-5: Results of Pearson's $r$ correlation tests between flood peak timing and maximum temperature series at $10 \%$ significance level. For each site, the X-days lead time yielding the highest correlation with flood peak timing is indicated. Black dots indicate sites for which no significant correlations were obtained; grey squares represent sites for which tests were not conducted. 


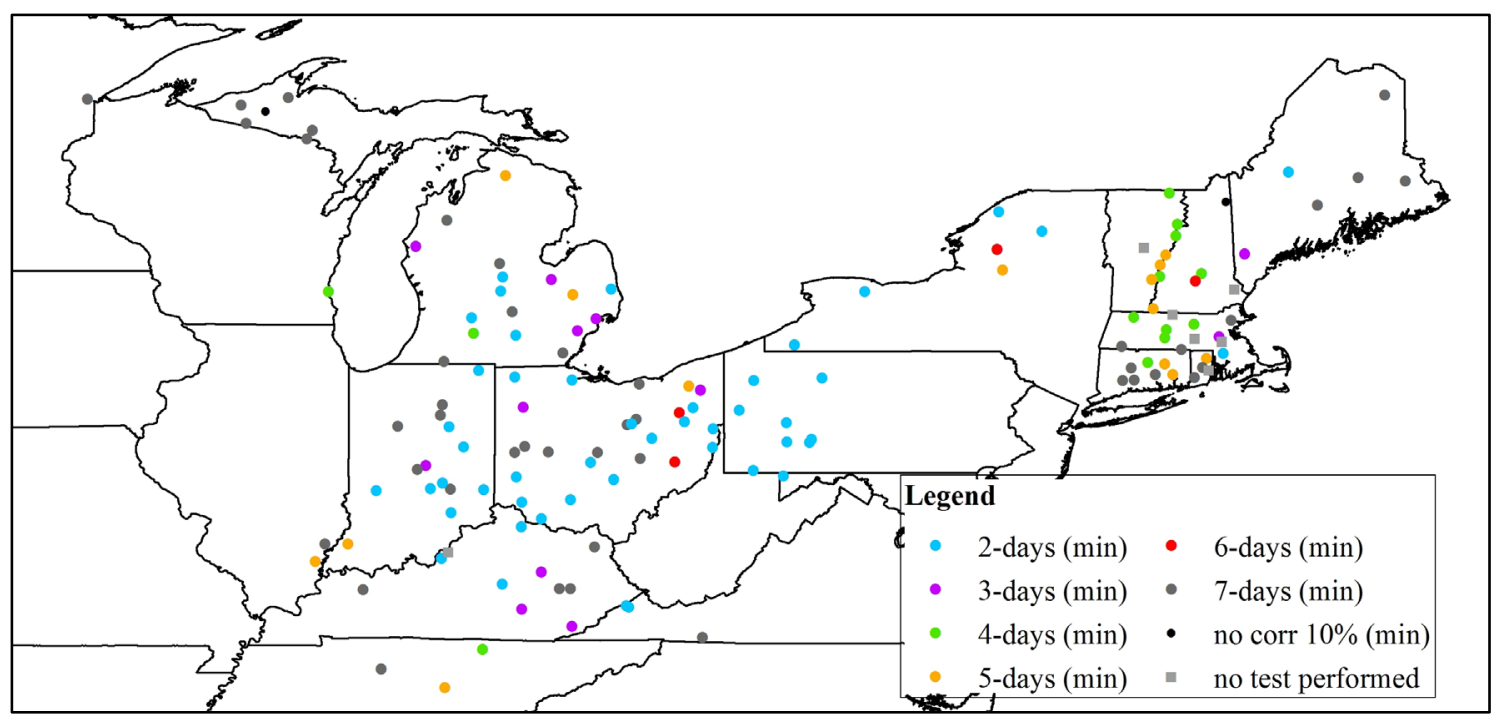

Figure 4-6: Results of Pearson's $r$ correlation tests between flood peak timing and minimum temperature series at $10 \%$ significance level. For each site, the X-days lead time yielding the highest correlation with flood peak timing is indicated. Black dots indicate sites for which no significant correlations were obtained; grey squares represent sites for which tests were not conducted.

\subsection{Climatic causes of non-stationarity}

In addition to meteorological variables, large-scale oceanic-atmospheric patterns were investigated as possible sources of the non-stationarity observed in annual maximum flood series. Correlation analyses were conducted to assess the strength of the relationship between annual maximum flood magnitudes and climate patterns. Significant relationships are indicative of the influence of climate patterns on flood magnitude and flood risk; these relationships are termed teleconnections.

\subsubsection{Climatic indices}

Teleconnections with annual maximum flood series were investigated for four largescale oceanic-atmospheric patterns: Pacific Decadal Oscillation (PDO), Atlantic Multidecadal Oscillation (AMO), North Atlantic Oscillation (NAO), and El Niño/Southern Oscillation (ENSO). These patterns are characterized by climate anomalies which represent deviations from the long-term mean sea surface temperature 
and/or sea level pressure, and alternate between cold (negative anomalies/below average) and warm (positive anomalies/above average) phases. The change in phase occurs on interdecadal and decadal time scales for PDO, AMO and NAO; whereas ENSO presents interannual variability. Two different indicators are used herein to describe ENSO: MEI (Multivariate ENSO Index) and NINO 3.4. Table 4.6 summarizes the available period of records and source of each climatic index employed herein; in each case, time series of climate anomalies are available on a monthly basis.

Table 4-6: Sources and available period of records for climate indices (anomalies) associated with large-scale oceanic-atmospheric patterns.

\begin{tabular}{|c|c|l|}
\hline $\begin{array}{c}\text { Climatic } \\
\text { Index }\end{array}$ & $\begin{array}{c}\text { Period of } \\
\text { Record }\end{array}$ & \multicolumn{1}{c|}{ Data Source } \\
\hline PDO & $\begin{array}{c}1900 \text { to } \\
2004\end{array}$ & $\begin{array}{l}\text { Joint Institute for the Study of the Atmosphere and Oceans, } \\
\text { University of Washington } \\
\text { ftp://ftp.atmos.washington.edu/mantua/pnw_impacts/INDIC } \\
\text { ES/PDO.latest }\end{array}$ \\
\hline AMO & $\begin{array}{c}1856 \text { to } \\
\text { present }\end{array}$ & $\begin{array}{l}\text { NOAA Earth System Research Laboratory } \\
\text { http://www.esrl.noaa.gov/psd/data/timeseries/AMO/ }\end{array}$ \\
\hline NAO & $\begin{array}{c}1950 \text { to } \\
\text { present }\end{array}$ & $\begin{array}{l}\text { NOAA Earth System Research Laboratory } \\
\text { http://www.cpc.ncep.noaa.gov/data/teledoc/nao.shtml }\end{array}$ \\
\hline NINO & $\begin{array}{c}1948 \text { to } \\
\text { present }\end{array}$ & $\begin{array}{l}\text { NOAA Earth System Research Laboratory } \\
\text { http://www.esrl.noaa.gov/psd/data/climateindices/list/ }\end{array}$ \\
\hline MEI & $\begin{array}{c}1950 \text { to } \\
\text { present }\end{array}$ & $\begin{array}{l}\text { NOAA Earth System Research Laboratory } \\
\text { http://www.esrl.noaa.gov/psd/enso/mei/table.html }\end{array}$ \\
\hline
\end{tabular}

The PDO anomalies represent the difference between monthly North Pacific sea surface temperature (SST) and monthly mean global average SST patterns, with shifts between warm and cold phases (positive and negative anomalies) occurring on the order of 50 years (Mantua and Hare, 2002; Mantua et al., 1997; Tootle et al., 2005); whereas the AMO anomalies are indicators of the North Atlantic Ocean SST with phase shifts occurring on the order of 65-80 years (Gray et al., 2004; Kerr, 2000; Tootle et al., 
2005). The NAO index relates to the difference in sea level pressure (SLP) between Iceland and the Azores (Hurrell and Van Loon, 1997) and has a decadal periodicity (Tootle et al., 2005). Finally, with respect to ENSO, shifts between its warm phase (El Niño) and cold phase (La Niña) occur with periodicity of 2 to 7 years (Philander, 1990; Tootle et al., 2005). The NINO 3.4 index relates to the East Central Tropical Pacific SST (Tootle et al., 2005), whereas MEI derives from a combination of six variables monitored over the tropical Pacific: SST, SLP, zonal and meridional components of surface wind, surface air temperature and total cloudiness fraction of the sky (NOAA, 2013).

\subsubsection{Teleconnections with annual maximum flood series}

The Kendall's $\tau$ correlation test was applied to evaluate the degree of association between each one of the five climatic indices discussed above and the observed magnitude of annual maximum flood peaks. The use of Kendall's $\tau$ is justified by its superior performance over Pearson's $r$ with respect to the power of the hypothesis test, and it is more robust than Spearman's $\rho$ (see Section 4.1.4).

Kashelikar (2009) applied Pearson's $r$ to investigate teleconnections for ENSO, PDO and NAO at unimpaired gauging stations across the United States. For each site considered, the correlation test was performed considering both the observed annual maximum flood values and a transformed data set using base-10 logarithms. The latter tests were conducted because probability models used in the US to estimate flood risk are based on the log-transformed flood series (IACWD, 1982). Kashelikar (2009) found similar results for both real and log-transformed flood series; for this reason, correlation tests applied in this thesis consider only the real (untransformed) flood series.

The time series employed in the correlation tests were obtained as follows. For each climate pattern, time series were composed using a 3-months average of the associated anomalies to reduce the monthly random variability. The three months to average over were identified by considering different lead times of $l$-months with respect to the month $(m)$ of occurrence of the flood peak in year $t$. For a specified lead time, the 
climate anomalies were averaged for the months $m-l, m-(l+1)$, and $m-(l+2)$. For example, with a lead time of 1-month, if the flood peak occurred in the month of May, the climate anomalies were averaged over February, March and April. Lead times of 3-, 6- and 9- months $(l=3,6$ and 9) were considered herein. An analogous procedure was adopted by Kashelikar (2009); however, instead of considering the actual month in which the flood peak occurred in a given year to compute the associated 3-months average anomaly, she assumed that the flood peaks occurred in April of every year. Fritsch (2012) conducted similar analyses for unimpaired sites throughout the US using the mode month of flood peak occurrence to determine the associated 3-months average climate index.

Following the work of Kashelikar (2009) and Fritsch (2012), the time series used to represent the annual maximum flood peaks herein was derived based on a 10-years moving average, such that the observation in year $t$ represents the mean of the annual maximum flood peaks observed from year $t-9$ to $t$. Using 1942 as the starting point, the first value in the series was thus computed as the average of the flood observations from 1942 to 1951, and then associated with the 3-months averaged climate index observed in 1951 or 1950 depending on the lead time employed and the timing of the flood peak. This 10-years moving window was applied through 2009 or 2010, depending on the record available at a given site. The choice of the year 1951 as the beginning of the 10years averaged flood series was dictated by the availability of the climate indices (monthly values for NAO and MEI are available as early as January 1950 as shown in Table 4.6). Further, the 10-years window for averaging annual maximum floods was selected considering the (multi)decadal variability of most of the climatic indices. Assuming the years from 1951 to 2009/2010 as the appropriate time period to perform the correlation test, 31 of the 143 sites were not suitable due to shorter record length. For this reason, results of the teleconnections analyses will be presented for 112 sites.

The Kendall's $\tau$ correlation test was performed at both 5\% and 10\% significance levels to assess the degree of association between the 10-years moving averaged flood series and the series of climate anomalies defined for a given lead time. Table 4.7 reports the 
number of sites for which a statistically significant correlation was obtained for each combination of climate index and lead time considered; for all the cases direct correlation was observed. Overall, the greatest potential for teleconnections with annual maximum floods was observed for PDO and AMO as, for these two climatic indices, the largest number of sites exhibiting significant correlation was identified for any lead time considered. With respect to possible ENSO teleconnections, NINO 3.4 anomalies presented a relatively low degree of correlation with flood magnitude as compared to MEI. For each climate index, additional results of the Kendall's $\tau$ correlation tests, including p-values, are provided in Appendix D.

Table 4-7: Number of sites with significant Kendall's $\tau$ correlation (at 5\% and $10 \%$ levels) between the 10-years moving averaged flood series and climate patterns represented by 3-months averaged climate indices with 3-, 6- and 9-months lead times.

\begin{tabular}{|c|c|c|c|c|c|c|}
\hline \multirow{2}{*}{ Climatic Index } & \multicolumn{3}{|c|}{$\alpha=\mathbf{1 0 \%}$} & \multicolumn{3}{c|}{$\boldsymbol{\alpha}=\mathbf{5 \%}$} \\
\cline { 2 - 7 } & $\mathbf{3}$ months & $\mathbf{6}$ months & $\mathbf{9}$ months & 3 months & 6 months & 9 months \\
\hline PDO & 49 & 54 & $\mathbf{6 7}$ & 38 & 43 & $\mathbf{5 4}$ \\
\hline AMO & $\mathbf{6 8}$ & 66 & 67 & $\mathbf{5 7}$ & 56 & 58 \\
\hline NAO & $\mathbf{1 7}$ & 5 & 15 & $\mathbf{1 2}$ & 2 & 7 \\
\hline NINO 3.4 & 2 & $\mathbf{1 2}$ & 9 & 0 & $\mathbf{6}$ & 6 \\
\hline MEI & 4 & 17 & $\mathbf{3 5}$ & 1 & 6 & $\mathbf{2 4}$ \\
\hline
\end{tabular}

The evidence of teleconnections with flood flows at the moderately impaired sites investigated herein further justifies the use of climate indices as variables in flood risk forecasting techniques as suggested in several studies for unimpaired locations (Fritsch, 2012; Griffis and Stedinger, 2007b; Kashelikar, 2009; Kashelikar and Griffis, 2008; Stedinger and Griffis, 2011). Nevertheless, significant correlations do not imply the existence of a causal dependency, only providing a measure of the association between the variability of flood series and climate patterns over time. However, to identify the most appropriate climate time series to be included in non-stationary flood risk forecasting techniques, the lead time which yielded the maximum number of sites with significant correlation at the $10 \%$ level was determined for each climate pattern. Namely, a 9-months lead time should be employed with PDO, and 3-months lead time should be used for AMO and NAO. For ENSO, however, different results were 
observed for NINO 3.4 and MEI anomalies with suggested lead times of 6-months and 9-months, respectively. The locations of the sites exhibiting significant correlation for these chosen lead times are shown in Figures 4.7-4.11. Potential teleconnections in response to PDO and AMO are evident across the Upper Midwest and Northeastern United States; however, no spatial coherency is observed in the results for NAO. In regards to ENSO, a fewer number of sites exhibited significant correlation with the NINO 3.4 index, suggesting the possible existence of a teleconnection in the Midwest; a moderate amount of potential influence from ENSO was also observed in the New England region with respect to MEI. Further, it should be noted that relatively fewer sites exhibiting a teleconnection in response to ENSO may have been observed due to the use of a 10-years averaged flood magnitude when phase shifts of ENSO occur more frequently ( 2 to 7 years).

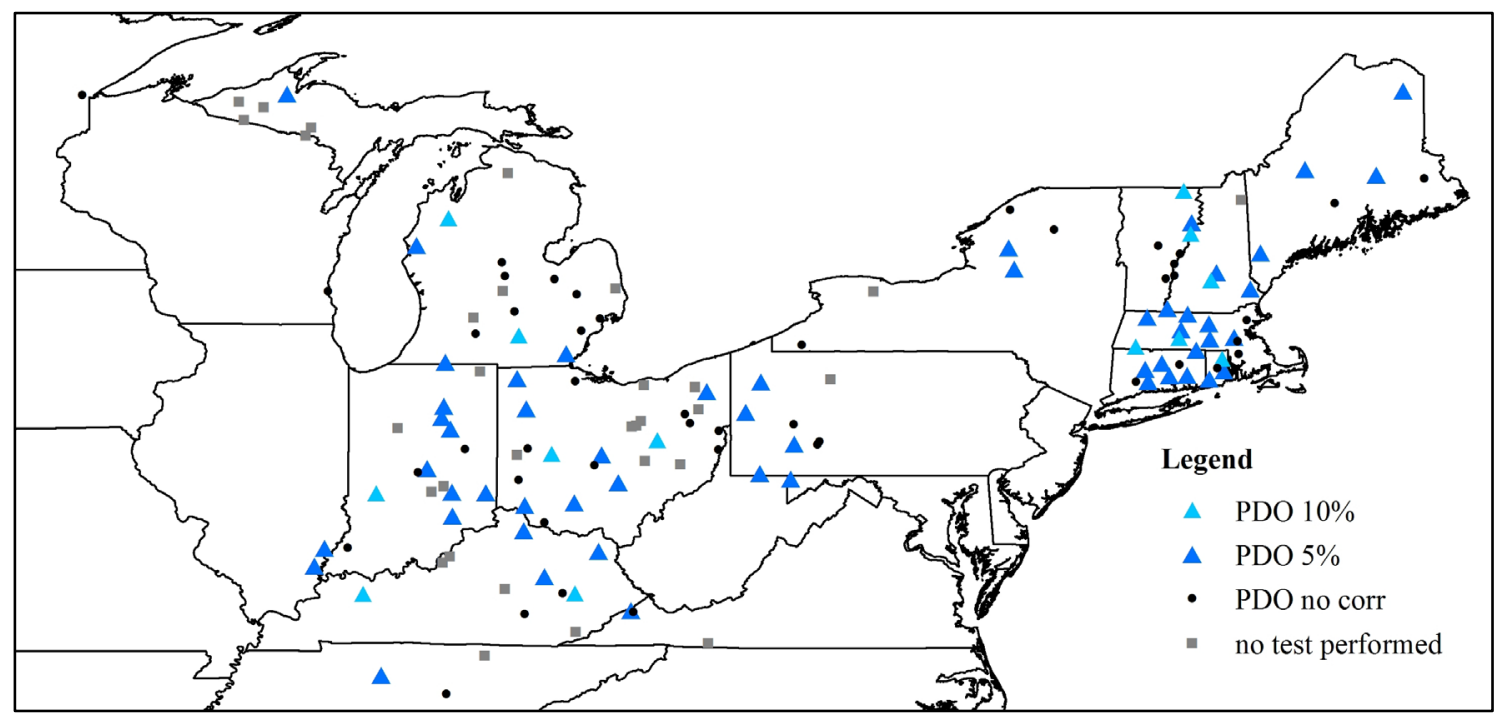

Figure 4-7: Results of Kendall's $\tau$ correlation tests (at 5\% and 10\% levels) between 10years moving averaged flood series and 3-months averaged PDO anomalies with 9months lead time. Black dots indicate sites for which no significant correlations were observed; grey squares represent sites for which tests were not conducted. 


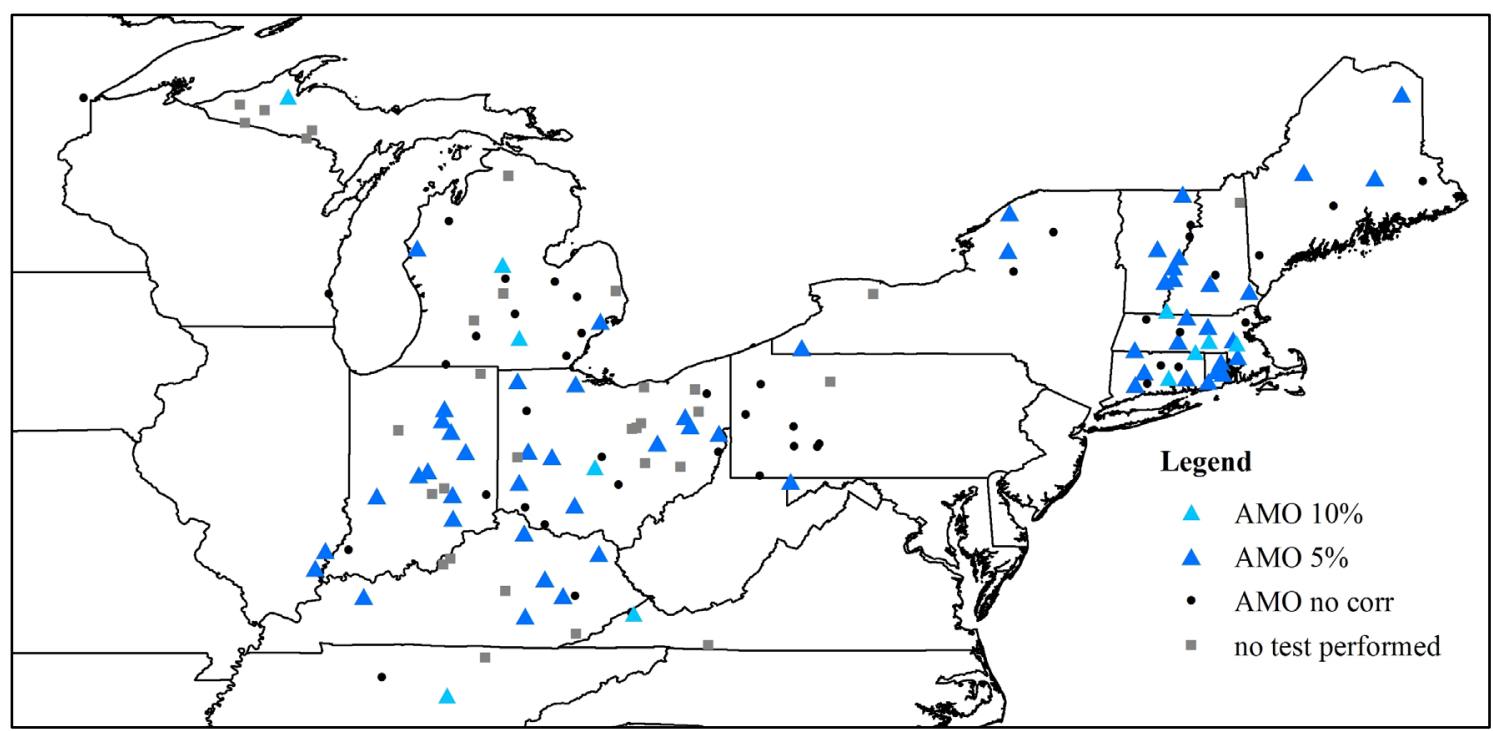

Figure 4-8: Results of Kendall's $\tau$ correlation tests (at 5\% and 10\% levels) between 10years moving averaged flood series and 3-months averaged AMO anomalies with 3months lead time. Black dots indicate sites for which no significant correlations were observed; grey squares represent sites for which tests were not conducted.

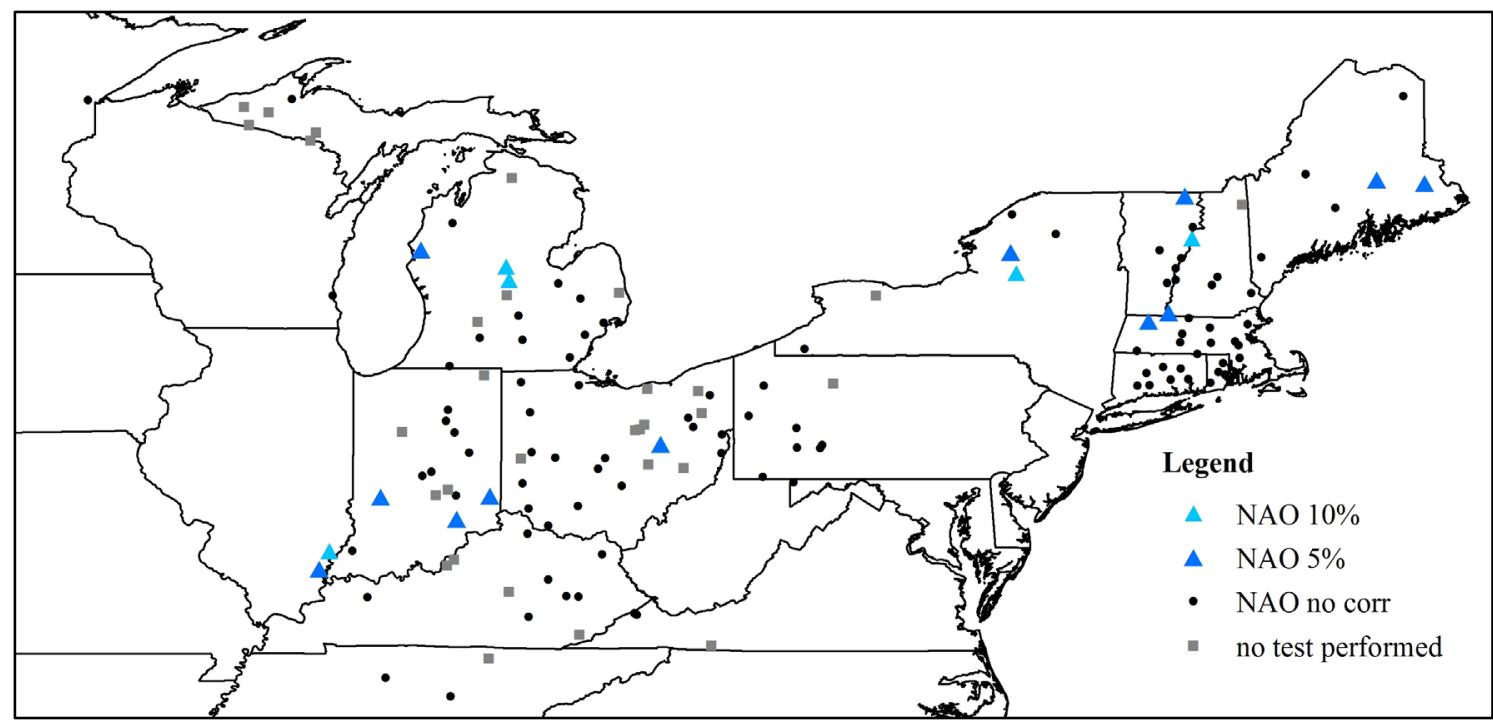

Figure 4-9: Results of Kendall's $\tau$ correlation tests (at 5\% and 10\% levels) between 10years moving averaged flood series and 3-months averaged NAO anomalies with 3months lead time. Black dots indicate sites for which no significant correlations were observed; grey squares represent sites for which tests were not conducted. 


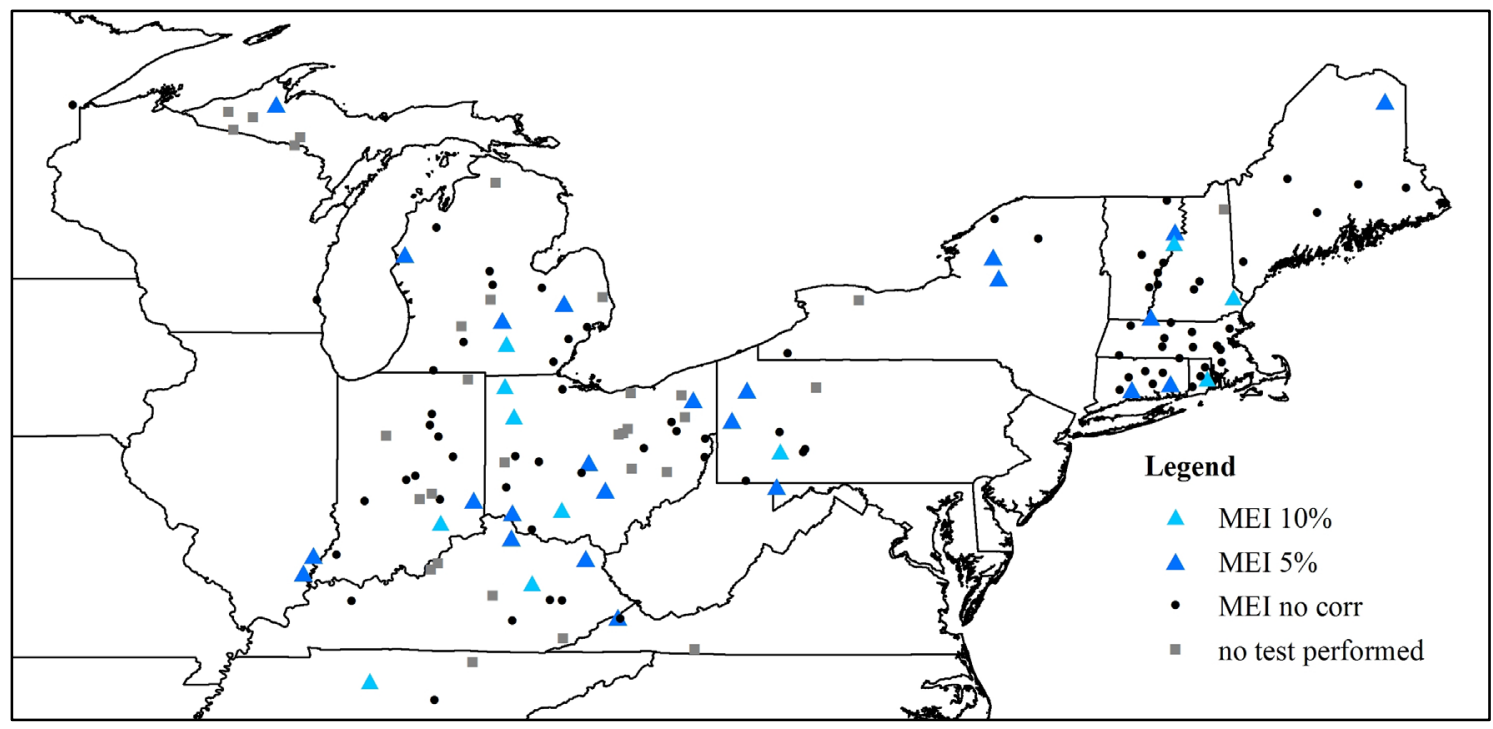

Figure 4-10: Results of Kendall's $\tau$ correlation tests (at 5\% and 10\% levels) between 10-years moving averaged flood series and 3-months averaged MEI anomalies with 9months lead time. Black dots indicate sites for which no significant correlations were observed; grey squares represent sites for which tests were not conducted.

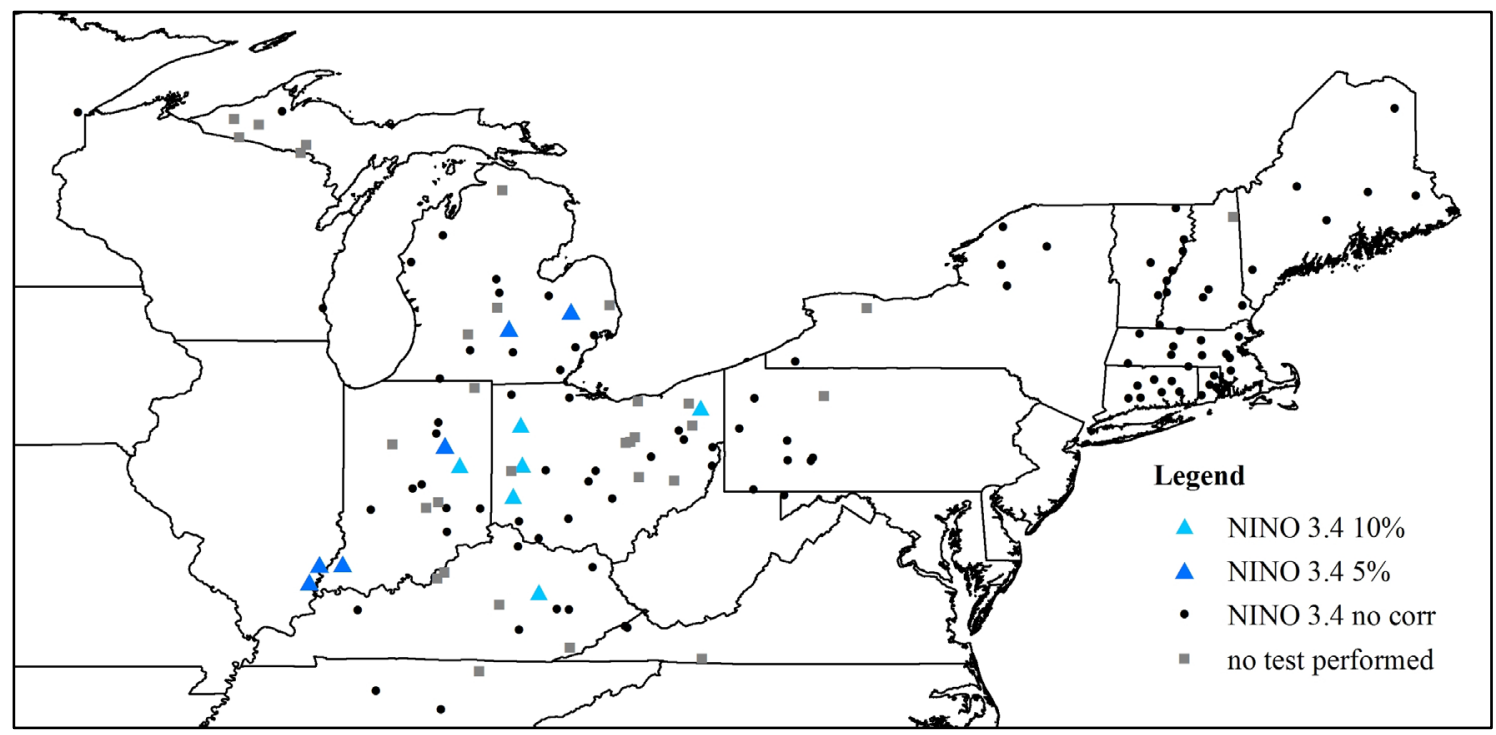

Figure 4-11: Results of Kendall's $\tau$ correlation tests (at 5\% and 10\% levels) between 10 -years moving averaged flood series and 3-months averaged NINO 3.4 anomalies with 6-months lead time. Black dots indicate sites for which no significant correlations were observed; grey squares represent sites for which tests were not conducted.

Findings similar to those presented herein for impaired sites were discussed in previous studies focusing on unimpaired watersheds in the continental United States (Fritsch, 
2012; Kashelikar, 2009; Kashelikar and Griffis, 2008). Fritsch (2012) identified the same X-months lead time for PDO, NAO and MEI; 6- and 9-months lead times were derived, respectively, for AMO and NINO 3.4. For the latter two indices, differences with 3- and 6- months lead times, respectively, consisted in only a few less sites exhibiting correlation at the 5\% level, and thus the 3-and 6-months lead times selected for use with these indices at impaired sites would be just as reasonable for use at unimpaired sites. Moreover, the author observed significant correlations with AMO, PDO and MEI for sites across the United States; for NAO, higher correlation was found at the regional scale in the Pacific Northwest, South Central US and New England (Fritsch, 2012). As observed herein for impaired watersheds, Fritsch (2012) found that the NINO 3.4 index yielded the lowest number of sites with significant correlation for unimpaired watersheds.

\subsection{Summary}

Analyses conducted in this chapter aimed to investigate natural sources of the observed non-stationarity in annual maximum flood series, and efforts were made to distinguish these influences from those of human activities. Results reveal significant correlation between flood magnitude and precipitation series, timing of flood peaks and temperature series, and existence of teleconnections in response to large-scale climate patterns, namely AMO and PDO. A relatively weaker teleconnection was observed in response to ENSO; however, the inability to identify significant correlations at a larger number of sites might be due to the use of a 10-years averaged flood magnitude to define the associated time series describing flood events. This may have resulted in excessive smoothing of the variability in flood magnitude relative to the 2-7 years periodicity of ENSO.

In an attempt to better understand the relationship between precipitation and annual maximum flood magnitude, non-stationarity in precipitation series was investigated in terms of both trends and change-points, and the findings were compared with the potential impacts of human activities identified in Chapter 3. Results suggest that a 
causative relationship between the two series is unlikely for the dataset of moderately impaired watersheds. These findings, as well as comparison with the results obtained by Fritsch (2012) for unimpaired watersheds, seem to support the idea that for impaired watersheds the influence of meteorological variables might be attenuated by human activities within the basins.

Overall, the results provided in this chapter confirm the importance of accounting for temporal changes in meteorological variables and teleconnections in the development of non-stationary flood frequency models for use in moderately impaired watersheds. Nevertheless, it is important to remember that in the presence of impairment, the relative contributions of atmospheric and land-based sources of non-stationarity in annual maximum flood series should be separately quantified. More work is needed to do so before the non-stationary flood risk forecasting techniques discussed in Chapter 1 can be effectively improved and applied in practice. 


\section{Conclusions}

Traditional procedures for flood frequency analysis and flood risk forecasting provided by Bulletin17B assume annual maximum flood series are stationary, implying the flood risk associated with a given flow magnitude (e.g., $1 \%$ annual exceedance probability for the 100-year event) is constant over time. As such, the potential effects of meteorological/climatic variability, climate change, and/or human activities within the watershed on annual maximum floods are neglected, and historical floods are assumed to be representative of future floods. This thesis provides evidence of the existence of non-stationarity in annual maximum flood peak series for several streams in the Upper Midwest and Northeastern United States, thereby providing further reason to question the assumption of stationarity and the necessity to update Bulletin 17B. These wellestablished techniques employed for design event computations in large-scale water planning and management (e.g., floodplain delineation, design of engineering structures for water uses and regulation, land-use/land-cover management) must be modified by developing non-stationary flood frequency models in order to guarantee environmental and human safety into the future.

A considerable amount of effort has already focused on evaluating the extent of nonstationarity in flood series associated with unimpaired watersheds (e.g., Fritsch, 2012; and references therein). However, the presence of human activities within many US basins and increasing impacts on the associated streamflows motivated the choice to study 143 moderately impaired watersheds herein. Non-stationarity in annual maximum flood series was investigated in terms of both trends and change-points by applying standard statistical analyses. At the $10 \%$ significance level, monotonic trends were detected for $18 \%$ of the 143 watersheds, and a statistically significant shift in the mean flood magnitude was identified for $40 \%$ of the sites. Further, a change-point was identified for all of the sites which exhibited a gradual trend, which is consistent with the findings of previous studies (Kalra et al., 2006; McCabe and Wolock, 2002a; Villarini and Smith, 2010; Villarini et al., 2011) indicating that non-stationarity in streamflows across the US often occurs as a step change rather than a gradual one. 
The influence of natural variables on flood magnitude and/or timing was investigated based on the correlation between annual maximum flood series and meteorological variables (precipitation and temperature) and large-scale atmospheric-oceanic climate patterns. Significant correlation between annual maximum flood peaks and floodgenerating precipitation series was identified for nearly $62 \%$ of the cases ${ }^{3}$ considered. To better understand the potential non-stationarity in flood series induced by temporal changes in precipitation, the presence of non-stationarity in precipitation series was investigated in terms of trends and change-points, and subsequently related to that of flood series. A few sites presented increasing trends in precipitation, but only one site also experienced increasing flood magnitudes over time. An abrupt shift in precipitation series was identified for 30 sites, but only 15 of those 30 sites also exhibited a changepoint in the mean annual maximum flood, and in most cases (13 out of 15) the shift in flood magnitude occurred before the shift in precipitation. Therefore, a causal relationship between precipitation and the non-stationarity of annual maximum flood series was unclear. In regards to minimum/maximum temperature series no significant relationship emerged with flood magnitude; however, for most of the sites (nearly 98.5\%) significant correlation was found with the day of the water year when the flood peak occurred. Overall, these findings do seem to support the idea that human-induced alterations of flows tend to attenuate the influence of meteorological variables.

Teleconnections of large-scale climatic patterns with 10-years moving averaged flood series were investigated as another potential atmospheric source of non-stationarity in annual maximum flood series. Results varied depending on the climate index considered. For PDO and AMO, high correlation was found for several sites distributed across the Upper Midwest and Northeastern US; however, relatively few statistically significant relationships were observed for NAO. Similar results were observed by Fritsch (2012) for unimpaired sites, and thus a teleconnection between NAO and flood series is unlikely. MEI and NINO 3.4 anomalies, selected as indicators to describe ENSO, yielded inconsistent results. Higher association was found between flood

\footnotetext{
${ }^{3}$ Correlation analyses between annual maximum flood series and meteorological variables were performed for 136 of the 143 sites due to availability of the data as mentioned in Section 4.2.
} 
magnitude and MEI throughout the study region, whereas NINO 3.4 anomalies were correlated with flood series at the fewest sites of any climate index considered. However, as all of the sites exhibiting correlation with the NINO 3.4 index were concentrated in the Upper Midwest, a regional teleconnection may exist. Further, the moderate degree of teleconnection observed in response to ENSO might be justified by the 10-years moving average adopted to define flood series. A 10-years window may excessively smooth the series relative to the variability potentially induced by phase shifts in ENSO which presents a higher frequency (2 to 7 years) compared to the decadal/multidecadal periodicity of the other climatic patterns. Nonetheless, results presented herein do indicate that the climatic anomalies considered could be useful in providing climate informed flood risk forecasts in areas of the study region.

Interesting findings were derived from the analysis of potential impacts of human activities on flood series. Increasing trends in annual maximum flood series were observed in lower New England where the watersheds are mainly developed; these increases in flood magnitude could thus be justified by an intensification of the runoff caused by the concomitance of increasing precipitation and increasing percentage of impervious surfaces. Moreover, decreasing trends were identified for three forested sites, two in Vermont and one in New Hampshire, which are likely related to intense reforestation based on the study of Collins (2009). The majority of the sites in the central area of the study region (Ohio, Illinois and Kentucky) where watersheds are mainly agricultural exhibited statistically significant decreasing trends. One possible reason is that changes in agricultural practices could have resulted in attenuation of flood peaks due to increased infiltration or construction of small dams or other diversions for irrigation. However, this hypothesis should be further investigated at the regional or local scale for which information about water surface withdrawals, agriculture-related dam uses, and changes over time in agricultural practices could be gathered.

Attempts were also made to relate identified change-points in annual maximum flood series to the years when water uses and management practices within the watersheds 
(e.g., power plants, diversions, dams, and reservoirs) started or were altered. Correspondence was found for six sites, at which human alterations of the flow started/shifted in the same year or the year prior to that in which the shift in the flood series occurred. However, the comparison could not be attempted for all of the watersheds considered herein due to the limited information available. Moreover, for several basins (nearly 68\%) exhibiting a change-point at the $10 \%$ level, the annual maximum flood series were coded by the US Geological Service as "discharge affected (to unknown degree) by regulation or diversions"; and for roughly $23 \%$ of these sites a maximum difference of \pm 4 years was found between the year of change-point in the flood series and the year in which the code was applied. For almost $40 \%$ of the sites, the change-point was observed in the period from 1960 to 1980, identified in several studies as a period of change in precipitation and flood series (Collins, 2009; Kalra et al., 2006; Mauget, 2003; McCabe and Wolock, 2002a; Perreault et al., 1999), and that resulted in this study to be characterized by an increasing construction of dams in the streams under consideration.

It follows that the analysis of non-stationarity in flood series for moderately impaired watersheds cannot prescind from accounting for both natural and anthropogenic factors, and future works should focus on quantifying their relative contributions and variability over time. Recent studies suggest computation of forecasted flood magnitudes as a function of forecasted climate pattern anomalies (Fritsch, 2012; Kashelikar, 2009). Nevertheless, further analyses at the watershed-scale should be conducted to assess the validity of these new statistical models, and improvements are required to extend their application for long-term forecasts (e.g., 10-, 50-, 100-years ahead). In this regard two major questions stand. First, which variables should be considered and how can longterm forecasts for these variables be derived. This involves forecasts not only of climate anomalies, but also of meteorological variables (e.g., precipitation and temperature) which could possibly be derived using General Circulation Models, and expected variations in the degree of impairment of a watershed (e.g., changes in land-cover/landuses, percentages of impervious surfaces, human alterations of the flow) which could be related to projections for population. Second, how to combine both natural and human 
factors in a comprehensive forecasting model is still not clear and it represents a major challenge for the scientific community.

Overall, this thesis provides further evidence that "stationarity is dead" (Milly et al., 2008) and scientific research needs to move forward. The additional contribution to the knowledge of non-stationarity in annual maximum flood peaks derived from this study represents an important input for the future development of non-stationary models for flood risk assessment. In particular, this work identified additional explanatory variables that could be included in the models to estimate future flood risk. Nevertheless, how to derive time series for each variable and how to combine both natural and human contributions in a comprehensive forecasting model is still not clear. A better understanding of the hydrologic response to multiple influencing factors is needed at the watershed specific scale before additional advancements can be made. 


\section{References}

Ashley, S.T., Ashley, W.S., 2008. Flood fatalities in the United States. Journal of Applied Meteorology and Climatology 47, 805-818.

Barlow, M., Nigam, S., Berbery, E., 2001. ENSO, Pacific decadal variability, and US summertime precipitation, drought, and stream flow. Journal of Climate 14, 2105-2128.

Billington, D.P., Jackson, D.C., 2006. Big dams of the New Deal era: A confluence of engineering and politics. University of Oklahoma Press.

Bonferroni, C.E., 1936. Teoria statistica delle classi e calcolo delle probabilita. Libreria internazionale Seeber.

Burn, D.H., Hag Elnur, M.A., 2002. Detection of hydrologic trends and variability. Journal of Hydrology 255, 107-122.

Cabin, R.J., Mitchell, R.J., 2000. To Bonferroni or not to Bonferroni: when and how are the questions. Bulletin of the Ecological Society of America 81, 246-248.

Caltrans, C.D.o.T., 2001. Basin Characteristics, Highway design manual, Sacramento, CA, p. 24.

Cayan, D.R., Kammerdiener, S.A., Dettinger, M.D., Caprio, J.M., Peterson, D.H., 2001. Changes in the onset of spring in the western United States. Bulletin-American Meteorological Society 82, 399-416.

Cayan, D.R., Redmond, K.T., Riddle, L.G., 1999. ENSO and Hydrologic Extremes in the Western United States*. Journal of Climate 12, 2881-2893.

Changnon, S.A., Demissie, M., 1996. Detection of changes in streamflow and floods resulting from climate fluctuations and land use-drainage changes. Climatic Change 32, 411-421.

Changnon, S.A., Kunkel, K.E., 1995. Climate-related fluctuations in midwestern floods during 1921-1985. Journal of Water Resources Planning and Management 121, 326-334.

Chiew, F.H.S., McMahon, T.A., 2002. Global ENSO-streamflow teleconnection, streamflow forecasting and interannual variability. Hydrological Sciences Journal 47, 505-522.

Collins, M.J., 2009. Evidence for Changing Flood Risk in New England Since the Late 20th Century1. JAWRA Journal of the American Water Resources Association 45, 279-290.

Croux, C., Dehon, C., 2010. Influence functions of the Spearman and Kendall correlation measures. Statistical Methods \& Applications 19, 497-515.

Cunderlik, J.M., Burn, D.H., 2003. Non-stationary pooled flood frequency analysis. Journal of Hydrology 276, 210-223. 
Dettinger, M.D., Cayan, D.R., 1995. Large-scale atmospheric forcing of recent trends toward early snowmelt runoff in California. Journal of Climate 8, 606-623.

Dettinger, M.D., Cayan, D.R., Meyer, M.K., Jeton, A.E., 2004. Simulated hydrologic responses to climate variations and change in the Merced, Carson, and American River basins, Sierra Nevada, California, 1900-2099. Climatic Change 62, 283317.

Douglas, E., Vogel, R., Kroll, C., 2000. Trends in floods and low flows in the United States: impact of spatial correlation. Journal of Hydrology 240, 90-105.

Dracup, J.A., Kahya, E., 1994. The relationships between US streamflow and La Niña events. Water Resources Research 30, 2133-2141.

Ehsanzadeh, E., Ouarda, T.B., Saley, H.M., 2011. A simultaneous analysis of gradual and abrupt changes in Canadian low streamflows. Hydrological Processes 25, 727-739.

El Adlouni, S., Ouarda, T., Zhang, X., Roy, R., Bobée, B., 2007. Generalized maximum likelihood estimators for the nonstationary generalized extreme value model. Water Resources Research 43, W03410.

Falcone, J., 2011. GAGES-II: geospatial attributes of gages for evaluating streamflow. Digital spatial data set.

Falcone, J.A., Carlisle, D.M., Weber, L.C., 2010a. Quantifying human disturbance in watersheds: Variable selection and performance of a GIS-based disturbance index for predicting the biological condition of perennial streams. Ecological Indicators 10, 264-273.

Falcone, J.A., Carlisle, D.M., Wolock, D.M., Meador, M.R., 2010b. GAGES: A stream gage database for evaluating natural and altered flow conditions in the conterminous United States. Ecology 91, 621-621.

Fearnhead, P., 2005. Exact Bayesian curve fitting and signal segmentation. Signal Processing, IEEE Transactions on 53, 2160-2166.

Fearnhead, P., 2006. Exact and efficient Bayesian inference for multiple changepoint problems. Statistics and computing 16, 203-213.

Franks, S.W., Kuczera, G., 2002. Flood frequency analysis: Evidence and implications of secular climate variability, New South Wales. Water resources research 38, 1062.

Fritsch, C.E., 2012. Evaluation of flood risk in response to climate variability, Civil and Environmental Engineering. Michigan Technological University, Houghton, MI.

Fry, J.A., Xian, G., Jin, S., Dewitz, J.A., Homer, C.G., Limin, Y., Barnes, C.A., Herold, N.D., Wickham, J.D., 2011. Completion of the 2006 national land cover database for the conterminous United States. Photogrammetric engineering and remote sensing 77, 858-864. 
Gray, S.T., Graumlich, L.J., Betancourt, J.L., Pederson, G.T., 2004. A tree-ring based reconstruction of the Atlantic Multidecadal Oscillation since $1567 \mathrm{AD}$. Geophysical Research Letters 31, L12205.

Griffis, V.W., Stedinger, J.R., 2007a. Evolution of flood frequency analysis with Bulletin 17. Journal of Hydrologic Engineering 12, 283-297.

Griffis, V.W., Stedinger, J.R., 2007b. Incorporating climate change and variability into Bulletin 17B LP3 model, World Environmental and Water Resources Congress 2007. ASCE, pp. 1-8.

Groisman, P.Y., Knight, R.W., Karl, T.R., 2001. Heavy precipitation and high streamflow in the contiguous United States: Trends in the twentieth century. Bulletin of the American Meteorological Society 82, 219-246.

Groisman, P.Y., Knight, R.W., Karl, T.R., Easterling, D.R., Sun, B., Lawrimore, J.H., 2004. Contemporary changes of the hydrological cycle over the contiguous United States: Trends derived from in situ observations. Journal of hydrometeorology 5, 64-85.

Hadley, R., Karlinger, M., Burns, A., Eschner, T., 1987. Water development and associated hydrologic changes in the Platte River, Nebraska, USA. Regulated Rivers: Research \& Management 1, 331-341.

Hamilton, J.P., Whitelaw, G.S., Fenech, A., 2001. Mean annual temperature and total annual precipitation trends at Canadian biosphere reserves. Environmental monitoring and assessment 67, 239-275.

Hamlet, A.F., Lettenmaier, D.P., 2007. Effects of 20th century warming and climate variability on flood risk in the western US. Water Resources Research 43, W06427.

Hamlet, A.F., Mote, P.W., Clark, M.P., Lettenmaier, D.P., 2005. Effects of Temperature and Precipitation Variability on Snowpack Trends in the Western United States*. Journal of Climate 18, 4545-4561.

Hejazi, M.I., Markus, M., 2009. Impacts of urbanization and climate variability on floods in Northeastern Illinois. Journal of Hydrologic Engineering 14, 606-616.

Helsel, D.R., Hirsch, R.M., 2002. Statistical methods in water resources. US Geological survey Reston, Va.

Hodgkins, G., Dudley, R., Huntington, T., 2003. Changes in the timing of high river flows in New England over the 20th century. Journal of Hydrology 278, 244252.

Hodgkins, G.A., Dudley, R.W., 2005. Changes in the magnitude of annual and monthly streamflows in New England, 1902-2002.

Hosking, J.R.M., Wallis, J.R., 2005. Regional frequency analysis: an approach based on L-moments. Cambridge University Press.

Huntington, T.G., Richardson, A.D., McGuire, K.J., Hayhoe, K., 2009. Climate and hydrological changes in the northeastern United States: recent trends and 103 
implications for forested and aquatic ecosystems. Canadian Journal of Forest Research 39, 199-212.

Hurrell, J.W., Van Loon, H., 1997. Decadal variations in climate associated with the North Atlantic Oscillation. Climatic change 36, 301-326.

IACWD, I.C.o.W.D., 1982. Guidelines for determining flood flow frequency, Bulletin No. 17B (revised and corrected), Washington, D.C.

IPCC, 1996. Climate change 1995: impacts, adaptations and mitigations of climate change: scientific-technical analyses., Contribution of working group II to the Second Assessment Report of the Intergovernmental Panel on Climate Change, Cambridge.

Jain, S., Lall, U., 2001. Floods in a changing climate: Does the past represent the future? Water Resources Research 37, 3193-3205.

Johnson, R.A., Wichern, D.W., 2002. Applied multivariate statistical analysis, Fifth Edition ed. Prentice hall Englewood Cliffs, NJ.

Juckem, P.F., Hunt, R.J., Anderson, M.P., Robertson, D.M., 2008. Effects of climate and land management change on streamflow in the driftless area of Wisconsin. Journal of Hydrology 355, 123-130.

Kalra, A., Piechota, T.C., Davies, R., Tootle, G.A., 2006. Is climate change evident in US streamflow?, World Environmental and Water Resource Congress 2006@ sExamining the Confluence of Environmental and Water Concerns. ASCE.

Karl, T.R., Knight, R.W., 1998. Secular trends of precipitation amount, frequency, and intensity in the United States. Bulletin of the American Meteorological Society $79,231-241$.

Kashelikar, A.S., 2009. Identification of teleconnections and improved flood risk forecasts using Bulletin 17B, Civil and Environmental Engineering. Michigan Technological University, Houghton, MI.

Kashelikar, A.S., Griffis, V.W., 2008. Improving Forecasts of Flood Risk by Incorporating Climate Variability into Bulletin 17B LP3 Model, World Environmental and Water Resources Congress 2008@sAhupua'A. ASCE, pp. $1-10$.

Katz, R.W., Brown, B.G., 1992. Extreme events in a changing climate: variability is more important than averages. Climatic change 21, 289-302.

Katz, R.W., Parlange, M.B., Naveau, P., 2002. Statistics of extremes in hydrology. Advances in water resources 25, 1287-1304.

Kendall, M., 1975. Rank correlation measures. Charles Griffin, London 202.

Kendall, M.G., 1962. Rank correlation methods, 3rd ed. Hafner Publishing Company, New York.

Kerr, R.A., 2000. A North Atlantic climate pacemaker for the centuries. Science 288, 1984-1985. 
Khaliq, M., Ouarda, T., Gachon, P., Sushama, L., St-Hilaire, A., 2009. Identification of hydrological trends in the presence of serial and cross correlations: A review of selected methods and their application to annual flow regimes of Canadian rivers. Journal of Hydrology 368, 117-130.

Kiem, A.S., Franks, S.W., Kuczera, G., 2003. Multi-decadal variability of flood risk. Geophysical Research Letters 30, 1035.

Konrad, C.P., 2003. Effects of urban development on floods. US Department of the Interior, US Geological Survey.

Krug, W.R., 1996. Simulation of temporal changes in rainfall-runoff characteristics, Coon Creek Basin, Wisconsin. JAWRA Journal of the American Water Resources Association 32, 745-752.

Kundzewicz, Z.W., Graczyk, D., Maurer, T., Pińskwar, I., Radziejewski, M., Svensson, C., Szwed, M., 2005. Trend detection in river flow series: 1. Annual maximum flow / Détection de tendance dans des séries de débit fluvial: 1. Débit maximum annuel. Hydrological Sciences Journal 50.

Kundzewicz, Z.W., Robson, A., Organization, W.M., Mondiale, O.M., Data, W.C., Programme, M., Unesco, 2000. Detecting Trend and Other Changes in Hydrological Data. World Meteorological Organization.

Kunkel, K.E., Andsager, K., Easterling, D.R., 1999. Long-term trends in extreme precipitation events over the conterminous United States and Canada. Journal of Climate 12, 2515-2527.

Kwon, H.-H., Brown, C., Lall, U., 2008. Climate informed flood frequency analysis and prediction in Montana using hierarchical Bayesian modeling. Geophysical Research Letters 35, L05404.

Lang, M., Ouarda, T., Bobée, B., 1999. Towards operational guidelines for overthreshold modeling. Journal of Hydrology 225, 103-117.

Lettenmaier, D.P., Wood, E.F., Wallis, J.R., 1994. Hydro-climatological trends in the continental United States, 1948-88. Journal of Climate 7, 586-607.

Lins, H.F., Michaels, P.J., 1994. Increasing US streamflow linked to greenhouse forcing. Eos, Transactions American Geophysical Union 75, 281-285.

Lins, H.F., Slack, J.R., 1999. Streamflow trends in the United States. Geophysical Research Letters 26, 227-230.

Mann, H.B., 1945. Nonparametric tests against trend. Econometrica: Journal of the Econometric Society, 245-259.

Mantua, N.J., Hare, S.R., 2002. The Pacific decadal oscillation. Journal of Oceanography $58,35-44$.

Mantua, N.J., Hare, S.R., Zhang, Y., Wallace, J.M., Francis, R.C., 1997. A Pacific interdecadal climate oscillation with impacts on salmon production. Bulletin of the American Meteorological Society 78, 1069-1079. 
Mauget, S.A., 2003. Multidecadal regime shifts in US streamflow, precipitation, and temperature at the end of the twentieth century. Journal of Climate 16, 39053916.

Maurer, E., Wood, A., Adam, J., Lettenmaier, D., Nijssen, B., 2002. A Long-Term Hydrologically Based Dataset of Land Surface Fluxes and States for the Conterminous United States*. Journal of Climate 15, 3237-3251.

McCabe, G.J., Dettinger, M.D., 1999. Decadal variations in the strength of ENSO teleconnections with precipitation in the western United States. International Journal of Climatology 19, 1399-1410.

McCabe, G.J., Wolock, D.M., 2002a. A step increase in streamflow in the conterminous United States. Geophysical Research Letters 29, 2185.

McCabe, G.J., Wolock, D.M., 2002b. Trends and temperature sensitivity of moisture conditions in the conterminous United States. Climate Research 20, 19-29.

McCormick, B.C., Eshleman, K.N., Griffith, J.L., Townsend, P.A., 2009. Detection of flooding responses at the river basin scale enhanced by land use change. Water Resources Research 45, W08401.

Meehl, G.A., Karl, T., Easterling, D.R., Changnon, S.A., Pielke, R.A., Changnon, D., Evans, J., Groisman, P.Y., Knutson, T.R., Kunkel, K.E., 2000. An introduction to trends in extreme weather and climate events: observations, socioeconomic impacts, terrestrial ecological impacts, and model projections. BulletinAmerican Meteorological Society 81, 413-416.

Miller, J.E., Frink, D.L., 1984. Changes in flood response of the Red River of the North basin, North Dakota-Minnesota. Available from Books and Open-File Reports Section, USGS Box 25425, Denver, CO 80225. USGS Water-Supply Paper 2243, 1984. 103 p, 17 fig, 13 tab, 66 ref, 11 append.

Milly, P., Julio, B., Malin, F., Robert, M., Zbigniew, W., Dennis, P., Ronald, J., 2008. Stationarity is dead. Science, American Association for the Advancement of Science 319, 573-574.

Milly, P., Wetherald, R., Dunne, K., Delworth, T., 2002. Increasing risk of great floods in a changing climate. Nature 415, 514-517.

Minitab16, 2012. Minitab StatGuide (online guide), State College, PA.

Mishra, B.K., Takara, K., Yamashiki, Y., Tachikawa, Y., 2010. An assessment of predictive accuracy for two regional flood-frequency estimation methods. Annual Journal of Hydraulic Engineering 54, 7-12.

Moglen, G.E., Schwartz, D.E., 2006. Methods for adjusting US Geological Survey rural regression peak discharges in an urban setting, US Geological Survey Investigations, Reston, Virginia.

Mote, P.W., 2003. Trends in temperature and precipitation in the Pacific Northwest during the twentieth century.

NOAA, E.S.R.L., 2013. Mutlivariate ENSO Index (MEI). 
Olsen, J.R., Stedinger, J.R., Matalas, N.C., Stakhiv, E.Z., 1999. Climate variability and flood frequency estimation for the Upper Mississippi and Lower Missouri Rivers. JAWRA Journal of the American Water Resources Association 35, 1509-1523.

Pegg, M.A., Pierce, C.L., Roy, A., 2003. Hydrological alteration along the Missouri River basin: a time series approach. Aquatic Sciences-Research Across Boundaries 65, 63-72.

Perreault, L., Haché, M., Slivitzky, M., Bobée, B., 1999. Detection of changes in precipitation and runoff over eastern Canada and US using a Bayesian approach. Stochastic Environmental Research and Risk Assessment 13, 201-216.

Perry, C.A., 1994. Effects of reservoirs on flood discharges in the Kansas and the Missouri River basins, 1993. Floods in the upper Mississippi basin, 1993.

Pettitt, A., 1979. A non-parametric approach to the change-point problem. Applied statistics, 126-135.

Philander, S.G., 1990. El Niño, La Niña, and the southern oscillation. Academic Press.

Pielke Jr, R.A., Downton, M.W., 2000. Precipitation and damaging floods: trends in the United States, 1932-97. Journal of Climate 13, 3625-3637.

Pielke, R.A., Downton, M.W., Miller, J.B., 2002. Flood Damage in the United States, 1926-2000: A Reanalysis of National Weather Service Estimates. University Corporation for Atmospheric Research Boulder, CO.

Poff, N.L., Bledsoe, B.P., Cuhaciyan, C.O., 2006. Hydrologic variation with land use across the contiguous United States: Geomorphic and ecological consequences for stream ecosystems. Geomorphology 79, 264-285.

Qi, S., Sun, G., Wang, Y., McNulty, S., Myers, J.M., 2009. Streamflow response to climate and landuse changes in a coastal watershed in North Carolina. Transactions of the ASABE 52, 739-749.

Raff, D., Pruitt, T., Brekke, L., 2009. A framework for assessing flood frequency based on climate projection information. Hydrology and Earth System Sciences 13, 2119.

Rasmussen, P., 2001. Bayesian estimation of change points using the general linear model. Water Resources Research 37, 2723-2731.

Reeves, J., Chen, J., Wang, X.L., Lund, R., Lu, Q.Q., 2007. A review and comparison of changepoint detection techniques for climate data. Journal of Applied Meteorology and Climatology 46, 900-915.

Rice, W.R., 1989. Analyzing tables of statistical tests. Evolution 43, 223-225.

Robson, A.J., 2002. Evidence for trends in UK flooding. Philosophical transactions. Series A, Mathematical, physical, and engineering sciences 360, 1327-1343.

Rodionov, S., 2005. A brief overview of the regime shift detection methods, Largescale disturbances (regime shifts) and recovery in aquatic ecosystems: 
challenges for management toward sustainability. UNESCO-ROSTE/BAS Workshop on Regime Shifts, Varna, Bulgaria, pp. 17-24.

Rose, S., Peters, N.E., 2001. Effects of urbanization on streamflow in the Atlanta area (Georgia, USA): a comparative hydrological approach. Hydrological Processes $15,1441-1457$.

Ruggieri, E., 2012. A Bayesian approach to detecting change points in climatic records. International Journal of Climatology.

Sankarasubramanian, A., Vogel, R.M., Limbrunner, J.F., 2001. Climate elasticity of streamflow in the United States. Water Resources Research 37, 1771-1781.

Sauer, V.B., Thomas, W., Stricker, V., Wilson, K., 1983. Flood characteristics of urban watersheds in the United States. US Government Printing Office.

Schilling, K.E., Jha, M.K., Zhang, Y.-K., Gassman, P.W., Wolter, C.F., 2008. Impact of land use and land cover change on the water balance of a large agricultural watershed: Historical effects and future directions. Water Resources Research 44, W00A09.

Schilling, K.E., Libra, R.D., 2007. Increased baseflow in Iowa over the second half of the 20th century. JAWRA Journal of the American Water Resources Association 39, 851-860.

Seidou, O., Asselin, J., Ouarda, T., 2007. Bayesian multivariate linear regression with application to change point models in hydrometeorological variables. Water Resources Research 43, W08401.

Seidou, O., Ouarda, T.B., 2007. Recursion-based multiple changepoint detection in multiple linear regression and application to river streamflows. Water Resources Research 43, W07404.

Shaffer, J.P., 1995. Multiple hypothesis testing. Annual review of psychology 46, 561584.

Sheppard, P.R., Comrie, A.C., Packin, G.D., Angersbach, K., Hughes, M.K., 2002. The climate of the US Southwest. Climate Research 21, 219-238.

Slack, J., Lumb, A., Landwehr, J., 1993. Hydro-Climate Data Network (HCDN)Steamflow Data Set, 1874-1988: US Geological Survey Water-Resources Investigations Report 93-4076. CD-ROM.

Slack, J.R., Landwehr, J.M., 1992. Hydro-Climatic Data Network(HCDN): A U. S. Geological Survey Streamflow Data Set for the United States for the Study of Climate Variations, 1874-1988. Available from Books and Open-File Report Section, USGS, Box 25425, Denver, CO 80225. USGS Open-File Report 92129, 1992. 193 p, 8 fig, 6 tab, 34 ref.

Stedinger, J.R., Griffis, V.W., 2011. Getting From Here to Where? Flood Frequency Analysis and Climate1. JAWRA Journal of the American Water Resources Association 47, 506-513. 
Storch, H., 1995. Misuses of statistical analysis in climate research, in: Storch, H.V., Navarra, A. (Eds.), Analysis of Climate Variability: Applications of Statistical Techniques. Springer-Verlag, New York, pp. 11-26.

Strupczewski, W., Singh, V., Feluch, W., 2001. Non-stationary approach to at-site flood frequency modelling I. Maximum likelihood estimation. Journal of Hydrology 248, 123-142.

Svensson, C., Kundzewicz, W.Z., Maurer, T., 2005. Trend detection in river flow series: 2. Flood and low-flow index series / Détection de tendance dans des séries de débit fluvial: 2. Séries d'indices de crue et d'étiage. Hydrological Sciences Journal 50.

Tootle, G.A., Piechota, T.C., Singh, A., 2005. Coupled oceanic-atmospheric variability and U.S. streamflow. Water Resources Research 41.

Villarini, G., Serinaldi, F., Smith, J.A., Krajewski, W.F., 2009a. On the stationarity of annual flood peaks in the continental United States during the 20th century. Water Resources Research 45, W08417.

Villarini, G., Smith, J.A., 2010. Flood peak distributions for the eastern United States. Water Resources Research 46, W06504.

Villarini, G., Smith, J.A., Baeck, M.L., Krajewski, W.F., 2011. Examining Flood Frequency Distributions in the Midwest US 1. JAWRA Journal of the American Water Resources Association 47, 447-463.

Villarini, G., Smith, J.A., Serinaldi, F., Bales, J., Bates, P.D., Krajewski, W.F., 2009 b. Flood frequency analysis for nonstationary annual peak records in an urban drainage basin. Advances in Water Resources 32, 1255-1266.

Wang, D., Hejazi, M., 2011. Quantifying the relative contribution of the climate and direct human impacts on mean annual streamflow in the contiguous United States. Water Resources Research 47.

Wilby, R.L., Beven, K.J., Reynard, N.S., 2008. Climate change and fluvial flood risk in the UK: more of the same? Hydrological Processes 22, 2511-2523.

Wood, A.W., Maurer, E.P., Kumar, A., Lettenmaier, D.P., 2002. Long-range experimental hydrologic forecasting for the eastern United States. J. Geophys. Res 107, 4429.

Young, C., McEnroe, B., Rome, A., 2009. Regional regression analysis and the rational method, Proc., World Environmental and Water Resources Congress 2009, pp. 6231-6238.

Yue, S., Pilon, P., Cavadias, G., 2002a. Power of the Mann-Kendall and Spearman's rho tests for detecting monotonic trends in hydrological series. Journal of Hydrology 259, 254-271.

Yue, S., Pilon, P., Phinney, B., Cavadias, G., 2002b. The influence of autocorrelation on the ability to detect trend in hydrological series. Hydrological Processes 16, 1807-1829. 
Yue, S., Wang, C., 2004. The Mann-Kendall test modified by effective sample size to detect trend in serially correlated hydrological series. Water Resources Management 18, 201-218.

Yue, S., Wang, C.Y., 2002. The applicability of pre-whitening to eliminate the influence of serial correlation on the Mann-Kendall test. Water Resources Research 38, 4-1-7.

Yulianti, J.S., Burn, D.H., 1998. Investigating links between climatic warming and low streamflow in the Prairies region of Canada. Canadian Water Resources Journal 23, 45-60.

Zhang, Y.K., Schilling, K.E., 2006. Increasing streamflow and baseflow in Mississippi River since the 1940s: Effect of land use change. Journal of Hydrology 324, 412-422. 


\section{Appendix A \\ AMF series and watersheds characteristics}

This appendix provides additional information pertaining to the annual maximum flood series and physical characteristics of the 143 moderately impaired watersheds located in the Upper Midwest and Northeastern United States which represent the dataset for the analyses conducted in this thesis. Indicators of the level of human disturbance within each watershed are also summarized.

\section{A1: Summary of watersheds features}

Table A-1 presents summary statistics for the annual maximum flood series for each of the 143 watersheds considered herein, including USGS site identification code, state in which the gauge is located, length of the annual maximum flood record, and the annual maximum flood magnitude averaged over the period of record. Table A-2 reports select physical characteristics: drainage area, mean watershed elevation, mean watershed slope and basin orientation. Table A-3 summarizes additional physical features with respect to land-use/land-cover, and provides information pertaining to the level of human disturbance within each of the 143 watersheds.

Table A-1: Hydrologic features of the143 moderately impaired watersheds.

\begin{tabular}{|c|c|c|c|}
\hline Site Number & State & Record Length & Mean AMF $\left[\mathbf{m}^{\mathbf{3}} / \mathbf{s}\right]$ \\
\hline 01017000 & $\mathrm{ME}$ & 80 & 708 \\
01019000 & $\mathrm{ME}$ & 82 & 42 \\
01034500 & $\mathrm{ME}$ & 109 & 1913 \\
01042500 & $\mathrm{ME}$ & 109 & 371 \\
01049000 & $\mathrm{ME}$ & 82 & 197 \\
01053500 & $\mathrm{NH}$ & 67 & 210 \\
01066000 & $\mathrm{ME}$ & 94 & 418 \\
01073000 & $\mathrm{NH}$ & 76 & 10 \\
01081000 & $\mathrm{NH}$ & 74 & 67 \\
01087000 & $\mathrm{NH}$ & 84 & 55 \\
01094500 & $\mathrm{MA}$ & 74 & 92
\end{tabular}


Table A-1, continued

\begin{tabular}{|c|c|c|c|}
\hline Site Number & State & Record Length & Mean AMF $\left[\mathrm{m}^{3} / \mathrm{s}\right]$ \\
\hline 01101500 & MA & 72 & 13 \\
\hline 01103500 & MA & 72 & 40 \\
\hline 01105000 & MA & 70 & 13 \\
\hline 01109000 & MA & 84 & 15 \\
\hline 01110000 & MA & 70 & 7 \\
\hline 01114500 & RI & 68 & 19 \\
\hline 01116000 & RI & 69 & 22 \\
\hline 01117000 & RI & 69 & 13 \\
\hline 01118000 & RI & 68 & 28 \\
\hline 01119500 & $\mathrm{CT}$ & 78 & 89 \\
\hline 01124000 & $\mathrm{CT}$ & 78 & 88 \\
\hline 01127500 & $\mathrm{CT}$ & 79 & 91 \\
\hline 01135500 & VT & 82 & 228 \\
\hline 01139000 & VT & 70 & 54 \\
\hline 01141500 & VT & 70 & 54 \\
\hline 01142500 & VT & 71 & 24 \\
\hline 01151500 & VT & 80 & 166 \\
\hline 01152500 & $\mathrm{NH}$ & 82 & 146 \\
\hline 01153000 & VT & 81 & 121 \\
\hline 01161000 & $\mathrm{NH}$ & 96 & 154 \\
\hline 01162500 & MA & 91 & 12 \\
\hline 01168500 & MA & 96 & 383 \\
\hline 01173500 & MA & 97 & 80 \\
\hline 01174500 & MA & 73 & 25 \\
\hline 01185500 & MA & 96 & 103 \\
\hline 01189000 & $\mathrm{CT}$ & 68 & 60 \\
\hline 01192500 & $\mathrm{CT}$ & 81 & 36 \\
\hline 01193500 & $\mathrm{CT}$ & 81 & 103 \\
\hline 01196500 & $\mathrm{CT}$ & 79 & 69 \\
\hline 01208500 & $\mathrm{CT}$ & 81 & 268 \\
\hline 03014500 & NY & 76 & 38 \\
\hline 03024000 & PA & 78 & 382 \\
\hline 03028500 & PA & 65 & 134 \\
\hline 03038000 & PA & 74 & 160 \\
\hline 03040000 & PA & 72 & 355 \\
\hline 03041000 & PA & 71 & 188 \\
\hline 03045000 & PA & 71 & 202 \\
\hline 03072000 & PA & 71 & 220 \\
\hline 03076500 & MD & 72 & 195 \\
\hline 03086500 & $\mathrm{OH}$ & 66 & 74 \\
\hline 03093000 & $\mathrm{OH}$ & 72 & 83 \\
\hline 03106500 & PA & 77 & 203 \\
\hline 03110000 & $\mathrm{OH}$ & 69 & 99 \\
\hline
\end{tabular}


Table A-1, continued

\begin{tabular}{|c|c|c|c|}
\hline Site Number & State & Record Length & Mean AMF $\left[\mathrm{m}^{3} / \mathrm{s}\right]$ \\
\hline 03111500 & $\mathrm{OH}$ & 68 & 88 \\
\hline 03117500 & $\mathrm{OH}$ & 71 & 110 \\
\hline 03118000 & $\mathrm{OH}$ & 70 & 21 \\
\hline 03131500 & $\mathrm{OH}$ & 76 & 94 \\
\hline 03133500 & $\mathrm{OH}$ & 69 & 39 \\
\hline 03135000 & $\mathrm{OH}$ & 69 & 46 \\
\hline 03140000 & $\mathrm{OH}$ & 73 & 49 \\
\hline 03141500 & $\mathrm{OH}$ & 69 & 21 \\
\hline 03147500 & $\mathrm{OH}$ & 68 & 237 \\
\hline 03157000 & $\mathrm{OH}$ & 70 & 90 \\
\hline 03165000 & VA & 66 & 62 \\
\hline 03208500 & VA & 84 & 437 \\
\hline 03209000 & VA & 84 & 193 \\
\hline 03216500 & KY & 71 & 235 \\
\hline 03227500 & $\mathrm{OH}$ & 89 & 639 \\
\hline 03228500 & $\mathrm{OH}$ & 71 & 156 \\
\hline 03232500 & $\mathrm{OH}$ & 70 & 131 \\
\hline 03238500 & $\mathrm{OH}$ & 70 & 312 \\
\hline 03245500 & $\mathrm{OH}$ & 71 & 898 \\
\hline 03253500 & KY & 122 & 1313 \\
\hline 03262000 & $\mathrm{OH}$ & 94 & 127 \\
\hline 03264000 & $\mathrm{OH}$ & 67 & 97 \\
\hline 03267000 & $\mathrm{OH}$ & 70 & 78 \\
\hline 03272000 & $\mathrm{OH}$ & 83 & 169 \\
\hline 03276500 & $\mathrm{IN}$ & 87 & 805 \\
\hline 03280000 & KY & 75 & 732 \\
\hline 03281000 & KY & 70 & 260 \\
\hline 03283500 & $\mathrm{KY}$ & 73 & 283 \\
\hline 03285000 & KY & 65 & 441 \\
\hline 03293000 & KY & 65 & 47 \\
\hline 03302000 & KY & 65 & 91 \\
\hline 03320000 & KY & 79 & 1524 \\
\hline 03325000 & IN & 87 & 484 \\
\hline 03326500 & IN & 87 & 345 \\
\hline 03328000 & IN & 81 & 130 \\
\hline 03329700 & IN & 67 & 142 \\
\hline 03347000 & IN & 80 & 154 \\
\hline 03352500 & IN & 81 & 133 \\
\hline 03353500 & $\mathrm{IN}$ & 71 & 181 \\
\hline 03360000 & IN & 80 & 390 \\
\hline 03361500 & IN & 67 & 212 \\
\hline 03362000 & IN & 68 & 117 \\
\hline 03363500 & IN & 80 & 217 \\
\hline
\end{tabular}


Table A-1, continued

\begin{tabular}{|c|c|c|c|}
\hline Site Number & State & Record Length & Mean AMF $\left[\mathrm{m}^{3} / \mathrm{s}\right]$ \\
\hline 03369500 & $\mathrm{IN}$ & 71 & 433 \\
\hline 03376500 & IN & 76 & 180 \\
\hline 03378000 & IL & 70 & 96 \\
\hline 03381500 & IL & 71 & 504 \\
\hline 03401000 & KY & 66 & 531 \\
\hline 03406500 & KY & 73 & 646 \\
\hline 03414500 & $\mathrm{TN}$ & 66 & 518 \\
\hline 03421000 & $\mathrm{TN}$ & 85 & 756 \\
\hline 03433500 & $\mathrm{TN}$ & 79 & 397 \\
\hline 04024000 & $\mathrm{MN}$ & 104 & 477 \\
\hline 04034500 & MI & 68 & 14 \\
\hline 04036000 & MI & 68 & 25 \\
\hline 04037500 & MI & 66 & 5 \\
\hline 04041500 & MI & 79 & 102 \\
\hline 04060993 & WI & 66 & 46 \\
\hline 04062500 & MI & 66 & 83 \\
\hline 04087000 & WI & 96 & 153 \\
\hline 04099000 & MI & 88 & 149 \\
\hline 04099510 & IN & 65 & 12 \\
\hline 04105500 & MI & 73 & 81 \\
\hline 04109000 & MI & 76 & 18 \\
\hline 04112500 & MI & 73 & 61 \\
\hline 04115000 & MI & 67 & 73 \\
\hline 04117500 & MI & 67 & 71 \\
\hline 04122500 & MI & 71 & 58 \\
\hline 04124000 & MI & 77 & 67 \\
\hline 04127997 & MI & 68 & 20 \\
\hline 04146000 & MI & 78 & 10 \\
\hline 04151500 & MI & 71 & 234 \\
\hline 04154000 & MI & 78 & 55 \\
\hline 04155000 & MI & 80 & 48 \\
\hline 04159492 & MI & 67 & 176 \\
\hline 04165500 & MI & 76 & 199 \\
\hline 04166500 & MI & 80 & 72 \\
\hline 04176500 & MI & 73 & 190 \\
\hline 04185000 & $\mathrm{OH}$ & 69 & 102 \\
\hline 04186500 & $\mathrm{OH}$ & 71 & 163 \\
\hline 04195500 & $\mathrm{OH}$ & 72 & 197 \\
\hline 04200500 & $\mathrm{OH}$ & 65 & 254 \\
\hline 04202000 & $\mathrm{OH}$ & 65 & 50 \\
\hline 04231000 & NY & 65 & 50 \\
\hline 04252500 & NY & 100 & 178 \\
\hline 04258000 & NY & 80 & 66 \\
\hline
\end{tabular}


Table A-1, continued

\begin{tabular}{|c|ccc|}
\hline Site Number & State & Record Length & Mean AMF $\left[\mathbf{m}^{\mathbf{3}} / \mathbf{s}\right]$ \\
\hline 04263000 & NY & 94 & 273 \\
04266500 & NY & 102 & 153 \\
04296500 & VT & 72 & 42 \\
\hline
\end{tabular}

Table A-2: Physical features of the143 moderately impaired watersheds.

\begin{tabular}{|c|c|c|c|c|c|}
\hline \multirow{2}{*}{$\begin{array}{c}\text { Site } \\
\text { Number }\end{array}$} & \multirow{2}{*}{$\begin{array}{c}\text { Drainage } \\
\text { Area }\left[\mathrm{km}^{2}\right]\end{array}$} & \multirow{2}{*}{$\begin{array}{c}\text { Mean } \\
\text { Elevation }[\mathrm{m}]\end{array}$} & \multirow{2}{*}{$\begin{array}{c}\text { Mean } \\
\text { Slope }[\%]\end{array}$} & \multicolumn{2}{|c|}{ Orientation } \\
\hline & & & & North/South & East/West \\
\hline 01017000 & 4279 & 272 & 4.8 & -0.50 & 0.86 \\
\hline 01019000 & 621 & 126 & 4.9 & -0.55 & 0.84 \\
\hline 01034500 & 17347 & 265 & 5.3 & -0.60 & 0.80 \\
\hline 01042500 & 4124 & 425 & 6.9 & -0.93 & 0.36 \\
\hline 01049000 & 1489 & 130 & 3.8 & -0.79 & 0.62 \\
\hline 01053500 & 2701 & 595 & 11.1 & -0.41 & -0.91 \\
\hline 01066000 & 3355 & 330 & 13.1 & -0.38 & 0.93 \\
\hline 01073000 & 31 & 58 & 3.0 & -0.39 & 0.92 \\
\hline 01081000 & 1217 & 220 & 6.8 & -0.71 & -0.70 \\
\hline 01087000 & 332 & 318 & 10.5 & -0.41 & 0.91 \\
\hline 01094500 & 280 & 254 & 6.4 & -0.11 & 0.99 \\
\hline 01101500 & 115 & 33 & 2.0 & -0.30 & 0.95 \\
\hline 01103500 & 473 & 69 & 3.1 & -0.23 & 0.97 \\
\hline 01105000 & 85 & 64 & 2.7 & 0.78 & 0.62 \\
\hline 01109000 & 113 & 54 & 1.6 & -0.52 & 0.85 \\
\hline 01110000 & 66 & 148 & 4.6 & -0.63 & 0.77 \\
\hline 01114500 & 99 & 109 & 4.7 & -0.45 & 0.89 \\
\hline 01116000 & 168 & 117 & 3.6 & 0.31 & 0.95 \\
\hline 01117000 & 60 & 58 & 2.4 & 0.12 & 0.99 \\
\hline 01118000 & 193 & 105 & 4.4 & -0.95 & 0.33 \\
\hline 01119500 & 315 & 213 & 6.6 & -0.92 & -0.39 \\
\hline 01124000 & 392 & 230 & 6.7 & -0.63 & 0.77 \\
\hline 01127500 & 231 & 124 & 4.9 & -0.12 & 0.99 \\
\hline 01135500 & 1125 & 441 & 11.8 & -0.94 & 0.33 \\
\hline 01139000 & 246 & 416 & 11.2 & 0.51 & 0.86 \\
\hline 01141500 & 338 & 386 & 14.6 & -0.32 & 0.95 \\
\hline 01142500 & 82 & 415 & 14.9 & -0.64 & 0.77 \\
\hline 01151500 & 576 & 458 & 18.2 & 0.26 & 0.97 \\
\hline 01152500 & 700 & 382 & 10.0 & -0.52 & -0.86 \\
\hline 01153000 & 412 & 460 & 14.5 & -0.06 & 1.00 \\
\hline 01161000 & 1090 & 333 & 9.8 & -0.77 & -0.64 \\
\hline 01162500 & 50 & 333 & 4.9 & -0.78 & 0.63 \\
\hline 01168500 & 939 & 594 & 13.8 & -0.48 & 0.88 \\
\hline 01173500 & 510 & 270 & 6.0 & -0.87 & -0.50 \\
\hline
\end{tabular}


Table A-2, continued

\begin{tabular}{|c|c|c|c|c|c|}
\hline \multirow{2}{*}{$\begin{array}{c}\text { Site } \\
\text { Number }\end{array}$} & \multirow{2}{*}{$\begin{array}{c}\text { Drainage } \\
\text { Area }\left[\mathbf{k m}^{2}\right]\end{array}$} & \multirow{2}{*}{$\begin{array}{c}\text { Mean } \\
\text { Elevation [m] }\end{array}$} & \multirow{2}{*}{$\begin{array}{c}\text { Mean } \\
\text { Slope [\%] }\end{array}$} & \multicolumn{2}{|c|}{ Orientation } \\
\hline & & & & North/South & East/West \\
\hline 01174500 & 113 & 283 & 6.5 & -0.76 & -0.64 \\
\hline 01185500 & 237 & 450 & 7.7 & -0.79 & 0.62 \\
\hline 01189000 & 116 & 194 & 6.1 & -0.37 & 0.93 \\
\hline 01192500 & 191 & 136 & 5.1 & -0.12 & -0.99 \\
\hline 01193500 & 271 & 147 & 6.0 & -1.00 & 0.05 \\
\hline 01196500 & 286 & 92 & 5.3 & -0.43 & 0.90 \\
\hline 01208500 & 674 & 238 & 8.0 & -0.89 & 0.46 \\
\hline 03014500 & 499 & 454 & 3.9 & 0.08 & -1.00 \\
\hline 03024000 & 2763 & 418 & 4.0 & 0.14 & -0.99 \\
\hline 03028500 & 527 & 591 & 9.9 & -0.94 & -0.34 \\
\hline 03038000 & 494 & 387 & 11.6 & -0.93 & -0.36 \\
\hline 03040000 & 1171 & 658 & 8.7 & 0.02 & -1.00 \\
\hline 03041000 & 481 & 632 & 9.8 & 0.21 & -0.98 \\
\hline 03045000 & 444 & 525 & 12.6 & 0.46 & -0.89 \\
\hline 03072000 & 588 & 371 & 18.1 & -0.71 & 0.70 \\
\hline 03076500 & 762 & 783 & 9.3 & 0.15 & -0.99 \\
\hline 03086500 & 232 & 359 & 2.6 & 0.79 & -0.62 \\
\hline 03093000 & 252 & 319 & 1.8 & 0.00 & 1.00 \\
\hline 03106500 & 1043 & 398 & 5.5 & -0.89 & -0.45 \\
\hline 03110000 & 381 & 349 & 10.6 & -0.69 & 0.73 \\
\hline 03111500 & 319 & 343 & 8.9 & -0.90 & 0.44 \\
\hline 03117500 & 656 & 354 & 6.1 & -1.00 & -0.07 \\
\hline 03118000 & 116 & 350 & 1.6 & 0.16 & -0.99 \\
\hline 03131500 & 904 & 355 & 2.8 & 1.00 & -0.02 \\
\hline 03133500 & 515 & 390 & 4.7 & 0.25 & 0.97 \\
\hline 03135000 & 690 & 339 & 2.2 & 0.48 & 0.88 \\
\hline 03140000 & 70 & 307 & 8.2 & -0.85 & -0.53 \\
\hline 03141500 & 306 & 320 & 11.8 & -1.00 & 0.05 \\
\hline 03147500 & 1925 & 313 & 3.7 & -0.48 & 0.88 \\
\hline 03157000 & 229 & 299 & 5.7 & 0.62 & 0.78 \\
\hline 03165000 & 102 & 810 & 9.6 & -0.49 & -0.87 \\
\hline 03208500 & 741 & 615 & 25.9 & 0.59 & -0.81 \\
\hline 03209000 & 572 & 603 & 21.5 & -0.56 & 0.83 \\
\hline 03216500 & 1037 & 272 & 11.7 & -0.74 & 0.68 \\
\hline 03227500 & 4205 & 302 & 0.6 & 0.80 & 0.60 \\
\hline 03228500 & 491 & 328 & 1.1 & -0.31 & -0.95 \\
\hline 03232500 & 363 & 307 & 3.5 & -0.14 & 0.99 \\
\hline 03238500 & 569 & 300 & 1.3 & -0.68 & -0.73 \\
\hline 03245500 & 3115 & 288 & 1.7 & -0.17 & -0.99 \\
\hline 03253500 & 8546 & 277 & 8.7 & -0.77 & 0.64 \\
\hline 03262000 & 667 & 299 & 0.5 & 0.61 & -0.79 \\
\hline 03264000 & 500 & 330 & 0.7 & 0.70 & 0.72 \\
\hline
\end{tabular}


Table A-2, continued

\begin{tabular}{|c|c|c|c|c|c|}
\hline \multirow{2}{*}{$\begin{array}{c}\text { Site } \\
\text { Number }\end{array}$} & \multirow{2}{*}{$\begin{array}{c}\text { Drainage } \\
\text { Area }\left[\mathrm{km}^{2}\right]\end{array}$} & \multirow{2}{*}{$\begin{array}{c}\text { Mean } \\
\text { Elevation [m] }\end{array}$} & \multirow{2}{*}{$\begin{array}{c}\text { Mean } \\
\text { Slope }[\%]\end{array}$} & \multicolumn{2}{|c|}{ Orientation } \\
\hline & & & & North/South & East/West \\
\hline 03267000 & 421 & 358 & 2.2 & -0.88 & -0.48 \\
\hline 03272000 & 721 & 308 & 1.0 & -0.19 & 0.98 \\
\hline 03276500 & 3173 & 308 & 2.5 & -1.00 & -0.04 \\
\hline 03280000 & 2851 & 413 & 25.4 & 0.07 & -1.00 \\
\hline 03281000 & 1393 & 427 & 27.2 & 0.89 & -0.46 \\
\hline 03283500 & 938 & 318 & 14.7 & -0.96 & 0.26 \\
\hline 03285000 & 822 & 315 & 6.0 & -0.19 & 0.98 \\
\hline 03293000 & 49 & 185 & 1.2 & -0.04 & -1.00 \\
\hline 03302000 & 167 & 161 & 2.5 & 0.17 & -0.99 \\
\hline 03320000 & 19591 & 214 & 5.3 & -0.22 & -0.98 \\
\hline 03325000 & 4697 & 262 & 0.5 & 1.00 & 0.00 \\
\hline 03326500 & 1770 & 286 & 0.7 & 0.83 & -0.55 \\
\hline 03328000 & 1086 & 262 & 1.0 & -0.97 & 0.25 \\
\hline 03329700 & 714 & 233 & 0.3 & 0.54 & -0.84 \\
\hline 03347000 & 627 & 327 & 0.9 & 0.80 & -0.60 \\
\hline 03352500 & 772 & 272 & 0.8 & 0.32 & -0.95 \\
\hline 03353500 & 451 & 284 & 0.7 & -0.76 & 0.66 \\
\hline 03360000 & 2151 & 288 & 2.0 & -0.85 & -0.52 \\
\hline 03361500 & 1088 & 296 & 1.1 & -0.64 & -0.77 \\
\hline 03362000 & 260 & 236 & 0.6 & -0.32 & 0.95 \\
\hline 03363500 & 772 & 310 & 1.1 & -0.29 & -0.96 \\
\hline 03369500 & 512 & 261 & 2.0 & -0.42 & -0.91 \\
\hline 03376500 & 2130 & 167 & 4.2 & -0.43 & -0.90 \\
\hline 03378000 & 591 & 145 & 1.4 & -1.00 & 0.10 \\
\hline 03381500 & 8033 & 149 & 0.9 & -0.88 & 0.48 \\
\hline 03401000 & 967 & 680 & 30.8 & 0.04 & -1.00 \\
\hline 03406500 & 1564 & 361 & 12.6 & -0.98 & 0.19 \\
\hline 03414500 & 522 & 503 & 10.9 & 0.86 & 0.51 \\
\hline 03421000 & 1664 & 424 & 6.8 & 0.54 & 0.84 \\
\hline 03433500 & 1056 & 236 & 6.0 & -0.90 & -0.43 \\
\hline 04024000 & 8841 & 434 & 1.0 & -0.81 & -0.59 \\
\hline 04034500 & 503 & 501 & 2.9 & 0.97 & -0.24 \\
\hline 04036000 & 419 & 440 & 2.0 & 0.96 & 0.27 \\
\hline 04037500 & 132 & 525 & 2.3 & -0.17 & -0.99 \\
\hline 04041500 & 870 & 453 & 2.7 & 0.71 & -0.70 \\
\hline 04060993 & 976 & 479 & 3.3 & -0.71 & 0.70 \\
\hline 04062500 & 1673 & 490 & 2.5 & -0.95 & 0.32 \\
\hline 04087000 & 1805 & 281 & 2.1 & -0.37 & 0.93 \\
\hline 04099000 & 4883 & 285 & 0.9 & -0.12 & -0.99 \\
\hline 04099510 & 273 & 309 & 1.2 & -0.94 & -0.35 \\
\hline 04105500 & 2132 & 294 & 1.3 & 0.46 & -0.89 \\
\hline 04109000 & 427 & 304 & 1.3 & 0.97 & 0.25 \\
\hline
\end{tabular}


Table A-2, continued

\begin{tabular}{|c|c|c|c|c|c|}
\hline \multirow{2}{*}{$\begin{array}{c}\text { Site } \\
\text { Number }\end{array}$} & \multirow{2}{*}{$\begin{array}{c}\text { Drainage } \\
\text { Area }\left[\mathrm{km}^{2}\right]\end{array}$} & \multirow{2}{*}{$\begin{array}{c}\text { Mean } \\
\text { Elevation }[\mathrm{m}]\end{array}$} & \multirow{2}{*}{$\begin{array}{c}\text { Mean } \\
\text { Slope }[\%]\end{array}$} & \multicolumn{2}{|c|}{ Orientation } \\
\hline & & & & North/South & East/West \\
\hline 04112500 & 891 & 277 & 0.7 & 0.86 & -0.52 \\
\hline 04115000 & 1088 & 225 & 0.5 & 0.39 & 0.92 \\
\hline 04117500 & 1101 & 276 & 1.5 & 0.87 & 0.50 \\
\hline 04122500 & 1769 & 271 & 2.4 & -0.43 & -0.91 \\
\hline 04124000 & 2244 & 355 & 2.2 & -0.50 & -0.87 \\
\hline 04127997 & 487 & 333 & 4.1 & 0.75 & 0.66 \\
\hline 04146000 & 131 & 291 & 1.9 & 0.91 & -0.41 \\
\hline 04151500 & 2165 & 232 & 0.6 & 0.56 & -0.83 \\
\hline 04154000 & 1038 & 295 & 1.3 & -0.25 & 0.97 \\
\hline 04155000 & 810 & 264 & 1.0 & -0.31 & 0.95 \\
\hline 04159492 & 1198 & 235 & 0.3 & 0.12 & 0.99 \\
\hline 04165500 & 1893 & 248 & 1.0 & -0.60 & 0.80 \\
\hline 04166500 & 476 & 234 & 1.2 & -0.72 & 0.69 \\
\hline 04176500 & 2686 & 251 & 1.1 & -0.34 & 0.94 \\
\hline 04185000 & 1064 & 262 & 0.9 & -0.69 & 0.73 \\
\hline 04186500 & 858 & 271 & 0.5 & 0.76 & -0.65 \\
\hline 04195500 & 1080 & 219 & 0.1 & 0.96 & -0.28 \\
\hline 04200500 & 1027 & 275 & 0.8 & 0.98 & -0.20 \\
\hline 04202000 & 390 & 363 & 2.0 & -0.95 & -0.30 \\
\hline 04231000 & 341 & 225 & 1.2 & 0.88 & 0.47 \\
\hline 04252500 & 784 & 499 & 5.2 & -0.45 & -0.89 \\
\hline 04258000 & 755 & 519 & 6.3 & -0.01 & -1.00 \\
\hline 04263000 & 2549 & 319 & 4.8 & 0.43 & -0.90 \\
\hline 04266500 & 1878 & 599 & 10.4 & 0.37 & -0.93 \\
\hline 04296500 & 375 & 453 & 8.9 & -0.04 & -1.00 \\
\hline
\end{tabular}

Table A-3: Land-use/land-cover composition and other indicators of human disturbance in each of the 143 moderately impaired watersheds.

\begin{tabular}{|c|c|c|c|c|c|c|}
\hline \multirow{2}{*}{$\begin{array}{c}\text { Site } \\
\text { Number }\end{array}$} & \multicolumn{3}{|c|}{ Percentages of areas } & \multirow{2}{*}{$\begin{array}{c}\text { Hydrologic } \\
\text { Disturbance }\end{array}$} & \multicolumn{2}{|c|}{ Number of } \\
\cline { 7 - 8 } & Urban & Forested & Agricultural & $\begin{array}{c}\text { Andex } \\
\text { Index }\end{array}$ & $\begin{array}{c}\text { Major } \\
\text { dams }\end{array}$ \\
\hline 01017000 & 0.5 & 73.9 & 1.7 & 5 & 4 & 2 \\
01019000 & 0.3 & 67.6 & 0.1 & 15 & 2 & 2 \\
01034500 & 1.2 & 71.4 & 1.0 & 13 & 65 & 23 \\
01042500 & 0.7 & 62.6 & 0.0 & 11 & 11 & 8 \\
01049000 & 5.4 & 66.8 & 7.8 & 17 & 18 & 4 \\
01053500 & 0.9 & 79.7 & 0.0 & 10 & 15 & 6 \\
01066000 & 4.1 & 82.2 & 2.1 & 10 & 43 & 6 \\
01073000 & 11.5 & 66.5 & 6.1 & 10 & 0 & 0 \\
01081000 & 7.7 & 62.6 & 2.8 & 26 & 31 & 6
\end{tabular}


Table A-3, continued

\begin{tabular}{|c|c|c|c|c|c|c|}
\hline \multirow{2}{*}{$\begin{array}{c}\text { Site } \\
\text { Number }\end{array}$} & \multicolumn{3}{|c|}{ Percentages of areas } & \multirow{2}{*}{$\begin{array}{c}\text { Hydrologic } \\
\text { Disturbance } \\
\text { Index }\end{array}$} & \multicolumn{2}{|c|}{ Number of } \\
\hline & Urban & Forested & Agricultural & & Dams & $\begin{array}{c}\text { Major } \\
\text { dams }\end{array}$ \\
\hline 01087000 & 3.7 & 86.1 & 2.8 & 17 & 9 & 1 \\
\hline 01094500 & 26.8 & 59.3 & 5.1 & 23 & 46 & 1 \\
\hline 01101500 & 54.7 & 25.1 & 1.0 & 26 & 10 & 1 \\
\hline 01103500 & 37.0 & 41.2 & 5.1 & 23 & 29 & 0 \\
\hline 01105000 & 46.7 & 35.2 & 2.5 & 21 & 11 & 0 \\
\hline 01109000 & 30.7 & 46.0 & 3.6 & 20 & 16 & 0 \\
\hline 01110000 & 60.3 & 26.7 & 1.3 & 18 & 7 & 0 \\
\hline 01114500 & 30.8 & 53.1 & 4.4 & 21 & 14 & 0 \\
\hline 01116000 & 15.5 & 65.1 & 2.7 & 16 & 8 & 1 \\
\hline 01117000 & 40.8 & 46.9 & 1.0 & 17 & 1 & 0 \\
\hline 01118000 & 8.7 & 70.8 & 4.4 & 11 & 16 & 0 \\
\hline 01119500 & 10.7 & 71.5 & 5.0 & 22 & 32 & 2 \\
\hline 01124000 & 12.0 & 69.0 & 5.4 & 29 & 43 & 5 \\
\hline 01127500 & 8.2 & 62.9 & 15.4 & 15 & 11 & 1 \\
\hline 01135500 & 5.8 & 80.2 & 8.5 & 12 & 12 & 0 \\
\hline 01139000 & 3.9 & 83.2 & 6.1 & 14 & 3 & 1 \\
\hline 01141500 & 3.4 & 86.9 & 6.3 & 12 & 10 & 1 \\
\hline 01142500 & 6.2 & 72.8 & 17.2 & 8 & 0 & 0 \\
\hline 01151500 & 4.9 & 84.1 & 8.2 & 16 & 22 & 1 \\
\hline 01152500 & 7.0 & 78.3 & 5.2 & 20 & 26 & 4 \\
\hline 01153000 & 4.9 & 83.2 & 7.3 & 23 & 18 & 8 \\
\hline 01161000 & 6.3 & 83.0 & 3.2 & 16 & 48 & 3 \\
\hline 01162500 & 4.4 & 78.5 & 2.3 & 8 & 2 & 0 \\
\hline 01168500 & 3.6 & 87.3 & 2.9 & 20 & 24 & 6 \\
\hline 01173500 & 7.2 & 69.1 & 8.3 & 31 & 49 & 2 \\
\hline 01174500 & 4.6 & 79.5 & 4.3 & 11 & 4 & 0 \\
\hline 01185500 & 5.8 & 80.5 & 1.6 & 20 & 20 & 3 \\
\hline 01189000 & 38.9 & 50.2 & 5.2 & 27 & 14 & 2 \\
\hline 01192500 & 44.7 & 40.8 & 6.9 & 26 & 17 & 2 \\
\hline 01193500 & 11.4 & 64.3 & 6.8 & 13 & 7 & 0 \\
\hline 01196500 & 56.0 & 36.0 & 1.6 & 22 & 18 & 0 \\
\hline 01208500 & 26.5 & 59.8 & 7.6 & 31 & 66 & 14 \\
\hline 03014500 & 9.9 & 48.4 & 21.5 & 31 & 3 & 1 \\
\hline 03024000 & 7.4 & 48.9 & 35.3 & 20 & 27 & 6 \\
\hline 03028500 & 2.5 & 79.9 & 5.2 & 15 & 2 & 1 \\
\hline 03038000 & 8.3 & 67.7 & 22.6 & 28 & 3 & 1 \\
\hline 03040000 & 7.6 & 64.7 & 23.9 & 23 & 12 & 7 \\
\hline 03041000 & 9.9 & 73.2 & 14.0 & 22 & 12 & 5 \\
\hline
\end{tabular}


Table A-3, continued

\begin{tabular}{|c|c|c|c|c|c|c|}
\hline \multirow{2}{*}{$\begin{array}{c}\text { Site } \\
\text { Number }\end{array}$} & \multicolumn{3}{|c|}{ Percentages of areas } & \multirow{2}{*}{$\begin{array}{l}\text { Hydrologic } \\
\text { Disturbance } \\
\text { Index }\end{array}$} & \multicolumn{2}{|c|}{ Number of } \\
\hline & Urban & Forested & Agricultural & & Dams & $\begin{array}{l}\text { Major } \\
\text { dams }\end{array}$ \\
\hline 03045000 & 8.3 & 78.3 & 12.8 & 17 & 8 & 1 \\
\hline 03072000 & 6.5 & 81.8 & 10.4 & 21 & 9 & 5 \\
\hline 03076500 & 8.2 & 68.3 & 18.1 & 17 & 14 & 2 \\
\hline 03086500 & 17.3 & 23.3 & 55.3 & 14 & 6 & 0 \\
\hline 03093000 & 8.7 & 48.2 & 32.4 & 11 & 2 & 0 \\
\hline 03106500 & 9.4 & 57.8 & 27.8 & 22 & 5 & 2 \\
\hline 03110000 & 5.9 & 71.6 & 19.9 & 16 & 5 & 0 \\
\hline 03111500 & 10.0 & 53.8 & 29.9 & 26 & 28 & 5 \\
\hline 03117500 & 8.4 & 39.1 & 48.8 & 19 & 24 & 2 \\
\hline 03118000 & 31.3 & 11.8 & 53.1 & 20 & 0 & 0 \\
\hline 03131500 & 15.9 & 29.8 & 51.7 & 20 & 6 & 1 \\
\hline 03133500 & 9.5 & 46.2 & 41.4 & 16 & 9 & 2 \\
\hline 03135000 & 10.2 & 24.7 & 62.6 & 22 & 12 & 1 \\
\hline 03140000 & 5.3 & 40.9 & 52.6 & 13 & 0 & 0 \\
\hline 03141500 & 6.5 & 69.5 & 17.8 & 16 & 4 & 2 \\
\hline 03147500 & 10.7 & 34.3 & 52.3 & 21 & 21 & 2 \\
\hline 03157000 & 6.0 & 37.9 & 55.2 & 17 & 6 & 2 \\
\hline 03165000 & 8.0 & 48.9 & 40.9 & 10 & 0 & 0 \\
\hline 03208500 & 7.3 & 82.0 & 4.7 & 8 & 0 & 0 \\
\hline 03209000 & 6.0 & 72.4 & 6.6 & 20 & 11 & 5 \\
\hline 03216500 & 6.0 & 76.4 & 11.0 & 14 & 4 & 1 \\
\hline 03227500 & 17.5 & 9.5 & 71.1 & 24 & 46 & 6 \\
\hline 03228500 & 9.2 & 25.1 & 61.6 & 20 & 4 & 1 \\
\hline 03232500 & 7.8 & 35.9 & 50.4 & 21 & 5 & 1 \\
\hline 03238500 & 6.8 & 23.7 & 68.6 & 14 & 5 & 0 \\
\hline 03245500 & 19.8 & 19.5 & 58.5 & 28 & 71 & 6 \\
\hline 03253500 & 6.1 & 49.0 & 40.4 & 17 & 49 & 4 \\
\hline 03262000 & 8.6 & 7.7 & 80.7 & 20 & 5 & 2 \\
\hline 03264000 & 9.8 & 6.8 & 81.4 & 22 & 1 & 0 \\
\hline 03267000 & 6.5 & 15.8 & 76.1 & 15 & 6 & 0 \\
\hline 03272000 & 7.3 & 10.0 & 80.8 & 18 & 3 & 1 \\
\hline 03276500 & 8.4 & 27.1 & 61.6 & 22 & 24 & 4 \\
\hline 03280000 & 6.9 & 74.8 & 0.6 & 18 & 40 & 25 \\
\hline 03281000 & 5.2 & 85.1 & 1.1 & 15 & 13 & 9 \\
\hline 03283500 & 6.8 & 76.3 & 11.2 & 13 & 8 & 3 \\
\hline 03285000 & 5.7 & 41.4 & 50.1 & 15 & 6 & 0 \\
\hline 03293000 & 77.8 & 18.2 & 3.2 & 22 & 1 & 0 \\
\hline 03302000 & 69.3 & 27.9 & 1.1 & 27 & 7 & 0 \\
\hline
\end{tabular}


Table A-3, continued

\begin{tabular}{|c|c|c|c|c|c|c|}
\hline \multirow{2}{*}{$\begin{array}{c}\text { Site } \\
\text { Number }\end{array}$} & \multicolumn{3}{|c|}{ Percentages of areas } & \multirow{2}{*}{$\begin{array}{l}\text { Hydrologic } \\
\text { Disturbance } \\
\text { Index }\end{array}$} & \multicolumn{2}{|c|}{ Number of } \\
\hline & Urban & Forested & Agricultural & & Dams & $\begin{array}{l}\text { Major } \\
\text { dams }\end{array}$ \\
\hline 03320000 & 5.9 & 47.6 & 41.4 & 21 & 146 & 25 \\
\hline 03325000 & 9.6 & 8.1 & 78.6 & 25 & 31 & 4 \\
\hline 03326500 & 9.8 & 7.4 & 80.8 & 22 & 14 & 0 \\
\hline 03328000 & 8.2 & 9.9 & 79.3 & 25 & 5 & 0 \\
\hline 03329700 & 6.7 & 3.7 & 88.0 & 20 & 0 & 0 \\
\hline 03347000 & 10.8 & 7.7 & 79.1 & 20 & 2 & 1 \\
\hline 03352500 & 25.3 & 7.0 & 63.9 & 21 & 2 & 1 \\
\hline 03353500 & 23.0 & 7.8 & 65.1 & 33 & 9 & 1 \\
\hline 03360000 & 5.8 & 29.0 & 62.7 & 25 & 40 & 4 \\
\hline 03361500 & 9.6 & 8.2 & 79.7 & 23 & 16 & 4 \\
\hline 03362000 & 22.5 & 5.3 & 71.4 & 25 & 4 & 0 \\
\hline 03363500 & 6.7 & 7.2 & 85.3 & 19 & 1 & 0 \\
\hline 03369500 & 4.9 & 44.6 & 48.5 & 22 & 6 & 4 \\
\hline 03376500 & 6.4 & 45.2 & 42.1 & 24 & 45 & 1 \\
\hline 03378000 & 6.2 & 16.1 & 76.7 & 11 & 6 & 0 \\
\hline 03381500 & 7.8 & 17.1 & 72.9 & 22 & 58 & 5 \\
\hline 03401000 & 7.3 & 85.1 & 0.3 & 15 & 16 & 11 \\
\hline 03406500 & 7.8 & 64.3 & 17.0 & 15 & 11 & 4 \\
\hline 03414500 & 5.2 & 75.3 & 10.2 & 14 & 10 & 0 \\
\hline 03421000 & 5.7 & 49.4 & 35.0 & 15 & 15 & 0 \\
\hline 03433500 & 15.7 & 41.9 & 38.2 & 17 & 20 & 1 \\
\hline 04024000 & 2.8 & 34.7 & 2.9 & 18 & 44 & 16 \\
\hline 04034500 & 3.2 & 65.2 & 0.3 & 9 & 2 & 1 \\
\hline 04036000 & 2.6 & 60.2 & 0.0 & 9 & 1 & 1 \\
\hline 04037500 & 3.7 & 48.4 & 0.2 & 13 & 1 & 1 \\
\hline 04041500 & 2.3 & 64.0 & 1.4 & 8 & 3 & 2 \\
\hline 04060993 & 4.1 & 60.7 & 5.2 & 9 & 2 & 0 \\
\hline 04062500 & 2.5 & 59.5 & 0.2 & 12 & 10 & 3 \\
\hline 04087000 & 17.5 & 14.0 & 51.4 & 19 & 21 & 0 \\
\hline 04099000 & 9.0 & 11.6 & 60.8 & 21 & 39 & 5 \\
\hline 04099510 & 10.2 & 5.1 & 64.5 & 23 & 3 & 0 \\
\hline 04105500 & 11.4 & 16.4 & 55.4 & 20 & 14 & 0 \\
\hline 04109000 & 22.8 & 16.6 & 35.0 & 25 & 8 & 1 \\
\hline 04112500 & 13.1 & 11.2 & 60.4 & 16 & 2 & 0 \\
\hline 04115000 & 6.5 & 7.9 & 74.3 & 20 & 9 & 2 \\
\hline 04117500 & 7.1 & 17.7 & 61.5 & 11 & 4 & 0 \\
\hline 04122500 & 5.0 & 61.4 & 9.3 & 9 & 6 & 0 \\
\hline 04124000 & 5.9 & 53.9 & 8.5 & 10 & 7 & 0 \\
\hline
\end{tabular}


Table A-3, continued

\begin{tabular}{|c|c|c|c|c|c|c|}
\hline \multirow{2}{*}{$\begin{array}{c}\text { Site } \\
\text { Number }\end{array}$} & \multicolumn{3}{|c|}{ Percentages of areas } & \multirow{2}{*}{$\begin{array}{c}\text { Hydrologic } \\
\text { Disturbance } \\
\text { Index }\end{array}$} & \multicolumn{2}{|c|}{ Number of } \\
\hline & Urban & Forested & Agricultural & & Dams & $\begin{array}{c}\text { Major } \\
\text { dams }\end{array}$ \\
\hline 04127997 & 7.2 & 61.3 & 6.3 & 11 & 6 & 0 \\
\hline 04146000 & 12.0 & 32.6 & 36.1 & 19 & 7 & 1 \\
\hline 04151500 & 6.9 & 19.8 & 57.1 & 20 & 4 & 0 \\
\hline 04154000 & 7.7 & 30.2 & 36.6 & 23 & 12 & 2 \\
\hline 04155000 & 6.5 & 17.7 & 55.4 & 16 & 4 & 0 \\
\hline 04159492 & 6.3 & 9.2 & 75.5 & 17 & 1 & 0 \\
\hline 04165500 & 51.3 & 15.0 & 20.3 & 26 & 30 & 1 \\
\hline 04166500 & 91.8 & 4.6 & 0.1 & 23 & 5 & 0 \\
\hline 04176500 & 10.9 & 11.1 & 67.3 & 27 & 22 & 3 \\
\hline 04185000 & 7.3 & 8.9 & 75.3 & 11 & 6 & 0 \\
\hline 04186500 & 9.6 & 6.7 & 81.5 & 22 & 1 & 0 \\
\hline 04195500 & 9.1 & 4.5 & 84.9 & 26 & 11 & 0 \\
\hline 04200500 & 11.7 & 22.9 & 56.7 & 21 & 27 & 0 \\
\hline 04202000 & 11.3 & 44.8 & 30.7 & 21 & 8 & 2 \\
\hline 04231000 & 8.6 & 10.2 & 64.8 & 13 & 4 & 0 \\
\hline 04252500 & 0.3 & 66.9 & 1.3 & 10 & 15 & 3 \\
\hline 04258000 & 0.2 & 62.9 & 2.4 & 9 & 13 & 4 \\
\hline 04263000 & 1.6 & 69.3 & 9.7 & 15 & 27 & 8 \\
\hline 04266500 & 1.1 & 73.1 & 0.1 & 14 & 12 & 3 \\
\hline 04296500 & 5.3 & 69.6 & 10.2 & 10 & 5 & 1 \\
\hline
\end{tabular}

\section{A2: Frequency distribution of watershed characteristics}

Histograms presented below describe the frequency of several hydrologic/physical variables within each of the five land-use/land-cover clusters identified in Section 2.5. The variables considered are mean annual maximum flood, drainage area, mean watershed elevation and mean watershed slope. 


\section{Mean annual maximum flood (AMF) frequency distributions}

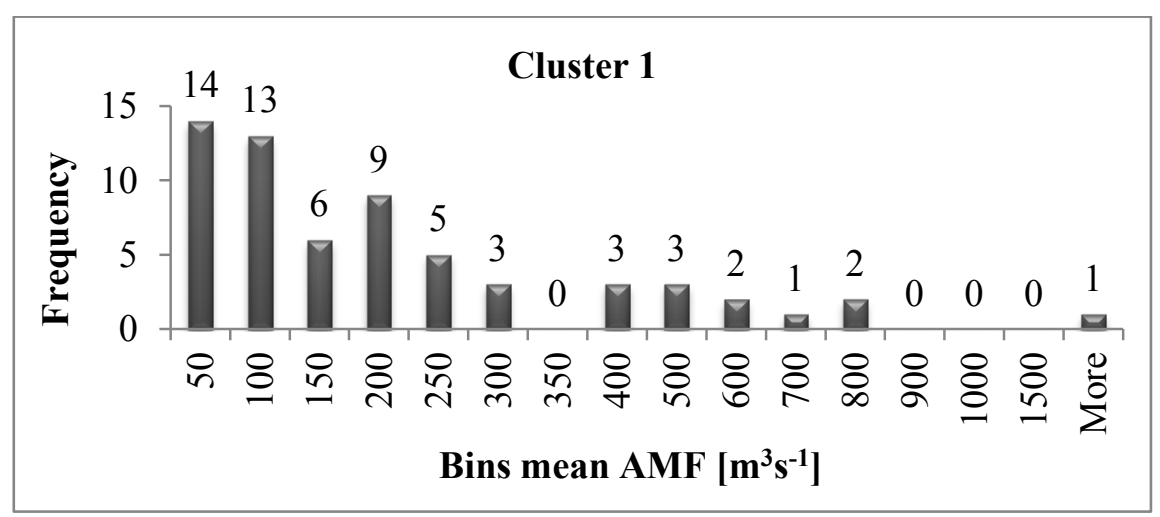

Figure A2-1: Mean AMF magnitude frequency distribution for watersheds in Cluster 1.

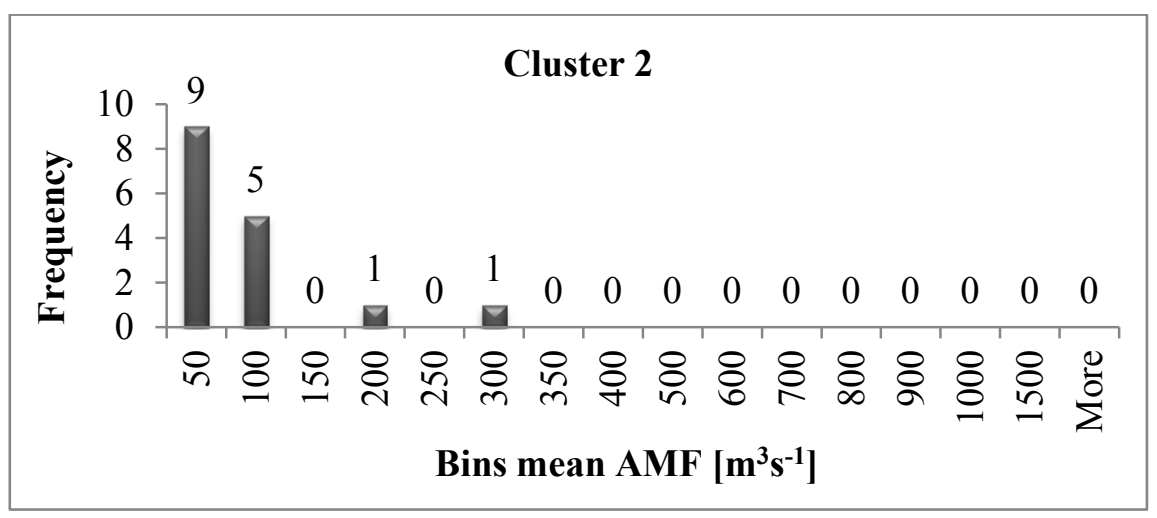

Figure A2-2: Mean AMF magnitude frequency distribution for watersheds in Cluster 2.

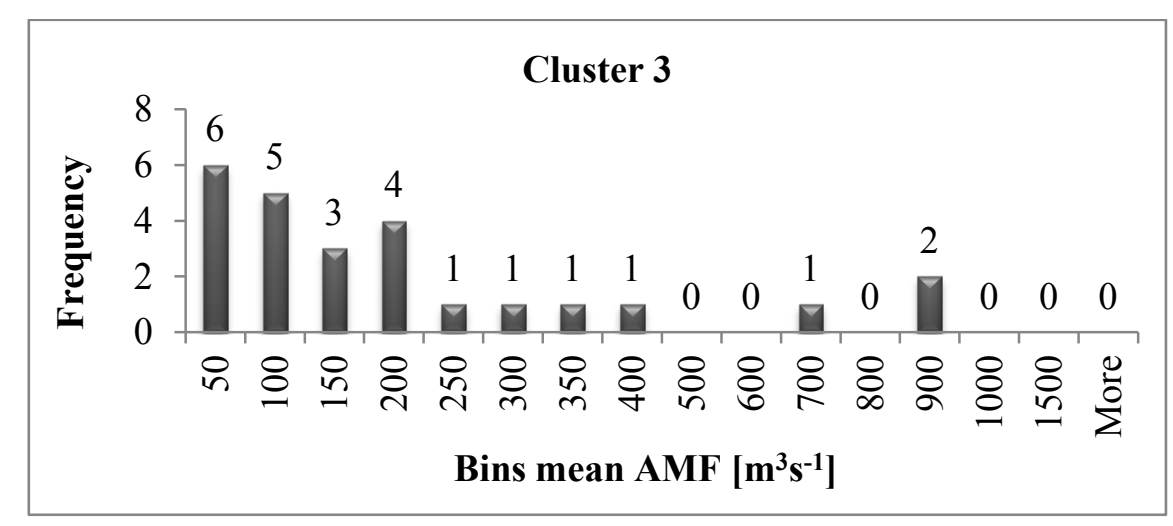

Figure A2-3: Mean AMF magnitude frequency distribution for watersheds in Cluster 3. 


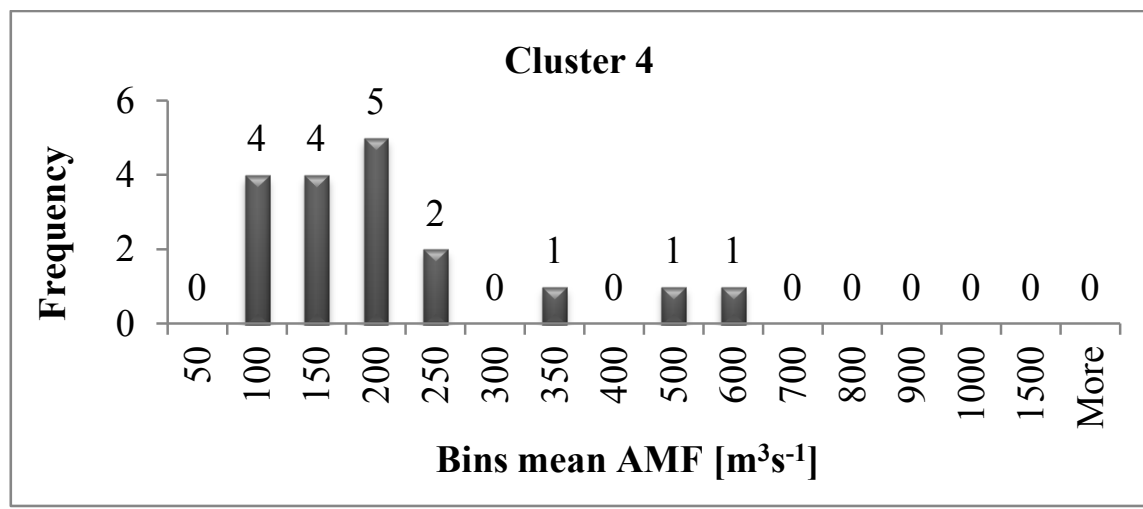

Figure A2-4: Mean AMF magnitude frequency distribution for watersheds in Cluster 4.

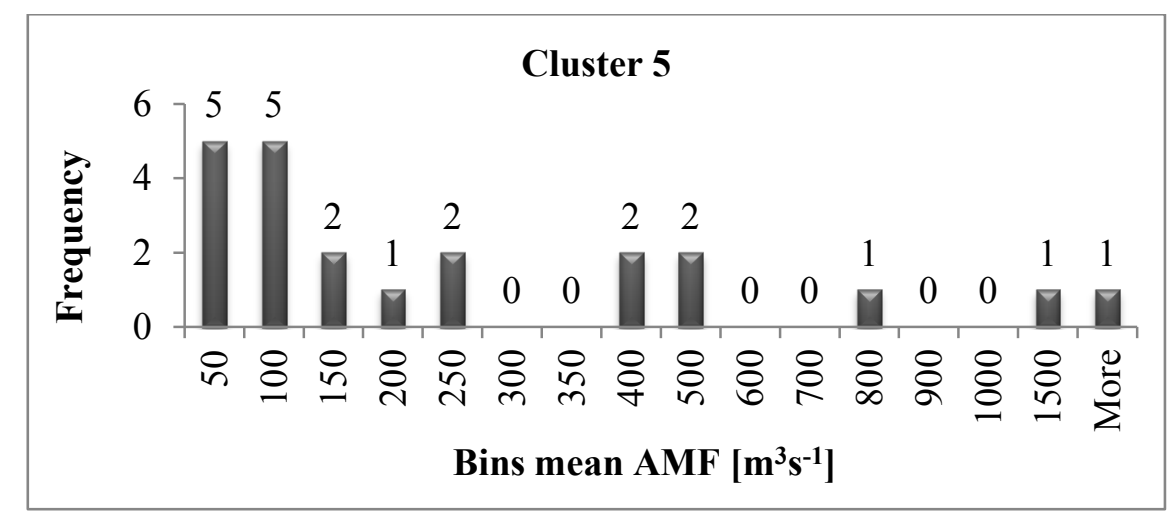

Figure A2-5: Mean AMF magnitude frequency distribution for watersheds in Cluster 5. 


\section{Drainage area frequency distributions}

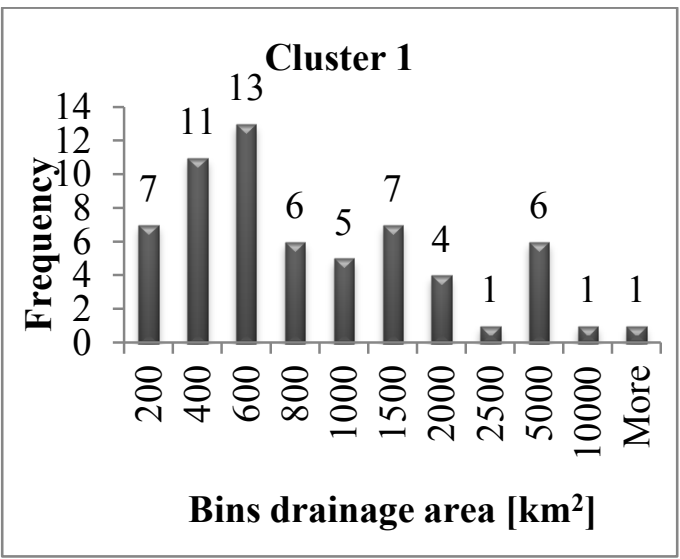

Figure A2-6: Drainage area frequency distribution for watersheds in Cluster 1 .

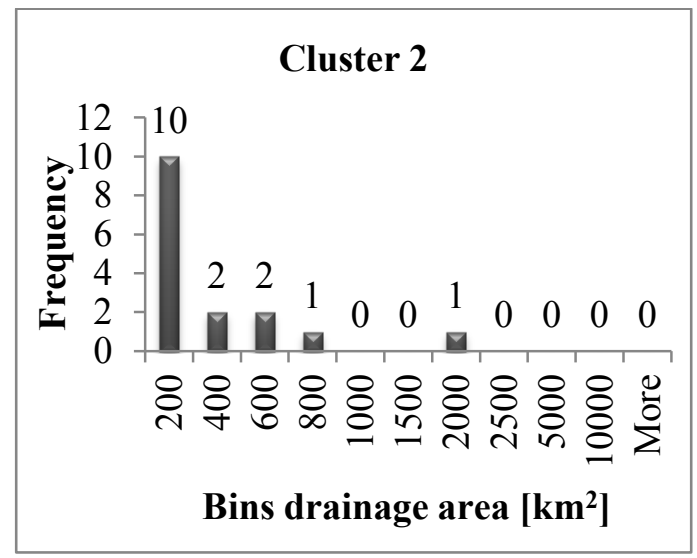

Figure A2-7: Drainage area frequency distribution for watersheds in Cluster 2.

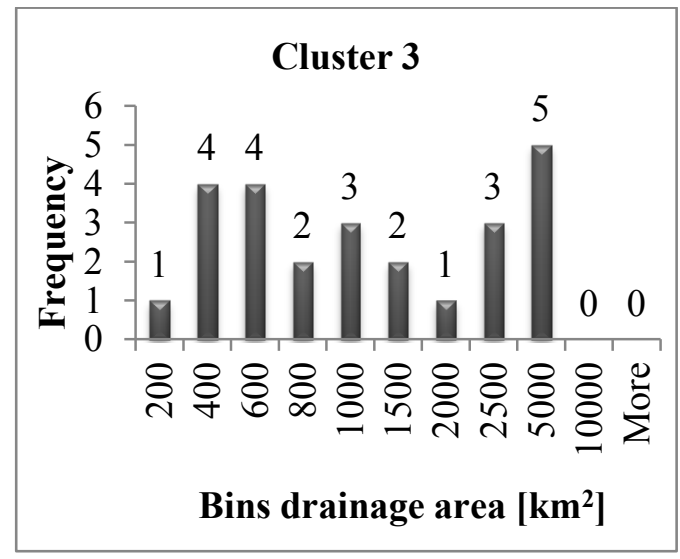

Figure A2-8: Drainage area frequency distribution for watersheds in Cluster 3.

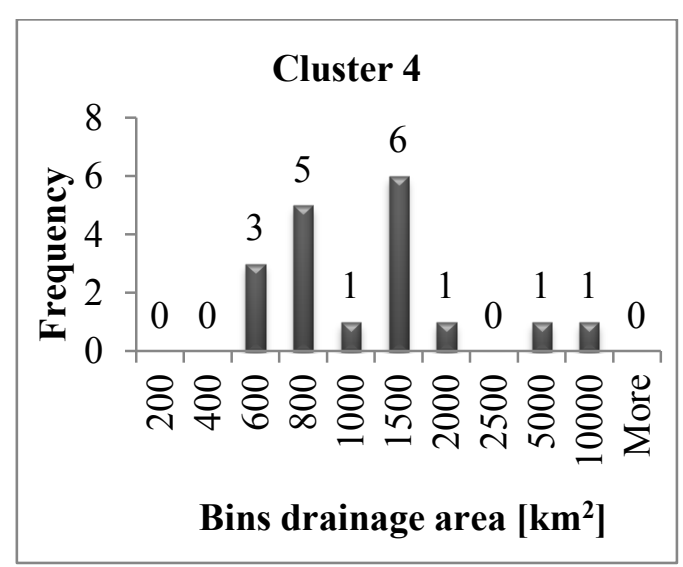

Figure A2-9: Drainage area frequency distribution for watersheds in Cluster 4.

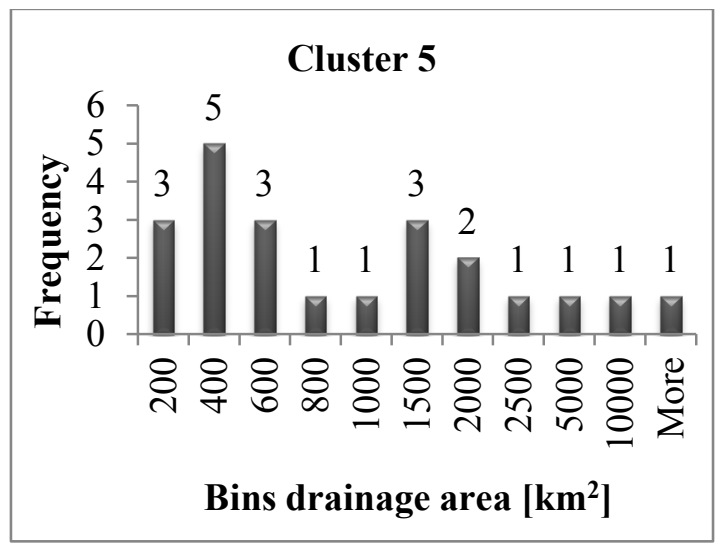

Figure A2-10: Drainage area frequency distribution for watersheds in Cluster 5. 


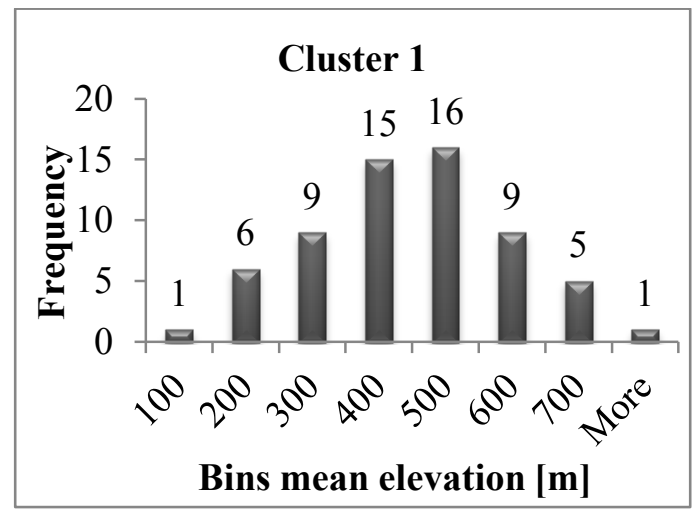

Figure A2-11: Mean elevation frequency distribution for watersheds in Cluster 1.

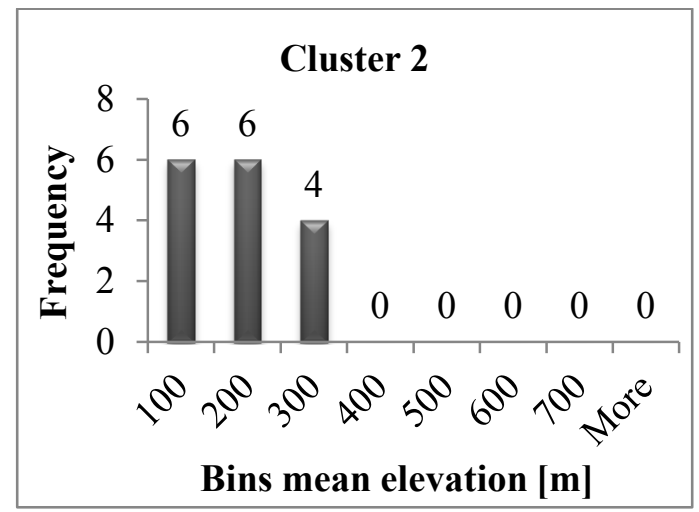

Figure A2-12: Mean elevation frequency distribution for watersheds in Cluster 2.

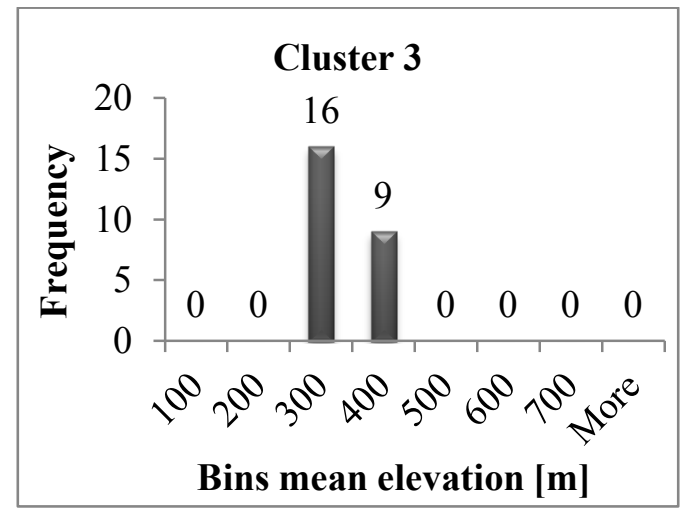

Figure A2-13: Mean elevation frequency distribution for watersheds in Cluster 3.

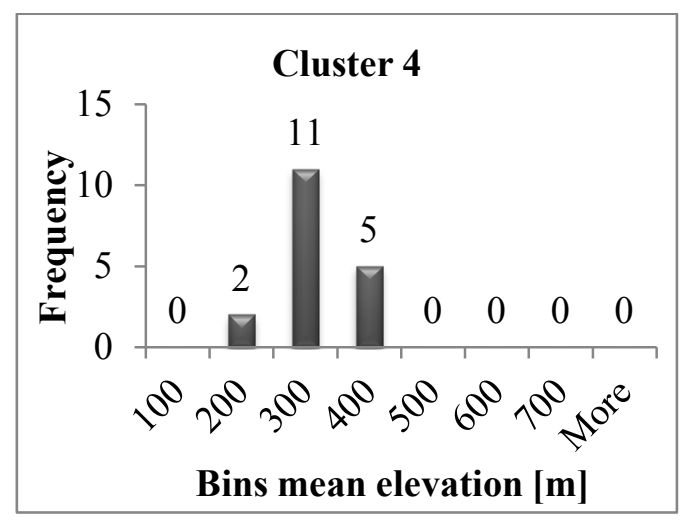

Figure A2-14: Mean elevation frequency distribution for watersheds in Cluster 4.

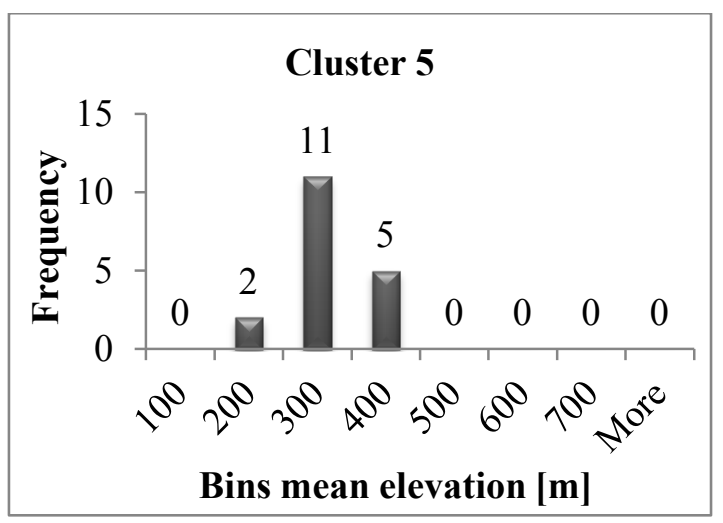

Figure A2-15: Mean elevation frequency distribution for watersheds in Cluster 5. 
Mean watershed slope frequency distributions

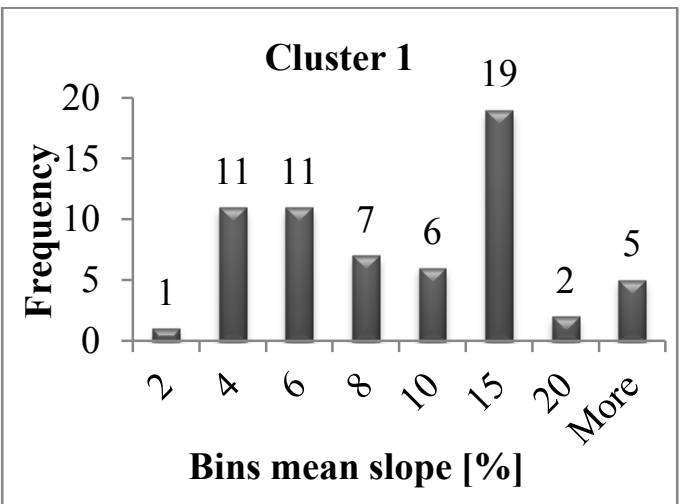

Figure A2-16: Mean slope frequency distribution for watersheds in Cluster 1 .

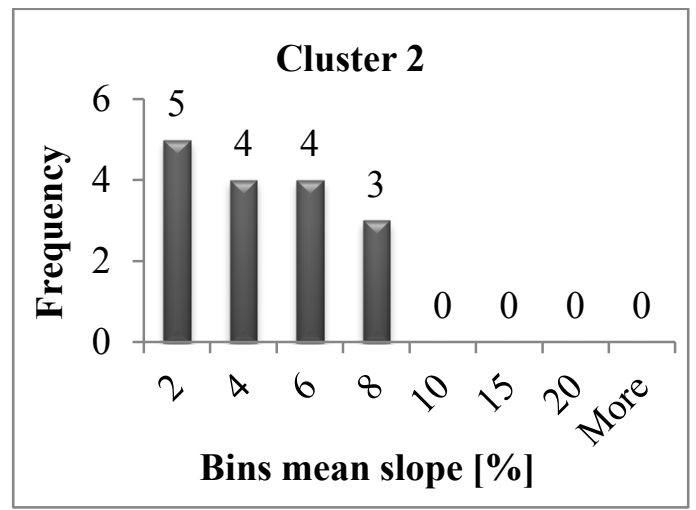

Figure A2-17: Mean slope frequency distribution for watersheds in Cluster 2.

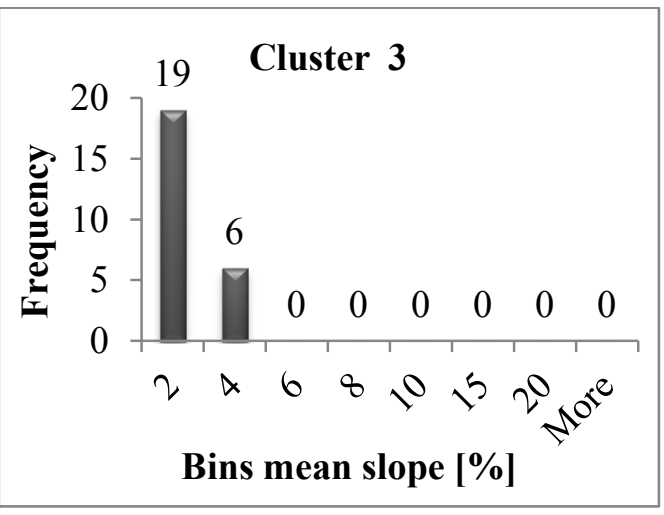

Figure A2-18: Mean slope frequency distribution for watersheds in Cluster 3.

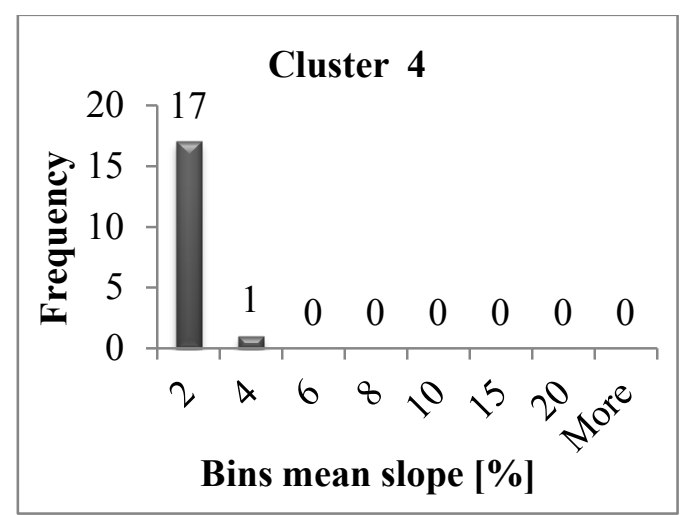

Figure A2-19: Mean slope frequency distribution for watersheds in Cluster 4.

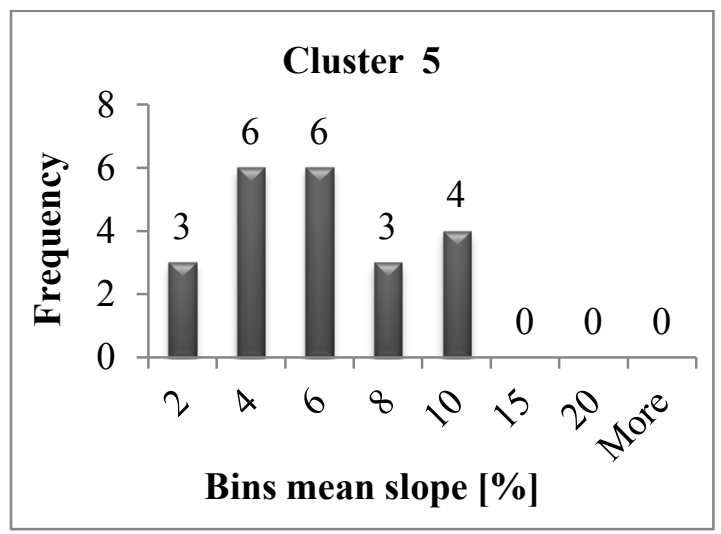

Figure A2-20: Mean slope frequency distribution for watersheds in Cluster 5. 


\section{Appendix B Non-stationarity in AMF series}

This appendix provides additional results of the analyses conducted in Chapter 3 to investigate non-stationarity in annual maximum flood (AMF) series for each of the 143 moderately impaired watersheds considered herein.

Table B-1 summarizes results of the Mann-Kendall trend tests (accounting for autocorrelation) and change-point Pettitt tests. Only the sites for which results were significant at the $10 \%$ level are reported in the table; results significant also at the $5 \%$ are in bold. Empty spaces imply results were not statistically significant.

Table B-2 provides a comparison between the results obtained by applying the Pettitt test for a single change-point detection (year of shift is reported if significant at the $10 \%$ level) and the multiple change-points (MCP) analysis. For MCP analysis, the likelihood that the specified number of change-points $(k)$ would occur is indicated by the corresponding posterior probability. Further, in the case change-points are observed, the years in which the shifts occur and the related posterior probabilities are included in the table as well. Sites for which both the Pettitt test and the Bayesian model did not identify any significant change-point(s) were omitted from this table.

Table B-1: Results of Mann-Kendall test and Pettitt test on AMF magnitude (significant at the 10\% and 5\% (bold) levels). Increasing (up) / decreasing (down) trends, year of change-point, positive $(+) /$ negative $(-)$ shifts are specified.

\begin{tabular}{|c|c|c|c|c|c|c|c|c|c|}
\hline \multirow{2}{*}{$\begin{array}{c}\text { Site } \\
\text { Number }\end{array}$} & \multicolumn{2}{|c|}{$\begin{array}{c}\text { Mann-Kendall } \\
\text { test }\end{array}$} & \multicolumn{3}{|c|}{ Pettitt test } & \multicolumn{2}{|c|}{$\begin{array}{c}\text { Before } \\
\text { Change-point }\end{array}$} & \multicolumn{2}{|c|}{$\begin{array}{c}\text { After } \\
\text { Change-point }\end{array}$} \\
\hline & p-value & trend & p-value & year & shift & p-value & trend & p-value & trend \\
\hline 01017000 & & & 0.087 & 1968 & + & & & & \\
\hline 01094500 & & & 0.026 & 1981 & + & & & & \\
\hline 01103500 & & & 0.092 & 1967 & + & & & & \\
\hline 01105000 & 0.008 & up & 0.000 & 1967 & + & & & & \\
\hline 01110000 & & & 0.098 & 1949 & + & & & & \\
\hline 01114500 & 0.053 & up & 0.005 & 1966 & + & & & & \\
\hline 01117000 & 0.015 & up & 0.000 & 1966 & + & & & & \\
\hline
\end{tabular}


Table B-1, continued

\begin{tabular}{|c|c|c|c|c|c|c|c|c|c|}
\hline \multirow{2}{*}{$\begin{array}{c}\text { Site } \\
\text { Number }\end{array}$} & \multicolumn{2}{|c|}{$\begin{array}{c}\text { Mann-Kendall } \\
\text { test }\end{array}$} & \multicolumn{3}{|c|}{ Pettitt test } & \multicolumn{2}{|c|}{$\begin{array}{c}\text { Before } \\
\text { Change-point }\end{array}$} & \multicolumn{2}{|c|}{$\begin{array}{c}\text { After } \\
\text { Change-point }\end{array}$} \\
\hline & p-value & trend & p-value & year & shift & p-value & trend & p-value & trend \\
\hline 01118000 & 0.074 & up & 0.024 & 1967 & + & & & & \\
\hline 01119500 & & & 0.036 & 1971 & + & & & & \\
\hline 01127500 & & & 0.023 & 1967 & + & & & & \\
\hline 01135500 & & & 0.025 & 1968 & + & & & & \\
\hline 01139000 & & & 0.026 & 1968 & + & & & & \\
\hline 01141500 & & & 0.057 & 1952 & - & & & & \\
\hline 01151500 & 0.003 & down & $<0.0001$ & 1960 & - & & & & \\
\hline 01153000 & 0.047 & down & $<0.0001$ & 1960 & - & & & 0.062 & up \\
\hline 01161000 & 0.063 & down & $<0.0001$ & 1940 & - & & & & \\
\hline 01168500 & & & 0.035 & 1952 & - & & & & \\
\hline 01173500 & & & 0.013 & 1972 & + & & & & \\
\hline 01189000 & & & 0.034 & 1978 & + & & & & \\
\hline 01192500 & 0.073 & up & 0.003 & 1971 & + & & & & \\
\hline 01196500 & 0.004 & up & $<0.0001$ & 1968 & + & & & & \\
\hline 01208500 & & & 0.062 & 1960 & - & & & & \\
\hline 03024000 & & & 0.055 & 1969 & - & & & & \\
\hline 03086500 & & & 0.030 & 1959 & - & & & & \\
\hline 03093000 & & & 0.005 & 1971 & + & & & & \\
\hline 03106500 & 0.038 & down & 0.017 & 1960 & - & & & & \\
\hline 03133500 & & & 0.012 & 1952 & - & 0.099 & down & & \\
\hline 03135000 & 0.000 & down & $<0.0001$ & 1974 & - & & & & \\
\hline 03141500 & 0.000 & up & $<0.0001$ & 1979 & + & & & & \\
\hline 03147500 & 0.061 & down & $<0.0001$ & 1969 & - & 0.049 & down & 0.003 & up \\
\hline 03208500 & & & 0.094 & 1979 & - & & & & \\
\hline 03209000 & 0.000 & down & $<0.0001$ & 1963 & - & & & & \\
\hline 03216500 & 0.021 & down & 0.000 & 1967 & - & & & & \\
\hline 03228500 & & & 0.014 & 1973 & - & & & & \\
\hline 03232500 & 0.072 & down & 0.001 & 1965 & - & & & & \\
\hline 03253500 & & & 0.054 & 1906 & + & & & 0.088 & down \\
\hline 03262000 & & & 0.061 & 1930 & - & 0.084 & down & & \\
\hline 03264000 & & & 0.069 & 1964 & - & & & & \\
\hline 03276500 & & & 0.080 & 1971 & - & & & & \\
\hline 03281000 & 0.037 & down & $<0.0001$ & 1963 & - & & & & \\
\hline 03302000 & 0.008 & up & $<0.0001$ & 1962 & + & & & & \\
\hline 03320000 & 0.043 & down & 0.009 & 1964 & - & & & & \\
\hline 03325000 & 0.003 & down & $<0.0001$ & 1964 & - & & & & \\
\hline 03328000 & 0.078 & up & 0.010 & 1977 & + & & & & \\
\hline 03378000 & 0.049 & up & 0.003 & 1976 & + & & & & \\
\hline 03381500 & 0.096 & up & 0.043 & 1981 & + & & & & \\
\hline 03433500 & & & 0.068 & 1972 & + & & & & \\
\hline 04024000 & & & 0.006 & 1940 & + & & & & \\
\hline
\end{tabular}


Table B-1, continued

\begin{tabular}{|c|c|c|c|c|c|c|c|c|c|}
\hline \multirow{2}{*}{$\begin{array}{c}\text { Site } \\
\text { Number }\end{array}$} & \multicolumn{2}{|c|}{$\begin{array}{c}\text { Mann-Kendall } \\
\text { test }\end{array}$} & \multicolumn{3}{|c|}{ Pettitt test } & \multicolumn{2}{|c|}{$\begin{array}{c}\text { Before } \\
\text { Change-point }\end{array}$} & \multicolumn{2}{|c|}{$\begin{array}{c}\text { After } \\
\text { Change-point }\end{array}$} \\
\hline & p-value & trend & p-value & year & shift & p-value & trend & p-value & trend \\
\hline 04034500 & & & 0.048 & 1955 & - & & & & \\
\hline 04036000 & 0.061 & down & 0.016 & 1986 & - & & & & \\
\hline 04062500 & & & 0.026 & 1985 & - & & & & \\
\hline 04099510 & 0.071 & up & 0.002 & 1975 & + & & & & \\
\hline 04112500 & & & 0.046 & 1957 & - & & & & \\
\hline 04122500 & 0.063 & up & 0.008 & 1973 & + & & & & \\
\hline 04185000 & & & 0.099 & 1980 & + & & & & \\
\hline 04252500 & & & 0.037 & 1971 & + & & & & \\
\hline 04258000 & & & 0.000 & 1968 & + & 0.060 & down & & \\
\hline
\end{tabular}

Table B-2: Comparison of results obtained by applying Pettitt test (at the 10\% level) and Multiple Change-Points analysis on AMF magnitude. Year(s) of shift, number of change-points and associated posterior probabilities are specified.

\begin{tabular}{|c|c|c|c|c|c|}
\hline \multirow{2}{*}{$\begin{array}{c}\text { Site } \\
\text { Number }\end{array}$} & \multirow{2}{*}{$\begin{array}{c}\text { Pettitt test } \\
\text { year }\end{array}$} & \multicolumn{4}{|c|}{ Multiple change-points $\left(\mathrm{cp}_{\mathrm{s}}\right)$ algorithm } \\
\hline & & $\begin{array}{c}\text { number } \\
\text { of } c p_{s}(k)\end{array}$ & $\begin{array}{c}\text { posterior } \\
\text { probability of } k\end{array}$ & years & $\begin{array}{c}\text { posterior } \\
\text { probability of } \mathrm{cp}_{\mathrm{s}}\end{array}$ \\
\hline 01017000 & 1968 & 0 & 1.000 & & \\
\hline 01087000 & & 1 & 1.000 & 1941 & 0.854 \\
\hline 01094500 & 1981 & 1 & 0.998 & 1956 & 0.556 \\
\hline 01103500 & 1967 & 0 & 1.000 & & \\
\hline 01105000 & 1967 & 0 & 0.997 & & \\
\hline 01110000 & 1949 & 0 & 0.999 & & \\
\hline 01114500 & 1966 & 0 & 0.998 & & \\
\hline 01117000 & 1966 & 1 & 0.938 & 1967 & 0.406 \\
\hline 01118000 & 1967 & 0 & 0.997 & & \\
\hline 01119500 & 1971 & 1 & 0.995 & 1955 & 0.612 \\
\hline 01127500 & 1967 & 0 & 1.000 & & \\
\hline 01135500 & 1968 & 0 & 1.000 & & \\
\hline 01139000 & 1968 & 0 & 0.977 & & \\
\hline 01141500 & 1952 & 1 & 0.840 & 1957 & 0.302 \\
\hline 01151500 & 1960 & 1 & 0.999 & 1960 & 0.460 \\
\hline 01153000 & 1960 & 1 & 1.000 & 1960 & 0.742 \\
\hline 01161000 & 1940 & 1 & 0.999 & 1940 & 0.792 \\
\hline 01162500 & & 1 & 1.000 & 1938 & 0.658 \\
\hline 01168500 & 1952 & 0 & 0.925 & & \\
\hline 01173500 & 1972 & 2 & 1.000 & $1935-1955$ & $0.852-0.756$ \\
\hline 01185500 & & 2 & 0.999 & $1935-1956$ & $0.676-0.796$ \\
\hline 01189000 & 1978 & 0 & 0.791 & & \\
\hline 01192500 & 1971 & 0 & 0.999 & & \\
\hline
\end{tabular}


Table B-2, continued

\begin{tabular}{|c|c|c|c|c|c|}
\hline \multirow{2}{*}{$\begin{array}{c}\text { Site } \\
\text { Number }\end{array}$} & \multirow{2}{*}{$\begin{array}{c}\text { Pettitt test } \\
\text { year }\end{array}$} & \multicolumn{4}{|c|}{ Multiple change-points $\left(\mathbf{c p}_{\mathrm{s}}\right)$ algorithm } \\
\hline & & $\begin{array}{c}\text { number } \\
\text { of } \mathrm{cp}_{\mathrm{s}}(\mathrm{k})\end{array}$ & $\begin{array}{c}\text { posterior } \\
\text { probability of } k\end{array}$ & years & $\begin{array}{c}\text { posterior } \\
\text { probability of } \mathrm{cp}_{\mathrm{s}}\end{array}$ \\
\hline 01196500 & 1968 & 0 & 0.999 & & \\
\hline 01208500 & 1960 & 1 & 0.981 & 1956 & 0.872 \\
\hline 03024000 & 1969 & 0 & 0.999 & & \\
\hline 03038000 & & 1 & 0.973 & 1995 & 0.518 \\
\hline 03086500 & 1959 & 0 & 0.719 & & \\
\hline 03093000 & 1971 & 0 & 0.998 & & \\
\hline 03106500 & 1960 & 0 & 0.993 & & \\
\hline 03133500 & 1952 & 0 & 0.984 & & \\
\hline 03135000 & 1974 & 1 & 0.984 & 1972 & 0.340 \\
\hline 03140000 & & 1 & 0.693 & 1979 & 0.452 \\
\hline 03141500 & 1979 & 0 & 0.999 & & \\
\hline 03147500 & 1969 & 1 & 1.000 & 1959 & 0.884 \\
\hline 03157000 & & 1 & 0.648 & 1968 & 0.302 \\
\hline 03208500 & 1979 & 0 & 0.999 & & \\
\hline 03209000 & 1963 & 1 & 1.000 & 1963 & 0.872 \\
\hline 03216500 & 1967 & 0 & 0.998 & & \\
\hline 03228500 & 1973 & 0 & 0.609 & & \\
\hline 03232500 & 1965 & 0 & 0.993 & & \\
\hline 03253500 & 1906 & 0 & 0.981 & & \\
\hline 03262000 & 1930 & 1 & 0.996 & 1961 & 0.260 \\
\hline 03264000 & 1964 & 0 & 0.999 & & \\
\hline 03267000 & & 1 & 0.575 & 1964 & 0.286 \\
\hline 03276500 & 1971 & 0 & 0.909 & & \\
\hline 03281000 & 1963 & 1 & 1.000 & 1958 & 0.846 \\
\hline 03302000 & 1962 & 0 & 0.794 & & \\
\hline 03320000 & 1964 & 1 & 0.989 & 1945 & 0.458 \\
\hline 03325000 & 1964 & 1 & 1.000 & 1964 & 0.372 \\
\hline 03328000 & 1977 & 0 & 1.000 & & \\
\hline 03378000 & 1976 & 0 & 1.000 & & \\
\hline 03381500 & 1981 & 0 & 1.000 & & \\
\hline 03433500 & 1972 & 0 & 1.000 & & \\
\hline 04024000 & 1940 & 0 & 1.000 & & \\
\hline 04034500 & 1955 & 0 & 0.618 & & \\
\hline 04036000 & 1986 & 0 & 1.000 & & \\
\hline 04062500 & 1985 & 0 & 1.000 & & \\
\hline 04099510 & 1975 & 0 & 1.000 & & \\
\hline 04112500 & 1957 & 0 & 0.994 & & \\
\hline 04122500 & 1973 & 0 & 0.997 & & \\
\hline 04166500 & & 1 & 0.977 & 1948 & 0.660 \\
\hline 04185000 & 1980 & 0 & 1.000 & & \\
\hline 04200500 & & 1 & 1.000 & 1969 & 0.770 \\
\hline
\end{tabular}


Table B-2, continued

\begin{tabular}{|c|c|c|c|c|c|}
\hline $\begin{array}{c}\text { Site } \\
\text { Number }\end{array}$ & Pettitt test & \multicolumn{4}{|c|}{ Multiple change-points $\left(\mathbf{c p}_{\mathbf{s}}\right)$ algorithm } \\
\cline { 2 - 6 } & year & $\begin{array}{c}\text { number } \\
\text { of }_{\mathbf{~} \mathbf{p}_{\mathbf{s}}(\mathbf{k})}\end{array}$ & $\begin{array}{c}\text { posterior } \\
\text { probability of } \mathbf{k}\end{array}$ & years & $\begin{array}{c}\text { posterior } \\
\text { probability of } \mathbf{c p}_{\mathbf{s}}\end{array}$ \\
\hline 04252500 & 1971 & 0 & 1.000 & & \\
04258000 & 1968 & 0 & 1.000 & & \\
\hline
\end{tabular}




\section{Appendix C \\ Meteorological variables}

This appendix provides additional results of the correlation analyses between annual maximum flood (AMF) series and the flood-generating precipitation and temperature series constructed for 136 watersheds as described in Chapter 4. Moreover, additional details are provided for analyses of non-stationarity in precipitation series in terms of both trends and change-points.

\section{C1: Correlation with AMF magnitude}

Table $\mathrm{C}-1$ provides the main results of the correlation analyses between the magnitude of AMF series and flood-generating total precipitation series. For each site the results obtained by performing the three correlation tests (Pearson's $r$, Kendall's $\tau$ and Spearman's $\rho$ ) are summarized, including the corresponding test statistics and p-values for the X-days lead time yielding the highest correlation (minimum p-value). Accounting for Bonferroni correction with $N=136$ sites, results are reported for all the watersheds for which statistically significant correlation was observed at the 10/N\% significance level and at the $5 / \mathrm{N} \%$ significance level if bold.

Accounting for Bonferroni correction, significant correlation was not observed between AMF magnitude and flood-generating minimum/maximum temperature series for the 136 watersheds considered. Only one site (01173500) exhibited correlation considering minimum temperature series and it is reported in italic. However, the results obtained by applying the three correlation tests (Pearson's $r$, Kendall's $\tau$ and Spearman's $\rho$ ), including corresponding test statistics and p-values, are summarized for all 136 watersheds in Tables C-2 and C-3 for maximum and minimum temperature, respectively. 
Table C-1: Results of correlation tests (Pearson's $r$, Kendall's $\tau$ and Spearman's $\rho$ ) between AMF magnitude and flood-generating precipitation series with X-days lead time yielding the highest correlation at the $10 / N \%$ and $5 / N \%$ (bold) levels.

\begin{tabular}{|c|c|c|c|c|c|c|c|c|c|}
\hline \multirow{2}{*}{$\begin{array}{c}\text { Site } \\
\text { Number }\end{array}$} & \multicolumn{3}{|c|}{ Pearson's $r$} & \multicolumn{3}{|c|}{ Kendall's $\tau$} & \multicolumn{3}{|c|}{ Spearman's $\rho$} \\
\hline & p-value & $r$ & X-days & p-value & $\tau$ & X-days & p-value & $\rho$ & X-days \\
\hline 01019000 & 0.000 & 0.629 & 2 & & & & 0.000 & 0.289 & 4 \\
\hline 01034500 & 0.000 & 0.567 & 6 & 0.000 & 0.408 & 6 & 0.000 & 0.593 & 7 \\
\hline 01042500 & 0.000 & 0.659 & 7 & 0.000 & 0.505 & 7 & 0.000 & 0.678 & 7 \\
\hline 01049000 & 0.000 & 0.598 & 5 & 0.000 & 0.441 & 6 & 0.000 & 0.612 & 6 \\
\hline 01053500 & 0.000 & 0.553 & 7 & 0.000 & 0.440 & 6 & 0.000 & 0.617 & 6 \\
\hline 01066000 & 0.000 & 0.578 & 4 & 0.000 & 0.381 & 4 & 0.000 & 0.551 & 4 \\
\hline 01081000 & 0.000 & 0.645 & 5 & 0.000 & 0.426 & 5 & 0.000 & 0.588 & 5 \\
\hline 01094500 & 0.000 & 0.650 & 4 & 0.000 & 0.436 & 5 & 0.000 & 0.612 & 5 \\
\hline 01101500 & 0.000 & 0.736 & 7 & 0.000 & 0.433 & 4 & 0.000 & 0.623 & 4 \\
\hline 01103500 & 0.000 & 0.552 & 6 & & & & & & \\
\hline 01109000 & 0.000 & 0.682 & 3 & 0.000 & 0.460 & 3 & 0.000 & 0.639 & 3 \\
\hline 01114500 & 0.000 & 0.697 & 7 & 0.000 & 0.493 & 7 & 0.000 & 0.668 & 6 \\
\hline 01116000 & 0.000 & 0.745 & 2 & 0.000 & 0.559 & 2 & 0.000 & 0.736 & 2 \\
\hline 01118000 & 0.000 & 0.648 & 5 & 0.000 & 0.409 & 7 & 0.000 & 0.559 & 4 \\
\hline 01119500 & 0.000 & 0.731 & 7 & 0.000 & 0.492 & 7 & 0.000 & 0.672 & 7 \\
\hline 01124000 & 0.000 & 0.726 & 2 & 0.000 & 0.552 & 3 & 0.000 & 0.714 & 3 \\
\hline 01127500 & 0.000 & 0.720 & 7 & 0.000 & 0.447 & 7 & 0.000 & 0.621 & 7 \\
\hline 01139000 & 0.000 & 0.560 & 4 & 0.000 & 0.394 & 7 & 0.000 & 0.584 & 4 \\
\hline 01151500 & 0.000 & 0.459 & 2 & & & & & & \\
\hline 01152500 & 0.000 & 0.491 & 3 & 0.000 & 0.319 & 3 & 0.000 & 0.467 & 4 \\
\hline 01161000 & 0.000 & 0.676 & 3 & 0.001 & 0.299 & 7 & & & \\
\hline 01168500 & 0.000 & 0.646 & 2 & 0.000 & 0.442 & 2 & 0.000 & 0.639 & 2 \\
\hline 01173500 & 0.000 & 0.724 & 2 & 0.000 & 0.435 & 7 & 0.000 & 0.598 & 7 \\
\hline 01174500 & 0.000 & 0.629 & 3 & 0.000 & 0.439 & 4 & 0.000 & 0.618 & 4 \\
\hline 01185500 & 0.000 & 0.783 & 7 & 0.000 & 0.509 & 7 & 0.000 & 0.682 & 7 \\
\hline 01189000 & 0.000 & 0.842 & 7 & 0.000 & 0.500 & 7 & 0.000 & 0.663 & 2 \\
\hline 01192500 & 0.000 & 0.641 & 7 & 0.000 & 0.391 & 4 & 0.000 & 0.576 & 3 \\
\hline 01193500 & 0.000 & 0.680 & 6 & 0.000 & 0.336 & 6 & 0.000 & 0.487 & 7 \\
\hline 01196500 & 0.000 & 0.649 & 7 & 0.000 & 0.452 & 3 & 0.000 & 0.620 & 3 \\
\hline 01208500 & 0.000 & 0.734 & 7 & 0.000 & 0.464 & 3 & 0.000 & 0.633 & 2 \\
\hline 03014500 & 0.000 & 0.519 & 3 & & & & & & \\
\hline 03028500 & 0.000 & 0.539 & 6 & & & & & & \\
\hline 03038000 & 0.000 & 0.694 & 2 & 0.001 & 0.297 & 3 & & & \\
\hline 03040000 & & & & 0.000 & 0.344 & 3 & 0.000 & 0.510 & 3 \\
\hline 03041000 & 0.000 & 0.595 & 4 & & & & & & \\
\hline 03045000 & 0.000 & 0.699 & 2 & 0.000 & 0.396 & 2 & 0.000 & 0.564 & 2 \\
\hline 03072000 & 0.000 & 0.631 & 2 & 0.000 & 0.468 & 2 & 0.000 & 0.645 & 2 \\
\hline 03076500 & 0.000 & 0.553 & 2 & 0.000 & 0.386 & 2 & 0.000 & 0.514 & 2 \\
\hline
\end{tabular}


Table C-1, continued

\begin{tabular}{|c|c|c|c|c|c|c|c|c|c|}
\hline \multirow{2}{*}{$\begin{array}{c}\text { Site } \\
\text { Number }\end{array}$} & \multicolumn{3}{|c|}{ Pearson's $r$} & \multicolumn{3}{|c|}{ Kendall's $\tau$} & \multicolumn{3}{|c|}{ Spearman's $\rho$} \\
\hline & p-value & $r$ & X-days & p-value & $\tau$ & X-days & p-value & $\rho$ & X-days \\
\hline 03093000 & 0.000 & 0.504 & 2 & & & & & & \\
\hline 03106500 & 0.000 & 0.530 & 3 & 0.000 & 0.342 & 4 & 0.000 & 0.453 & 4 \\
\hline 03110000 & 0.000 & 0.484 & 4 & & & & & & \\
\hline 03111500 & 0.000 & 0.658 & 3 & 0.000 & 0.376 & 3 & 0.000 & 0.528 & 3 \\
\hline 03118000 & 0.000 & 0.552 & 3 & 0.000 & 0.352 & 3 & 0.000 & 0.508 & 3 \\
\hline 03131500 & 0.000 & 0.762 & 3 & 0.000 & 0.388 & 5 & 0.000 & 0.529 & 5 \\
\hline 03133500 & & & & 0.000 & 0.329 & 4 & 0.000 & 0.460 & 5 \\
\hline 03135000 & 0.000 & 0.662 & 2 & & & & & & \\
\hline 03140000 & 0.000 & 0.707 & 2 & 0.000 & 0.379 & 6 & 0.000 & 0.536 & 2 \\
\hline 03141500 & 0.000 & 0.708 & 2 & & & & 0.000 & 0.539 & 5 \\
\hline 03147500 & 0.000 & 0.697 & 3 & & & & & & \\
\hline 03157000 & 0.000 & 0.634 & 4 & 0.000 & 0.490 & 3 & 0.000 & 0.658 & 4 \\
\hline 03165000 & 0.000 & 0.462 & 2 & 0.000 & 0.396 & 2 & 0.000 & 0.557 & 2 \\
\hline 03208500 & 0.000 & 0.723 & 3 & 0.000 & 0.491 & 5 & 0.000 & 0.637 & 5 \\
\hline 03209000 & 0.000 & 0.698 & 2 & 0.000 & 0.309 & 6 & 0.000 & 0.452 & 6 \\
\hline 03216500 & 0.000 & 0.681 & 6 & 0.000 & 0.394 & 5 & 0.000 & 0.557 & 7 \\
\hline 03227500 & 0.000 & 0.629 & 3 & 0.000 & 0.515 & 3 & 0.000 & 0.715 & 3 \\
\hline 03228500 & 0.000 & 0.626 & 2 & 0.000 & 0.444 & 2 & 0.000 & 0.636 & 2 \\
\hline 03232500 & 0.000 & 0.609 & 7 & 0.000 & 0.437 & 5 & 0.000 & 0.600 & 5 \\
\hline 03238500 & 0.000 & 0.653 & 3 & 0.000 & 0.440 & 3 & 0.000 & 0.585 & 3 \\
\hline 03245500 & 0.000 & 0.778 & 3 & 0.000 & 0.512 & 3 & 0.000 & 0.694 & 3 \\
\hline 03253500 & 0.000 & 0.714 & 7 & 0.000 & 0.429 & 5 & 0.000 & 0.570 & 5 \\
\hline 03262000 & 0.000 & 0.620 & 6 & 0.000 & 0.448 & 4 & 0.000 & 0.642 & 4 \\
\hline 03264000 & 0.000 & 0.526 & 6 & 0.000 & 0.372 & 6 & 0.000 & 0.526 & 5 \\
\hline 03267000 & 0.000 & 0.473 & 3 & 0.001 & 0.308 & 3 & 0.000 & 0.437 & 3 \\
\hline 03272000 & 0.000 & 0.611 & 3 & 0.000 & 0.465 & 7 & 0.000 & 0.642 & 7 \\
\hline 03276500 & 0.000 & 0.747 & 2 & 0.000 & 0.545 & 2 & 0.000 & 0.739 & 2 \\
\hline 03280000 & 0.000 & 0.786 & 4 & 0.000 & 0.629 & 4 & 0.000 & 0.827 & 6 \\
\hline 03281000 & 0.001 & 0.434 & 4 & 0.000 & 0.414 & 7 & 0.000 & 0.593 & 7 \\
\hline 03283500 & 0.000 & 0.840 & 7 & 0.000 & 0.647 & 4 & 0.000 & 0.823 & 4 \\
\hline 03285000 & 0.000 & 0.750 & 7 & 0.000 & 0.616 & 3 & 0.000 & 0.796 & 3 \\
\hline 03302000 & 0.000 & 0.547 & 6 & & & & & & \\
\hline 03325000 & 0.000 & 0.454 & 6 & 0.000 & 0.323 & 5 & 0.000 & 0.453 & 5 \\
\hline 03326500 & 0.000 & 0.595 & 5 & 0.000 & 0.409 & 4 & 0.000 & 0.554 & 4 \\
\hline 03328000 & 0.000 & 0.466 & 4 & 0.000 & 0.327 & 4 & 0.000 & 0.507 & 4 \\
\hline 03329700 & 0.000 & 0.720 & 3 & 0.000 & 0.385 & 3 & 0.000 & 0.529 & 3 \\
\hline 03347000 & 0.000 & 0.748 & 3 & 0.000 & 0.524 & 3 & 0.000 & 0.704 & 3 \\
\hline 03352500 & 0.000 & 0.702 & 4 & 0.000 & 0.445 & 4 & 0.000 & 0.632 & 4 \\
\hline 03353500 & 0.000 & 0.638 & 2 & 0.000 & 0.385 & 3 & 0.000 & 0.553 & 3 \\
\hline 03360000 & 0.000 & 0.736 & 3 & 0.000 & 0.527 & 3 & 0.000 & 0.720 & 3 \\
\hline
\end{tabular}


Table C-1, continued

\begin{tabular}{|c|c|c|c|c|c|c|c|c|c|}
\hline Site & \multicolumn{3}{|c|}{ Pearson's } & \multicolumn{3}{c|}{ Kendall's $\boldsymbol{c}$} & \multicolumn{3}{c|}{ Spearman's $\boldsymbol{\rho}$} \\
Number & p-value & $\boldsymbol{r}$ & X-days & p-value & $\boldsymbol{\tau}$ & X-days & p-value & $\boldsymbol{\rho}$ & X-days \\
\hline 03361500 & $\mathbf{0 . 0 0 0}$ & 0.565 & 4 & $\mathbf{0 . 0 0 0}$ & 0.389 & 4 & $\mathbf{0 . 0 0 0}$ & 0.542 & 4 \\
03362000 & $\mathbf{0 . 0 0 0}$ & 0.620 & 5 & $\mathbf{0 . 0 0 0}$ & 0.546 & 4 & $\mathbf{0 . 0 0 0}$ & 0.734 & 4 \\
03363500 & $\mathbf{0 . 0 0 0}$ & 0.682 & 3 & $\mathbf{0 . 0 0 0}$ & 0.519 & 5 & $\mathbf{0 . 0 0 0}$ & 0.712 & 3 \\
03369500 & $\mathbf{0 . 0 0 0}$ & 0.796 & 2 & $\mathbf{0 . 0 0 0}$ & 0.590 & 3 & $\mathbf{0 . 0 0 0}$ & 0.750 & 3 \\
03376500 & $\mathbf{0 . 0 0 0}$ & 0.606 & 7 & $\mathbf{0 . 0 0 0}$ & 0.332 & 7 & $\mathbf{0 . 0 0 0}$ & 0.450 & 7 \\
03378000 & $\mathbf{0 . 0 0 0}$ & 0.839 & 7 & $\mathbf{0 . 0 0 0}$ & 0.635 & 6 & $\mathbf{0 . 0 0 0}$ & 0.811 & 5 \\
03401000 & $\mathbf{0 . 0 0 0}$ & 0.798 & 3 & $\mathbf{0 . 0 0 0}$ & 0.622 & 3 & $\mathbf{0 . 0 0 0}$ & 0.804 & 3 \\
03406500 & $\mathbf{0 . 0 0 0}$ & 0.828 & 3 & $\mathbf{0 . 0 0 0}$ & 0.591 & 3 & $\mathbf{0 . 0 0 0}$ & 0.775 & 3 \\
03414500 & $\mathbf{0 . 0 0 0}$ & 0.720 & 3 & $\mathbf{0 . 0 0 0}$ & 0.574 & 3 & $\mathbf{0 . 0 0 0}$ & 0.775 & 3 \\
03421000 & $\mathbf{0 . 0 0 0}$ & 0.839 & 5 & $\mathbf{0 . 0 0 0}$ & 0.704 & 3 & $\mathbf{0 . 0 0 0}$ & 0.846 & 6 \\
03433500 & $\mathbf{0 . 0 0 0}$ & 0.860 & 7 & $\mathbf{0 . 0 0 0}$ & 0.628 & 6 & $\mathbf{0 . 0 0 0}$ & 0.793 & 6 \\
04034500 & & & & & & & $\mathbf{0 . 0 0 1}$ & -0.430 & 2 \\
04099000 & $\mathbf{0 . 0 0 0}$ & 0.518 & 7 & & & & & & \\
04105500 & 0.000 & 0.438 & 5 & & & & & & \\
04109000 & $\mathbf{0 . 0 0 0}$ & 0.469 & 7 & & & & 0.001 & 0.430 & 7 \\
04112500 & & & & & & & & & \\
04115000 & $\mathbf{0 . 0 0 0}$ & 0.689 & 3 & 0.001 & 0.305 & 3 & 0.001 & 0.419 & 3 \\
04117500 & $\mathbf{0 . 0 0 0}$ & 0.451 & 5 & & & & & & \\
04122500 & $\mathbf{0 . 0 0 0}$ & 0.767 & 4 & $\mathbf{0 . 0 0 0}$ & 0.358 & 4 & $\mathbf{0 . 0 0 0}$ & 0.509 & 4 \\
04127997 & $\mathbf{0 . 0 0 1}$ & 0.429 & 7 & & & & & & \\
04146000 & $\mathbf{0 . 0 0 0}$ & 0.607 & 4 & $\mathbf{0 . 0 0 0}$ & 0.335 & 4 & $\mathbf{0 . 0 0 0}$ & 0.488 & 4 \\
04151500 & $\mathbf{0 . 0 0 0}$ & 0.549 & 3 & & & & & & \\
04154000 & $\mathbf{0 . 0 0 0}$ & 0.612 & 4 & & & & & & \\
04155000 & $\mathbf{0 . 0 0 0}$ & 0.611 & 4 & & & & 0.001 & 0.425 & 4 \\
04166500 & $\mathbf{0 . 0 0 0}$ & 0.478 & 4 & & & & & & \\
04185000 & 0.001 & 0.432 & 4 & $\mathbf{0 . 0 0 0}$ & 0.318 & 3 & $\mathbf{0 . 0 0 0}$ & 0.451 & 3 \\
04186500 & $\mathbf{0 . 0 0 0}$ & 0.488 & 4 & & & & & & \\
04195500 & $\mathbf{0 . 0 0 0}$ & 0.498 & 4 & $\mathbf{0 . 0 0 0}$ & 0.331 & 4 & $\mathbf{0 . 0 0 0}$ & 0.450 & 4 \\
04200500 & $\mathbf{0 . 0 0 0}$ & 0.642 & 3 & $\mathbf{0 . 0 0 0}$ & 0.320 & 4 & $\mathbf{0 . 0 0 0}$ & 0.462 & 4 \\
04202000 & & & & & & & 0.001 & 0.426 & 3 \\
04252500 & $\mathbf{0 . 0 0 0}$ & 0.637 & 3 & $\mathbf{0 . 0 0 0}$ & 0.408 & 3 & $\mathbf{0 . 0 0 0}$ & 0.595 & 3 \\
04258000 & $\mathbf{0 . 0 0 0}$ & 0.560 & 5 & $\mathbf{0 . 0 0 0}$ & 0.319 & 5 & 0.000 & 0.434 & 5 \\
\hline
\end{tabular}


Table C-2: Results of correlation tests (Pearson's $r$, Kendall's $\tau$ and Spearman's $\rho$ ) between AMF magnitude and flood-generating maximum temperature series with X-days lead time yielding the highest correlation.

\begin{tabular}{|c|c|c|c|c|c|c|c|c|c|}
\hline \multirow{2}{*}{$\begin{array}{c}\text { Site } \\
\text { Number }\end{array}$} & \multicolumn{3}{|c|}{ Pearson's $r$} & \multicolumn{3}{|c|}{ Kendall's $\tau$} & \multicolumn{3}{|c|}{ Spearman's $\rho$} \\
\hline & p-value & $r$ & X-days & p-value & $\tau$ & X-days & p-value & $\rho$ & X-days \\
\hline 01017000 & 0.107 & -0.209 & 2 & 0.055 & -0.169 & 2 & 0.060 & -0.243 & 2 \\
\hline 01019000 & 0.354 & -0.121 & 7 & 0.273 & -0.097 & 7 & 0.294 & -0.137 & 7 \\
\hline 01034500 & 0.391 & -0.112 & 4 & 0.522 & 0.057 & 7 & 0.478 & 0.093 & 7 \\
\hline 01042500 & 0.732 & -0.045 & 3 & 0.486 & 0.062 & 7 & 0.430 & 0.103 & 2 \\
\hline 01049000 & 0.210 & 0.163 & 3 & 0.163 & 0.123 & 3 & 0.140 & 0.191 & 3 \\
\hline 01053500 & 0.218 & 0.160 & 7 & 0.206 & 0.112 & 7 & 0.210 & 0.163 & 7 \\
\hline 01066000 & 0.585 & 0.071 & 7 & 0.304 & 0.091 & 3 & 0.370 & 0.117 & 3 \\
\hline 01081000 & 0.008 & 0.336 & 7 & 0.026 & 0.197 & 7 & 0.018 & 0.303 & 7 \\
\hline 01087000 & 0.011 & 0.324 & 2 & 0.013 & 0.221 & 2 & 0.011 & 0.325 & 2 \\
\hline 01094500 & 0.025 & 0.290 & 7 & 0.029 & 0.195 & 7 & 0.022 & 0.296 & 7 \\
\hline 01101500 & 0.209 & -0.165 & 2 & 0.091 & -0.150 & 2 & 0.084 & -0.225 & 2 \\
\hline 01103500 & 0.394 & 0.112 & 2 & 0.536 & 0.055 & 2 & 0.594 & 0.070 & 2 \\
\hline 01109000 & 0.087 & 0.223 & 4 & 0.456 & 0.067 & 5 & 0.490 & 0.091 & 5 \\
\hline 01114500 & 0.085 & 0.224 & 2 & 0.047 & 0.176 & 2 & 0.042 & 0.264 & 2 \\
\hline 01116000 & 0.254 & 0.149 & 3 & 0.064 & 0.165 & 2 & 0.096 & 0.217 & 2 \\
\hline 01118000 & 0.186 & 0.173 & 2 & 0.195 & 0.116 & 2 & 0.184 & 0.174 & 2 \\
\hline 01119500 & 0.037 & 0.269 & 7 & 0.669 & -0.038 & 4 & 0.701 & -0.051 & 4 \\
\hline 01124000 & 0.007 & 0.344 & 6 & 0.436 & 0.070 & 7 & 0.460 & 0.097 & 7 \\
\hline 01127500 & 0.144 & 0.191 & 7 & 0.149 & 0.128 & 7 & 0.165 & 0.182 & 2 \\
\hline 01135500 & 0.470 & 0.094 & 7 & 0.610 & 0.045 & 6 & 0.613 & 0.066 & 6 \\
\hline 01139000 & 0.002 & 0.391 & 7 & 0.028 & 0.194 & 7 & 0.026 & 0.284 & 7 \\
\hline 01141500 & 0.039 & 0.265 & 7 & 0.135 & 0.133 & 7 & 0.097 & 0.215 & 7 \\
\hline 01151500 & 0.056 & 0.246 & 6 & 0.440 & -0.068 & 2 & 0.447 & 0.099 & 7 \\
\hline 01152500 & 0.323 & 0.129 & 7 & 0.095 & 0.147 & 7 & 0.124 & 0.199 & 7 \\
\hline 01153000 & 0.106 & 0.209 & 5 & 0.263 & 0.099 & 5 & 0.251 & 0.149 & 5 \\
\hline 01161000 & 0.001 & 0.410 & 7 & 0.042 & 0.179 & 6 & 0.055 & 0.247 & 6 \\
\hline 01168500 & 0.038 & 0.268 & 7 & 0.032 & 0.191 & 5 & 0.045 & 0.259 & 5 \\
\hline 01173500 & 0.007 & 0.347 & 2 & 0.216 & 0.110 & 2 & 0.242 & 0.153 & 2 \\
\hline 01174500 & 0.105 & 0.211 & 2 & 0.157 & 0.126 & 2 & 0.130 & 0.198 & 2 \\
\hline 01185500 & 0.033 & 0.276 & 6 & 0.051 & 0.174 & 6 & 0.052 & 0.252 & 6 \\
\hline 01189000 & 0.183 & 0.174 & 6 & 0.764 & 0.027 & 5 & 0.656 & -0.059 & 2 \\
\hline 01192500 & 0.580 & -0.073 & 3 & 0.452 & -0.067 & 5 & 0.425 & -0.105 & 5 \\
\hline 01193500 & 0.645 & 0.061 & 2 & 0.575 & 0.050 & 2 & 0.642 & 0.061 & 2 \\
\hline 01196500 & 0.398 & 0.111 & 7 & 0.532 & 0.056 & 3 & 0.572 & 0.074 & 3 \\
\hline 01208500 & 0.085 & 0.224 & 5 & 0.407 & 0.074 & 6 & 0.494 & 0.090 & 6 \\
\hline 03014500 & 0.406 & 0.108 & 2 & 0.322 & -0.088 & 5 & 0.465 & -0.095 & 7 \\
\hline 03024000 & 0.055 & -0.247 & 2 & 0.055 & -0.170 & 2 & 0.062 & -0.240 & 2 \\
\hline 03028500 & 0.530 & 0.082 & 2 & 0.370 & -0.079 & 7 & 0.415 & -0.106 & 7 \\
\hline 03038000 & 0.028 & 0.282 & 6 & 0.200 & 0.114 & 6 & 0.213 & 0.162 & 3 \\
\hline
\end{tabular}


Table C-2, continued

\begin{tabular}{|c|c|c|c|c|c|c|c|c|c|}
\hline \multirow{2}{*}{$\begin{array}{c}\text { Site } \\
\text { Number }\end{array}$} & \multicolumn{3}{|c|}{ Pearson's $r$} & \multicolumn{3}{|c|}{ Kendall's $\tau$} & \multicolumn{3}{|c|}{ Spearman's $\rho$} \\
\hline & p-value & $r$ & X-days & p-value & $\tau$ & X-days & p-value & $\rho$ & X-days \\
\hline 03041000 & 0.002 & 0.390 & 5 & 0.040 & 0.181 & 5 & 0.057 & 0.245 & 5 \\
\hline 03040000 & 0.014 & 0.314 & 5 & 0.187 & 0.116 & 5 & 0.197 & 0.168 & 5 \\
\hline 03045000 & 0.094 & 0.216 & 5 & 0.232 & 0.106 & 5 & 0.238 & 0.153 & 3 \\
\hline 03072000 & 0.494 & -0.089 & 4 & 0.426 & -0.071 & 7 & 0.458 & -0.097 & 7 \\
\hline 03076500 & 0.485 & 0.091 & 6 & 0.394 & 0.075 & 6 & 0.336 & 0.125 & 5 \\
\hline 03086500 & 0.161 & 0.186 & 2 & 0.246 & 0.105 & 2 & 0.235 & 0.158 & 2 \\
\hline 03093000 & 0.539 & 0.081 & 3 & 0.436 & -0.070 & 7 & 0.446 & -0.100 & 7 \\
\hline 03106500 & 0.816 & -0.030 & 2 & 0.426 & -0.071 & 3 & 0.466 & -0.095 & 3 \\
\hline 03110000 & 0.316 & -0.132 & 7 & 0.117 & -0.140 & 7 & 0.119 & -0.203 & 2 \\
\hline 03111500 & 0.339 & 0.126 & 5 & 0.623 & 0.044 & 5 & 0.730 & 0.046 & 5 \\
\hline 03117500 & 0.284 & -0.141 & 6 & 0.161 & -0.125 & 5 & 0.186 & -0.173 & 5 \\
\hline 03118000 & 0.247 & 0.151 & 2 & 0.490 & 0.061 & 2 & 0.490 & 0.090 & 2 \\
\hline 03131500 & 0.134 & 0.199 & 2 & 0.485 & -0.064 & 7 & 0.607 & -0.069 & 5 \\
\hline 03133500 & 0.176 & 0.180 & 3 & 0.058 & 0.173 & 3 & 0.053 & 0.255 & 3 \\
\hline 03135000 & 0.035 & 0.277 & 2 & 0.217 & 0.113 & 2 & 0.212 & 0.166 & 2 \\
\hline 03140000 & 0.008 & 0.338 & 2 & 0.008 & 0.234 & 2 & 0.008 & 0.339 & 2 \\
\hline 03141500 & 0.283 & -0.143 & 6 & 0.207 & -0.115 & 6 & 0.273 & -0.146 & 6 \\
\hline 03147500 & 0.062 & -0.247 & 7 & 0.189 & -0.119 & 7 & 0.208 & -0.168 & 7 \\
\hline 03157000 & 0.830 & -0.028 & 6 & 0.628 & -0.044 & 4 & 0.618 & -0.066 & 4 \\
\hline 03165000 & 0.122 & 0.200 & 2 & 0.252 & 0.101 & 2 & 0.190 & 0.170 & 2 \\
\hline 03208500 & 0.623 & 0.064 & 7 & 0.257 & 0.100 & 5 & 0.282 & 0.140 & 5 \\
\hline 03209000 & 0.536 & -0.081 & 6 & 0.530 & 0.056 & 2 & 0.497 & 0.089 & 2 \\
\hline 03216500 & 0.408 & 0.109 & 3 & 0.740 & 0.030 & 2 & 0.719 & 0.047 & 2 \\
\hline 03227500 & 0.294 & -0.138 & 6 & 0.528 & 0.057 & 2 & 0.579 & 0.073 & 2 \\
\hline 03228500 & 0.023 & -0.293 & 5 & 0.301 & -0.092 & 5 & 0.275 & -0.143 & 5 \\
\hline 03232500 & 0.629 & 0.064 & 3 & 0.674 & 0.038 & 2 & 0.745 & 0.043 & 2 \\
\hline 03238500 & 0.656 & 0.059 & 3 & 0.475 & 0.064 & 6 & 0.523 & 0.084 & 6 \\
\hline 03245500 & 0.717 & 0.048 & 3 & 0.436 & 0.070 & 4 & 0.429 & 0.104 & 3 \\
\hline 03253500 & 0.327 & -0.129 & 2 & 0.298 & -0.093 & 2 & 0.269 & -0.145 & 2 \\
\hline 03262000 & 0.118 & 0.204 & 2 & 0.335 & 0.086 & 2 & 0.375 & 0.117 & 2 \\
\hline 03264000 & 0.393 & -0.112 & 5 & 0.320 & -0.089 & 4 & 0.286 & -0.140 & 4 \\
\hline 03267000 & 0.270 & -0.145 & 5 & 0.674 & 0.038 & 2 & 0.773 & 0.038 & 2 \\
\hline 03272000 & 0.050 & -0.254 & 2 & 0.017 & -0.212 & 2 & 0.014 & -0.317 & 2 \\
\hline 03276500 & 0.002 & -0.380 & 5 & 0.013 & -0.218 & 3 & 0.010 & -0.328 & 3 \\
\hline 03280000 & 0.224 & 0.159 & 7 & 0.183 & 0.119 & 2 & 0.206 & 0.166 & 7 \\
\hline 03281000 & 0.175 & -0.178 & 4 & 0.448 & 0.068 & 4 & 0.440 & 0.101 & 4 \\
\hline 03283500 & 0.872 & 0.021 & 7 & 0.843 & 0.018 & 2 & 0.834 & 0.028 & 2 \\
\hline 03285000 & 0.396 & 0.115 & 7 & 0.425 & -0.073 & 2 & 0.425 & -0.108 & 2 \\
\hline 03302000 & 0.294 & 0.138 & 4 & 0.072 & 0.160 & 4 & 0.073 & 0.233 & 4 \\
\hline 03320000 & 0.538 & 0.081 & 2 & 0.081 & 0.156 & 2 & 0.078 & 0.229 & 2 \\
\hline 03325000 & 0.381 & 0.114 & 2 & 0.169 & 0.122 & 2 & 0.140 & 0.191 & 2 \\
\hline 03326500 & 0.053 & 0.249 & 2 & 0.070 & 0.160 & 3 & 0.082 & 0.224 & 3 \\
\hline
\end{tabular}


Table C-2, continued

\begin{tabular}{|c|c|c|c|c|c|c|c|c|c|}
\hline \multirow{2}{*}{$\begin{array}{c}\text { Site } \\
\text { Number }\end{array}$} & \multicolumn{3}{|c|}{ Pearson's $r$} & \multicolumn{3}{|c|}{ Kendall's $\tau$} & \multicolumn{3}{|c|}{ Spearman's $\rho$} \\
\hline & p-value & $r$ & X-days & p-value & $\tau$ & X-days & p-value & $\rho$ & X-days \\
\hline 03328000 & 0.405 & -0.108 & 7 & 0.440 & -0.068 & 7 & 0.423 & -0.104 & 7 \\
\hline 03329700 & 0.288 & 0.138 & 2 & 0.641 & 0.042 & 2 & 0.642 & 0.061 & 2 \\
\hline 03347000 & 0.518 & 0.084 & 4 & 0.803 & 0.022 & 7 & 0.756 & 0.041 & 7 \\
\hline 03352500 & 0.297 & 0.136 & 7 & 0.351 & 0.083 & 7 & 0.387 & 0.113 & 7 \\
\hline 03353500 & 0.365 & 0.119 & 7 & 0.660 & -0.040 & 4 & 0.686 & -0.053 & 3 \\
\hline 03360000 & 0.318 & 0.130 & 2 & 0.659 & 0.039 & 7 & 0.648 & 0.060 & 7 \\
\hline 03361500 & 0.109 & -0.207 & 5 & 0.247 & -0.102 & 5 & 0.195 & -0.168 & 5 \\
\hline 03362000 & 0.127 & 0.198 & 2 & 0.290 & 0.094 & 2 & 0.294 & 0.136 & 2 \\
\hline 03363500 & 0.110 & -0.207 & 4 & 0.110 & -0.141 & 5 & 0.128 & -0.197 & 3 \\
\hline 03369500 & 0.059 & 0.243 & 2 & 0.010 & 0.226 & 7 & 0.011 & 0.325 & 7 \\
\hline 03376500 & 0.197 & 0.167 & 6 & 0.338 & 0.085 & 7 & 0.300 & 0.135 & 7 \\
\hline 03378000 & 0.611 & 0.066 & 7 & 0.584 & 0.049 & 7 & 0.690 & 0.052 & 4 \\
\hline 03381500 & 0.487 & 0.091 & 3 & 0.718 & -0.032 & 7 & 0.758 & 0.052 & 7 \\
\hline 03401000 & 0.446 & 0.104 & 4 & 0.745 & 0.031 & 4 & 0.731 & 0.047 & 4 \\
\hline 03406500 & 0.259 & 0.148 & 7 & 0.198 & 0.115 & 7 & 0.175 & 0.177 & 7 \\
\hline 03414500 & 0.543 & -0.081 & 4 & 0.320 & -0.090 & 5 & 0.357 & -0.122 & 5 \\
\hline 03421000 & 0.653 & -0.059 & 3 & 0.592 & -0.048 & 3 & 0.713 & -0.048 & 3 \\
\hline 03433500 & 0.333 & 0.126 & 2 & 0.663 & 0.039 & 3 & 0.662 & 0.057 & 4 \\
\hline 04024000 & 0.256 & -0.148 & 3 & 0.263 & -0.099 & 7 & 0.206 & -0.164 & 7 \\
\hline 04034500 & 0.012 & -0.321 & 2 & 0.007 & -0.239 & 3 & 0.009 & -0.332 & 3 \\
\hline 04036000 & 0.149 & 0.187 & 6 & 0.181 & 0.118 & 6 & 0.189 & 0.170 & 6 \\
\hline 04037500 & 0.317 & 0.130 & 6 & 0.135 & 0.132 & 5 & 0.140 & 0.191 & 4 \\
\hline 04041500 & 0.024 & 0.288 & 4 & 0.070 & 0.160 & 6 & 0.071 & 0.233 & 6 \\
\hline 04060993 & 0.103 & 0.211 & 5 & 0.455 & 0.066 & 5 & 0.508 & 0.086 & 5 \\
\hline 04062500 & 0.053 & 0.249 & 6 & 0.293 & 0.093 & 7 & 0.314 & 0.131 & 7 \\
\hline 04087000 & 0.373 & 0.116 & 2 & 0.474 & -0.063 & 6 & 0.502 & -0.088 & 6 \\
\hline 04099000 & 0.101 & -0.212 & 2 & 0.018 & -0.208 & 2 & 0.019 & -0.300 & 2 \\
\hline 04099510 & 0.165 & -0.180 & 2 & 0.021 & -0.203 & 2 & 0.016 & -0.306 & 2 \\
\hline 04105500 & 0.311 & -0.132 & 2 & 0.181 & -0.118 & 2 & 0.242 & -0.152 & 2 \\
\hline 04109000 & 0.007 & 0.341 & 2 & 0.009 & 0.230 & 2 & 0.007 & 0.344 & 2 \\
\hline 04112500 & 0.543 & -0.079 & 2 & 0.335 & -0.085 & 6 & 0.304 & -0.134 & 6 \\
\hline 04115000 & 0.053 & 0.249 & 2 & 0.100 & 0.145 & 2 & 0.115 & 0.204 & 2 \\
\hline 04117500 & 0.247 & 0.150 & 5 & 0.350 & 0.083 & 4 & 0.334 & 0.126 & 4 \\
\hline 04122500 & 0.187 & 0.171 & 4 & 0.304 & 0.091 & 3 & 0.322 & 0.129 & 3 \\
\hline 04124000 & 0.147 & 0.188 & 5 & 0.165 & 0.123 & 5 & 0.122 & 0.200 & 6 \\
\hline 04127997 & 0.430 & 0.103 & 7 & 0.509 & 0.059 & 4 & 0.582 & 0.072 & 4 \\
\hline 04146000 & 0.106 & 0.209 & 3 & 0.636 & 0.042 & 3 & 0.626 & -0.064 & 7 \\
\hline 04151500 & 0.469 & 0.094 & 6 & 0.494 & -0.061 & 3 & 0.478 & -0.093 & 3 \\
\hline 04154000 & 0.040 & 0.264 & 2 & 0.093 & 0.149 & 2 & 0.066 & 0.237 & 2 \\
\hline 04155000 & 0.760 & 0.040 & 4 & 0.408 & -0.073 & 7 & 0.432 & -0.102 & 6 \\
\hline 04159492 & 0.040 & -0.264 & 2 & 0.022 & -0.202 & 2 & 0.012 & -0.318 & 2 \\
\hline 04165500 & 0.430 & -0.103 & 2 & 0.502 & -0.060 & 7 & 0.492 & -0.090 & 7 \\
\hline
\end{tabular}


Table C-2, continued

\begin{tabular}{|c|ccc|c|c|c|c|c|c|c|}
\hline $\begin{array}{c}\text { Site } \\
\text { Number }\end{array}$ & \multicolumn{3}{|c|}{ Pearson's $\boldsymbol{r}$} & \multicolumn{3}{c|}{ Kendall's $\boldsymbol{\tau}$} & \multicolumn{3}{c|}{ Spearman's $\boldsymbol{\rho}$} \\
\hline 04166500 & 0.183 & 0.173 & 6 & 0.296 & 0.092 & 7 & 0.306 & 0.133 & 7 \\
04176500 & 0.303 & -0.134 & 2 & 0.165 & -0.123 & 3 & 0.195 & -0.168 & 2 \\
04185000 & 0.795 & 0.034 & 4 & 0.467 & 0.065 & 4 & 0.476 & 0.094 & 4 \\
04186500 & 0.556 & -0.077 & 7 & 0.187 & -0.116 & 7 & 0.177 & -0.175 & 7 \\
04195500 & 0.146 & -0.189 & 7 & 0.271 & -0.097 & 7 & 0.226 & -0.157 & 7 \\
04200500 & 0.103 & 0.213 & 2 & 0.515 & -0.058 & 5 & 0.559 & 0.077 & 2 \\
04202000 & 0.019 & -0.302 & 7 & 0.008 & -0.234 & 7 & 0.011 & -0.327 & 6 \\
04231000 & 0.339 & 0.125 & 2 & 0.257 & 0.100 & 3 & 0.240 & 0.153 & 3 \\
04252500 & 0.059 & 0.243 & 2 & 0.071 & 0.159 & 2 & 0.089 & 0.220 & 2 \\
04258000 & 0.233 & 0.155 & 7 & 0.223 & 0.108 & 7 & 0.258 & 0.147 & 7 \\
04263000 & 0.351 & -0.122 & 3 & 0.530 & -0.056 & 3 & 0.516 & -0.085 & 3 \\
04266500 & 0.501 & 0.088 & 2 & 0.354 & 0.082 & 3 & 0.266 & 0.145 & 2 \\
04296500 & 0.009 & 0.333 & 3 & 0.006 & 0.243 & 3 & 0.006 & 0.347 & 3 \\
\hline
\end{tabular}

Table C-3: Results of correlation tests (Pearson's $r$, Kendall's $\tau$ and Spearman's $\rho$ ) between AMF magnitude and flood-generating minimum temperature series with $\mathrm{X}$-days lead time yielding the highest correlation.

\begin{tabular}{|c|c|c|c|c|c|c|c|c|c|}
\hline Site & \multicolumn{3}{|c|}{ Pearson's $\boldsymbol{r}$} & \multicolumn{3}{c|}{ Kendall's $\boldsymbol{\tau}$} & \multicolumn{3}{c|}{ Spearman's $\boldsymbol{\rho}$} \\
Number & p-value & $\boldsymbol{r}$ & X-days & p-value & $\boldsymbol{\tau}$ & X-days & p-value & $\boldsymbol{\rho}$ & X-days \\
\hline 01017000 & 0.224 & 0.158 & 3 & 0.139 & 0.131 & 3 & 0.130 & 0.196 & 3 \\
01019000 & 0.673 & 0.055 & 2 & 0.784 & 0.025 & 2 & 0.732 & 0.045 & 2 \\
01034500 & 0.232 & 0.155 & 7 & 0.010 & 0.227 & 7 & 0.012 & 0.319 & 7 \\
01042500 & 0.452 & 0.098 & 2 & 0.149 & 0.128 & 2 & 0.162 & 0.181 & 2 \\
01049000 & 0.159 & 0.182 & 4 & 0.031 & 0.190 & 5 & 0.037 & 0.268 & 5 \\
01053500 & 0.044 & 0.259 & 5 & 0.008 & 0.233 & 4 & 0.006 & 0.346 & 4 \\
01066000 & 0.098 & 0.214 & 4 & 0.019 & 0.207 & 4 & 0.030 & 0.278 & 4 \\
01081000 & 0.001 & 0.421 & 3 & 0.001 & 0.299 & 2 & 0.001 & 0.417 & 2 \\
01087000 & 0.021 & 0.296 & 7 & 0.009 & 0.230 & 7 & 0.013 & 0.316 & 7 \\
01094500 & 0.008 & 0.340 & 7 & 0.003 & 0.267 & 3 & 0.001 & 0.417 & 3 \\
01101500 & 0.024 & 0.290 & 2 & 0.131 & 0.135 & 3 & 0.133 & 0.196 & 2 \\
01103500 & 0.082 & 0.226 & 3 & 0.134 & 0.134 & 3 & 0.125 & 0.200 & 3 \\
01109000 & 0.012 & 0.321 & 3 & 0.067 & 0.163 & 2 & 0.081 & 0.227 & 2 \\
01114500 & 0.076 & 0.231 & 2 & 0.120 & 0.139 & 2 & 0.107 & 0.210 & 2 \\
01116000 & 0.039 & 0.268 & 2 & 0.017 & 0.212 & 2 & 0.025 & 0.290 & 2 \\
01118000 & 0.140 & 0.193 & 2 & 0.579 & -0.050 & 5 & 0.654 & 0.059 & 2 \\
01119500 & 0.005 & 0.359 & 6 & 0.545 & 0.054 & 7 & 0.492 & 0.090 & 7 \\
01124000 & 0.003 & 0.377 & 6 & 0.109 & 0.143 & 2 & 0.122 & 0.202 & 2 \\
01127500 & 0.203 & 0.167 & 7 & 0.161 & 0.125 & 7 & 0.249 & 0.151 & 7 \\
01135500 & 0.154 & 0.185 & 2 & 0.509 & 0.059 & 4 & 0.539 & 0.080 & 4 \\
01139000 & 0.001 & 0.406 & 2 & 0.002 & 0.276 & 6 & 0.004 & 0.365 & 6
\end{tabular}


Table C-3, continued

\begin{tabular}{|c|c|c|c|c|c|c|c|c|c|}
\hline \multirow{2}{*}{$\begin{array}{c}\text { Site } \\
\text { Number }\end{array}$} & \multicolumn{3}{|c|}{ Pearson's $r$} & \multicolumn{3}{|c|}{ Kendall's $\tau$} & \multicolumn{3}{|c|}{ Spearman's $\rho$} \\
\hline & p-value & $r$ & X-days & p-value & $\tau$ & X-days & p-value & $\rho$ & X-days \\
\hline 01141500 & 0.026 & 0.286 & 5 & 0.252 & 0.102 & 5 & 0.159 & 0.183 & 5 \\
\hline 01151500 & 0.028 & 0.282 & 2 & 0.117 & 0.138 & 6 & 0.112 & 0.206 & 7 \\
\hline 01152500 & 0.102 & 0.211 & 3 & 0.011 & 0.224 & 3 & 0.015 & 0.309 & 3 \\
\hline 01153000 & 0.098 & 0.214 & 4 & 0.505 & 0.059 & 2 & 0.465 & 0.095 & 2 \\
\hline 01161000 & 0.001 & 0.415 & 6 & 0.020 & 0.205 & 7 & 0.018 & 0.301 & 3 \\
\hline 01168500 & 0.089 & 0.221 & 6 & 0.053 & 0.172 & 3 & 0.064 & 0.241 & 3 \\
\hline 01173500 & 0.000 & 0.458 & 2 & 0.100 & 0.146 & 2 & 0.099 & 0.215 & 2 \\
\hline 01174500 & 0.059 & 0.245 & 2 & 0.051 & 0.174 & 2 & 0.065 & 0.240 & 2 \\
\hline 01185500 & 0.009 & 0.334 & 6 & 0.013 & 0.221 & 5 & 0.011 & 0.327 & 5 \\
\hline 01189000 & 0.055 & 0.249 & 6 & 0.448 & 0.068 & 5 & 0.586 & 0.072 & 5 \\
\hline 01192500 & 0.810 & -0.032 & 4 & 0.418 & -0.072 & 4 & 0.437 & -0.102 & 4 \\
\hline 01193500 & 0.676 & 0.055 & 2 & 0.655 & -0.040 & 3 & 0.688 & -0.053 & 3 \\
\hline 01196500 & 0.404 & 0.110 & 7 & 0.683 & 0.037 & 6 & 0.684 & 0.054 & 6 \\
\hline 01208500 & 0.033 & 0.276 & 5 & 0.207 & 0.113 & 7 & 0.290 & 0.139 & 6 \\
\hline 03014500 & 0.418 & 0.106 & 2 & 0.474 & -0.064 & 7 & 0.456 & -0.097 & 6 \\
\hline 03024000 & 0.041 & -0.263 & 2 & 0.075 & -0.157 & 2 & 0.084 & -0.223 & 2 \\
\hline 03028500 & 0.745 & 0.043 & 7 & 0.332 & -0.086 & 6 & 0.317 & -0.130 & 6 \\
\hline 03038000 & 0.035 & 0.271 & 7 & 0.307 & 0.091 & 6 & 0.342 & 0.124 & 6 \\
\hline 03040000 & 0.016 & 0.307 & 3 & 0.223 & 0.108 & 2 & 0.187 & 0.171 & 3 \\
\hline 03041000 & 0.006 & 0.351 & 3 & 0.091 & 0.149 & 2 & 0.107 & 0.208 & 2 \\
\hline 03045000 & 0.083 & 0.224 & 5 & 0.195 & 0.114 & 5 & 0.172 & 0.177 & 4 \\
\hline 03072000 & 0.691 & -0.052 & 7 & 0.263 & -0.099 & 7 & 0.291 & -0.137 & 7 \\
\hline 03076500 & 0.232 & 0.155 & 5 & 0.124 & 0.136 & 5 & 0.123 & 0.199 & 5 \\
\hline 03086500 & 0.189 & 0.175 & 2 & 0.365 & 0.082 & 7 & 0.385 & 0.116 & 7 \\
\hline 03093000 & 0.498 & -0.089 & 7 & 0.180 & -0.119 & 7 & 0.193 & -0.170 & 7 \\
\hline 03106500 & 0.754 & -0.041 & 2 & 0.338 & -0.085 & 7 & 0.361 & -0.119 & 2 \\
\hline 03110000 & 0.341 & -0.125 & 3 & 0.076 & -0.158 & 3 & 0.085 & -0.224 & 3 \\
\hline 03111500 & 0.258 & 0.148 & 5 & 0.440 & 0.069 & 5 & 0.427 & 0.105 & 4 \\
\hline 03117500 & 0.204 & -0.166 & 5 & 0.095 & -0.149 & 4 & 0.127 & -0.199 & 4 \\
\hline 03118000 & 0.422 & 0.105 & 2 & 0.580 & 0.049 & 2 & 0.564 & 0.075 & 2 \\
\hline 03131500 & 0.178 & 0.179 & 2 & 0.537 & -0.056 & 5 & 0.548 & -0.081 & 5 \\
\hline 03133500 & 0.327 & 0.131 & 3 & 0.191 & 0.119 & 4 & 0.202 & 0.170 & 2 \\
\hline 03135000 & 0.063 & 0.245 & 2 & 0.629 & 0.044 & 4 & 0.638 & 0.063 & 3 \\
\hline 03140000 & 0.016 & 0.309 & 2 & 0.030 & 0.193 & 2 & 0.034 & 0.275 & 2 \\
\hline 03141500 & 0.459 & 0.099 & 2 & 0.413 & -0.075 & 5 & 0.427 & -0.106 & 5 \\
\hline 03147500 & 0.031 & -0.283 & 7 & 0.302 & -0.094 & 7 & 0.300 & -0.138 & 7 \\
\hline 03157000 & 0.689 & -0.053 & 7 & 0.418 & -0.072 & 5 & 0.371 & -0.117 & 5 \\
\hline 03165000 & 0.183 & 0.173 & 2 & 0.332 & 0.086 & 2 & 0.338 & 0.125 & 2 \\
\hline 03208500 & 0.585 & 0.071 & 7 & 0.268 & 0.098 & 7 & 0.238 & 0.153 & 7 \\
\hline 03209000 & 0.577 & -0.073 & 7 & 0.614 & 0.045 & 7 & 0.615 & 0.066 & 7 \\
\hline 03216500 & 0.256 & 0.149 & 3 & 0.436 & 0.070 & 3 & 0.497 & 0.089 & 3 \\
\hline 03227500 & 0.348 & -0.123 & 6 & 0.503 & 0.060 & 2 & 0.542 & 0.080 & 2 \\
\hline
\end{tabular}


Table C-3, continued

\begin{tabular}{|c|c|c|c|c|c|c|c|c|c|}
\hline \multirow{2}{*}{$\begin{array}{c}\text { Site } \\
\text { Number }\end{array}$} & \multicolumn{3}{|c|}{ Pearson's $r$} & \multicolumn{3}{|c|}{ Kendall's $\tau$} & \multicolumn{3}{|c|}{ Spearman's $\rho$} \\
\hline & p-value & $r$ & X-days & p-value & $\tau$ & X-days & p-value & $\rho$ & X-days \\
\hline 03228500 & 0.058 & -0.246 & 4 & 0.532 & -0.056 & 3 & 0.541 & -0.080 & 4 \\
\hline 03232500 & 0.567 & 0.075 & 4 & 0.838 & -0.019 & 2 & 0.892 & -0.018 & 7 \\
\hline 03238500 & 0.792 & 0.035 & 6 & 0.959 & 0.005 & 5 & 0.910 & 0.015 & 5 \\
\hline 03245500 & 0.659 & -0.058 & 7 & 0.422 & 0.072 & 7 & 0.428 & 0.104 & 7 \\
\hline 03253500 & 0.232 & -0.157 & 2 & 0.073 & -0.160 & 2 & 0.072 & -0.234 & 2 \\
\hline 03262000 & 0.198 & 0.169 & 2 & 0.281 & 0.096 & 7 & 0.356 & 0.121 & 7 \\
\hline 03264000 & 0.482 & -0.093 & 5 & 0.507 & -0.059 & 5 & 0.477 & -0.094 & 5 \\
\hline 03267000 & 0.142 & -0.192 & 4 & 0.716 & -0.033 & 3 & 0.538 & -0.081 & 3 \\
\hline 03272000 & 0.117 & -0.204 & 2 & 0.031 & -0.192 & 2 & 0.028 & -0.284 & 2 \\
\hline 03276500 & 0.002 & -0.391 & 4 & 0.016 & -0.212 & 2 & 0.017 & -0.305 & 2 \\
\hline 03280000 & 0.104 & 0.212 & 7 & 0.118 & 0.139 & 2 & 0.141 & 0.192 & 2 \\
\hline 03281000 & 0.403 & -0.110 & 2 & 0.062 & 0.166 & 3 & 0.051 & 0.253 & 3 \\
\hline 03283500 & 0.503 & 0.088 & 2 & 0.418 & 0.072 & 2 & 0.400 & 0.111 & 2 \\
\hline 03285000 & 0.325 & 0.133 & 7 & 0.483 & -0.065 & 4 & 0.465 & -0.099 & 5 \\
\hline 03302000 & 0.337 & 0.126 & 3 & 0.112 & 0.141 & 3 & 0.112 & 0.207 & 7 \\
\hline 03320000 & 0.721 & 0.047 & 2 & 0.176 & 0.121 & 2 & 0.146 & 0.190 & 2 \\
\hline 03325000 & 0.674 & 0.055 & 4 & 0.304 & -0.091 & 7 & 0.473 & -0.094 & 7 \\
\hline 03326500 & 0.020 & 0.297 & 2 & 0.087 & 0.151 & 2 & 0.089 & 0.220 & 2 \\
\hline 03328000 & 0.323 & -0.129 & 7 & 0.390 & -0.076 & 5 & 0.313 & -0.131 & 6 \\
\hline 03329700 & 0.316 & 0.131 & 2 & 0.808 & 0.022 & 3 & 0.778 & 0.037 & 3 \\
\hline 03347000 & 0.390 & 0.112 & 3 & 0.559 & 0.052 & 2 & 0.492 & 0.090 & 4 \\
\hline 03352500 & 0.202 & 0.166 & 3 & 0.142 & 0.130 & 3 & 0.157 & 0.183 & 3 \\
\hline 03353500 & 0.406 & 0.109 & 7 & 0.833 & -0.019 & 2 & 0.781 & -0.037 & 2 \\
\hline 03360000 & 0.178 & 0.175 & 2 & 0.408 & 0.073 & 2 & 0.409 & 0.108 & 2 \\
\hline 03361500 & 0.116 & -0.203 & 4 & 0.390 & -0.076 & 3 & 0.340 & -0.124 & 3 \\
\hline 03362000 & 0.164 & 0.181 & 2 & 0.247 & 0.102 & 2 & 0.275 & 0.142 & 2 \\
\hline 03363500 & 0.135 & -0.193 & 5 & 0.220 & -0.108 & 6 & 0.235 & -0.154 & 6 \\
\hline 03369500 & 0.092 & 0.218 & 2 & 0.005 & 0.250 & 3 & 0.003 & 0.372 & 3 \\
\hline 03376500 & 0.127 & 0.197 & 7 & 0.257 & 0.100 & 7 & 0.208 & 0.164 & 7 \\
\hline 03378000 & 0.368 & 0.117 & 4 & 0.319 & 0.088 & 4 & 0.376 & 0.115 & 4 \\
\hline 03381500 & 0.473 & 0.094 & 2 & 0.700 & 0.035 & 2 & 0.628 & 0.063 & 3 \\
\hline 03401000 & 0.327 & 0.133 & 3 & 0.276 & 0.101 & 3 & 0.348 & 0.128 & 3 \\
\hline 03406500 & 0.138 & 0.194 & 7 & 0.078 & 0.157 & 7 & 0.058 & 0.247 & 7 \\
\hline 03414500 & 0.147 & 0.191 & 7 & 0.395 & 0.157 & 7 & 0.062 & 0.245 & 7 \\
\hline 03421000 & 0.397 & 0.111 & 7 & 0.440 & 0.068 & 7 & 0.444 & 0.100 & 7 \\
\hline 03433500 & 0.421 & 0.105 & 2 & 0.672 & -0.038 & 5 & 0.719 & -0.047 & 5 \\
\hline 04024000 & 0.165 & -0.180 & 3 & 0.126 & -0.135 & 3 & 0.126 & -0.198 & 3 \\
\hline 04034500 & 0.002 & -0.393 & 2 & 0.007 & -0.236 & 2 & 0.007 & -0.340 & 2 \\
\hline 04036000 & 0.151 & 0.186 & 5 & 0.065 & 0.163 & 5 & 0.070 & 0.233 & 5 \\
\hline 04037500 & 0.265 & 0.145 & 5 & 0.074 & 0.158 & 5 & 0.088 & 0.220 & 5 \\
\hline 04041500 & 0.072 & 0.232 & 5 & 0.191 & 0.116 & 4 & 0.192 & 0.169 & 5 \\
\hline 04060993 & 0.160 & 0.182 & 7 & 0.592 & -0.048 & 2 & 0.626 & -0.064 & 2 \\
\hline
\end{tabular}


Table C-3, continued

\begin{tabular}{|c|c|c|c|c|c|c|c|c|c|}
\hline \multirow{2}{*}{$\begin{array}{c}\text { Site } \\
\text { Number }\end{array}$} & \multicolumn{3}{|c|}{ Pearson's $r$} & \multicolumn{3}{|c|}{ Kendall's $\tau$} & \multicolumn{3}{|c|}{ Spearman's $\rho$} \\
\hline & p-value & $r$ & X-days & p-value & $\tau$ & X-days & p-value & $\rho$ & X-days \\
\hline 04062500 & 0.042 & 0.261 & 5 & 0.085 & 0.152 & 5 & 0.084 & 0.223 & 5 \\
\hline 04087000 & 0.190 & 0.170 & 2 & 0.588 & -0.048 & 6 & 0.663 & -0.057 & 6 \\
\hline 04099000 & 0.199 & -0.167 & 2 & 0.027 & -0.195 & 7 & 0.026 & -0.285 & 7 \\
\hline 04099510 & 0.278 & -0.141 & 2 & 0.050 & -0.173 & 3 & 0.036 & -0.269 & 3 \\
\hline 04105500 & 0.524 & -0.083 & 2 & 0.360 & -0.081 & 2 & 0.355 & -0.121 & 2 \\
\hline 04109000 & 0.006 & 0.348 & 2 & 0.006 & 0.242 & 2 & 0.006 & 0.348 & 2 \\
\hline 04112500 & 0.768 & -0.039 & 7 & 0.677 & -0.037 & 7 & 0.745 & -0.043 & 7 \\
\hline 04115000 & 0.013 & 0.315 & 2 & 0.075 & 0.157 & 2 & 0.076 & 0.229 & 2 \\
\hline 04117500 & 0.138 & 0.192 & 5 & 0.411 & 0.073 & 3 & 0.431 & 0.103 & 5 \\
\hline 04122500 & 0.047 & 0.256 & 4 & 0.265 & 0.099 & 4 & 0.302 & 0.134 & 4 \\
\hline 04124000 & 0.212 & 0.162 & 7 & 0.134 & 0.133 & 7 & 0.123 & 0.200 & 7 \\
\hline 04127997 & 0.490 & 0.090 & 6 & 0.645 & 0.041 & 6 & 0.682 & 0.054 & 6 \\
\hline 04146000 & 0.051 & 0.251 & 3 & 0.404 & 0.074 & 3 & 0.449 & 0.099 & 3 \\
\hline 04151500 & 0.487 & 0.091 & 5 & 0.718 & -0.032 & 4 & 0.784 & -0.036 & 2 \\
\hline 04154000 & 0.130 & 0.196 & 2 & 0.440 & 0.069 & 2 & 0.429 & 0.103 & 2 \\
\hline 04155000 & 0.693 & 0.052 & 3 & 0.563 & -0.051 & 7 & 0.507 & -0.087 & 2 \\
\hline 04159492 & 0.086 & -0.222 & 2 & 0.029 & -0.192 & 2 & 0.022 & -0.293 & 2 \\
\hline 04165500 & 0.338 & -0.125 & 2 & 0.370 & -0.079 & 4 & 0.347 & -0.123 & 4 \\
\hline 04166500 & 0.224 & 0.158 & 6 & 0.279 & 0.096 & 2 & 0.307 & 0.133 & 2 \\
\hline 04176500 & 0.545 & -0.079 & 2 & 0.310 & -0.090 & 2 & 0.333 & -0.126 & 2 \\
\hline 04185000 & 0.680 & -0.054 & 7 & 0.320 & 0.089 & 3 & 0.319 & 0.131 & 3 \\
\hline 04186500 & 0.771 & -0.038 & 7 & 0.247 & -0.102 & 7 & 0.280 & -0.140 & 7 \\
\hline 04195500 & 0.168 & -0.179 & 7 & 0.173 & -0.120 & 7 & 0.166 & -0.180 & 7 \\
\hline 04200500 & 0.142 & 0.192 & 3 & 0.674 & -0.038 & 7 & 0.722 & -0.047 & 7 \\
\hline 04202000 & 0.007 & -0.344 & 7 & 0.004 & -0.258 & 7 & 0.004 & -0.362 & 7 \\
\hline 04231000 & 0.403 & 0.109 & 2 & 0.367 & 0.080 & 2 & 0.357 & 0.120 & 2 \\
\hline 04252500 & 0.013 & 0.315 & 2 & 0.058 & 0.167 & 3 & 0.051 & 0.251 & 2 \\
\hline 04258000 & 0.095 & 0.215 & 2 & 0.033 & 0.188 & 2 & 0.037 & 0.267 & 2 \\
\hline 04263000 & 0.325 & -0.128 & 2 & 0.429 & -0.070 & 3 & 0.418 & -0.105 & 2 \\
\hline 04266500 & 0.426 & -0.104 & 5 & 0.668 & 0.038 & 2 & 0.658 & 0.058 & 2 \\
\hline 04296500 & 0.043 & 0.260 & 4 & 0.002 & 0.277 & 5 & 0.002 & 0.390 & 5 \\
\hline
\end{tabular}

\section{C2: Correlation with AMF timing}

Table C-4 provides the results obtained from the Pearson's $r$ correlation test between the timing of AMF peaks and the flood-generating minimum/maximum temperature series for the X-days lead time yielding the highest degree of correlation. For each site, the resulting test statistic and p-value are reported. Only results significant at the $10 \%$ significance level are included; those sites significant also at the 5\% level are in bold. 
Table C-4: Results of Pearson's $r$ correlation test between AMF timing and floodgenerating minimum and maximum temperature series with X-days lead time yielding the highest correlation.

\begin{tabular}{|c|c|c|c|c|c|c|c|}
\hline \multirow{2}{*}{$\begin{array}{c}\text { Site } \\
\text { Number }\end{array}$} & \multirow{2}{*}{$\mathbf{n}$} & \multicolumn{3}{|c|}{ maximum temperature } & \multicolumn{3}{|c|}{ minimum temperature } \\
\hline & & p-value & $r$ & X-days & p-value & $r$ & X-days \\
\hline 01017000 & 61 & 0.000 & 0.584 & 7 & 0.003 & 0.373 & 7 \\
\hline 01019000 & 61 & 0.000 & 0.703 & 7 & 0.000 & 0.649 & 7 \\
\hline 01034500 & 61 & 0.000 & 0.540 & 7 & 0.000 & 0.440 & 7 \\
\hline 01042500 & 61 & 0.000 & 0.699 & 7 & 0.000 & 0.657 & 2 \\
\hline 01049000 & 61 & 0.000 & 0.439 & 7 & 0.040 & 0.263 & 7 \\
\hline 01066000 & 61 & 0.000 & 0.596 & 2 & 0.000 & 0.492 & 3 \\
\hline 01081000 & 61 & 0.000 & 0.757 & 6 & 0.000 & 0.677 & 4 \\
\hline 01087000 & 61 & 0.000 & 0.600 & 7 & 0.000 & 0.529 & 6 \\
\hline 01094500 & 60 & 0.000 & 0.607 & 3 & 0.000 & 0.522 & 4 \\
\hline 01101500 & 60 & 0.044 & 0.261 & 7 & 0.009 & 0.335 & 7 \\
\hline 01103500 & 60 & 0.000 & 0.640 & 6 & 0.000 & 0.687 & 3 \\
\hline 01109000 & 60 & 0.000 & 0.605 & 4 & 0.000 & 0.530 & 2 \\
\hline 01114500 & 60 & 0.000 & 0.674 & 6 & 0.000 & 0.631 & 5 \\
\hline 01116000 & 60 & 0.000 & 0.508 & 5 & 0.000 & 0.481 & 7 \\
\hline 01118000 & 60 & 0.000 & 0.527 & 4 & 0.000 & 0.499 & 7 \\
\hline 01119500 & 60 & 0.000 & 0.698 & 6 & 0.000 & 0.660 & 5 \\
\hline 01124000 & 60 & 0.000 & 0.697 & 5 & 0.000 & 0.599 & 7 \\
\hline 01127500 & 60 & 0.001 & 0.428 & 7 & 0.000 & 0.447 & 5 \\
\hline 01135500 & 61 & 0.000 & 0.618 & 5 & 0.000 & 0.499 & 4 \\
\hline 01139000 & 61 & 0.000 & 0.591 & 5 & 0.000 & 0.525 & 4 \\
\hline 01141500 & 61 & 0.000 & 0.503 & 6 & 0.000 & 0.451 & 5 \\
\hline 01151500 & 61 & 0.000 & 0.499 & 5 & 0.001 & 0.410 & 5 \\
\hline 01152500 & 61 & 0.000 & 0.627 & 6 & 0.000 & 0.660 & 4 \\
\hline 01153000 & 61 & 0.000 & 0.728 & 6 & 0.000 & 0.743 & 5 \\
\hline 01161000 & 61 & 0.001 & 0.414 & 6 & 0.000 & 0.457 & 5 \\
\hline 01168500 & 60 & 0.000 & 0.585 & 6 & 0.000 & 0.573 & 4 \\
\hline 01173500 & 60 & 0.000 & 0.707 & 6 & 0.000 & 0.645 & 4 \\
\hline 01174500 & 60 & 0.000 & 0.725 & 6 & 0.000 & 0.672 & 4 \\
\hline 01185500 & 60 & 0.000 & 0.627 & 7 & 0.000 & 0.618 & 7 \\
\hline 01189000 & 60 & 0.000 & 0.681 & 5 & 0.000 & 0.681 & 7 \\
\hline 01192500 & 60 & 0.000 & 0.703 & 5 & 0.000 & 0.684 & 4 \\
\hline 01193500 & 60 & 0.000 & 0.536 & 5 & 0.000 & 0.504 & 7 \\
\hline 01196500 & 60 & 0.000 & 0.724 & 5 & 0.000 & 0.694 & 7 \\
\hline 01208500 & 60 & 0.000 & 0.677 & 5 & 0.000 & 0.695 & 7 \\
\hline 03014500 & 61 & 0.000 & 0.585 & 4 & 0.000 & 0.531 & 2 \\
\hline 03024000 & 61 & 0.000 & 0.585 & 4 & 0.000 & 0.593 & 2 \\
\hline 03028500 & 61 & 0.000 & 0.633 & 2 & 0.000 & 0.555 & 2 \\
\hline 03038000 & 61 & 0.000 & 0.694 & 5 & 0.000 & 0.683 & 2 \\
\hline 03040000 & 61 & 0.000 & 0.659 & 7 & 0.000 & 0.675 & 2 \\
\hline
\end{tabular}


Table C-4, continued

\begin{tabular}{|c|c|c|c|c|c|c|c|}
\hline \multirow{2}{*}{$\begin{array}{c}\text { Site } \\
\text { Number }\end{array}$} & \multirow{2}{*}{$\mathbf{n}$} & \multicolumn{3}{|c|}{ maximum temperature } & \multicolumn{3}{|c|}{ minimum temperature } \\
\hline & & p-value & $r$ & X-days & p-value & $r$ & X-days \\
\hline 03041000 & 61 & 0.000 & 0.537 & 2 & 0.000 & 0.535 & 2 \\
\hline 03045000 & 61 & 0.000 & 0.742 & 2 & 0.000 & 0.753 & 2 \\
\hline 03072000 & 61 & 0.000 & 0.460 & 3 & 0.000 & 0.438 & 2 \\
\hline 03076500 & 61 & 0.000 & 0.743 & 6 & 0.000 & 0.742 & 2 \\
\hline 03086500 & 58 & 0.000 & 0.770 & 3 & 0.000 & 0.815 & 2 \\
\hline 03093000 & 60 & 0.000 & 0.758 & 4 & 0.000 & 0.713 & 3 \\
\hline 03106500 & 61 & 0.000 & 0.789 & 7 & 0.000 & 0.797 & 2 \\
\hline 03110000 & 60 & 0.000 & 0.827 & 4 & 0.000 & 0.856 & 2 \\
\hline 03111500 & 60 & 0.000 & 0.776 & 2 & 0.000 & 0.759 & 2 \\
\hline 03117500 & 60 & 0.000 & 0.737 & 7 & 0.000 & 0.811 & 2 \\
\hline 03118000 & 61 & 0.000 & 0.891 & 7 & 0.000 & 0.866 & 6 \\
\hline 03131500 & 58 & 0.000 & 0.845 & 6 & 0.000 & 0.836 & 2 \\
\hline 03133500 & 58 & 0.000 & 0.849 & 7 & 0.000 & 0.840 & 7 \\
\hline 03135000 & 58 & 0.000 & 0.814 & 7 & 0.000 & 0.773 & 7 \\
\hline 03140000 & 60 & 0.000 & 0.758 & 3 & 0.000 & 0.746 & 2 \\
\hline 03141500 & 58 & 0.000 & 0.701 & 6 & 0.000 & 0.657 & 6 \\
\hline 03147500 & 58 & 0.000 & 0.893 & 7 & 0.000 & 0.873 & 7 \\
\hline 03157000 & 60 & 0.000 & 0.779 & 2 & 0.000 & 0.720 & 2 \\
\hline 03165000 & 61 & 0.000 & 0.596 & 6 & 0.000 & 0.624 & 7 \\
\hline 03208500 & 61 & 0.000 & 0.652 & 4 & 0.000 & 0.715 & 2 \\
\hline 03209000 & 61 & 0.000 & 0.682 & 2 & 0.000 & 0.705 & 2 \\
\hline 03216500 & 60 & 0.000 & 0.672 & 6 & 0.000 & 0.624 & 7 \\
\hline 03227500 & 60 & 0.000 & 0.877 & 7 & 0.000 & 0.841 & 2 \\
\hline 03228500 & 60 & 0.000 & 0.843 & 7 & 0.000 & 0.821 & 7 \\
\hline 03232500 & 60 & 0.000 & 0.802 & 5 & 0.000 & 0.786 & 2 \\
\hline 03238500 & 60 & 0.000 & 0.751 & 2 & 0.000 & 0.740 & 2 \\
\hline 03245500 & 60 & 0.000 & 0.855 & 7 & 0.000 & 0.849 & 2 \\
\hline 03253500 & 60 & 0.000 & 0.700 & 2 & 0.000 & 0.660 & 2 \\
\hline 03262000 & 60 & 0.000 & 0.814 & 7 & 0.000 & 0.817 & 7 \\
\hline 03264000 & 60 & 0.000 & 0.844 & 7 & 0.000 & 0.800 & 7 \\
\hline 03267000 & 60 & 0.000 & 0.757 & 7 & 0.000 & 0.718 & 7 \\
\hline 03272000 & 60 & 0.000 & 0.558 & 2 & 0.000 & 0.569 & 2 \\
\hline 03276500 & 61 & 0.000 & 0.712 & 7 & 0.000 & 0.690 & 2 \\
\hline 03280000 & 60 & 0.000 & 0.505 & 7 & 0.000 & 0.526 & 7 \\
\hline 03281000 & 60 & 0.000 & 0.623 & 7 & 0.000 & 0.603 & 7 \\
\hline 03283500 & 60 & 0.000 & 0.686 & 7 & 0.000 & 0.619 & 3 \\
\hline 03285000 & 57 & 0.000 & 0.629 & 2 & 0.000 & 0.637 & 2 \\
\hline 03302000 & 60 & 0.000 & 0.776 & 7 & 0.000 & 0.749 & 2 \\
\hline 03320000 & 60 & 0.000 & 0.725 & 6 & 0.000 & 0.701 & 7 \\
\hline 03325000 & 61 & 0.000 & 0.861 & 7 & 0.000 & 0.812 & 7 \\
\hline 03326500 & 61 & 0.000 & 0.838 & 2 & 0.000 & 0.839 & 2 \\
\hline 03328000 & 61 & 0.000 & 0.719 & 7 & 0.000 & 0.656 & 7 \\
\hline
\end{tabular}


Table C-4, continued

\begin{tabular}{|c|c|c|c|c|c|c|c|}
\hline \multirow{2}{*}{$\begin{array}{c}\text { Site } \\
\text { Number }\end{array}$} & \multirow{2}{*}{$\mathbf{n}$} & \multicolumn{3}{|c|}{ maximum temperature } & \multicolumn{3}{|c|}{ minimum temperature } \\
\hline & & p-value & $r$ & X-days & p-value & $r$ & X-days \\
\hline 03329700 & 61 & 0.000 & 0.818 & 7 & 0.000 & 0.790 & 7 \\
\hline 03347000 & 61 & 0.000 & 0.802 & 7 & 0.000 & 0.801 & 2 \\
\hline 03352500 & 61 & 0.000 & 0.712 & 7 & 0.000 & 0.684 & 3 \\
\hline 03353500 & 60 & 0.000 & 0.742 & 7 & 0.000 & 0.698 & 7 \\
\hline 03360000 & 61 & 0.000 & 0.705 & 7 & 0.000 & 0.714 & 2 \\
\hline 03361500 & 61 & 0.000 & 0.671 & 3 & 0.000 & 0.703 & 2 \\
\hline 03362000 & 61 & 0.000 & 0.707 & 7 & 0.000 & 0.740 & 2 \\
\hline 03363500 & 61 & 0.000 & 0.811 & 7 & 0.000 & 0.798 & 7 \\
\hline 03369500 & 61 & 0.000 & 0.742 & 7 & 0.000 & 0.772 & 2 \\
\hline 03376500 & 61 & 0.000 & 0.764 & 6 & 0.000 & 0.746 & 5 \\
\hline 03378000 & 61 & 0.000 & 0.723 & 7 & 0.000 & 0.687 & 7 \\
\hline 03381500 & 61 & 0.000 & 0.846 & 5 & 0.000 & 0.811 & 5 \\
\hline 03401000 & 56 & 0.001 & 0.420 & 7 & 0.005 & 0.372 & 3 \\
\hline 03406500 & 60 & 0.000 & 0.518 & 4 & 0.000 & 0.515 & 3 \\
\hline 03414500 & 59 & 0.000 & 0.442 & 4 & 0.000 & 0.440 & 4 \\
\hline 03421000 & 61 & 0.020 & 0.298 & 4 & 0.074 & 0.231 & 5 \\
\hline 03433500 & 61 & 0.000 & 0.487 & 2 & 0.001 & 0.421 & 7 \\
\hline 04024000 & 61 & 0.000 & 0.560 & 7 & 0.000 & 0.528 & 7 \\
\hline 04036000 & 61 & 0.000 & 0.603 & 7 & 0.000 & 0.563 & 7 \\
\hline 04037500 & 61 & 0.000 & 0.541 & 7 & 0.000 & 0.442 & 7 \\
\hline 04041500 & 61 & 0.001 & 0.423 & 7 & 0.000 & 0.435 & 7 \\
\hline 04060993 & 61 & 0.000 & 0.518 & 7 & 0.000 & 0.512 & 7 \\
\hline 04062500 & 61 & 0.000 & 0.588 & 7 & 0.000 & 0.558 & 7 \\
\hline 04087000 & 61 & 0.000 & 0.700 & 4 & 0.000 & 0.679 & 4 \\
\hline 04099000 & 61 & 0.000 & 0.617 & 2 & 0.000 & 0.593 & 7 \\
\hline 04099510 & 61 & 0.000 & 0.682 & 2 & 0.000 & 0.702 & 2 \\
\hline 04105500 & 61 & 0.000 & 0.712 & 6 & 0.000 & 0.677 & 4 \\
\hline 04109000 & 61 & 0.000 & 0.690 & 7 & 0.000 & 0.681 & 2 \\
\hline 04112500 & 61 & 0.000 & 0.654 & 7 & 0.000 & 0.603 & 7 \\
\hline 04115000 & 61 & 0.000 & 0.633 & 7 & 0.000 & 0.607 & 2 \\
\hline 04117500 & 61 & 0.000 & 0.523 & 7 & 0.000 & 0.470 & 2 \\
\hline 04122500 & 61 & 0.000 & 0.548 & 2 & 0.000 & 0.503 & 3 \\
\hline 04124000 & 61 & 0.003 & 0.375 & 4 & 0.012 & 0.321 & 7 \\
\hline 04127997 & 61 & 0.000 & 0.553 & 7 & 0.000 & 0.515 & 5 \\
\hline 04146000 & 61 & 0.000 & 0.505 & 5 & 0.000 & 0.460 & 5 \\
\hline 04151500 & 61 & 0.000 & 0.617 & 7 & 0.000 & 0.624 & 3 \\
\hline 04154000 & 61 & 0.000 & 0.724 & 7 & 0.000 & 0.678 & 7 \\
\hline 04155000 & 61 & 0.000 & 0.589 & 4 & 0.000 & 0.614 & 2 \\
\hline 04159492 & 61 & 0.000 & 0.529 & 2 & 0.000 & 0.541 & 2 \\
\hline 04165500 & 61 & 0.000 & 0.655 & 4 & 0.000 & 0.665 & 3 \\
\hline 04166500 & 61 & 0.000 & 0.708 & 4 & 0.000 & 0.713 & 3 \\
\hline 04176500 & 61 & 0.000 & 0.698 & 7 & 0.000 & 0.681 & 7 \\
\hline
\end{tabular}


Table C-4, continued

\begin{tabular}{|c|c|c|c|c|cccc|}
\hline $\begin{array}{c}\text { Site } \\
\text { Number }\end{array}$ & \multirow{n}{*}{} & \multicolumn{2}{|c|}{ maximum temperature } & \multicolumn{3}{c|}{ minimum temperature } \\
\cline { 3 - 8 } & & p-value & $\boldsymbol{r}$ & X-days & p-value & $\boldsymbol{r}$ & X-days \\
\hline 04185000 & 60 & $\mathbf{0 . 0 0 0}$ & 0.709 & 2 & $\mathbf{0 . 0 0 0}$ & 0.666 & 2 \\
04186500 & 61 & $\mathbf{0 . 0 0 0}$ & 0.848 & 5 & $\mathbf{0 . 0 0 0}$ & 0.840 & 3 \\
04195500 & 61 & $\mathbf{0 . 0 0 0}$ & 0.832 & 7 & $\mathbf{0 . 0 0 0}$ & 0.791 & 2 \\
04200500 & 60 & $\mathbf{0 . 0 0 0}$ & 0.871 & 7 & $\mathbf{0 . 0 0 0}$ & 0.819 & 7 \\
04202000 & 60 & $\mathbf{0 . 0 0 0}$ & 0.728 & 6 & $\mathbf{0 . 0 0 0}$ & 0.710 & 5 \\
04231000 & 61 & $\mathbf{0 . 0 0 0}$ & 0.644 & 2 & $\mathbf{0 . 0 0 0}$ & 0.620 & 2 \\
04252500 & 61 & $\mathbf{0 . 0 0 0}$ & 0.555 & 7 & $\mathbf{0 . 0 0 0}$ & 0.502 & 5 \\
04258000 & 61 & $\mathbf{0 . 0 0 0}$ & 0.574 & 7 & $\mathbf{0 . 0 0 0}$ & 0.487 & 6 \\
04263000 & 61 & $\mathbf{0 . 0 0 0}$ & 0.456 & 2 & 0.079 & 0.227 & 2 \\
04266500 & 61 & $\mathbf{0 . 0 0 0}$ & 0.636 & 3 & $\mathbf{0 . 0 0 0}$ & 0.601 & 2 \\
04296500 & 61 & $\mathbf{0 . 0 0 0}$ & 0.500 & 7 & $\mathbf{0 . 0 0 1}$ & 0.417 & 4 \\
\hline
\end{tabular}

\section{C3: Non-stationarity in precipitation series}

Table C-5 summarizes the sites for which trends and/or change-points were detected in precipitation series. For each site non-stationarity was investigated considering the precipitation series with X-days lead time yielding the highest correlation with AMF series as reported in Table C-1. Only sites with results significant at the $10 \%$ are reported in the table; results also significant at the $5 \%$ are in bold.

Table C-5: Results of Mann-Kendall tests and Pettitt tests (significant at the 10\% and $5 \%$ (bold) significance levels) on precipitation series with X-days lead time yielding the highest correlation with AMF magnitude. Increasing (up) / decreasing (down) trends, year of change-point, positive $(+) /$ negative $(-)$ shifts are specified.

\begin{tabular}{|c|l|cc|ccc|}
\hline $\begin{array}{c}\text { Site } \\
\text { Number }\end{array}$ & \multirow{2}{*}{$\mathbf{n}$} & \multicolumn{2}{|c|}{ Mann-Kendall test } & \multicolumn{3}{|c|}{ Pettitt test } \\
\cline { 3 - 7 } & & p-value & trend & p-value & year & shift \\
\hline 01053500 & 61 & 0.357 & & $\mathbf{0 . 0 4 4}$ & 1995 & + \\
01094500 & 60 & 0.076 & up & $\mathbf{0 . 0 2 2}$ & 1973 & + \\
01101500 & 60 & 0.055 & up & $\mathbf{0 . 0 0 4}$ & 1978 & + \\
01109000 & 60 & 0.094 & up & & 1997 & \\
01114500 & 60 & 0.267 & & $\mathbf{0 . 0 3 7}$ & 1977 & + \\
01116000 & 60 & 0.146 & & 0.053 & 1966 & + \\
01119500 & 60 & 0.278 & & $\mathbf{0 . 0 4 5}$ & 1972 & + \\
01135500 & 61 & 0.423 & & 0.059 & 1994 & + \\
01141500 & 61 & 0.586 & & 0.063 & 1987 & + \\
01161000 & 61 & 0.116 & & $\mathbf{0 . 0 0 7}$ & 1973 & + \\
01168500 & 60 & 0.387 & & 0.062 & 1968 & +
\end{tabular}


Table C-5, continued

\begin{tabular}{|c|c|ccc|c|cc|}
\hline \multirow{2}{*}{$\begin{array}{c}\text { Site } \\
\text { Number }\end{array}$} & \multirow{2}{*}{$\mathbf{n}$} & \multicolumn{2}{|c|}{ Mann-Kendall test } & \multicolumn{3}{|c|}{ Pettitt test } \\
\cline { 3 - 7 } & & p-value & trend & p-value & year & shift \\
\hline 01173500 & 60 & 0.063 & up & $\mathbf{0 . 0 0 2}$ & 1972 & + \\
01174500 & 60 & $\mathbf{0 . 0 4 5}$ & up & $\mathbf{0 . 0 0 1}$ & 1973 & + \\
01185500 & 60 & 0.324 & & $\mathbf{0 . 0 2 5}$ & 1968 & + \\
01192500 & 60 & 0.137 & & 0.059 & 1973 & + \\
01193500 & 60 & 0.148 & & $\mathbf{0 . 0 0 5}$ & 1969 & + \\
01196500 & 60 & 0.227 & & $\mathbf{0 . 0 2 3}$ & 1977 & + \\
01208500 & 60 & 0.154 & & $\mathbf{0 . 0 1 8}$ & 1973 & + \\
03326500 & 61 & 0.706 & & 0.091 & 1988 & + \\
03328000 & 61 & 0.382 & & $\mathbf{0 . 0 4 2}$ & 1989 & + \\
03363500 & 61 & 0.346 & & 0.053 & 1987 & + \\
03376500 & 61 & 0.301 & & 0.098 & 1976 & + \\
03378000 & 61 & 0.186 & & $\mathbf{0 . 0 3 6}$ & 1981 & + \\
04099000 & 61 & 0.176 & & $\mathbf{0 . 0 1 5}$ & 1983 & + \\
04099510 & 61 & $\mathbf{0 . 0 1 8}$ & up & $<\mathbf{0 . 0 0 0 1}$ & 1986 & + \\
04105500 & 61 & $\mathbf{0 . 0 3 9}$ & up & $\mathbf{0 . 0 1 1}$ & 1984 & + \\
04115000 & 61 & 0.229 & & $\mathbf{0 . 0 1 8}$ & 1984 & + \\
04117500 & 61 & 0.188 & & $\mathbf{0 . 0 0 4}$ & 1986 & + \\
04151500 & 61 & 0.158 & & $\mathbf{0 . 0 2 4}$ & 1967 & + \\
04176500 & 61 & 0.170 & & 0.081 & 1974 & - \\
04185000 & 60 & 0.361 & & 0.084 & 1984 & + \\
\hline
\end{tabular}




\section{Appendix D \\ Large-scale climate patterns}

This appendix reports the main results of Kendall's $\tau$ correlation tests employed to investigate the association between the 10-years moving averaged series of flood flows and 3-months averaged climatic anomalies representing PDO, AMO, NAO and ENSO. Only results significant at the $10 \%$ significance level are included in the tables; results also significant at the 5\% level are in bold. The test was run for 112 watersheds as discussed in Chapter 4. A separate table is provided for each of the five climatic anomalies considered with 3-, 6- and 9-months lead time. However, for each climatic index, the X-months lead time yielding the highest correlation with AMF magnitude was: 9-months for PDO and MEI; 3-months for AMO and NAO; and 6-months for NINO 3.4.

Table D-1: Results of Kendall's $\tau$ correlation tests (significant at the $10 \%$ and $5 \%$ (bold) levels) between 10-years moving averaged series of AMF magnitude and 3-months averaged PDO anomalies with 3-, 6- and 9-months lead time.

\begin{tabular}{|c|c|cc|c|c|cc|}
\hline \multirow{2}{*}{$\begin{array}{c}\text { Site } \\
\text { Number }\end{array}$} & \multirow{n}{*}{} & \multicolumn{2}{|c|}{ 3-months } & \multicolumn{2}{c|}{ 6-months } & \multicolumn{2}{c|}{ 9-months } \\
\cline { 3 - 8 } & & p-value & $\boldsymbol{\tau}$ & \multicolumn{1}{|c|}{ p-value } & $\boldsymbol{\tau}$ & p-value & $\boldsymbol{\tau}$ \\
\hline 01017000 & 54 & $\mathbf{0 . 0 0 4}$ & 0.071 & $\mathbf{0 . 0 0 3}$ & 0.079 & $\mathbf{0 . 0 0 3}$ & 0.079 \\
01034500 & 54 & $\mathbf{0 . 0 2 8}$ & 0.043 & $\mathbf{0 . 0 0 8}$ & 0.062 & $\mathbf{0 . 0 1 0}$ & 0.058 \\
01042500 & 54 & $\mathbf{0 . 0 1 1}$ & 0.058 & $\mathbf{0 . 0 1 5}$ & 0.052 & $\mathbf{0 . 0 3 3}$ & 0.040 \\
01066000 & 54 & & & & & $\mathbf{0 . 0 1 7}$ & 0.050 \\
01081000 & 54 & $\mathbf{0 . 0 0 3}$ & 0.078 & 0.063 & 0.031 & $\mathbf{0 . 0 1 2}$ & 0.056 \\
01087000 & 54 & $\mathbf{0 . 0 1 1}$ & 0.058 & & & 0.072 & 0.029 \\
01094500 & 54 & & & & & $\mathbf{0 . 0 2 6}$ & 0.044 \\
01101500 & 54 & 0.093 & 0.025 & & & & \\
01103500 & 54 & 0.052 & 0.034 & 0.064 & 0.030 & $\mathbf{0 . 0 4 7}$ & 0.035 \\
01109000 & 54 & 0.070 & 0.029 & & & & \\
01114500 & 54 & $\mathbf{0 . 0 0 9}$ & 0.060 & $\mathbf{0 . 0 2 9}$ & 0.042 & 0.076 & 0.028 \\
01116000 & 54 & 0.053 & 0.033 & & & & \\
01118000 & 54 & $\mathbf{0 . 0 1 8}$ & 0.049 & 0.057 & 0.032 & $\mathbf{0 . 0 0 5}$ & 0.070 \\
01124000 & 54 & & & & & $\mathbf{0 . 0 3 4}$ & 0.040 \\
01127500 & 54 & $\mathbf{0 . 0 0 2}$ & 0.087 & $\mathbf{0 . 0 0 1}$ & 0.098 & $\mathbf{0 . 0 0 2}$ & 0.086 \\
01135500 & 54 & $\mathbf{0 . 0 3 4}$ & 0.040 & $\mathbf{0 . 0 2 9}$ & 0.042 & $\mathbf{0 . 0 2 7}$ & 0.043 \\
01139000 & 54 & 0.060 & 0.031 & $\mathbf{0 . 0 2 7}$ & 0.043 & 0.063 & 0.031
\end{tabular}


Table D-1 (PDO), continued

\begin{tabular}{|c|c|c|c|c|c|c|c|}
\hline \multirow{2}{*}{$\begin{array}{c}\text { Site } \\
\text { Number }\end{array}$} & \multirow{2}{*}{$\mathbf{n}$} & \multicolumn{2}{|c|}{ 3-months } & \multicolumn{2}{|c|}{ 6-months } & \multicolumn{2}{|c|}{ 9-months } \\
\hline & & p-value & $\tau$ & p-value & $\tau$ & p-value & $\tau$ \\
\hline 01153000 & 54 & & & .060 & 0.031 & & \\
\hline 01161000 & 54 & 0.007 & 0.065 & 0.004 & 0.073 & 0.001 & 0.100 \\
\hline 01168500 & 54 & & & 0.071 & 0.029 & 0.003 & 0.081 \\
\hline 01173500 & 54 & & & & & 0.096 & 0.025 \\
\hline 01174500 & 54 & 0.013 & 0.054 & 0.049 & 0.034 & 0.050 & 0.034 \\
\hline 01185500 & 54 & & & & & 0.064 & 0.030 \\
\hline 89000 & 54 & & & & & 0.028 & 0.043 \\
\hline 92500 & 54 & 0.022 & 0.046 & 0.018 & 0.049 & 0.003 & 0.078 \\
\hline 500 & 54 & 0.025 & 0.045 & 0.018 & 0.049 & 0.018 & 0.050 \\
\hline 01196500 & 54 & 0.008 & 0.061 & 0.000 & 0.112 & $<0.0001$ & 0.156 \\
\hline 03024000 & 54 & & & 0.016 & 0.051 & 0.002 & 0.084 \\
\hline & 54 & & & & & 0.042 & 0.036 \\
\hline 000 & 54 & 0.044 & 0.036 & & & 0.023 & 0.046 \\
\hline 0307 & 54 & 0.030 & 0.041 & 0.017 & 0.051 & 0.023 & 0.046 \\
\hline 0309 & 54 & 0.001 & 0.094 & 0.001 & 0.098 & $<0.0001$ & 0.230 \\
\hline 500 & 54 & & & 0.078 & 0.027 & 0.044 & 0.036 \\
\hline & 54 & & & 0.030 & 0.041 & & \\
\hline 0314 & 54 & & & & & 0.057 & 0.032 \\
\hline 000 & 54 & 0.010 & 0.058 & 0.009 & 0.061 & $<0.0001$ & 0.136 \\
\hline 000 & 54 & 0.005 & 0.068 & 0.001 & 0.094 & 0.000 & 0.130 \\
\hline & 54 & 0.015 & 0.052 & & 0.108 & & 0.080 \\
\hline & 54 & 0.006 & 0.066 & & 0.115 & 0.000 & 0.132 \\
\hline 032 & 54 & 0.003 & 0.078 & 0.000 & 0.116 & 0.000 & 0.108 \\
\hline 032 & 54 & 0.020 & 0.048 & 0.000 & 0.109 & 0.000 & 0.111 \\
\hline & 54 & 0.001 & 0.094 & 0.001 & 0.100 & 0.004 & 0.073 \\
\hline & 54 & 0.003 & 0.075 & & 0.027 & & 0.027 \\
\hline & 54 & 0.001 & 0.102 & 0.000 & 0.117 & $<0.0$ & 0.145 \\
\hline 03280000 & 54 & & & & & 0.077 & 0.028 \\
\hline 000 & 54 & 0.085 & 0.026 & 0.034 & 0.040 & & \\
\hline & 54 & 0.042 & 0.037 & 0.006 & 0.067 & & 0.110 \\
\hline & 54 & & & & & & 0.027 \\
\hline 03325000 & 54 & 0.008 & 0.062 & 0.034 & 0.040 & 0.004 & 0.074 \\
\hline 03326500 & 54 & & & & & 0.026 & 0.044 \\
\hline & 54 & & & 0.073 & 0.028 & 0.048 & 0.035 \\
\hline & 54 & & & & 0.038 & 0.041 & 0.037 \\
\hline 03360000 & 54 & 0.022 & 0.046 & 0.008 & 0.062 & 0.059 & 0.032 \\
\hline 03363500 & 54 & 0.009 & 0.060 & 0.003 & 0.077 & 0.011 & 0.056 \\
\hline & 5 & 0.056 & 0.032 & 0.003 & 0.079 & 0.001 & 0.095 \\
\hline 03378000 & 54 & 0.096 & 0.025 & 0.065 & 0.030 & 0.003 & 0.077 \\
\hline
\end{tabular}


Table D-1 (PDO), continued

\begin{tabular}{|c|c|c|c|c|c|cc|}
\hline \multirow{2}{*}{$\begin{array}{c}\text { Site } \\
\text { Number }\end{array}$} & \multirow{n}{*}{} & \multicolumn{2}{|c|}{ 3-months } & \multicolumn{2}{c|}{ 6-months } & \multicolumn{2}{c|}{ 9-months } \\
\cline { 3 - 8 } & & p-value & $\boldsymbol{\tau}$ & p-value & $\boldsymbol{\tau}$ & p-value & $\boldsymbol{\tau}$ \\
\hline 03381500 & 54 & & & & & $\mathbf{0 . 0 2 3}$ & 0.046 \\
03433500 & 54 & $\mathbf{0 . 0 4 3}$ & 0.036 & $\mathbf{0 . 0 1 3}$ & 0.054 & $\mathbf{0 . 0 0 2}$ & 0.086 \\
04041500 & 54 & & & & & $\mathbf{0 . 0 1 6}$ & 0.051 \\
04099000 & 54 & 0.077 & 0.028 & $\mathbf{0 . 0 0 4}$ & 0.074 & $\mathbf{0 . 0 1 8}$ & 0.050 \\
04105500 & 54 & & & 0.086 & 0.026 & & \\
04109000 & 54 & 0.058 & 0.032 & $\mathbf{0 . 0 2 6}$ & 0.044 & 0.053 & 0.033 \\
04122500 & 54 & $\mathbf{0 . 0 2 9}$ & 0.042 & $\mathbf{0 . 0 0 1}$ & 0.097 & $\mathbf{0 . 0 0 1}$ & 0.099 \\
04124000 & 54 & & & & & 0.080 & 0.027 \\
04176500 & 54 & $\mathbf{0 . 0 3 3}$ & 0.040 & $\mathbf{0 . 0 1 1}$ & 0.058 & $\mathbf{0 . 0 2 8}$ & 0.043 \\
04185000 & 54 & & & $\mathbf{0 . 0 0 6}$ & 0.066 & $\mathbf{0 . 0 0 7}$ & 0.065 \\
04186500 & 54 & & & $\mathbf{0 . 0 1 3}$ & 0.055 & $\mathbf{0 . 0 0 0}$ & 0.117 \\
04252500 & 54 & $\mathbf{0 . 0 0 8}$ & 0.062 & $\mathbf{0 . 0 0 7}$ & 0.065 & $\mathbf{0 . 0 2 1}$ & 0.047 \\
04258000 & 54 & 0.051 & 0.034 & $\mathbf{0 . 0 4 7}$ & 0.035 & $\mathbf{0 . 0 1 5}$ & 0.053 \\
04296500 & 54 & & & $\mathbf{0 . 0 3 6}$ & 0.039 & 0.062 & 0.031 \\
01073000 & 54 & $\mathbf{0 . 0 0 7}$ & 0.065 & & & $\mathbf{0 . 0 0 4}$ & 0.073 \\
01105000 & 54 & $\mathbf{0 . 0 2 4}$ & 0.045 & 0.071 & 0.029 & & \\
01110000 & 54 & & & & & $\mathbf{0 . 0 4 2}$ & 0.037 \\
01117000 & 54 & $\mathbf{0 . 0 0 5}$ & 0.070 & $\mathbf{0 . 0 0 4}$ & 0.072 & $\mathbf{0 . 0 0 6}$ & 0.066 \\
01162500 & 54 & $\mathbf{0 . 0 3 2}$ & 0.041 & $\mathbf{0 . 0 1 4}$ & 0.054 & $\mathbf{0 . 0 2 2}$ & 0.047 \\
\hline
\end{tabular}

Table D-2: Results of Kendall's $\tau$ correlation tests (significant at the $10 \%$ and $5 \%$ (bold) levels) between 10-years moving averaged series of AMF magnitude and 3-months averaged AMO anomalies with 3-, 6- and 9-months lead time.

\begin{tabular}{|c|c|c|c|c|c|c|c|}
\hline \multirow{2}{*}{$\begin{array}{c}\text { Site } \\
\text { Number }\end{array}$} & \multirow{2}{*}{$\mathbf{n}$} & \multicolumn{2}{|c|}{3 months } & \multicolumn{2}{|c|}{6 months } & \multicolumn{2}{|c|}{9 months } \\
\hline & & p-value & $\tau$ & p-value & $\tau$ & p-value & $T$ \\
\hline 01017000 & 57 & 0.022 & 0.044 & 0.013 & 0.051 & 0.006 & 0.063 \\
\hline 01034500 & 57 & 0.000 & 0.122 & 0.000 & 0.126 & $<0.0001$ & 0.132 \\
\hline 01042500 & 57 & 0.000 & 0.115 & 0.000 & 0.110 & 0.000 & 0.122 \\
\hline 01087000 & 57 & $<0.0001$ & 0.133 & $<0.0001$ & 0.130 & 0.000 & 0.124 \\
\hline 01094500 & 57 & $<0.0001$ & 0.152 & $<0.0001$ & 0.156 & $<0.0001$ & 0.155 \\
\hline 01103500 & 57 & 0.006 & 0.062 & 0.008 & 0.059 & 0.006 & 0.063 \\
\hline 01109000 & 57 & 0.008 & 0.059 & 0.007 & 0.060 & 0.006 & 0.063 \\
\hline 01114500 & 57 & 0.000 & 0.115 & 0.000 & 0.117 & 0.000 & 0.123 \\
\hline 01116000 & 57 & 0.021 & 0.045 & 0.021 & 0.044 & 0.016 & 0.048 \\
\hline 01118000 & 57 & 0.041 & 0.035 & 0.040 & 0.035 & 0.025 & 0.042 \\
\hline 01124000 & 57 & 0.056 & 0.031 & 0.044 & 0.034 & 0.057 & 0.030 \\
\hline 01127500 & 57 & 0.033 & 0.038 & 0.028 & 0.040 & 0.021 & 0.044 \\
\hline
\end{tabular}


Table D-2 (AMO), continued

\begin{tabular}{|c|c|c|c|c|c|c|c|}
\hline \multirow{2}{*}{$\begin{array}{c}\text { Site } \\
\text { Number }\end{array}$} & \multirow{2}{*}{$\mathbf{n}$} & \multicolumn{2}{|c|}{3 months } & \multicolumn{2}{|c|}{6 months } & \multicolumn{2}{|c|}{9 months } \\
\hline & & p-value & $\tau$ & p-value & $\tau$ & p-value & $\tau$ \\
\hline 01141500 & 57 & 0.004 & 0.070 & 0.008 & 0.060 & 0.014 & 0.051 \\
\hline 01151500 & 57 & 0.001 & 0.086 & 0.002 & 0.082 & 0.002 & 0.079 \\
\hline 01152500 & 57 & 0.026 & 0.042 & 0.029 & 0.040 & 0.025 & 0.042 \\
\hline 01153000 & 57 & $<0.0001$ & 0.455 & $<0.0001$ & 0.450 & $<0.0001$ & 0.446 \\
\hline 01161000 & 57 & 0.098 & 0.023 & 0.057 & 0.030 & 0.035 & 0.037 \\
\hline 01173500 & 57 & 0.030 & 0.039 & 0.027 & 0.041 & 0.038 & 0.036 \\
\hline 01185500 & 57 & 0.019 & 0.046 & 0.018 & 0.047 & 0.013 & 0.051 \\
\hline 01189000 & 57 & 0.012 & 0.052 & 0.011 & 0.054 & 0.012 & 0.052 \\
\hline 01192500 & 57 & & & & & 0.082 & 0.025 \\
\hline 01193500 & 57 & 0.063 & 0.029 & 0.083 & 0.025 & 0.070 & 0.027 \\
\hline 01196500 & 57 & & & & & 0.077 & 0.026 \\
\hline 01208500 & 57 & 0.000 & 0.118 & 0.000 & 0.121 & 0.000 & 0.114 \\
\hline 03014500 & 57 & 0.005 & 0.067 & 0.003 & 0.073 & 0.003 & 0.074 \\
\hline 03076500 & 57 & 0.023 & 0.043 & 0.012 & 0.052 & 0.006 & 0.063 \\
\hline 03093000 & 57 & & & & & 0.094 & 0.023 \\
\hline 03110000 & 57 & $<0.0001$ & 0.192 & $<0.0001$ & 0.207 & $<0.0001$ & 0.219 \\
\hline 03117500 & 57 & 0.000 & 0.119 & $<0.0001$ & 0.133 & $<0.0001$ & 0.135 \\
\hline 03118000 & 57 & 0.001 & 0.088 & 0.001 & 0.098 & 0.001 & 0.100 \\
\hline 03140000 & 57 & 0.000 & 0.115 & 0.000 & 0.102 & 0.001 & 0.090 \\
\hline 03208500 & 57 & 0.094 & 0.023 & & & & \\
\hline 03216500 & 57 & 0.000 & 0.103 & 0.000 & 0.121 & $<0.0001$ & 0.134 \\
\hline 03227500 & 57 & 0.061 & 0.029 & 0.076 & 0.026 & 0.079 & 0.026 \\
\hline 03228500 & 57 & & & 0.085 & 0.025 & 0.066 & 0.028 \\
\hline 03232500 & 57 & 0.036 & 0.037 & 0.027 & 0.041 & 0.020 & 0.045 \\
\hline 03253500 & 57 & 0.047 & 0.033 & 0.051 & 0.032 & 0.047 & 0.033 \\
\hline 03262000 & 57 & 0.000 & 0.124 & 0.000 & 0.120 & 0.000 & 0.110 \\
\hline 03267000 & 57 & 0.000 & 0.125 & $<0.0001$ & 0.136 & $<0.0001$ & 0.149 \\
\hline 03272000 & 57 & 0.005 & 0.065 & 0.004 & 0.068 & 0.005 & 0.066 \\
\hline 03281000 & 57 & $<0.0001$ & 0.260 & $<0.0001$ & 0.284 & $<0.0001$ & 0.288 \\
\hline 03283500 & 57 & 0.017 & 0.047 & 0.020 & 0.045 & 0.024 & 0.043 \\
\hline 03320000 & 57 & 0.024 & 0.043 & 0.013 & 0.051 & 0.010 & 0.056 \\
\hline 03325000 & 57 & $<0.0001$ & 0.137 & $<0.0001$ & 0.162 & $<0.0001$ & 0.173 \\
\hline 03326500 & 57 & $<0.0001$ & 0.180 & $<0.0001$ & 0.178 & $<0.0001$ & 0.169 \\
\hline 03328000 & 57 & 0.010 & 0.055 & 0.014 & 0.050 & 0.015 & 0.049 \\
\hline 03347000 & 57 & $<0.0001$ & 0.136 & $<0.0001$ & 0.145 & $<0.0001$ & 0.154 \\
\hline 03352500 & 57 & $<0.0001$ & 0.262 & $<0.0001$ & 0.275 & $<0.0001$ & 0.297 \\
\hline 03353500 & 57 & 0.003 & 0.074 & 0.001 & 0.085 & 0.001 & 0.093 \\
\hline 03360000 & 57 & 0.002 & 0.079 & 0.002 & 0.083 & 0.001 & 0.094 \\
\hline 03363500 & 57 & $<0.0001$ & 0.184 & $<0.0001$ & 0.190 & $<0.0001$ & 0.193 \\
\hline
\end{tabular}


Table D-2 (AMO), continued

\begin{tabular}{|c|c|c|c|c|c|c|c|}
\hline \multirow{2}{*}{$\begin{array}{c}\text { Site } \\
\text { Number }\end{array}$} & \multirow{2}{*}{$\mathbf{n}$} & \multicolumn{2}{|c|}{3 months } & \multicolumn{2}{|c|}{6 months } & \multicolumn{2}{|c|}{9 months } \\
\hline & & p-value & $\tau$ & p-value & $\tau$ & p-value & $\tau$ \\
\hline 03369500 & 57 & 0.029 & 0.040 & 0.018 & 0.047 & 0.012 & 0.052 \\
\hline 03378000 & 57 & 0.001 & 0.097 & 0.002 & 0.084 & 0.003 & 0.073 \\
\hline 03381500 & 57 & 0.000 & 0.122 & 0.000 & 0.114 & 0.000 & 0.109 \\
\hline 03406500 & 57 & 0.013 & 0.051 & 0.009 & 0.057 & 0.006 & 0.062 \\
\hline 03421000 & 57 & 0.084 & 0.025 & & & & \\
\hline 04041500 & & 0.084 & 0.025 & & & & \\
\hline 04109000 & 57 & 0.058 & 0.030 & 0.057 & 0.030 & 0.044 & 0.034 \\
\hline 04122500 & 57 & 0.002 & 0.077 & 0.001 & 0.092 & 0.000 & 0.102 \\
\hline 04154000 & 57 & 0.057 & 0.030 & 0.049 & 0.032 & 0.050 & 0.032 \\
\hline 04165500 & 57 & 0.005 & 0.066 & 0.009 & 0.057 & 0.012 & 0.053 \\
\hline 0418 & 57 & 0.049 & 0.032 & 0.080 & 0.026 & & \\
\hline 0419 & 57 & 0.000 & 0.118 & 0.000 & 0.105 & 0.001 & 0.093 \\
\hline 04258000 & 57 & 0.041 & 0.035 & 0.072 & 0.027 & & \\
\hline 04263000 & 57 & $<0.0001$ & 0.226 & $<0.0001$ & 0.212 & $<0.0001$ & 0.210 \\
\hline 04296500 & 57 & 0.028 & 0.041 & 0.018 & 0.047 & 0.014 & 0.051 \\
\hline 01073000 & 57 & $<0.0001$ & 0.171 & $<0.0001$ & 0.160 & $<0.0001$ & 0.148 \\
\hline 01105000 & 57 & 0.096 & 0.023 & 0.096 & 0.023 & 0.084 & 0.025 \\
\hline 01110000 & 57 & 0.077 & 0.026 & 0.068 & 0.028 & 0.069 & 0.028 \\
\hline 01117000 & 57 & 0.002 & 0.080 & 0.001 & 0.088 & 0.001 & 0.098 \\
\hline 01142500 & 57 & 0.000 & 0.118 & 0.000 & 0.105 & 0.001 & 0.099 \\
\hline 01162500 & 57 & 0.012 & 0.053 & 0.012 & 0.053 & 0.013 & 0.052 \\
\hline
\end{tabular}

Table D-3: Results of Kendall's $\tau$ correlation tests (significant at the $10 \%$ and $5 \%$ (bold) levels) between 10-years moving averaged series of AMF magnitude and 3-months averaged NAO anomalies with 3-, 6- and 9-months lead time.

\begin{tabular}{|c|c|cc|c|c|c|c|}
\hline \multirow{2}{*}{$\begin{array}{c}\text { Site } \\
\text { Number }\end{array}$} & \multirow{2}{*}{$\mathbf{n}$} & \multicolumn{2}{|c|}{ 3 months } & \multicolumn{2}{c|}{ 6 months } & \multicolumn{2}{c|}{ 9 months } \\
\cline { 3 - 8 } & & p-value & $\boldsymbol{\tau}$ & p-value & $\boldsymbol{\tau}$ & p-value & $\boldsymbol{\tau}$ \\
\hline 01019000 & 60 & $\mathbf{0 . 0 2 4}$ & 0.040 & 0.065 & 0.027 & & \\
01034500 & 60 & $\mathbf{0 . 0 4 4}$ & 0.032 & & & & \\
01139000 & 60 & 0.074 & 0.025 & & & & \\
01141500 & 60 & & & & & 0.086 & 0.023 \\
01161000 & 60 & $\mathbf{0 . 0 0 6}$ & 0.060 & & & & \\
01168500 & 59 & $\mathbf{0 . 0 0 8}$ & 0.056 & & & & \\
01208500 & 59 & & & $\mathbf{0 . 0 3 9}$ & 0.034 & & \\
03072000 & 60 & & & & & 0.065 & 0.027 \\
03093000 & 59 & & & & & 0.083 & 0.024 \\
03111500 & 59 & & & & & 0.053 & 0.030
\end{tabular}


Table D-3 (NAO), continued

\begin{tabular}{|c|c|c|c|c|c|c|c|}
\hline \multirow{2}{*}{$\begin{array}{c}\text { Site } \\
\text { Number }\end{array}$} & \multirow{2}{*}{$\mathbf{n}$} & \multicolumn{2}{|c|}{3 months } & \multicolumn{2}{|c|}{6 months } & \multicolumn{2}{|c|}{9 months } \\
\hline & & p-value & $\tau$ & p-value & $\tau$ & p-value & $\tau$ \\
\hline 03140000 & 59 & 0.001 & 0.092 & 0.074 & 0.026 & & \\
\hline 03209000 & 60 & & & & & 0.008 & 0.056 \\
\hline 03253500 & 59 & & & & & 0.007 & 0.059 \\
\hline 03267000 & 59 & & & & & 0.000 & 0.108 \\
\hline 03276500 & 60 & 0.002 & 0.076 & & & & \\
\hline 03281000 & 59 & & & 0.098 & 0.022 & & \\
\hline 03328000 & 60 & & & & & 0.076 & 0.025 \\
\hline 03352500 & 60 & & & & & 0.026 & 0.039 \\
\hline 03360000 & 60 & 0.043 & 0.032 & & & 0.029 & 0.038 \\
\hline 03369500 & 60 & 0.002 & 0.076 & & & & \\
\hline 03378000 & 60 & 0.070 & 0.026 & & & & \\
\hline 03381500 & 60 & 0.039 & 0.034 & & & & \\
\hline 03421000 & 60 & & & & & 0.099 & 0.022 \\
\hline 04122500 & 60 & 0.012 & 0.049 & & & & \\
\hline 04154000 & 60 & 0.057 & 0.029 & & & & \\
\hline 04155000 & 60 & 0.071 & 0.026 & & & & \\
\hline 04165500 & 60 & & & & & 0.039 & 0.034 \\
\hline 04186500 & 60 & & & & & 0.068 & 0.026 \\
\hline 04195500 & 60 & & & & & 0.012 & 0.050 \\
\hline 04252500 & 60 & 0.084 & 0.024 & & & & \\
\hline 04258000 & 60 & 0.012 & 0.050 & & & & \\
\hline 04296500 & 60 & 0.031 & 0.037 & & & & \\
\hline 01142500 & 60 & & & 0.032 & 0.036 & 0.063 & 0.027 \\
\hline
\end{tabular}

Table D-4: Results of Kendall's $\tau$ correlation tests (significant at the $10 \%$ and $5 \%$ (bold) levels) between 10-years moving averaged series of AMF magnitude and 3-months averaged MEI anomalies with 3-, 6- and 9-months lead time.

\begin{tabular}{|c|l|c|c|c|c|c|c|}
\hline \multirow{2}{*}{$\begin{array}{c}\text { Site } \\
\text { Number }\end{array}$} & \multirow{2}{*}{$\mathbf{n}$} & \multicolumn{2}{|c|}{ 3 months } & \multicolumn{2}{c|}{ 6 months } & \multicolumn{2}{c|}{ 9 months } \\
\cline { 3 - 7 } & & p-value & $\boldsymbol{\tau}$ & p-value & $\boldsymbol{\tau}$ & p-value & $\boldsymbol{T}$ \\
\hline 01017000 & 60 & & & 0.095 & 0.022 & $\mathbf{0 . 0 1 0}$ & 0.052 \\
01127500 & 59 & & & 0.095 & 0.022 & $\mathbf{0 . 0 2 8}$ & 0.039 \\
01135500 & 60 & & & & & $\mathbf{0 . 0 4 2}$ & 0.033 \\
01139000 & 60 & & & & & 0.096 & 0.022 \\
01161000 & 60 & & & & & $\mathbf{0 . 0 2 5}$ & 0.040 \\
01196500 & 59 & & & 0.058 & 0.029 & $\mathbf{0 . 0 0 5}$ & 0.062 \\
03024000 & 60 & & & & & $\mathbf{0 . 0 0 8}$ & 0.055 \\
03045000 & 60 & 0.086 & 0.023 & & & 0.062 & 0.028
\end{tabular}


Table D-4 (MEI), continued

\begin{tabular}{|c|c|c|c|c|c|cc|}
\hline Site & \multirow{2}{*}{$\mathbf{n}$} & \multicolumn{2}{|c|}{ 3 months } & \multicolumn{2}{c|}{ 6 months } & \multicolumn{2}{c|}{$\mathbf{9}$ months } \\
\cline { 3 - 8 } Number & & p-value & $\boldsymbol{\tau}$ & p-value & $\boldsymbol{\tau}$ & p-value & $\boldsymbol{\tau}$ \\
\hline 03076500 & 60 & & & & & $\mathbf{0 . 0 4 7}$ & 0.031 \\
03093000 & 59 & $\mathbf{0 . 0 0 5}$ & 0.064 & $\mathbf{0 . 0 0 1}$ & 0.096 & $\mathbf{0 . 0 0 3}$ & 0.069 \\
03106500 & 60 & & & & & $\mathbf{0 . 0 2 4}$ & 0.040 \\
03157000 & 59 & & & & & $\mathbf{0 . 0 0 7}$ & 0.059 \\
03209000 & 60 & & & & & $\mathbf{0 . 0 4 5}$ & 0.032 \\
03216500 & 59 & & & 0.099 & 0.022 & $\mathbf{0 . 0 1 5}$ & 0.048 \\
03228500 & 59 & & & $\mathbf{0 . 0 4 8}$ & 0.031 & $\mathbf{0 . 0 0 3}$ & 0.069 \\
03232500 & 59 & & & & & 0.056 & 0.029 \\
03245500 & 59 & & & & & $\mathbf{0 . 0 1 9}$ & 0.044 \\
03253500 & 59 & & & & & $\mathbf{0 . 0 3 4}$ & 0.036 \\
03262000 & 59 & & & $\mathbf{0 . 0 3 0}$ & 0.038 & & \\
03267000 & 59 & & & 0.058 & 0.029 & & \\
03276500 & 60 & & & 0.077 & 0.025 & $\mathbf{0 . 0 0 4}$ & 0.064 \\
03283500 & 59 & & & $\mathbf{0 . 0 2 2}$ & 0.042 & 0.061 & 0.028 \\
03326500 & 60 & & & $\mathbf{0 . 0 1 2}$ & 0.050 & & \\
03369500 & 60 & & & & & 0.093 & 0.022 \\
03378000 & 60 & 0.084 & 0.024 & 0.057 & 0.029 & $\mathbf{0 . 0 0 3}$ & 0.069 \\
03381500 & 60 & & & 0.087 & 0.023 & $\mathbf{0 . 0 2 6}$ & 0.039 \\
03433500 & 60 & & & 0.062 & 0.028 & 0.050 & 0.030 \\
04041500 & 60 & & & & & $\mathbf{0 . 0 2 9}$ & 0.038 \\
04109000 & 60 & & & & & 0.084 & 0.024 \\
04112500 & 60 & & & & & $\mathbf{0 . 0 3 8}$ & 0.034 \\
04122500 & 60 & & & 0.089 & 0.023 & $\mathbf{0 . 0 1 6}$ & 0.046 \\
04146000 & 60 & & & & & $\mathbf{0 . 0 1 2}$ & 0.049 \\
04185000 & 59 & & & 0.092 & 0.023 & 0.065 & 0.027 \\
04186500 & 60 & 0.068 & 0.026 & $\mathbf{0 . 0 0 2}$ & 0.076 & 0.100 & 0.021 \\
04252500 & 60 & & & & & $\mathbf{0 . 0 3 3}$ & 0.036 \\
04258000 & 60 & & & & & $\mathbf{0 . 0 2 1}$ & 0.042 \\
01073000 & 60 & & & & & 0.077 & 0.025 \\
01117000 & 60 & & & & & 0.079 & 0.025 \\
\hline
\end{tabular}


Table D-5: Results of Kendall's $\tau$ correlation tests (significant at the $10 \%$ and $5 \%$ (bold) levels) between 10-years moving averaged series of AMF magnitude and 3-months averaged NINO3.4 anomalies with 3-, 6- and 9-months lead time.

\begin{tabular}{|c|c|c|c|c|c|cc|}
\hline \multirow{2}{*}{$\begin{array}{c}\text { Site } \\
\text { Number }\end{array}$} & \multirow{n}{*}{$\mathbf{n}$} & \multicolumn{2}{|c|}{ 3 months } & \multicolumn{2}{c|}{ 6 months } & \multicolumn{2}{c|}{ 9 months } \\
\cline { 3 - 8 } & & p-value & $\boldsymbol{\tau}$ & p-value & $\boldsymbol{\tau}$ & p-value & $\boldsymbol{T}$ \\
\hline 03093000 & 59 & 0.062 & 0.028 & 0.087 & 0.024 & $\mathbf{0 . 0 5 0}$ & 0.031 \\
03262000 & 59 & & & 0.077 & 0.025 & 0.058 & 0.029 \\
03272000 & 59 & & & 0.087 & 0.024 & & \\
03283500 & 59 & & & 0.054 & 0.030 & 0.088 & 0.024 \\
03326500 & 60 & 0.066 & 0.027 & $\mathbf{0 . 0 0 8}$ & 0.055 & 0.079 & 0.024 \\
03347000 & 60 & & & 0.069 & 0.026 & & \\
03353500 & 59 & & & & & $\mathbf{0 . 0 2 7}$ & 0.039 \\
03376500 & 60 & & & $\mathbf{0 . 0 2 9}$ & 0.038 & & \\
03378000 & 60 & & & $\mathbf{0 . 0 3 0}$ & 0.037 & $\mathbf{0 . 0 2 9}$ & 0.038 \\
03381500 & 60 & & & $\mathbf{0 . 0 4 9}$ & 0.031 & $\mathbf{0 . 0 2 1}$ & 0.042 \\
04112500 & 60 & & & $\mathbf{0 . 0 4 1}$ & 0.033 & $\mathbf{0 . 0 1 4}$ & 0.048 \\
04146000 & 60 & & & $\mathbf{0 . 0 2 8}$ & 0.038 & $\mathbf{0 . 0 0 6}$ & 0.059 \\
04186500 & 60 & & & 0.099 & 0.022 & & \\
\hline
\end{tabular}

